
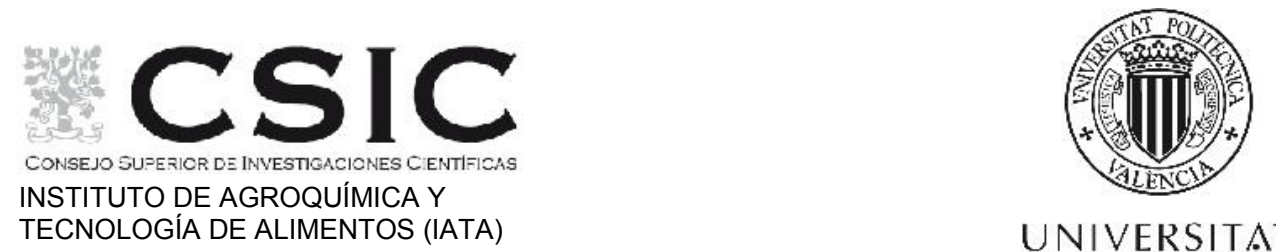

UNIVERSITAT

POLITÈCNICA

DE VALÈNCIA

\title{
DESARROLLO DE MÉTODOS RÁPIDOS DE DETECCIÓN DE RESIDUOS MEDICAMENTOSOS EN ANIMALES DE GRANJA
}

TESIS DOCTORAL

Presentada por:

María Milagro Reig Riera

Dirigida por:

Prof. Dr. Fidel Toldrá Vilardell

Valencia, Septiembre de 2010 
FIDEL TOLDRÁ VILARDELL, DOCTOR EN CIENCIAS QUÍMICAS Y PROFESOR DE INVESTIGACIÓN DEL INSTITUTO DE AGROQUÍMICA Y TECNOLOGÍA DE ALIMENTOS DEL CONSEJO SUPERIOR DE INVESTIGACIONES CIENTÍFICAS.

HACE CONSTAR: que el trabajo de investigación titulado "Desarrollo de métodos rápidos de detección de residuos medicamentosos en animales de granja" que presenta Dña. María Milagro Reig Riera por la Universidad Politécnica de Valencia, ha sido realizado en el Instituto de Agroquímica y Tecnología de Alimentos (IATA-CSIC) bajo mi dirección y que reúne las condiciones para optar al grado de doctor.

Y para que conste a los efectos oportunos, firmo la presente en Valencia a 1 de Septiembre de 2010.

Fdo: Prof. Dr. Fidel Toldrá 



\section{Resumen}

El uso de sustancias medicamentosas como promotores de crecimiento en la alimentación de animales de granja y en acuicultura es una práctica ilegal en la Unión Europea. Dada la incidencia que puedan tener las sustancias administradas a los animales para la salud de los consumidores, la Unión Europea estableció un reglamento para todos los países miembros que corresponde a la voluntad de proteger la salud pública.

La prohibición de dichas sustancias promotoras del crecimiento ha motivado un mercado negro a nivel europeo que precisa de estrictos controles sistemáticos para su detección. Los medicamentos veterinarios más utilizados en estos casos fraudulentos son aquellos que tienen una acción anabolizante, hormonal o tireostática.

El objetivo principal de este trabajo consiste en el desarrollo de métodos analíticos rápidos y la evaluación de su aplicación como técnicas de "screening" o criba en el control sanitario de residuos medicamentosos y de sustancias promotoras del crecimiento en animales de granja. Concretamente, se desarrollan protocolos de análisis rápidos y específicos para detectar residuos de $\beta$-agonistas (clembuterol y mabuterol), lactonas del ácido resorcílico (zeranol), antimicrobianos (carbadox), agentes antitiroideos (metil-tiouracilo) y corticoides (dexametasona) en muestras de agua de beber, orina y pienso de distintas especies animales.

Se han utilizado los métodos inmunológicos tipo ELISA debido a su especificidad, rapidez y gran número de muestras que se pueden analizar de forma simultánea. La cromatografía líquida de alta resolución ha sido también una herramienta muy eficaz para la detección de varias sustancias.

Todos los métodos puestos a punto y optimizados para los analitos y respectivas matrices estudiados demostraron buena sensibilidad y robustez y han podido ser validados conforme a la normativa vigente que afecta a todos los países miembros de la Unión Europea (Decisión 2002/657/EC). 



\section{Resum}

L'ús de substàncies medicamentose com a promotors de creixement en l'alimentació d'animals de granja i en aqüicultura és una pràctica il.legal a la Unió Europea. Atesa la incidència que puguin tenir les substàncies administrades als animals, la Unió Europea va establir un reglament per a tots els països membres que correspon a la voluntat de protegir la salut pública.

La prohibició d'aquestes substàncies promotores del creixement ha motivat un mercat negre a nivell europeu que necessita estrictes controls sistemàtics per a la seva detecció. Els medicaments veterinaris més utilitzats en aquests casos fraudulents són aquells que tenen una acció anabolitzant, hormonal o tireostàtica.

L'objectiu principal d'aquest treball consisteix en el desenvolupament de mètodes analítics ràpids i l'avaluació de la seva aplicació com a tècniques de screening o cribatge en el control sanitari de residus medicamentosos $i$ de substàncies promotores del creixement en animals de granja. Concretament, es desenvolupen protocols d'anàlisi ràpids $i$ específics per detectar residus de $\beta$ agonistes (clenbuterol i mabuterol), lactones de l'àcid resorcílico (zeranol), antimicrobians (carbadox), agents antitiroïdals (metil-tiouracilo) i corticoides (dexametasona) en mostres de aigua de beure, orina i pinso de diferents espècies animals.

S'han utilitzat els mètodes immunològics tipus ELISA per la seva especificitat, rapidesa i gran nombre de mostres que es poden realitzar de forma simultània. La cromatografia líquida d'alta resolució ha estat també una eina molt eficaç per a la detecció de diverses substàncies.

Tots els mètodes posats a punt $\mathrm{i}$ optimitzats per als analits $\mathrm{i}$ respectives matrius estudiades van demostrar bona sensibilitat i robustesa i han pogut ser validats d'acord amb la normativa vigent que afecta tots els països membres de la Unió Europea (Decisió 2002/657/EC). 



\begin{abstract}
The use of veterinary drugs as growth promoters in feed for farm animals and aquaculture is illegal in the European Union. Given the impact that these administered substances may have for consumers' health, the EU established a regulation for all member countries that corresponds to the desire to protect the public health.

The ban for the use of such growth promoters created a black market at an European level that required a strict and systematic control for its detection. Veterinary drugs most used in these fraudulent cases are those with an anabolic, hormonal or thyrostatic effect.

The main goal of this work consists of the development of rapid analytical methods and the evaluation of its application as screening techniques for the sanitary control of veterinary substances and growth promoters in farm animals. More specifically, protocols for rapid and specific analysis are developed for residues of $\beta$ agonists (clenbuterol and mabuterol) resorcycilic acid lactones (zeranol), antibacterial (carbadox), antithyroid agents (methyl thiouracil), and corticosteroids (dexamethasone) in samples of drinking water, urine and feed of various animal species.

Immunological methods have been used due to their specificity, rapid processing time and large number of samples that may be performed simultaneously. The high resolution liquid chromatography has also been a very effective tool for the detection of several substances in a relatively short period of time.

All the developed and optimised methods for the analysis of analytes in their respective matrices have shown good stability and robustness and have been validated according to the current normative affecting to all European Union member countries. All these methods have been validated according to Decision 2002/657/EC.
\end{abstract}



A mi padre 



\section{AGRADECIMIENTOS}

Quiero expresar mi más profundo y sincero agradecimiento a mi director de tesis, el Doctor Fidel Toldrá Vilardell, por su confianza, su dirección y su valiosa ayuda en mi formación profesional e investigadora.

A las compañeras del Laboratorio de Residuos, Natalia y Leticia, por los momentos compartidos de trabajo, alegría y buen humor. $Y$ también a Lorena por los buenos y malos momentos.

A los compañeros del Laboratorio de Ciencia de la Carne por su amistad y a todas las personas del IATA con quienes compartí mi tiempo durante la realización de esta tesis.

A mi familia, en especial a mis hijos, Fidel y Silvia, que siempre han sabido entender mis necesidades a pesar de su edad y siempre me han animado a continuar.

A mi marido, Fidel, por tener siempre su cariño, su apoyo incondicional, su comprensión y su amistad.

A los evaluadores del borrador de esta tesis por el interés mostrado y por el tiempo dedicado. Sus correcciones y sugerencias contribuyeron a mejorar la presente tesis.

Gracias a todos 
Se agradece el proyecto realizado dentro del Convenio con la Conselleria de Agricultura, Pesca y Alimentación de la Generalitat Valenciana, 2001 a 2005, titulado "Realización de un plan de análisis integrado en el programa de control de residuos en animales vivos y sustancias para la alimentación animal" así como los proyectos "Desarrollo y validación de métodos cromatográficos rápidos para el screening de antibióticos en carne" A-05/08 en 2008, y "Desarrollo y validación de métodos cromatográficos rápidos para el screening de antibióticos, tipo nitrofuranos y sus metabolitos, en carne" A-01/09 en 2009, ambos financiados por la Plataforma de Investigación en Seguridad Alimentaria de la Conselleria de Sanidad de la Generalitat Valenciana. 
Indice 



\section{ÍNDICE}

ABREVIATURAS Y ACRÓNIMOS

ÍNDICE GENERAL

ÍNDICE DE FIGURAS

ÍNDICE DE TABLAS

1. INTRODUCCIÓN 1

2. ANTECEDENTES BIBLIOGRÁFICOS 11

2.1. Principales grupos de promotores de crecimiento y sus

efectos en los animales

2.1.1. Agentes Antitiroideos 13

2.1.2. Corticoides 15

2.1.3. $\beta$-Agonistas 16

2.1.4. Hormonas esteroideas y otras sustancias con 17 acción hormonal.

2.1.5. Tranquilizantes 18

2.1.6. Antibióticos 19

2.2. Problemática del uso de sustancias promotoras del

Crecimiento. Historial de intoxicaciones 20

2.3. Legislación Internacional Reguladora: Unión Europea 23

2.3.1. Plan de vigilancia de residuos 24

2.3.2. Límite máximo de residuos 34

2.4. Regulaciones en otros países 38

2.5. Normativas Reguladoras de la metodología analítica 39

2.5.1. Directiva Europea de métodos analíticos 39

2.5.2. Interpretación de los resultados 40

2.5.3. Definiciones de los límites de decisión y

Capacidad de detección 
2.5.4. Validación

2.5.5. Procedimiento de validación 43

2.6. Metodologías analíticas $\quad 44$

2.6.1. Muestras 46

2.6.2. Preparación de las muestras 47

2.6.2.1. Agua 50

2.6.2.2. Piensos 50

2.6.2.3. Orina 50

2.6.2.4. Pelo 51

2.6.3. Métodos de criba o screening 51

2.6.3.1. Ensayos ELISA 52

2.6.3.1. Cromatografía de inmunoafinidad 59

2.6.3.2. Técnicas cromatográficas 61

2.6.4. Métodos confirmatorios 62

2.6.5. Criterios de funcionamiento adicionales y otros requisitos 65

que deben cumplir todos los métodos cuantitativos

2.6.5.1. Veracidad de los métodos cuantitativos 65

2.6.5.2. Precisión 65

2.7. Descripción de los principales grupos y sustancias más representativas $\quad 65$

2.7.1. Análisis de sustancias del grupo $A \quad 68$

2.7.2. Análisis de sustancias del grupo $B \quad 70$

3. OBJETIVOS 75

4. PLAN DE TRABAJO 81

5. MATERIALES Y MÉTODOS 85

5.1. Determinación de residuos mediante ensayos ELISA 87

$\begin{array}{ll}\text { 5.1.1. Materiales } & 87\end{array}$ 
5.1.2. Reactivos 87

5.1.3. Preparación de la muestra 87

5.1.3.1. Protocolo de extracción de $\beta$-agonistas en agua 87

5.1.3.2. Protocolo de extracción de $\beta$-agonistas en orina 88

5.1.3.3. Protocolo de extracción de $\beta$-agonistas en pienso 88

5.1.3.4. Protocolo de extracción de zeranol en pienso 88

5.1.4. Condiciones de uso para los ensayos ELISA 88

5.1.4.1. $\beta$-agonistas 89

5.1.4.2. Zeranol 90

5.1.5. Procedimiento a seguir en los ensayos ELISA 91

5.1.5.1. $\beta$-agonistas 91

5.1.5.2. Zeranol 92

5.2. Determinación de residuos de sustancias por cromatografía líquida de alta resolución con detección por red de diodos (HPLC-DAD) 92

5.2.1. Materiales 92

5.2.2. Reactivos 93

5.2.3. Determinación de carbadox 93

5.2.3.1. Preparación de la muestra de pienso 94

5.2.3.2. Extracción 94

5.2.3.3. Purificación 94

5.2.3.4. Determinación mediante HPLC-DAD

94

5.2.3.5. Procedimiento general 95

5.2.3.6. Confirmación: Co-cromatografía 96

5.2.4. Determinación de metil-tiouracilo en orina 97

5.2.4.1. Preparación de la muestra de orina y protocolo 
5.2.4.2. Determinación mediante HPLC-DAD

97

5.2.4.3. Procedimiento general

98

5.2.4.4. Confirmación: Co-cromatografía 99

5.2.5. Determinación de dexametasona

5.2.5.1. Preparación de la muestra y protocolo de extracción para pienso

Preparación de la muestra y protocolo de extracción para agua

5.2.5.2. Determinación mediante HPLC-DAD 101

5.2.5.3. Procedimiento general 102

5.2.5.4. Confirmación: Co-cromatografía 103

5.3. Análisis estadístico 104

6. RESULTADOS Y DISCUSIÓN 105

6.1. Validación de métodos de criba con ensayos ELISA para $\beta$-agonistas

6.1.1. Especificidad

6.1.2. Aplicabilidad (cambios menores) 108

6.1.3. Estabilidad 109

6.1.4. Capacidad de detección (CC $\beta$ ) 109

6.1.5. Robustez (cambios importantes)

6.2. Validación de métodos de criba con ensayos ELISA para zeranol ( $\alpha$-zearalenol)

6.2.1. Especificidad

6.2.2. Aplicabilidad (cambios menores) 
6.2.4. Capacidad de detección (CC $\beta$ ) 112

6.2.5. Robustez (cambios importantes) 113

6.3. Validación del método de criba por cromatografía líquida de alta resolución (HPLC) para carbadox 114

6.3.1. Especificidad 114

6.3.2. Aplicabilidad (cambios menores) 115

6.3.3. Estabilidad 116

6.3.4. Rectas de calibrado 116

6.3.5. Recuperación 117

6.3.6. Repetibilidad 118

6.3.7. Reproducibilidad intralaboratorio 120

6.3.8. Limite de decisión (CCa) 120

6.3.9. Capacidad de detección (CC $\beta$ ) 121

6.3.10. Robustez (cambios importantes) 121

6.4. Validación del método de análisis de metil-tiouracilo mediante cromatografía líquida de alta resolución (HPLC) 121

6.4.1. Especificidad 121

6.4.2. Aplicabilidad (cambios menores) 122

6.4.3. Estabilidad 123

6.4.4. Rectas de calibrado $\quad 125$

6.4.4.1 Recta de calibrado con patrones puros 125

6.4.4.2 Recta de calibrado sobre orina enriquecida con patrones puros 126

6.4.5. Recuperación 126

6.4.6. Repetibilidad 128

6.4.7. Reproducibilidad intralaboratorio 128

6.4.8. Límite de decisión (CCa) 129 
6.4.9. Capacidad de detección (CC $\beta$ ) 129

6.4.10. Robustez (cambios importantes) 129

6.5. Validación del método de análisis de dexametasona mediante cromatografía líquida de alta resolución (HPLC) 131

6.5.1. Especificidad

6.5.2. Aplicabilidad (cambios menores)

6.5.3. Estabilidad 132

6.5.4. Rectas de calibrado 133

6.5.4.1. Rectas de calibrado de patrones puros 133

6.5.4.2. Rectas de calibrado sobre agua 134

6.5.4.3. Rectas de calibrado sobre pienso 136

6.5.5. Recuperación 136

6.5.6. Repetibilidad 137

6.5.7. Reproducibilidad intra-laboratorio 137

6.5.8. Límite de decisión (CCa) 139

6.5.9. Capacidad de detección (CC $\beta)$ 140

6.5.10. Robustez (cambios importantes) 140

6.5.11. Precisión 140

7. CONCLUSIONES 143

8. BIBLIOGRAFÍA 147

9. APÉNDICES

I. Stability of $\beta$-agonist methyl boronic derivatives before GC-MS analysis. Analytica Chimica Acta, 2005, 529, 293-297.

II. Methods for rapid detection of chemical and veterinary drug residues in animal foods. Trends in Food 
Science and Technology, 2006, 17, 482-489.

175

III. A chromatography method for the screening and

confirmatory detection of dexamethasone. Meat Science, 2006, 74, 676-680.

IV. Liquid chromatography for the rapid screening of growth promoter residues in meat. Food Analytical Methods, 2008, $1,2-9$

V. Veterinary drug residues in meat: Concerns and rapid methods for detection. Meat Science, 2008, 78, 60-67.

VI. Capítulos de libro 


\section{ABREVIATURAS Y ACRÓNIMOS}

CE

CEE

$\mathrm{CL}$

CV

DAD

DX

EDTA

EIA

ELISA

EFSA

EMEA

ENAC

FAO

FDA

GC

GC-MS

HPLC

HPTLC

IC

IDA

IS

LC-MS

LLE

LMR
Comisión Europea

Comunidad Económica Europea

Cromatografía Líquida

Coeficiente de variación

Detector de diodos

Dexametasona

Ácido etilendiamin tetraacético

Inmunoensayo

Inmunoensayo enzimático competitivo

Agencia Europea de Seguridad

Alimentaria

Agencia Europea del Medicamento

Entidad Nacional de Acreditación

Food and Agricultural Organization

Food and Drug Administration

Cromatografía de gases

Cromatografía de gases con detector de masas

Cromatografía Líquida de Alta Resolución

Cromatografía en Capa Fina de Alto

Resolución

Columna de Inmunoafinidad

Ingesta Diaria Admisible

Patrón Interno

Cromatografía Líquida con Detector de Masas

Extracción Líquido - Líquido con

disolventes

Límite Máximo de Residuos 


\begin{tabular}{|c|c|}
\hline $\mathrm{mm}$ & Milímetro \\
\hline M & Molar \\
\hline $\mathrm{m} / \mathrm{z}$ & Masa/Carga \\
\hline $\mathrm{MeOH}$ & Metanol \\
\hline $\mathrm{mg}$ & Miligramo \\
\hline Min & Minuto \\
\hline MIP & polímeros de impresión molecular \\
\hline $\mathrm{mL}$ & Mililitro \\
\hline MRLP & $\begin{array}{l}\text { Límite Mínimo Exigido de } \\
\text { Funcionamiento }\end{array}$ \\
\hline MS & Espectrometría de masas \\
\hline$N$ & Normal \\
\hline $\mathrm{nm}$ & Nanómetro \\
\hline $\mathrm{ng}$ & Nanogramo \\
\hline${ }^{\circ} \mathrm{C}$ & Grado Centígrado \\
\hline OMS & Organización Mundial de la Salud \\
\hline $\mathrm{PI}$ & Patrón interno \\
\hline PNIR & $\begin{array}{l}\text { Plan Nacional de Investigación de } \\
\text { Residuos } \\
\text { Partes por billón }\end{array}$ \\
\hline ppm & Partes por millón \\
\hline $\mathrm{R}^{2}$ & Coeficiente de Correlación \\
\hline Rec. & Recuperación \\
\hline RIVM & $\begin{array}{l}\text { Instituto Nacional para la Salud Pública y } \\
\text { Medioambiente de Holanda }\end{array}$ \\
\hline rpm & Revoluciones por minuto \\
\hline SD & Desviación Standard \\
\hline SANCO & $\begin{array}{l}\text { Directorado General para la Salud y el } \\
\text { Consumo de la Comisión Europea }\end{array}$ \\
\hline SPE & Extracción en Fase Sólida \\
\hline $\mathrm{T}$ & Temperatura \\
\hline
\end{tabular}


$t_{r}$

UE

UNE

USDA

UV

UV-VIS

X

$\mu$

$\mu \mathrm{L}$

$\mu \mathrm{m}$

$\lambda$
Tiempo de Retención

Unión Europea

Una Norma Europea

Departamento de Agricultura de EEUU

Ultravioleta

Ultravioleta-Visible

Media

Micra

Microlitro

Micrómetro

Longitud de Onda 



\section{INDICE DE FIGURAS}

Figura

Pié de figura

Página

1

Estructura química, 6 - metil - tiouracilo

14

2

Estructura química, 1 metil-imidazol 2 tiol

14

Estructura química de la dexametasona

16

Estructura química del clembuterol

17

Estructura química del carbadox

20

Evolución de las técnicas analíticas en el tiempo (De

Brabender et al., 2009).

Protocolo de preparación de la muestra por

49

extracción en fase sólida

Principio básico de la técnica ELISA indirecto o

competitivo. A) Se fija el antígeno a los pocillos. B)

Se añade al pocillo la muestra previamente incubada con el antígeno primario. C) Adición del anticuerpo secundario marcado con una enzima cuyo producto es coloreado

9

Diferencias de absorbancia para un mismo tiempo de lectura entre una muestra conforme (negativa) y una no conforme (positiva)

Ejemplo del esquema general del procedimiento a seguir en el análisis de residuos en carne muestras (C) lavado de la placa (D) adición de sustrato y (E) lectura de absorbancia. lectura a $365 \mathrm{~nm}$. (b) lectura a $306 \mathrm{~nm}$. 
enriquecido con $80 \mu \mathrm{g} / \mathrm{g}$ de carbadox, nitrofurazona, nitrofurantoína, furazolidona y furaltadona. (a) lectura a $365 \mathrm{~nm}$. (b) lectura a $306 \mathrm{~nm}$. Cromatograma de una solución patrón de $20 \mu \mathrm{g} / \mathrm{mL}$ de carbadox carbadox adición de 5,6 dimetil - tiouracilo (PI) retención de 5,6 dimetil tiouracilo (DMTU), 6-propil2tiouracilo (PTU), 2-tiouracilo (TU), y 6 metil-2tiouracilo (MTU) puros enriquecida a nivel de límite de decisión.

Betametasona (BT), dexametasona (DX), patrón interno (IS) almacenado en congelación siendo las muestras fortificadas con dexametasona a nivel de CCa y almacenadas en congelación 

en agua

30

Recta de calibrado en el análisis de dexametasona en pienso

31 Cromatograma de agua fortificada con dexametasona a nivel de CCa (26 ppb) 


\section{INDICE DE TABLAS}

Tabla

Título

Página

1 Directivas, Reglamentos y Decisiones de la Unión Europea en relación con los residuos de medicamentos veterinarios 96/23/EC

3 Ejemplos de kits ELISA disponibles comercialmente para el análisis de sustancias promotoras del crecimiento

Límites de detección de kits ELISA para diferentes residuos y distintas matrices

$5 \quad$ Métodos de screening o criba utilizados en la detección de determinados analitos específicos

Métodos de confirmación adecuados para residuos de algunas de las sustancias de los grupos A y B del Anexo I de la Directiva 96/23/CE

Lista de sustancias pertenecientes al grupo A según la Directiva 96/23/EC y algunas de las sustancias más representativas

$8 \quad$ Lista de sustancias pertenecientes al grupo B según la Directiva 96/23/EC y algunas de las sustancias más representativas

Resumen de los principales métodos de análisis de las sustancias pertenecientes a los grupos $A$ y $B$ según la Directiva 96/23/EC

11 Secuencia de adición de reactivos y muestras de zeranol en los kits ELISA

12 Recuperación de carbadox en muestras de pienso avícola con adición de cantidades controladas 
13 Repetibilidad de las muestras de pienso enriquecidas con 3 concentraciones distintas de carbadox

14 Reproducibilidad intralaboratorio del método de análisis de piensos enriquecidos con 4 concentraciones de carbadox

15 Estabilidad del analito en la matriz orina enriquecida con 200 $\mathrm{ng} / \mathrm{mL}$ de MTU

16 Pérdida del analito en la matriz orina enriquecida con 200 $\mathrm{ng} / \mathrm{mL}$ de MTU y conservada en frascos de vidrio o plástico y en fresco o $4^{\circ} \mathrm{C}$

17 Recuperación de MTU en el análisis de muestras de orina enriquecidas a distintos niveles

18 Repetibilidad del análisis de MTU en muestras de orina enriquecidas a distintos niveles

19 Reproducibilidad intralaboratorio de los análisis de MTU en muestras de orina enriquecidas a distintos niveles

20 Recuperación de dexametasona en muestras de agua y pienso

21 Repetibilidad en el análisis de dexametasona en muestras de agua y pienso

22 Reproducibilidad intralaboratorio en el análisis de dexametasona en muestras de agua y pienso

23 Reproducibilidad calculada mediante la ecuación de Hortwitz como referencia para la precisión del método de análisis de la dexametasona en agua y pienso 
1. Introducción 



\section{INTRODUCCIÓN}

Desde el advenimiento de la era industrial, las personas compran los alimentos cuando antes los producían para su autoconsumo. Este cambio provocó la aparición de los sistemas de producción agropecuarios intensivos así como de la industria alimentaria. La contaminación, tanto microbiológica como química o física, se venía produciendo de manera natural, pero con la necesidad de las nuevas prácticas y de nuevos procedimientos industriales, han ido apareciendo nuevos tipos de contaminación. De hecho, los contaminantes abióticos pueden ingresar en cualquier punto de la cadena alimentaria.

La seguridad de los alimentos que consumimos se ha convertido en una prioridad fundamental tanto para los consumidores como para las industrias productoras y los poderes públicos.

Recientemente hemos sufrido muchas crisis tanto en Europa como en el resto del mundo, lo cual ha acrecentado la sensibilidad de los consumidores a las cuestiones alimentarias. Se podrían citar como ejemplos la enfermedad de las vacas locas, la contaminación de carne de ave con dioxinas, las hormonas, los antibióticos, etc. Todos estos acontecimientos afectan y comprometen la salud de los consumidores, los cuales demandan un mayor y más sensible nivel de control pero también la introducción de nuevos sistemas de producción, nuevas tecnologías y nuevos hábitos alimentarios. Todo esto conlleva a que la legislación alimentaría se reoriente hacia una política más dirigida hacia la vigilancia como mecanismo de prevención. Ante esta presión, la Unión Europea se ha comprometido a reformar su normativa en materia de alimentos, buscando un nivel de protección más elevado para sus consumidores. 
La contaminación alimentaria se puede definir como la introducción o la presencia de contaminantes en los alimentos o en la cadena alimentaria que suponen un riesgo para la salud humana (Codex alimentarius, 1999). Los contaminantes son, por tanto, "agentes de peligro" presentes en los alimentos que hacen que éstos pierdan su inocuidad. Lógicamente, la contaminación de los alimentos conlleva un riesgo sanitario para las personas que consumen esos alimentos.

La OMS define como residuo a cualquier sustancia química que persiste en un medio dado tras haber sido introducida en él voluntariamente o no y cuya presencia es cuantitativa o cualitativamente anormal. Su origen puede estar en el ambiente, en la aplicación de promotores del crecimiento o de medicamentos de uso veterinario, en los aditivos incorporados en los alimentos $o$ bien en sustancias procedentes de transformaciones tecnológicas o tratamientos culinarios.

La contaminación ambiental constituye un buen ejemplo ya que es, hoy por hoy, una fuente importante de residuos y contaminantes químicos en los alimentos. La explotación intensiva del suelo y la producción industrial contribuyen de forma importante a la presencia de contaminantes químicos en los alimentos. En este grupo de residuos se incluyen los pesticidas organoclorados, bifenilos policlorados (PCBs), metales pesados y dioxinas, entre otros.

La transformación industrial de los alimentos (obtención, procesamiento y conservación) debe ser controlada de forma estricta de manera que se asegure la inocuidad de los productos obtenidos. Las principales fuentes de contaminación en este ámbito son los siguientes: efluentes y aguas; equipos, utensilios y superficies de trabajo; ingredientes y aditivos; los procesos tecnológicos; envases y embalajes. 
En ganadería, los tratamientos zootécnicos, profilácticos y terapéuticos son causa frecuente del ingreso de contaminantes químicos en la cadena alimentaria, siendo capaces de producir importantes intoxicaciones. Esto supone un problema de salud pública importante ya que se originan residuos en los alimentos procedentes de los animales tratados. Dentro del amplio grupo de residuos derivados del uso de tratamientos veterinarios se incluyen los compuestos antibacterianos, antimicóticos y antiparasitarios que se emplean en la profilaxis, en el tratamiento de diferentes enfermedades animales y como promotores del crecimiento (tranquilizantes, compuestos de acción tireostática y compuestos de acción hormonal).

A partir de los años cincuenta la ganadería logró incrementar espectacularmente su rendimiento, mediante la progresiva incorporación de diversas innovaciones tecnológicas. Como ejemplo, se podría citar el uso de medicamentos para prevenir y curar enfermedades. Dentro de los medicamentos veterinarios, los antimicrobianos fueron los más empleados debido a las infecciones que presentan los animales durante su crecimiento y desarrollo. El uso de los antibióticos ha generado numerosos problemas con el transcurso de los años y su uso abusivo, destacando la aparición de problemas de resistencias a antibióticos en humanos. Por otra parte, el uso de otras sustancias tales como los $\beta$-agonistas han demostrado efectos cancerígenos. Algunas de estas sustancias han sido objeto de un uso indebido o mal uso, es decir, que pasaron de ser usadas de forma terapéutica y profiláctica a ser utilizados en dosis que potencian el crecimiento de los animales, llegando a la utilización de mezclas muy equilibradas de varias sustancias (cócteles) con un efecto potenciador del crecimiento y que son difícilmente detectables por los controles oficiales que se realizan en los laboratorios destinados a este fin. Así pues, ha habido una evolución en el uso de los medicamentos veterinarios, que han pasado a ser 
utilizados en muchos casos como promotores del crecimiento (Courtheyn et al., 2002; Van Peteguem y Daeselaire, 2004).

El uso de fármacos veterinarios en la producción agropecuaria hace que los consumidores de alimentos de origen animal estén potencialmente expuestos al consumo de residuos de sustancias que pueden tener cierto grado de toxicidad, ya que los compuestos permanecen en el organismo animal como consecuencia del tratamiento recibido, incluyendo el principio activo original y/o los productos de su biotransformación (metabolitos). Estas sustancias también están presentes en los productos derivados de estos animales como son la carne, la leche, los huevos o la miel. La presencia de estos residuos, en mayor o menor proporción, está relacionada con: la naturaleza del producto, la dosis utilizada, la forma de aplicación y el tiempo transcurrido desde su aplicación hasta el sacrificio de los animales (en el caso de la carne y las vísceras) o hasta la recolección del producto cuando se trata de leche, huevos o miel.

El uso terapéutico de los medicamentos veterinarios se realiza bajo control de un veterinario responsable. El uso de hormonas en animales, tales como testosterona, 17ß-estradiol, progesterona y sus derivados pueden estar autorizados por algunos de los estados miembros de la Unión Europea. También se autorizan para uso terapéutico en algunos estados miembros los productos medicamentosos que contienen trembolona, administrada oralmente o algún $\beta$-agonista en equinos y animales de compañía. Estos medicamentos deben ser utilizados siempre siguiendo las instrucciones del fabricante (prospecto). Los $\beta$-agonistas también se pueden utilizar en los procesos de inducción al parto (tocólisis) en rumiantes. Una vez más, estos medicamentos deben ser administrados por un veterinario bajo su estricta responsabilidad. 
Otra aplicación de los medicamentos veterinarios consiste en el uso de algunas sustancias o mezclas de sustancias para el engorde de animales. (Kopochick y Cioffi, 1991). Como ejemplo podemos citar los esteroides y otras sustancias que tienen una actividad farmacológica similar y mejoran la conversión del pienso en proteína. Esta mejora de conversión revierte en un crecimiento o desarrollo del animal más rápido que permite que sea sacrificado antes alcanzando incluso mayor peso en las canales. Esto reporta un claro beneficio económico para el ganadero pero no se tienen en cuenta los efectos nocivos para la salud de los consumidores. Otro grupo de sustancias son los antitiroideos, algunas veces llamados antihormonas porque inhiben la actividad de la glándula tiroidea y producen una mayor retención de agua en la carne.

Dada la incidencia que puedan tener las sustancias administradas a los animales, la Unión Europea estableció un reglamento para todos los países miembros que responde a la voluntad de proteger la salud pública. De esta forma, la Unión Europea prohíbe el uso de medicamentos veterinarios como promotores de crecimiento en la alimentación de animales de granja y acuicultura destinados al consumo humano. Los medicamentos veterinarios más utilizados en estos casos fraudulentos son aquellos que tienen una acción anabolizante, hormonal o tireostática. Los estados miembros prohíben el uso de dichas sustancias tanto en granjas como en piscifactorías debido a que en ambos casos los animales y sus derivados van a ser destinados al consumo humano (Reig y Toldrá, 2008b, 2008c)

Algunos tratamientos zootécnicos constituyen la segunda excepción a esta prohibición general de uso de medicamentos que tienen una acción estrogénica, androgénica o gestágena. Concretamente, hoy en día se centra en los procesos de implantación de embriones en lo que se refiere a animales de granja y en el caso de la acuicultura, se centra en los alevines 
que pueden ser tratados con productos o medicamentos que tienen acción androgénica durante los primeros tres meses con el objetivo de la inversión sexual.

Resulta evidente después de lo expuesto que era necesario desarrollar un programa de metodología analítica y un plan de vigilancia que permitiera cumplir la normativa que regula la aplicación de la Directiva 96/23/EC. Los criterios usados para la identificación y confirmación de los métodos cuantitativos y cualitativos estaban regulados por las decisiones 93/256/EEC y 93/257/EEC. Estos criterios fueron re-examinados en base a los nuevos conocimientos científicos y tecnológicos y dieron lugar al documento de la SANCO (1085/2000) que es la Decisión de la Comisión 2002/657/EC del 12 de agosto de 2002. Este documento ha sido adaptado en todos los países miembros de la Unión Europea desde su entrada en funcionamiento el 1 de septiembre de 2002 para los métodos analíticos de todas las sustancias del grupo A del anexo I de la Directiva 93/23/EC. Los métodos aplicados para la detección de las sustancias listadas en el grupo $B$ del mismo anexo entraron en vigor cinco años después de la publicación de la Decisión 2002/257/EC. Así pues, actualmente nos encontramos de pleno en el cumplimiento de esta decisión tanto para las sustancias del grupo A como del grupo B.

La Decisión 2002/657/EC define los criterios de actuación de los métodos analíticos para residuos, incluye la validación de los métodos y la identificación de los analitos. Además, esta Decisión introduce el concepto de puntos de identificación (IP's), que corresponde al mínimo número de créditos que hay que alcanzar antes de concluir que una muestra es conforme o no conforme. Para las sustancias del grupo $A$, que son sustancias prohibidas, se requieren cuatro puntos de identificación para probar la identidad de la sustancia. Para las sustancias del grupo B, solo se 
exigen tres puntos de identificación (Le Bizec et al., 2009). Esta nueva forma de verificación de que las muestras son conformes o no conformes en base a los puntos de identificación hace que hoy en día sea indispensable el uso de la espectrometría de masas acoplada a los respectivos cromatográfos para la realización de los análisis confirmatorios pero también hace necesario disponer de técnicas sencillas, rápidas, asequibles y efectivas para la criba (screening) previa de un gran número de muestras. 
2. Antecedentes bibliográficos 



\section{ANTECEDENTES BIBLIOGRÁFICOS}

\subsection{Principales grupos de promotores de crecimiento y sus efectos en los animales}

Los promotores del crecimiento incluyen una serie de sustancias muy heterogéneas entre las que destacan los antibióticos, los compuestos hormonales anabolizantes, los agentes antitiroideos, llamados finalizadores cárnicos y los $\beta$-agonistas o agentes de reparto.

Uno de los principales efectos de los promotores de crecimiento es el aumento de la cantidad de proteína y un descenso del contenido en grasa lo cual le da a las canales un aspecto más magro. Esto se traduce en una mayor eficiencia del pienso aunque la carne pierda parte de su jugosidad.

\subsubsection{Agentes antitiroideos}

Los agentes antitiroideos inhiben la producción de la hormona tiroidea (tiroxina) produciendo un aumento de peso de los animales debido a la retención de agua. El aumento de peso es debido a un aumento del contenido de agua en el tracto gastrointestinal y a una retención de agua en los tejidos. La carne procedente de estos animales tratados con agentes antitiroideos es de calidad inferior.

Los agentes antitiroideos o tireostáticos se dividen en dos grupos:

1. El primer grupo contiene análogos del tiouracilo, tales como el tiouracilo (TU), el metiltiouracilo (MTU), propiltiouracilo (PTU), y el feniltiouracilo (PhTU). La figura 1 muestra la estructura química del 6metil-tiouracilo. 
<smiles>Cc1cc(O)nc(S)n1</smiles>

Figura 1 - Estructura química del 6-metil-tiouracilo.

2. El segundo grupo abarca los análogos del mercaptoimidazol, de los cuales el tapasol (1-metil-imidazol-2- tiol), cuya estructura química se muestra en la figura 2, es el más importante.<smiles>Cn1ccnc1S</smiles>

Figura 2 - Estructura química del 1-metil-imidazol-2- tiol.

La Unión Europea prohibió el uso de estas sustancias en animales destinados al consumo humano mediante la Directiva 96/22/CE, de forma que no debe encontrarse ningún residuo de ellas ni en los animales, ni en los productos derivados de ellos. Esto afecta tanto a animales producidos en la Unión Europea como a las importaciones.

Los animales así tratados son fácilmente reconocibles tanto cuando están vivos, por su aspecto más redondeado, como en el matadero dónde se aprecia que sus órganos internos muestran síntomas de haber sufrido hipotiroidismo. 


\subsubsection{Corticoides}

Los cócteles de hormonas administradas como inyectables o en forma de parches se suelen utilizar con frecuencia y tienen un efecto cancerígeno. (Leffers et al., 2001).

Los corticosteroides son hormonas del cortex adrenal que están implicados en una variedad de mecanismos fisiológicos, incluyendo aquellos que regulan la inflamación, el sistema inmunitario, el metabolismo de hidratos $\underline{\text { de carbono }}$, el catabolismo de proteínas, los niveles electrolíticos en plasma $y$, por último, los que caracterizan la respuesta frente al estrés.

Los glucocorticoides, como la dexametasona cuya estructura química se muestra en la figura 3 , ejercen una variedad de efectos secundarios en animales, cuando son administrados a altas dosis. Por ejemplo, la acción catabólica de las grasas y proteínas que queda reflejada por el desgaste de los tejidos, por la reducción de la masa muscular, por osteoporosis, por adelgazamiento de la piel y por la alteración de los patrones de la grasa corporal (Van Peteghem et al., 2001).

Ahora bien, a veces estos fármacos, como por ejemplo la dexametasona, pueden ser utilizados para fines no terapéuticos. Si la administración es a dosis bajas durante largos periodos de tiempo y en función de su biodisponibilidad, su metabolismo y/o su asociación con otras moléculas tales como $\beta$-agonistas, van a producir un aumento de la ganancia de peso y un incremento de la relación músculo/grasa debido a la retención de agua en el músculo, pudiendo utilizarse, en este caso ilegalmente, como promotores de crecimiento (Van Peteghem y Daeselaire, 2004; Croubels et al., 2004). Su uso continuado a bajas dosis conlleva una serie de efectos negativos para el animal que lo recibe, como la degeneración del timo en el ganado, o la producción de una carne de menor 
calidad (Monson et al., 2007; Brambilla, 1997), como para el consumidor de los productos de estos animales.

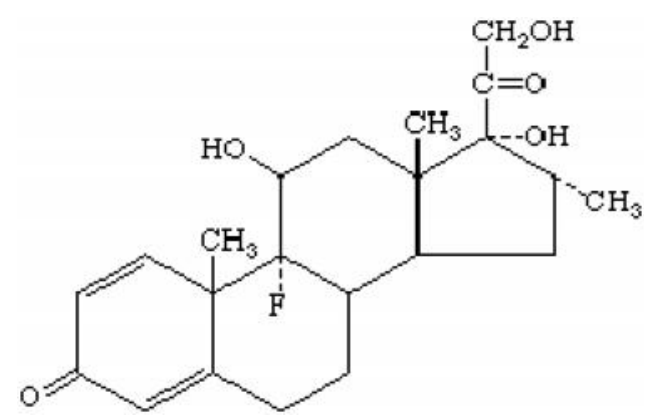

Figura 3 - Estructura química de la dexametasona.

\subsection{3. $\beta$-agonistas}

Los $\beta$-agonistas son usados en medicina veterinaria como broncodilatadores y en los procesos relacionados con el parto como relajantes uterinos pero cuando son usados en grandes dosis ejercen acciones de promotores del crecimiento que tienen un efecto de engorde, dónde el animal gana peso, aumenta la proteína y decrece o disminuye la capa de grasa. La calidad de la carne se ve afectada por el uso de los promotores del crecimiento ya que la producción de tejido conectivo aumenta y se entrecruza más el colágeno resultando en una carne más dura. Además, las proteasas musculares responsables de la ruptura de proteínas en el proceso postmortem son inhibidas (Fiems et al., 1990). Son sustancias obtenidas por síntesis química que se ligan a receptores y actúan como los mediadores biológicos naturales. Se parecen por lo tanto a la adrenalina y noradrenalina, no sólo por su mecanismo de acción, sino por su estructura química. El más conocido es el clembuterol (ver figura 4). 


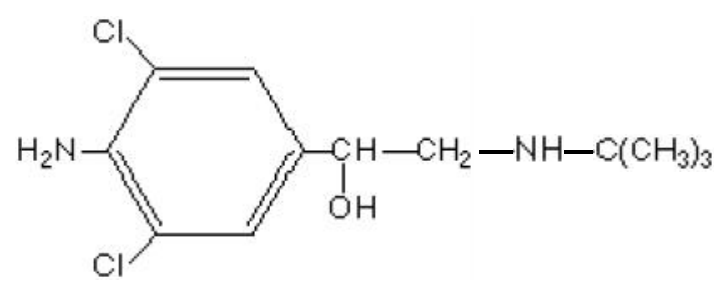

Figura 4 - Estructura química del clembuterol

\subsubsection{Hormonas esteroideas y otras sustancias con acción hormonal}

El uso de esteroides anabolizantes reduce el marmoleo o infiltración de grasa y la terneza lo cual afecta a la palatabilidad de la carne. Estas sustancias ejercen efecto promotor del crecimiento y entre ellas se encuentran la testosterona, trenbolona, zeranol y acetato de melengestrol. Las hormonas esteroideas intervienen en numerosas funciones fisiológicas y de desarrollo. Las hormonas sintéticas parecen enlazarse a los receptores esteroideos con parecida afinidad a las naturales (Wilson et al., 2002; Perry et al., 2005). Así, la trenbolona se une al receptor de andrógeno, el zeranol al receptor de estrógeno y el melengestrol al receptor de progestinas (EFSA, 2007). Límites máximos de residuos han sido establecidos por las autoridades nacionales y por el Codex Alimentario. La Comisión del Codex Alimentario es un foro internacional que busca la normalización de la alimentación humana y animal, con el objeto de garantizar la salud de la población y asegurar prácticas equitativas en el comercio nacional e internacional de alimentos. Estas normas establecen que el uso de antibióticos en la alimentación animal no debe sobrepasar el Límite Máximo de Residuos (LMR) determinado por el Codex.

En algunos casos, resulta difícil la diferenciación entre la producción endógena y la administración exógena. 


\subsubsection{Tranquilizantes}

Los tranquilizantes son suministrados al animal para el transporte, lo cual reduce el estrés y se evita así deficiencias en la calidad de las carnes y de sus productos derivados. Es necesario que el animal no esté estresado ni lesionado durante las operaciones anteriores al sacrificio, para no consumir innecesariamente las reservas de glucógeno muscular. También es importante que el animal esté bien descansado durante las 24 horas anteriores a su sacrificio, con el fin de permitir que el organismo vaya reponiendo el glucógeno muscular lo más posible. Los cerdos son una excepción a la anterior regla. Deben viajar y ser sacrificados de la manera menos estresante posible, pero sin descansar durante largos períodos antes de su sacrificio. También es importante que los niveles de glucógeno en los músculos de la canal sean los más altos posibles, con el fin de desarrollar la máxima cantidad de ácido láctico en la carne. La generación de ácido láctico produce un descenso del $\mathrm{pH}$ por debajo de 6,2. Un $\mathrm{pH}$ a las 24 horas superior a 6,2 indica que el animal estuvo estresado, lesionado o enfermo antes del sacrificio (http://www.fao.org/DOCREP/005).

Las condiciones de estrés dan lugar a carnes (de porcino y avícola) de baja calidad que pueden ser PSE (pálida, blanda y exudativa) caracterizada por un metabolismo acelerado en el momento del sacrificio con una rápida bajada de $\mathrm{pH}$ a valores inferiores a 5,5 a las dos horas postmortem. Por otra parte, la carne DFD (oscura, firme y seca) caracterizada por una escasa bajada de $\mathrm{pH}(\mathrm{pH}>6,2$ a las dos horas postmortem), pueden presentarse en canales de ganado vacuno u ovino, y ocasionalmente en cerdos y pavos, al poco tiempo de su sacrificio. La carne de la canal es más oscura y más seca de lo normal, y tiene una textura más firme. El glucógeno muscular se consume durante el transporte y el manejo en el período anterior al sacrificio. Por consiguiente, hay poca generación de 
ácido láctico tras el sacrificio, produciéndose así una carne DFD. Esta carne es de riesgo higiénico-sanitario debido a su $\mathrm{pH}$ cercano a la neutralidad que favorece posibles crecimientos microbianos.

Los tranquilizantes se suministran pocas horas antes del sacrificio, y por tanto, la presencia de estos fármacos en los animales es evidente por lo que la inspección en matadero debe tenerlo presente ya que debe cumplirse el periodo de supresión.

\subsubsection{Antibióticos}

Los antibióticos han sido ampliamente utilizados en producción animal en forma terapéutica, preventiva y como promotores del crecimiento. A pesar de los beneficios que supone su uso para la salud animal, se ha demostrado que su utilización en la producción animal supone una pérdida de su eficiencia con el tiempo y el desarrollo de resistencias bacterianas que se transmiten a los humanos. Esto ha generado una polémica a nivel mundial dando como resultado la prohibición del uso de los antibióticos en la alimentación animal, lo cual supone un nuevo desafío para los productores ya que se enfrentan a la búsqueda de alternativas para prevenir las enfermedades de los animales y garantizar su salud (CFR, 2008).

El proceso de prohibición se inició en la Unión Europea en 1994; quedando sólo algunos antibióticos permitidos para el uso en dietas de aves, cerdos y bovinos. Posteriormente, debido a la preocupación generalizada por la resistencia a los antibióticos, se prohibió su uso en dietas animales de producción a partir del 2006.

Como ejemplo está el carbadox que es un antibiótico usado en medicina veterinaria pero que también ha sido utilizado de manera ilegal como promotor del crecimiento. 


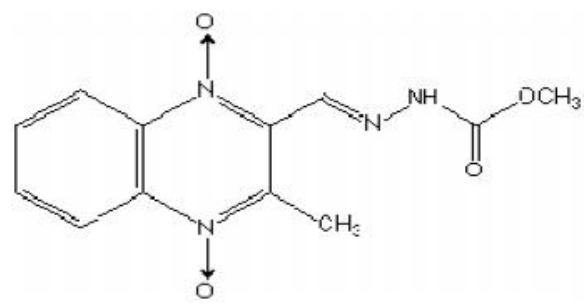

Figura 5 - Estructura química del carbadox

Actualmente está prohibido su uso en animales destinados al consumo humano. Cuando se administra al animal de esta forma incorrecta, suele ser a través del pienso y posteriormente este residuo o su metabolito pasa a ser detectado en la carne que ingiere el consumidor, lo cual es un riesgo para la salud. Puede causar reacciones alérgicas en individuos sensibles o sensibilizados. Sin embargo, el peligro principal de este antimicrobiano es el desarrollo de resistencias a cepas bacterianas, ya que el organismo esta ingiriendo dosis subterapéuticas de este antimicrobiano (Cerniglia et al., 2005; Chadwick el al., 1992; Cerniglia, et al., 1998). La resistencia puede ser transferida a otras bacterias con lo cual la respuesta normal del organismo humano frente a un fármaco se ve mermada o incluso llega a ser nula.

\subsection{Problemática del uso de sustancias promotoras del crecimiento: historial de intoxicaciones}

La presencia de residuos de estas sustancias y/o sus metabolitos en carnes y otros alimentos de origen animal (huevos, leche, miel etc.) pueden causar efectos adversos en la salud de la población que los consume. Algunos de estos efectos adversos se describen a continuación. Precisamente el efecto dañino para la salud hace que el control de estos 
residuos veterinarios usados en animales de granja sea una medida muy importante para asegurar la protección del consumidor (Byrnes, 2005). De hecho, el uso de medicamentos veterinarios en animales está estrechamente regulado en la Unión Europea. Sin embargo, el uso fraudulento continua siendo un factor de riesgo que hay que controlar mediante inspecciones periódicas que se encuentran programadas y diseñadas en los planes vigilancia y control de residuos que se elaboran anualmente en todos los países miembros de la Unión Europea.

En España se detectó el primer brote de intoxicación por clembuterol en Asturias en 1990. No se había registrado ningún brote de ese tipo y se inició la investigación para establecer las causas de aquella intoxicación que se manifestaba con los siguientes síntomas: temblores, palpitaciones y taquicardia acompañados frecuentemente de nerviosismo, cefalea y mialgias, náuseas, inquietud, vómitos, dolor de pecho, boca seca y calambres musculares, con una duración media de 40 horas, aunque llegó a alcanzar un máximo de 6 días.

Al sospechar una intoxicación alimentaria las encuestas realizadas a los afectados incluyeron todo tipo de alimentos ingeridos en los últimos 7 días, encontrando que, generalmente, poco antes del inicio de los síntomas todos los afectados habían consumido hígado de ternera, con un comienzo brusco, después de un período de latencia entre 30 minutos y 6 horas, con una media de dos horas (Barbosa et al., 2005). El clembuterol es un fármaco $\beta$-agonista con afinidad para receptores $\beta 1$ y $\beta 2$. Está autorizado su uso como broncodilatador en humanos (tanto en España como en la Comunidad Europea), así como su uso en animales para el tratamiento de afecciones respiratorias y como relajante uterino en el parto.

Los efectos anabólicos del clembuterol sobre la masa muscular y la grasa corporal han favorecido su uso ilegal en la alimentación animal. Causa 
disminución de la grasa corporal, crecimiento de la masa muscular y ganancia de peso, sobre todo en el ganado vacuno joven. Se acumula en el hígado en grandes cantidades y en menor grado en el músculo, por lo que el consumo de las vísceras conlleva mayor riesgo que el de la carne.

La intoxicación en humanos se produce por ingestión del producto contaminado. Se detecta en orina y sangre de las personas afectadas, dentro de las primeras 48 horas. Este corto período de permanencia de la sustancia en el organismo hace a veces difícil su detección. Los efectos adversos por el consumo de carne contaminada con clembuterol se empezaron a publicar hacia el año 1990 en Europa sobre todo en España e Inglaterra. En la actualidad, en el ámbito internacional, está prohibido el uso de clembuterol como promotor de crecimiento y no hay un valor mínimo que se pueda considerar seguro por lo que su detección en productos cárnicos se considera un delito. A pesar de lo anterior, siguen reportándose problemas de salud por la ingestión a través de productos cárnicos en diversos países como China, Irlanda, México y países del Centro y Sur de América entre otros.

El año en que se presentaron mayor número de brotes y casos fue 1992, desde entonces, la evolución es marcadamente decreciente. El mayor brote fue registrado en 1994 en Madrid con 155 casos.

Durante septiembre de 2006, una serie de enfermedades por alimentos estalló en Shanghai que afectó a más de 300 personas. Se confirmó que estaban relacionadas con comidas de intestinos de cerdos que contenían clembuterol. En junio del mismo año, los empleados de un hotel en Foshan sufrieron una intoxicación alimenticia con clembuterol; y en mayo cientos de trabajadores de una fábrica de vidrio de la provincia de Guangdong se intoxicaron por comer cerdo contaminado con clembuterol. En 2008, 70 empleados de la compañía de productos plásticos Zhongmao de 
la ciudad de Jiaxing, provincia de Zhejiang (China), fueron diagnosticados de intoxicación con clembuterol, tras consumir cerdo en la comida servida por el comedor de la fábrica.

\subsection{Legislación Reguladora en la Unión Europea}

Desde el año 1981, hace casi 30 años, la Unión Europea lleva regulando el uso de ciertas sustancias químicas que, con efecto hormonal o promotor del crecimiento, pueden ser susceptibles de emplearse en la cría del ganado. Ejemplo de ello es la prohibición de la administración a animales productores de alimentos de sustancias como la testosterona, zeranol, acetato de melengestrol, etc.

Considerando que los residuos que dejan en la carne y otros productos de origen animal y que algunas sustancias de efecto tireostático y de efecto estrogénico, androgénico o gestágeno pueden ser peligrosas para los consumidores y pueden también afectar a la calidad de los productos alimenticios de origen animal, se establece la vigilancia de dichas sustancias en la legislación alimentaria para la Unión Europea.

En la tabla 1 se hace referencia a las directivas, reglamentos y decisiones que están actualmente en vigor y que afectan a todos los estados miembros de la Unión Europea.

Actualmente, la norma básica que recoge todas estas medidas en nuestro país, es el Real Decreto 2178/2004, de 12 de Noviembre de 2004, por el que se prohíbe utilizar determinadas sustancias de efecto hormonal y tireostático y sustancias $\beta$-agonistas de uso en la cría de ganado (B.O.E. 13.11.2004) modificado recientemente por el Real Decreto 562/2009 . Esta normativa constituye la transposición de la Directiva 96/22/CE, del Consejo de 29 de abril de 1996, por la que se prohíbe utilizar determinadas sustancias 
de efecto hormonal y tireostático y sustancias $\beta$-agonistas en la cría del ganado y sus posteriores modificaciones.

Tabla 1 - Directivas, Reglamentos y Decisiones de la Unión Europea en relación con los residuos de medicamentos veterinarios.

\section{Temática}

Prohibiciones de sustancias hormonales, tireostáticas y otros medicamentos

Normas de vigilancia y medidas de control

\section{veterinarios}

\section{Legislación}

Directiva 85/358/CE

Directiva 96/22/CE$$
\text { y medidas de control }
$$

Directiva 85/358/CEE

Directiva 86/469/CEE

Decisión 87/410/CEE

Real Decreto 1423/87

Decisión 93/257/CEE

Decisión 93/256/CEE

Real Decreto 1749/98

Decisión 2002/657/CE

Límites máximos de residuos

\author{
Reglamento \\ 2377/90/CEE \\ Reglamento 1308/99/CE \\ Reglamento \\ 470/2009/CE \\ Reglamento 37/2010/UE
}

Aditivos autorizados en alimentación animal

\author{
Directiva 70/524/CEE \\ Reglamento \\ 1831/2003/CE
}

\title{
2.3.1 Plan de vigilancia de residuos
}

La Directiva 96/23/CE del Consejo Europeo, de 29 de abril de 1996, relativa a las medidas de control aplicables a determinadas sustancias y sus residuos en los animales vivos y sus productos y por la que se derogan las 
Directivas 85/358/CEE y 86/469/CEE y las Decisiones 89/187/CEE y 91/664/CEE, incorporada a nuestro ordenamiento jurídico interno mediante el Real Decreto 1749/1998, desarrolla la creación y organización de planes de vigilancia de residuos en los productos de origen animal, estableciéndose entre otros aspectos las medidas de seguimiento ante resultados no conformes, a la vez que pretende que los productores y todas aquellas personas que intervengan en el sector ganadero asuman una mayor responsabilidad en lo que respecta a la inocuidad de cualquier producto de origen animal de su propiedad que se despache al consumo humano.

Las sustancias sobre las cuales se ejercen las citadas medidas de control son clasificadas en el Anexo I de la Directiva 96/23/EC tal como se muestra en la tabla 2.

Los animales y productos cubiertos por la Directiva 96/23/CE son los siguientes:

- Bovinos (animales vivos y su carne)

- Ovinos y caprinos (animales vivos y su carne)

- Porcinos (animales vivos y su carne)

- Équidos (animales vivos y su carne)

- Aves de corral (aves vivas y su carne)

- Acuicultura (animales vivos y sus productos)

- Leche

- Huevos

- Conejos (animales vivos y su carne)

- Caza silvestre (carne)

- Caza de cría (animales vivos y su carne)

- Miel

Dicha Directiva consta de siete capítulos mediante los cuales se establece unas medidas de funcionamiento comunes a todos los países 
miembros de la Comunidad Europea y que son de obligado cumplimiento. Estos capítulos son brevemente descritos a continuación.

Tabla 2.- Clasificación de sustancias del Anexo I de la Directiva 96/23/EC.

GRUPO A - Sustancias con efecto anabolizante y sustancias no autorizadas

1. Estilbenos, derivados de los estilbenos, sus sales y ésteres.

2. Agentes antitiroideos.

3. Esteroides.

4. Lactonas del ácido resorcílico (incluido Zeranol).

5. Beta-agonistas.

6. Sustancias incluidas en el Anexo IV del Reglamento (CEE) No 2377/90 del Consejo del 23 de junio.

\section{GRUPO B - Medicamentos veterinarios y contaminantes}

1. Sustancias antibacterianas, incluidas las sulfamidas, quinolonas.

2. Otros medicamentos veterinarios:

- Antihelmínticos.

- Anticoccidianos, incluidos los nitroimidazoles.

- Carbamatos y piretroides.

- Tranquilizantes.

- Antiinflamatorios no esteroideos (AINS).

- Otras sustancias que ejerzan una actividad farmacológica.

3.Otras sustancias y contaminantes medioambientales:

- Compuestos organoclorados, incluidos los PCB.

- Compuestos organofosforados.

- Elementos químicos.

- Micotoxinas.

- Colorantes.

- Otros. 
Capítulo I Ámbito de aplicación y definiciones

La directiva establece las medidas de control relativas a las sustancias y a los grupos de residuos enumerados en la tabla 2 (Anexo I de la Directiva 96/23/EC). A efectos de la directiva se aplican definiciones habitualmente utilizadas en el campo del análisis de alimentos:

- Alimento: Según el Codex Alimentarius se define como toda sustancia elaborada, semielaborada o bruta que se destina al consumo humano, incluyendo las bebidas, el chicle y cualesquiera otras sustancias que se utilicen en la fabricación, preparación o tratamiento de los alimentos, pero no incluye los cosméticos, ni el tabaco, ni las sustancias utilizadas solamente como medicamentos.

- Analito o sustancia: sustancia que debe ser detectada, identificada y/o cuantificada y los derivados de la misma que se formen durante el análisis.

- Animal: El plan Nacional de Investigación de Residuos lo define como todo animal de las especies contempladas en la Directiva 90/425/CEE.

- Autoridad competente: la autoridad central de un Estado miembro competente en materia veterinaria o cualquier otra autoridad en que aquella haya delegado ésta.

- Carne: El Código Alimentario Español (Anon, 1991) define la carne como la parte comestible de los músculos de los animales destinados al consumo humano (mamíferos o aves) y otras porciones de piel, hueso, nervios, tendones y vasos que los acompañan normalmente. Distingue así el tejido muscular de los llamados despojos que incluyen riñones, hígado y otros órganos y tejidos. El Codex Alimentarius define la carne como la parte comestible de cualquier mamífero (Codex 1996). 
- Contaminante: Según el Codex Alimentarius se define como cualquier sustancia no añadida intencionadamente al alimento, que está presente en dicho alimento como resultado de la producción (incluidas las operaciones realizadas en agricultura, zootecnia y medicina veterinaria), fabricación elaboración, preparación, tratamiento, envasado, empaquetado, transporte o almacenamiento de dicho alimento o como resultado de contaminación ambiental. Este término no abarca fragmentos de insectos, pelos de roedores y otras materias extrañas.

- Laboratorio autorizado: un laboratorio autorizado por la autoridad competente de un Estado miembro para proceder al examen de una muestra oficial con el fin de detectar la presencia de residuos.

- Material de referencia: material del que se haya confirmado una o varias propiedades, por medio de un método validado, de manera que pueda utilizarse para calibrar un aparato o comprobar un método de medición.

- Medicamento veterinario: el Codex Alimentario lo define como cualquier sustancia aplicada o administrada a cualquier animal destinado a la producción de alimentos, como los que producen carne o leche, las aves de corral, peces o abejas, tanto con fines terapéuticos como profilácticos o de diagnóstico o para modificar las funciones fisiológicas o el comportamiento.

- Método de Criba o screening: métodos utilizados para detectar la presencia de una sustancia o tipo de sustancias al nivel de interés. Estos métodos permiten tratar un elevado número de muestras y se utilizan para cribar grandes cantidades de muestras en busca de posibles resultados no conformes. 
- Método de confirmación: método que proporciona información total o complementaría que permite identificar y cuantificar de una manera inequívoca la sustancia a nivel de interés.

- Muestra conforme: se define como una muestra con ausencia de analito o sustancia a investigar.

- Muestra no conforme: se define como una muestra en la cual se ha detectado una cantidad cuantificable de sustancia o analito a investigar.

- Muestra oficial: una muestra tomada por la autoridad competente y que lleve, para el examen de los residuos o de las sustancias incluidas en el Anexo I, la indicación de la especie, la naturaleza, la cantidad y el método de muestreo, así como la indicación del sexo del animal y del origen del animal o del producto animal.

- Nivel de interés: concentración de una sustancia o un analito en una muestra que es significativa para determinar su conformidad con la legislación.

- Patrón de calibración: mecanismo de medición que representa la cantidad total de sustancia de interés de modo que su valor este vinculado a una base de referencia.

- Patrón Interno: sustancia no contenida en la muestra, de propiedades fisicoquímicas lo más próximas posible a las del analito que debe ser identificado, que se añade a cada muestra y sirve como patrón de calibración.

- Residuo: el residuo de sustancia de acción farmacológica, de sus productos de transformación y de otras sustancias que se trasmitan a los productos animales y puedan resultar nocivos para la salud humana. 
- Sustancia: materia de constitución química particular o confirmada y sus metabolitos.

- Sustancias o productos no autorizados: las sustancias o productos cuya administración a un animal estén prohibidas por la normativa comunitaria.

- Tratamiento ilegal: La utilización de sustancias o productos no autorizados o la utilización de productos o sustancias autorizadas por la normativa comunitaria pero para fines o en condiciones distintas de las establecidas en la normativa comunitaria o en las distintas legislaciones nacionales.

Capitulo II: Planes de vigilancia para la detección de residuos o sustancias.

Los Estados miembros de la Unión Europea confiarán a un servicio público central la tarea de coordinar la ejecución de las detecciones de residuos o sustancias previstas en su territorio nacional. Este servicio elaborará un plan para que los servicios competentes se encarguen de efectuarlo. Se coordinarán las actividades de los servicios centrales y regionales encargados de la vigilancia de los diversos residuos. Se reportarán anualmente todos los datos y resultados obtenidos.

Capítulo III: Autocontrol y corresponsabilidad de los operadores

Todos los que comercialicen animales de explotación y toda persona física o jurídica que proceda al comercio de dichos animales serán objeto de inscripción previa ante la autoridad competente y se comprometerán a respetar las normativas comunitarias y nacionales pertinentes. 
Los propietarios o responsables de establecimientos de primera transformación de los productos primarios de origen animal, tomarán todas las medidas necesarias, en particular mediante autocontroles, para:

- Aceptar únicamente animales para los que el productor esté en condiciones de garantizar que se han respetado los plazos de espera.

- Asegurarse que los animales no presentan niveles de residuos que rebasen los límites máximos autorizados.

- No presenten indicios de sustancias o productos prohibidos.

- Los productores o responsables sólo comercializarán animales a los que no se les hayan administrado sustancias o productos no autorizados o que no hayan sido objeto de un tratamiento ilegal con arreglo a la directiva 96/23/EC y animales que en el supuesto que hayan sido tratados con sustancias autorizadas se haya respetado el plazo de espera recomendado para dichas sustancias.

\section{Capitulo IV: Controles oficiales}

Independientemente de los planes de vigilancia establecidos por los servicios centrales de cada país miembro de la Unión Europea, se podrán proceder a controles oficiales por muestreo en los casos como:

- En la fase de fabricación de las sustancias enumeradas en el grupo A del Anexo I así como en la fase de manipulación, almacenamiento, transporte, distribución y venta o adquisición de las mismas.

- En la fase de la cadena de producción y de distribución de alimentos para animales.

- A lo largo de toda la cadena de producción de los animales y de los productos básicos de origen animal.

Los controles se realizarán por las autoridades competentes sin previo aviso. La autoridad competente en caso de sospecha de tratamiento ilegal, 
solicitará al propietario que facilite toda la documentación que permita justificar la naturaleza del tratamiento.

En caso de que dicha investigación confirmara el hecho de la administración de sustancias no autorizadas, se efectuarán controles por muestreo de los animales en sus explotaciones de origen o de procedencia.

La estrategia de muestreo es la siguiente:

El plan de supervisión de los residuos está encaminado a examinar y poner de manifiesto las razones de los riesgos que entraña la existencia de residuos en los productos alimenticios de origen animal en las explotaciones, los mataderos, las industrias lecheras, los establecimientos de transformación de pescado y los centros de recogida y envasado de huevos.

El muestreo debe realizarse de forma imprevista, habrá de ser en momentos inesperados y no fijos y en días de la semana no especificados. Hay que mantener el elemento sorpresa en los controles.

En lo referente a sustancias del grupo A, la supervisión deberá ir encaminada a la detección de la administración de sustancias prohibidas y a la detección de la administración abusiva de sustancias autorizadas. La acción debe concentrarse en niveles y frecuencia de muestreo. Se definirá el número mínimo de animales que deben someterse a muestreo. Cada una de las muestras podrá analizarse para detectar una o más sustancias.

Las muestras deben apuntar a un plan específico, teniendo en cuento criterios como: sexo, edad, especie, sistema de engorde.

En el caso de las sustancias del grupo B, la supervisión debe ir dirigida al control de los residuos de medicamentos veterinarios y al control de la concentración de los contaminantes medioambientales. 
Capitulo V: Medidas que deberán tomarse en caso de infracción.

En el caso de descubrir sustancias o productos no autorizados o sustancias mencionadas en el grupo A y en el grupo B1 y B2, del Anexo I (tabla 2), dichas sustancias o productos no autorizados deberán quedar bajo control oficial hasta que la autoridad competente adopte las disposiciones apropiadas.

Durante el período de consignación de los animales, estos deberán permanecer en la explotación hasta que se tomen las medidas cautelares convenientes en función de la naturaleza de las sustancias detectadas.

En caso de comprobarse el tratamiento ilegal, la explotación ganadera afectada se verá sometida inmediatamente a un control de toma de muestras oficial para su investigación, el tamaño de la muestra debe ser representativo. También se verificará que todos los animales estén provistos de una marca o identificación oficial.

Posteriormente durante un periodo de tiempo de doce meses como mínimo, se someterá a la explotación a un control con vistas a una posible detección de los residuos considerados.

Capitulo VI: Importaciones procedentes de países terceros.

Se establece en la normativa comunitaria que sólo puede autorizarse la importación de un producto de origen animal si éste procede de un tercer país o parte de un tercer país que, entre otros requisitos, tenga aprobado, para el producto en cuestión, el correspondiente plan de vigilancia de residuos de conformidad con la Directiva 96/23/CE del Consejo. La Decisión 2004/432/CE enumera los terceros países que han presentado un plan de vigilancia de residuos de conformidad a la Directiva 96/23/CE.

"La admisión o el mantenimiento en las listas de países terceros previstas en la normativa comunitaria de los que los estados miembros estén 
autorizados a importar animales y productos de origen animal incluidos en el ámbito de aplicación de la presente Directiva quedarán subordinados a la presentación, por parte del país tercero interesado, de un plan en el que se precisarán las garantías ofrecidas por dicho país tercero en cuanto a la vigilancia de los grupos de residuos y sustancias contempladas en el Anexo I de la Directiva 96/23/CE ".

Por tanto, sólo se autorizará la importación de los productos arriba mencionados si proceden de terceros países o parte de ellos, que conforme al Anexo de la Decisión 2004/432/CE (modificado por última vez por la Decisión 2009/800/CE ), tienen aprobado un plan de vigilancia de residuos para el producto en cuestión. Ejemplos de medidas de emergencia aplicables a la importación de productos de origen animal en relación a la posible presencia de residuos de medicamentos veterinarios son las Decisiones 2002/994/CE, actualizada por la Decisión 2009/799/CE, aplicable a productos procedentes de China, y la Decisión 2009/727/CE aplicable a los crustáceos de la India.

\subsubsection{Límite máximo de residuos (LMR)}

Otro punto legislativo muy importante es la legislación referente a los límites máximos de residuos veterinarios.

Los medicamentos veterinarios se usan para garantizar la salud y el bienestar de los animales, pero su utilización en animales productores de alimentos puede dejar residuos. Con el fin de proteger la salud de los consumidores se hace indispensable el realizar una evaluación de seguridad para estas sustancias teniendo en cuenta sus rasgos toxicológicos, la contaminación ambiental y los efectos farmacológicos. Como consecuencia de esta mención, una sustancia farmacológicamente activa sólo se podrá emplear en animales productores cuando se haya realizado una evaluación 
de riesgo, con sólida base científica y resultados favorables. Se establecen, pues, los límites máximos de residuos (LMR) para esta sustancia cuando se considera necesario proteger la salud humana.

El límite máximo de residuos se podría definir como "el contenido de residuos resultante de la utilización de un medicamento veterinario legalmente autorizado en la Unión Europea y considerado admisible desde el punto de vista de la seguridad del consumidor en un producto alimenticio." (Reglamento 2377/90).

Para fijar los límites máximos de residuos se tendrán en cuenta las características toxicológicas y su uso será en base a buenas conductas de prácticas veterinarias, resultados de ensayos de depleción etc. Todos estos estudios servirán para poder fijar el periodo o tiempo de espera en las autorizaciones de comercialización de los medicamentos, es decir, el tiempo que debe transcurrir desde la administración del fármaco hasta el sacrificio del animal.

Actualmente, el Reglamento 470/2009/CE es el que regula los límites máximos de residuos. Este reglamento tiene dos objetivos importantes:

1) La protección de la salud humana y animal, para lo cual se establece que:

a) Una sustancia farmacológicamente activa sólo podrá utilizarse en animales productores de alimentos (carne, pescado, leche, huevos y miel) si ha sido objeto de una evaluación favorable por la Agencia Europea de Medicamentos (EMEA). La evaluación científica de los riesgos tendrá en cuenta el metabolismo y la eliminación de las sustancias activas y la ingesta diaria admisible (IDA). Este reglamento obliga a que el dictamen de la EMEA deberá tener en cuenta todo hallazgo científico pertinente de la Autoridad Europea de Seguridad Alimentaria (EFSA). 
b) Como consecuencia de lo anterior se hará una clasificación de las sustancias activas y de las categorías terapéuticas a las cuales pertenecen, indicándose un LMR, un LMR provisional, la ausencia de establecer un LMR o bien la prohibición de uso de esta sustancia.

2) Garantizar la disponibilidad de medicamentos veterinarios adecuados para enfermedades que afecten a animales productores de alimentos, para lo cual se debe:

a) Establecer un procedimiento de extrapolaciones de LMR ya fijados para una sustancia activa en un alimento/especie a otros alimentos derivados o especies animales diferentes.

b) La incorporación, sin necesidad de dictamen previo de la EMEA, de aquellos LMR adoptados mediante Decisión del Codex Alimentarius para los cuales la delegación de la Unión Europea no haya expresado una objeción.

De manera complementaría a estos objetivos y para facilitar el control de la presencia en los alimentos de sustancias farmacológicamente activas que no hayan sido objeto de una clasificación en la Unión Europea (UE), esta norma también ha fijado un procedimiento para establecer valores de referencia en concentraciones de residuos, es decir, en la menor concentración de un residuo que pueda ser detectada y confirmada por un laboratorio de control oficial. De una manera práctica, se explica que concentraciones por debajo de este valor de referencia fijado para una sustancia no autorizada no podrán dar lugar a incumplimientos de la legislación comunitaria. Anteriormente este concepto era expresado a través de los "Límites mínimos de funcionamiento exigidos" (MRLP).

De forma complementaria a este reglamento 470/2009/CE, con fecha 20 de enero de 2010 se ha publicado el Reglamento 37/2010/CE que recoge la información contenida en los anexos del ya derogado Reglamento 
2377/1990, es decir, los límites máximos de residuos (LMRs) de sustancias farmacológicamente activas en los alimentos de origen animal, y se introducen novedades como son:

- Se crean únicamente dos listas en lugar de los cuatro anexos anteriores: LMRs para sustancias permitidas y lista de sustancias prohibidas.

> Se introduce información acerca de la clasificación terapéutica de las sustancias, así como posibles condiciones o restricciones de su utilización.

$>$ Se ordenan alfabéticamente.

El listado de sustancias farmacológicamente activas para las que no puede establecerse límite máximo alguno que sea seguro para el consumidor de forma que su utilización en animales productores de alimentos está prohibida, incluye las siguientes:

- $\quad$ Aristolochia spp. y sus formulaciones

- Cloranfenicol

- Cloroformo

- Clorpromacina

- Colchicina

- Dapsona

- Dimetridazol

- Metronidazol

- Nitrofuranos

- Ronidazol

El Reglamento de LMR de sustancias farmacológicamente activas también recoge los LMR de aditivos utilizados en alimentación animal 
autorizados en base al Reglamento 1831/2003/CE, por supuesto contando con una evaluación favorable de la EFSA.

La tabla 1 resume todas las Directivas, Reglamentos y Decisiones de la UE para la vigilancia y control de residuos de medicamentos veterinarios en alimentos.

\subsection{Regulaciones en otros países}

Algunos países permiten el uso de ciertas sustancias prohibidas en la Unión Europea, como por ejemplo, el uso de sustancias con actividad hormonal. En países como Canadá, Nueva Zelanda, Australia y Estados Unidos, están autorizadas. Así, la trenbolona, progesterona, zeranol, 17- $\beta$ estradiol, testosterona y la somatotropina bovina están autorizadas en los Estados Unidos y han sido fuente de conflicto permanente con la Unión Europea.

La autorización en Estados Unidos de la utilización de la hormona somatotropina bovina (BST) para aumentar la producción láctea de las vacas lecheras y su prohibición por parte de la UE generó una gran polémica que todavía continúa. La FDA estadounidense ha señalado, mediante estudios toxicológicos, que el empleo de BST en el ganado vacuno no conlleva riesgos para la salud humana (Daughaday et al., 1990; Grossman, 1990; Guest, 1990). Su empleo en los animales disminuye el consumo de pienso lo cual hace que se deposite menos grasa en la canal, haya un aumento de síntesis proteica y, por lo tanto, un mayor crecimiento (Beerman,1989; Kopchick y Cioffi, 1991).

En Estados Unidos, el "Programa Nacional de Control de Resistencia Antimicrobiana" fue iniciado en 1996, a través del trabajo conjunto del Centro de Prevención y Control de Enfermedades (Center for Disease Control and Prevention), de la FDA (Food and Drugs Administration) y el Departamento 
de Agricultura (USDA). El programa controla la presencia de alteraciones en la susceptibilidad microbiana de patógenos entéricos zoonóticos en humanos, especies animales (enfermos y sanos) y en canales.

El control de residuos veterinarios en EEUU se realiza mediante el Programa Nacional de Residuos (NRP). Este programa depende del USDA y está controlado por el Servicio de Inspección y Seguridad Alimentaria (FSIS). Hay dos programas, uno de muestreo interno y el otro que controla las muestras procedentes de importaciones. El programa del FSIS para el control interno está diseñado para realizar muestreos para el control y la prevención de la aparición de posibles restos de medicamentos veterinarios en animales de granja destinados a consumo humano y sus productos. Este programa también controla mataderos. (Reig y Toldrá, 2009).

En Brasil, los programas de control de residuos en alimentos siguen las normas establecidas por el Ministerio de Agricultura y por el Codex Alimentarius, código internacional de alimentos creado en 1962 por la Organización de las Naciones Unidas para la Alimentación y Agricultura (FAO), en conjunto con la Organización Mundial de la Salud (OMS).

Brasil define las normas de inspección y fiscalización obligatorias de productos destinados a la alimentación animal a través de la Ley $n^{\circ} 6.198$ de 26/12/74 y el subsiguiente Decreto $n^{\circ} 76.986$ de 06/01/76.

\subsection{Normativas Reguladoras de la metodología analítica}

\subsubsection{Directiva Europea de métodos analíticos}

Las inspecciones oficiales y los servicios analíticos vigilan el control de residuos y sustancias no autorizadas siguiendo la Directiva 96/23/CE. La metodología analítica debe incluir criterios para la identificación y confirmación de las sustancias no autorizadas y los residuos incluidos todos ellos en el Anexo I de la Directiva 96/23/CE, la cual fue implementada por la 
Decisión de la comisión 2002/657/CE la cual nos aporta las reglas que deben cumplir los métodos analíticos usados en el análisis de muestras oficiales y un criterio especifico común para la interpretación de los resultados analíticos de las muestras oficiales. La metodología analítica incluye los criterios para la identificación de los analitos mediante métodos de barrido rápido, criba o screening y para métodos de confirmación del analito detectado mediante métodos de confirmación.

Nuevos conceptos como el límite de decisión (CC $\alpha)$ y la capacidad de detección (CC $\beta$ ) se incluyen en esta Decisión de la Comisión 2002/657/CE.

Los Estados miembros garantizan que las muestras oficiales tomadas de acuerdo con la Directiva 96/23/CE se analicen según métodos que:

- Están documentados en las instrucciones de ensayo.

- Cumplen los criterios de funcionamiento y otros requisitos y procedimientos de los métodos analíticos.

- Han sido validados de acuerdo con los procedimientos descritos en la Decisión de la comisión 2002/657/CE.

- Cumplen los límites mínimos de funcionamiento exigidos (MRPL) establecidos.

Los estados miembros aseguran la calidad de los resultados de los análisis de las muestras tomadas de acuerdo con la Directiva 96/23/CE, en particular comprobando los ensayos y/o las calibraciones de acuerdo con la norma ISO 17025.

\subsubsection{Interpretación de los resultados}

El resultado de un análisis se considerará no conforme si se supera el límite de decisión del método de confirmación para el analito. 
Si se ha establecido un límite permitido para una sustancia, el límite de decisión es la concentración por encima de la cual puede decidirse con una certeza estadística de 1- $\alpha$ que se ha superado el límite permitido.

Si no se ha establecido límite para una sustancia, el límite de decisión es la concentración más baja a partir de la cual un método puede detectar la presencia del analito en cuestión con una certeza estadística de 1- $\alpha$.

Las técnicas analíticas que se utilizan para el cribado deben estar validadas, hecho que se debe demostrar documentalmente y además tiene que tener un porcentaje de falsos conformes menor al 5\% (error $\beta$ ) al nivel de interés. Las muestras que resultan sospechosas son confirmadas mediante técnicas de confirmación.

\subsubsection{Definiciones del límite de decisión y capacidad de detección}

Las definiciones que se dan a continuación para ambos parámetros están descritas en la Decisión 2002/657/CE (EC, 2002).

El límite de decisión $\mathrm{CC} \alpha$ se define como el límite en el cual y por encima del cual se puede concluir con error de probabilidad alfa que una muestra es no conforme.

La capacidad de detección CC $\beta$ es definida como el menor contenido de una sustancia que puede ser detectada, identificada y/o cuantificada en una muestra con una probabilidad $\beta$ de error. En el caso de sustancias para las que no se ha establecido un límite permitido, la capacidad de detección es la concentración mínima en la que un método puede detectar muestras realmente contaminadas con una certeza estadística de 1- $\beta$.

Ambos límites $\mathrm{CC} \alpha$ y $\mathrm{CC} \beta$ son básicos para demostrar el buen funcionamiento de los métodos específicos que se utilizan en el laboratorio y del equipo específico que se están utilizando para la detección y 
confirmación de los analitos bajo unas condiciones de laboratorio especificas para el control de las muestras.

En el Anexo I de la Directiva 96/23/CE aparecen listadas dentro del grupo A las sustancias no autorizadas, que tienen un efecto anabolizante (ver tabla 2). Por otra parte las sustancias del grupo B son un amplio grupo de medicamentos veterinarios algunos de los cuales tienen establecido un límite máximo de residuo (MRL).

\subsubsection{Validación}

En primer lugar se define el concepto de validación. El concepto de validación ha sido definido por la norma UNE-EN-ISO 8402 (UNE, 1995) como "la confirmación mediante el examen y la aportación de evidencias objetivas de que se han cumplido los requisitos particulares para una utilización específica prevista."

Los laboratorios que realizan el control oficial de las muestras del Plan Nacional de Residuos (PNIR) deben estar acreditados por la entidad acreditadora (ENAC en España). La acreditación no se concede para un laboratorio en su conjunto, sino que se acredita para la realización de técnicas concretas, actualmente se rige por la norma europea 17025. Las técnicas no normalizadas deben ser validadas en cada laboratorio.

La validación permite demostrar que un método analítico cumple los criterios relativos a las características de funcionamiento aplicables. Para cada tipo de método hay que determinar unas características de funcionamiento:

Métodos de criba cualitativos, se debe determinar la capacidad de detección (CC $\beta)$, la selectividad/especificidad y la robustez/estabilidad. 
Métodos de criba cuantitativos, se deben determinar la capacidad de detección (CC $\beta)$, el límite de decisión ( $C C \alpha)$, la precisión, la selectividad/especificidad y la robustez/estabilidad.

\subsubsection{Procedimiento de validación}

La validación de métodos puede realizarse a través de estudios interlaboratorios o de acuerdo con estudios en un solo laboratorio o validación interna. El procedimiento de validación tendrá que cumplir unos parámetros de funcionamiento independientes del modelo y otros dependientes del modelo según se recoge en la Decisión CE 2002/657/CE (EC, 2002). Entre los independientes del modelo están las características comunes de funcionamiento que son:

1. Especificidad

2. Veracidad

3. Aplicabilidad/Robustez (cambios menores)

4. Estabilidad.

Por otra parte, están los parámetros dependientes del modelo, que para la validación interna deben cumplir los siguientes requisitos:

5. Recuperación

6. Repetibilidad

7. Reproducibilidad intralaboratorio

8. Reproducibilidad

9. Límite de decisión ( $\mathrm{CC} \alpha)$

10. Capacidad de detección (CC $\beta$ )

11. Curvas de calibrado

12. Robustez (cambios importantes) 


\subsection{Metodologías analíticas}

El análisis de residuos en alimentos ha sufrido una evolución con el paso del tiempo, todo ello debido al avance tecnológico y al uso sofisticado de nuevos equipos de análisis instrumental, que con el paso de los años se han ido introduciendo en los laboratorios de referencia y en muchos casos se ha visto favorecido por un relativo descenso de su cuantía económica. La figura 6 muestra la rápida evolución de las técnicas analíticas en función del tiempo

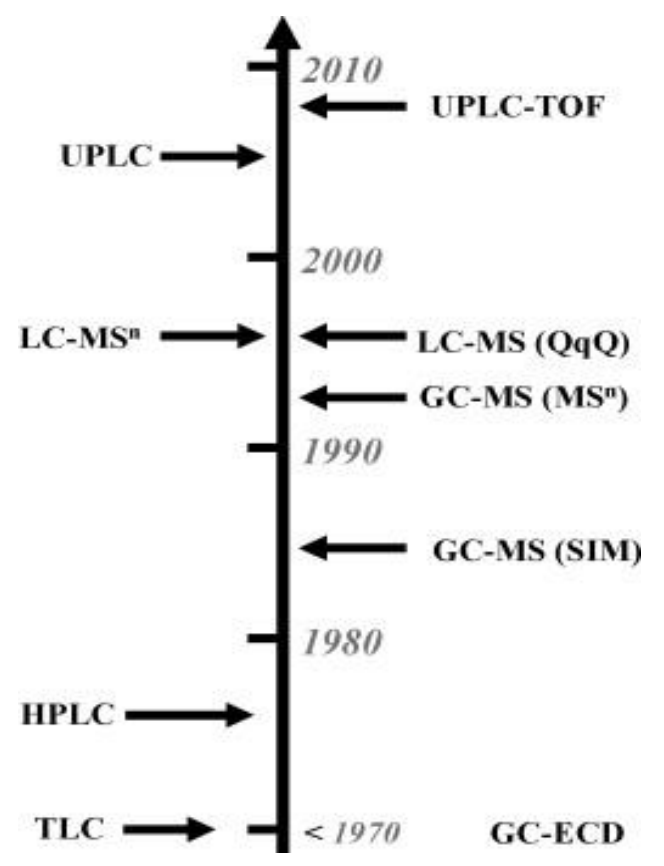

Figura 6 - Evolución de las técnicas analíticas en el tiempo (De Brabender et al., 2009).

La capacidad de detección ha mejorado mucho con el uso de los nuevos equipos de análisis instrumental, ya que para las sustancias del grupo A la legislación exige una detección de residuos lo más baja posible, 
tolerancia cero. La mejora en la detección se ha visto muy influenciada por la preparación de las muestras, paso previo, que también ha sufrido un notable avance, el uso de técnicas de extracción y concentración como son la extracción en fase sólida (SPE) mediante cartuchos o columnas desechables, la extracción mediante columnas de inmunoafinidad (IAC) y el uso de polímeros de impresión molecular (MIP's), la cromatografía líquida de alta resolución (HPLC). Otro punto fundamental consiste en conocer el metabolismo de las sustancias del grupo A y del grupo B ya que a menudo, se tienen que detectar los metabolitos de las sustancias (De Brabander et al; 2009)

El análisis de los residuos de medicamentos veterinarios tiene como objetivo la evaluación de los efectos nocivos bajo un enfoque rigurosamente científico. Para comprender la complejidad de estos métodos analíticos hay que documentar cada una de las partes de que consta el proceso y hay que dar al residuo su dimensión toxicológica, ya que es una sustancia nociva para el organismo. Así pues se definen:

1. la naturaleza de las muestras,

2. el tratamiento de las muestras y

3. el método instrumental empleado en la técnica analítica que se aplica en cada caso.

Los métodos de screening o de criba tienen un papel fundamental para detectar con rapidez la presencia o ausencia de analito de interés en la muestra y están diseñados para evitar falsos negativos. Las técnicas de análisis utilizadas para el análisis inicial suelen ser métodos inmunológicos (biosensores, ELISA), microbiológicos y cromatográficos (HPLC, HPTLC) (Toldrá y Reig, 2006). 
Los métodos de confirmación por el contrario, son aquellos que permiten obtener información adicional para la cuantificación e identificación inequívoca del analito (Decisión de la comisión 2002/657/CE).

\subsubsection{Muestras}

Las muestras utilizadas para el control de residuos proceden de explotaciones ganaderas, son muestras biológicas de animales vivos, como la orina y el pelo de bovino, también se analiza el pienso de distintas especies (avícola, cunícola, bovino, porcino, caprino, ovino y equino) y el agua de beber del ganado vacuno. Estas muestras pueden contener concentraciones traza del analito de interés del orden de $\mu \mathrm{g} / \mathrm{Kg}$ y gran cantidad de compuestos interferentes que dificultan la detección de los residuos.

Los métodos microbiológicos fueron utilizados durante años para detectar los compuestos con actividad antimicrobiana, pero actualmente están en desuso ya que no permiten discriminar sustancias entre una misma familia terapéutica. Por otra parte, tampoco son validos para la detección de compuestos sin actividad microbiana (Aerts at al., 1995).

Cada muestra tiene sus propios requisitos que se resumen brevemente a continuación:

El agua es una matriz fácil de tratar, la muestra debe ser representativa y se mantiene en congelación hasta el momento del análisis.

Las muestras de pienso son muy heterogéneas debido a los distintos tipos de piensos que se formulan para cada especie animal por lo que la muestra debe ser suficientemente grande y representativa.

Las muestras de orina se congelan después de su toma y se mantienen en congelación hasta el momento de su análisis. La orina es un fluido biológico que no necesita homogenización. 
El pelo de vacuno procede de animales de pelo oscuro, siempre que sea posible, las muestras se toman de la parte del cuello del animal. Requiere una preparación laboriosa de la muestra.

\subsubsection{Preparación de las muestras}

Los protocolos generales para el tratamiento de las muestras constan de una etapa de extracción y otra de purificación al objeto de aislar los analitos de interés de las distintas matrices. Los protocolos análiticos de extracción y purificación de una matriz biológica deben adaptarse en función de la especificidad y sensibilidad de las técnicas utilizadas para su detección (Kinsella et al., 2009). La elaboración de un buen protocolo de análisis se basa en el conocimiento de las características químicas del analito a detectar: solubilidad, polaridad, etc., lo cual permite determinar su comportamiento en la extracción bien con disolventes o bien en fase sólida. En segundo lugar, se valoran los parámetros de reproducibilidad, precisión, exactitud y seguridad, permitiendo realizar el trabajo de análisis de las muestras de una forma automática, con el menor tiempo posible y con un coste razonable. Una vez establecido este protocolo de análisis se procede a la validación del método.

El primer paso dentro del protocolo de extracción consiste en la preparación de la muestra. La preparación de la muestra es un procedimiento de vital importancia para el análisis químico ya que según algunas estimaciones entre el 60 y el $80 \%$ del trabajo y del coste de un laboratorio analítico se utiliza para el tratamiento o preparación de la muestra. El sistema de preparación de la muestra va a depender fundamentalmente de la matriz y de la estabilidad de los analitos. Puede ser necesario un ajuste de $\mathrm{pH}$ para que las condiciones de extracción y purificación sean las adecuadas o una dilución de la misma para reducir la 
viscosidad y asegurar una fluidez adecuada para su análisis. La preparación de la muestra en el análisis de residuos permite concentrar los componentes hasta los niveles adecuados para poder proceder a su detección y también, eliminar la presencia de elementos que puedan interferir y/o dificultar la detección de las sustancias de interés (Bogialli et al., 2007).

Los métodos más utilizados para la preparación de las muestras incluyen la extracción líquido-líquido, la centrifugación y la extracción en fase sólida.

La extracción líquido-líquido (LLE) se basa en el empleo de disolventes adecuados para extraer los analitos de interés de la muestra, generalmente se utilizan disolventes orgánicos (hexano, tert-butilmetileter, etc.) logrando una separación de los compuestos de interés en la fracción orgánica. Básicamente la extracción se realiza de la siguiente manera, considerando que la muestra contiene los analitos disueltos en una muestra acuosa, se realiza un lavado líquido/líquido (LLE) añadiendo un cierto volumen de un disolvente orgánico, seguidamente la muestra se agita o se sonica con un ultrasonidos y se centrifuga, siendo en este último paso donde se separan las fases. En la fase orgánica es donde se encuentran los analitos de interés, en la fase acuosa permanecerán los compuestos hidrófilos, iónicos y las sales.

En algunos casos puede interesar la ionización de los analitos de interés, añadiendo por ejemplo ácido clorhídrico, al objeto de que estos permanezcan en la solución acuosa y posteriormente añadir un disolvente orgánico para separar los compuestos apolares de interés. La utilización de una solución ácida permite la extracción de compuestos nitrogenados, mientras que la utilización de una solución alcalina permite ionizar ciertos ácidos orgánicos, compuestos fenólicos y otros pigmentos. 
La extracción en fase sólida (SPE) se basa en las interacciones de uniones lábiles (electrostáticas, iónicas, de Van der Waals, etc) entre los constituyentes de la fase líquida (muestra) y una fase estacionaria sólida. Esta fase estacionaria está constituida, normalmente por sílice con agrupaciones químicas de tipo polar (cadenas alquilo), de polaridad intermedia $\left(-\mathrm{OH},-\mathrm{CN},-\mathrm{NH}_{2}, \ldots\right)$ o muy polares. La fase estacionaría viene empaquetada en un cartucho de polipropileno o cualquier otro polímero inerte y son de un solo uso. Este relleno es el que interacciona con la muestra reteniendo los analitos de interés. La extracción en fase sólida consiste en el acondicionamiento del cartucho, la carga de la muestra, lavado y elución de la muestra. Un protocolo típico de extracción en fase sólida se muestra en la figura 7 .

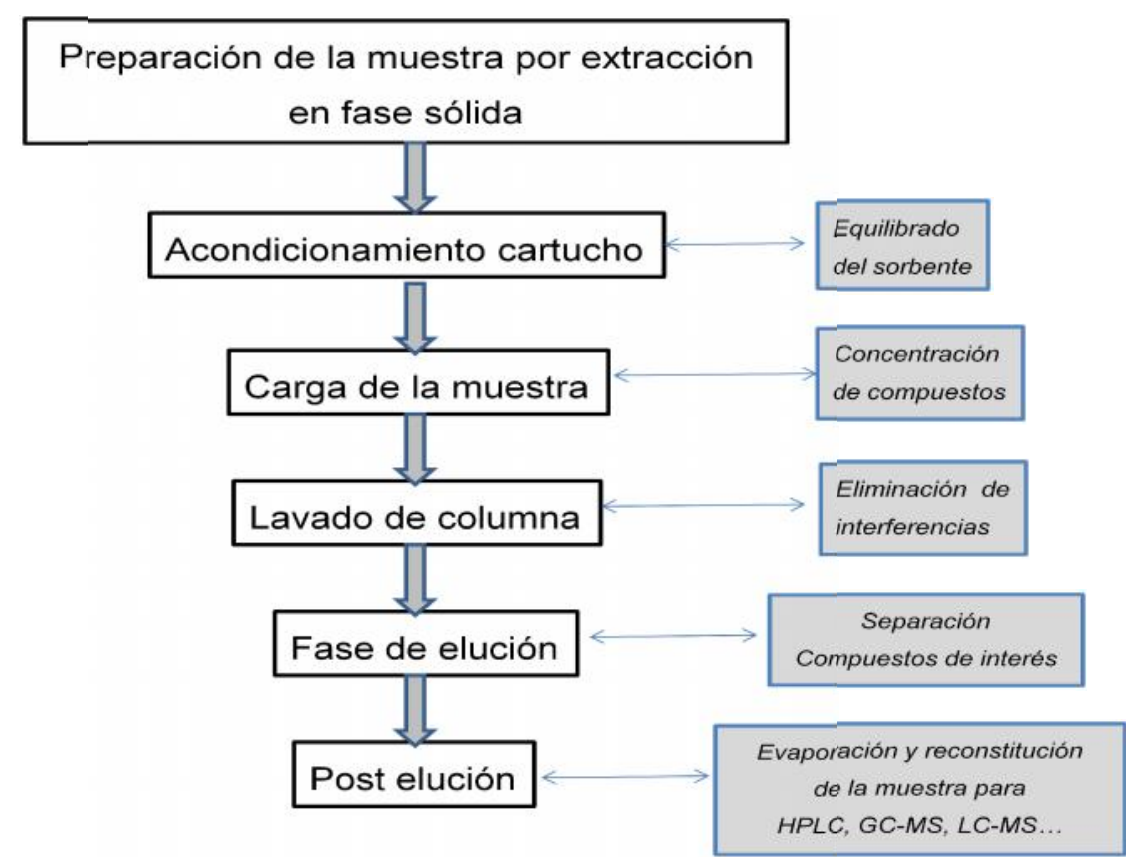

Figura 7 - Protocolo de preparación de la muestra por extracción en fase sólida. 


\subsubsection{Agua}

Las muestras de agua llegan al laboratorio congeladas y hasta el momento de procesarlas se mantienen en congelación. Una vez descongelada, el agua necesita ser centrifugada para eliminar posibles partículas en suspensión y queda disponible para el análisis.

\subsubsection{Pienso}

La muestra de pienso es muy heterogénea debido a los distintos tipos de piensos que se formulan para cada especie animal. Los piensos se someten a un proceso de molienda para homogeneizarlos, se mantienen en oscuridad y en lugar seco, y posteriormente se someten a una adecuada extracción líquida o bien a su disolución, filtración y posterior extracción en fase sólida (SPE) para la limpieza y concentración de la muestra.

\subsubsection{Orina}

La orina es un fluido que no necesita homogenización pero sí centrifugación para eliminar partículas en suspensión. Después de centrifugar se toma una alícuota, se diluye con tampón y se ajusta el $\mathrm{pH}$. Algunos analitos forman conjugados, tales como glucurónidos, de manera que es necesario someter a la muestra a una hidrolisis para liberar al analito. La hidrólisis enzimática con Helix pomatia, que contiene sulfatasa y $\beta$ glucoronidasa, es un tratamiento suave y suele ser la más utilizada dado que da buenos resultados.

Se deben tomar precauciones a la hora de realizar otros tipos de hidrólisis ya que en algunos casos, hidrólisis ácidas o alcalinas son más agresivas y pueden afectar o incluso degradar el analito. 


\subsubsection{Pelo}

El pelo, debe ser lavado con detergente (SDS) y posteriormente ser extraido con metanol y llevado a sequedad con nitrógeno. Algunos métodos preparativos incluyen una hidrólisis ácida o alcalina. (Gleixner y Meyer, 1996; Haasnoot el al., 1998).

\subsubsection{Métodos de criba o screening}

Los métodos de criba, también conocidos como de cribado o de screening, son utilizados para detectar la presencia de una sustancia o grupo de sustancias al nivel de interés. Estos métodos permiten tratar un gran número de muestras simultáneamente y se utilizan para cribar gran número de muestras en busca de posibles resultados no conformes.

Todos los métodos analíticos que se utilicen para la criba o screening deben cumplir unos requisitos generales. En primer lugar, la manipulación de la muestra debe garantizar que se evite la contaminación accidental o la pérdida del analito, obteniéndose la máxima probabilidad de detectar la sustancia. En segundo lugar, se debe determinar la recuperación y la especificidad. La definición de ambos términos (EC, 2002) es la siguiente:

La recuperación es el porcentaje de la concentración real de una sustancia recuperado durante el procedimiento analítico. Se emplea material en blanco enriquecido con el analito de interés. Este factor siempre se determina en la validación si no se dispone de material certificado de referencia.

La especificidad es la capacidad de un método para distinguir entre el analito que se está midiendo y otras sustancias.

De acuerdo con la Decisión 2002/657/CE que se aplica a la Directiva 96/23/CE, para el cribado o screening se utilizarán técnicas analíticas respecto de las cuales se pueda demostrar de modo documental que están 
validadas y que tienen un porcentaje de falsos conformes $<5 \%$ ( error $\beta$ ) al nivel de interés.

\subsubsection{Ensayos ELISA}

Hay distintas técnicas disponibles para el screening o barrido rápido de muestras pero en los últimos años las técnicas basadas en inmunoafinidad, como los test ELISA que consisten en ensayos con inmunosorbentes ligados a una enzima ("enzyme linked immunosorbent assay") han sido ampliamente usados para este tipo de análisis inicial debido a que son fáciles de usar, sensibles, rápidos y permiten analizar gran número de muestras de forma simultánea (Hahnau y Jülicher, 1996; Toldrá y Reig, 2006; Reig y Toldrá, 2008a).

Actualmente, existen muchos kits ELISA en el mercado. En la tabla 3 se muestran algunos de los diferentes tipos de kits disponibles comercialmente según la sustancia o grupos de sustancias que se quiera detectar.

Los límites de detección dependerán de la extracción y limpieza que se le haga a la muestra. Dependiendo de la matriz a analizar, la preparación de la muestra consta desde una simple dilución con tampón, en el caso más sencillo, hasta una hidrólisis enzimática y una extracción en fase sólida (SPE).

Los métodos inmunológicos son específicos para cada tipo de analito, están basados en una reacción antígeno-anticuerpo. En los últimos años se han desarrollado un gran número de inmunoensayos para la detección de residuos en alimentos. Las reacciones antígeno-anticuerpo han sido usadas durante muchos años para detectar una gran variedad de constituyentes de alimentos incluyendo las sustancias responsables de adulteraciones y contaminantes. La interacción antígeno anticuerpo es muy específica y muy 
útil en la detección de residuos químicos y de medicamentos veterinarios que aparecen en los alimentos de origen animal. La técnica más usada consiste en un ensayo basado en una enzima ligada a un inmunosorbente (ELISA) y el sistema de detección por lectura espectrofotométrica. Hay diferentes formatos para la cuantificación por antígenos.

Tabla 3.- Ejemplos de kits ELISA disponibles comercialmente para al análisis de sustancias promotoras del crecimiento.

\begin{tabular}{lclc}
\multicolumn{1}{c}{ Tipo de residuo } & Grupo & $\begin{array}{c}\text { Principal } \\
\text { sustancia a detectar }\end{array}$ & $\begin{array}{c}\text { Límite } \\
\text { de detección } \\
\text { (ng/mL) }\end{array}$ \\
\hline $\begin{array}{l}\text { Estrógenos } \\
\text { Esteroides }\end{array}$ & A 1 & Dietilestilbestrol & 0.2 \\
Lactonas del ácido & A 3 & Trembolona & 0.5 \\
resorcílico & A 4 & Zeranol & 0.25 \\
B-agonistas & A 5 & Clembuterol & 0.3 \\
Antibioticos & A 6 & Cloranfenicol & 0.5 \\
Antibioticos & B 1 & Sulfonamidas & 0.5 \\
Antibioticos & B 1 & Tilosina & 5.0 \\
Antibioticos & B 1 & Gentamicina & 1.5 \\
Corticoides & B 2f & Dexametasona & 2.5 \\
\hline
\end{tabular}

El test ELISA competitivo consiste en un anticuerpo primario, por ejemplo en el caso de $\beta$-agonistas se emplea el anticuerpo de oveja antiinmunoglobulina $\mathrm{G}$ de conejo, que recubre cada uno de los pocillos. En una primera incubación se mezclan los anticuerpos específicos, el conjugado y se incuba con el extracto de la muestras a analizar o los patrones que contienen los antígenos. Los anticuerpos específicos se unen a los anticuerpos inmovilizados en el pocillo y al mismo tiempo los $\beta$-agonistas o el analito problema presente en la muestra compite con el conjugado enzimático por la 
unión en los sitios específicos de los anticuerpos. Después de un tiempo de incubación, los reactivos que no se han unido son eliminados de los pocillos mediante el lavado. La cantidad de conjugado unido se visualiza a través de la adición del sustrato cromógeno (tetrametilbenzidina), es decir, se añade el sustrato apropiado se incuba la placa y se desarrolla el color. Esta reacción finaliza con la adición de un ácido. Se mide la intensidad del color leyendo la absorbancia óptica a $450 \mathrm{~nm}$, cuyo valor es inversamente proporcional a la concentración de analito problema en la muestra.

La figura 8 muestra un esquema de los pasos más importantes del ensayo ELISA competitivo o indirecto.

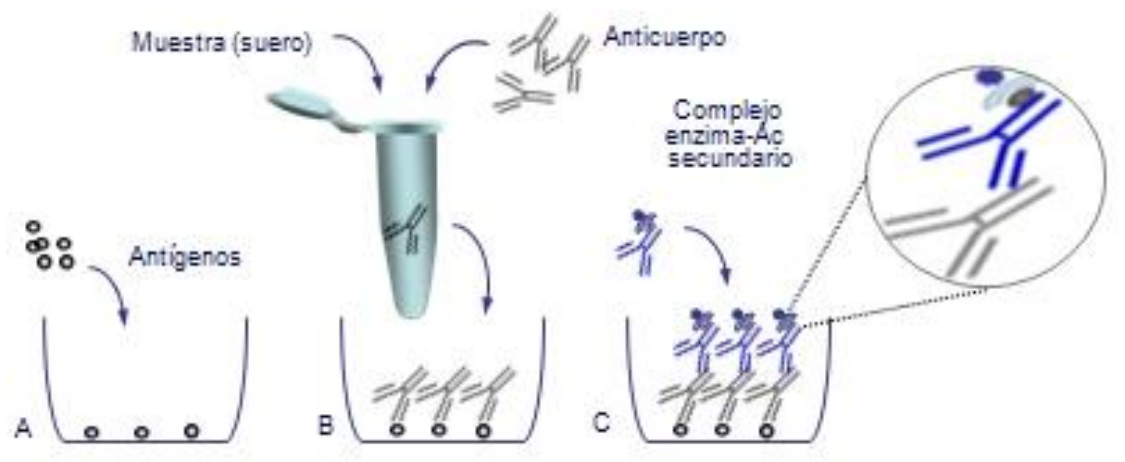

Figura 8 - Principio básico de la técnica ELISA indirecto o competitivo. A) Se fija el antígeno a los pocillos. B) Se añade al pocillo la muestra previamente incubada con el anticuerpo primario. C) Adición del anticuerpo secundario marcado con una enzima cuyo producto es coloreado.

La lectura e interpretación de los resultados se basa en la variación de la absorbancia en función del tiempo para muestras positivas y negativas y tiempo óptimo de lectura o parada de la reacción (Figura 9). 


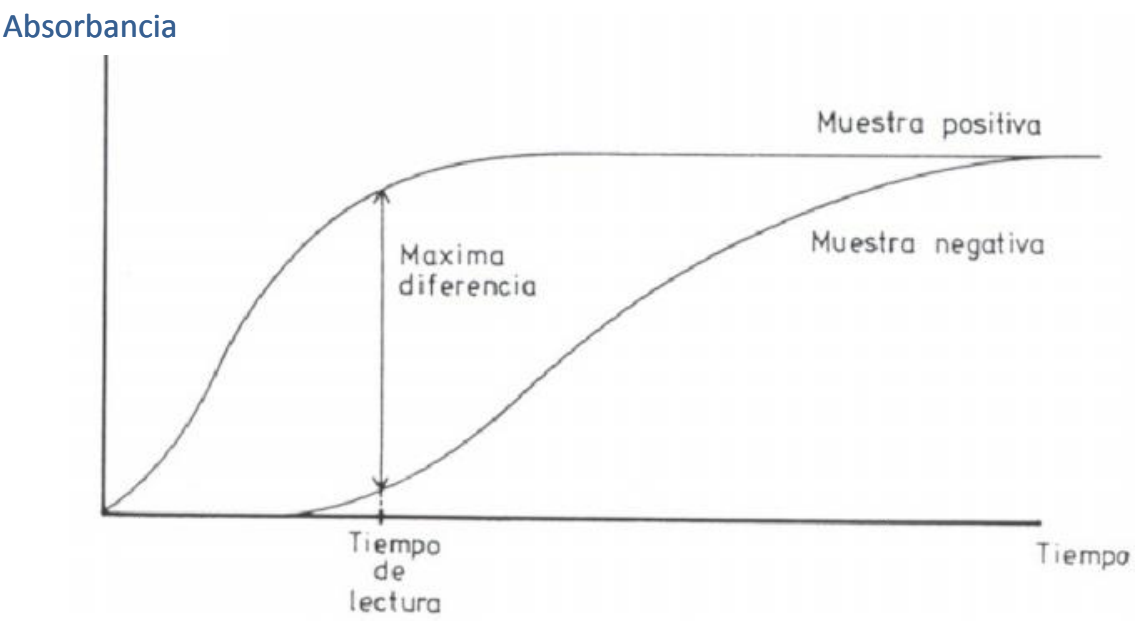

Figura 9 - Diferencias de absorbancia para un mismo tiempo de lectura entre una muestra conforme (negativa) y una no conforme (positiva).

La lectura de los resultados puede ser valorada tanto visual como colorimétricamente. A simple vista, pueden ser leídos ciertos ensayos rutinarios en los que no haga falta una cuantificación y no se presenten abundantes casos dudosos (el ojo humano no es capaz de discernir una variación de 0,1 de densidad óptica) ya que dicha lectura visual tendrá el inconveniente de la subjetividad y el de diagnosticar equivocadamente los casos límite. No obstante, evita la adquisición de aparatos relativamente costosos como son los lectores de microplacas.

Una de las grandes ventajas de la técnica ELISA es la posible automatización de la lectura $\mathrm{y}$, por lo tanto, su objetividad. Dicha automatización se puede conseguir con un simple colorímetro o espectrofotómetro de cubeta o con sofisticados equipos de lectura automática de microplacas.

Los resultados finales de la lectura colorimétrica se reflejan numéricamente mediante valores de absorbancia o densidad óptica que se 
obtendrán a la longitud de onda más adecuada para la coloración final alcanzada.

Los kits ELISA ofrecen la ventaja de poder analizar un gran número de muestras por kit, en un tiempo relativamente corto, con buena especificidad y sensibilidad cuando se compara con métodos tradicionales (Hahnau y Jülicher, 1996; Toldrá y Reig, 2006).

Además de los kits ELISA basados en el desarrollo de color y que se encuentran hoy día en el mercado, existen otros muchos ensayos de tipo ELISA, desarrollados en laboratorio para distintos residuos y que se resumen en la tabla 4 con sus respectivos límites de detección.

En general, los límites de detección dependen de la extracción y de la purificación previa que se le haga a la muestra (De Wasch et al; 2001, Gaudin et al; 2003, Cooper, Delahaut et al; 2004a). Los kits ELISA son muy sensibles para la mayoría de las sustancias analizadas por este método y se pueden obtener resultados semicuantitativos, pero siempre hay que tener presente que es una técnica de criba o barrido rápido. Esto significa que se pueden dar falsos positivos como por ejemplo debido a interferencias con otras sustancias que presenten reacciones cruzadas debido a que su estructura química es similar o más raramente, debido a cambios de $\mathrm{pH}$ o composición de los tampones. Esto va a depender en parte, de la selectividad de cada kit. Por ejemplo, algunos kits ELISA solo detectan el clembuterol pero pueden presentar, y de hecho presentan, reacciones cruzadas para otros $\beta$-agonistas cuya estructura química es parecida al clembuterol. La parte positiva de estas interacciones es que la detección del residuo tiene valor de técnica multiresiduo pero siempre se tendrán que utilizar métodos de confirmación para poder asegurar y confirmar el analito o analitos que se están detectando. Todas las muestras con resultado no conforme o dudoso deben ser confirmadas. 
Tabla 4. Límites de detección de kits ELISA para diferentes residuos y distintas matrices.

\begin{tabular}{|c|c|c|c|c|}
\hline Tipo de residuo & Grupo & Matriz & $\begin{array}{l}\text { Límite de } \\
\text { Detección }\end{array}$ & Referencia \\
\hline $\begin{array}{l}\text { Eritromicina } \\
\text { Tilosina }\end{array}$ & Antibiótico & $\begin{array}{l}\text { Carne de } \\
\text { bovino }\end{array}$ & $\begin{array}{l}0,4 \mathrm{ng} / \mathrm{mL} \\
4 \mathrm{ng} / \mathrm{mL}\end{array}$ & $\begin{array}{l}\text { Draisci et al, } \\
2001 .\end{array}$ \\
\hline $\begin{array}{l}\text { Oxitetraciclina } \\
\text { Clortetraciclina } \\
\text { Tetraciclina }\end{array}$ & & $\begin{array}{l}\text { Carne de } \\
\text { pollo }\end{array}$ & $<\mathrm{EU} M \mathrm{MRL}^{-}$ & $\begin{array}{c}\text { De Walsch et al, } \\
2001 .\end{array}$ \\
\hline $\begin{array}{l}\text { Bacitracina } \\
\text { Tilosina } \\
\text { Espiramicina } \\
\text { Virginiamicina } \\
\text { Olaquindox }\end{array}$ & & Pienso & $1 \mu \mathrm{g} / \mathrm{g}$ & $\begin{array}{l}\text { Situ y Elliott, } \\
2005 .\end{array}$ \\
\hline Sulfaclorpiridacina & & $\begin{array}{l}\text { Carne de } \\
\text { pollo }\end{array}$ & $100 \mathrm{ng} / \mathrm{g}$ & Wang et al, 2006 . \\
\hline Tetraciclina & & $\begin{array}{l}\text { Plasma de } \\
\text { cerdo }\end{array}$ & $10 \mathrm{ng} / \mathrm{mL}$ & Lee et al, 2001. \\
\hline $\begin{array}{l}\text { Tilosina } \\
\text { Tetraciclina }\end{array}$ & & Agua & $\begin{array}{l}0,1 \mathrm{ng} / \mathrm{mL} \\
0,05 \mathrm{ng} / \mathrm{mL}\end{array}$ & $\begin{array}{l}\text { Kumar et al, } \\
2004 \text {. }\end{array}$ \\
\hline Cloranfenicol & & $\begin{array}{l}\text { Carne de } \\
\text { pollo }\end{array}$ & $6 \mathrm{ng} / \mathrm{mL}$ & $\begin{array}{c}\text { Zhang et al., } \\
2006 \text {. }\end{array}$ \\
\hline Dietilestilbestrol & Estrógeno & $\begin{array}{l}\text { Carne de } \\
\text { pollo }\end{array}$ & $0,07 \mathrm{ng} / \mathrm{mL}$ & Xu et al., 2006 . \\
\hline Hexoestrol & & $\begin{array}{l}\text { Carne de } \\
\text { cerdo }\end{array}$ & $0,07 \mathrm{ng} / \mathrm{mL}$ & Xu et al., $2006 \mathrm{~b}$ \\
\hline Avermectina & Insecticida & $\begin{array}{l}\text { Hígado de } \\
\text { bovino }\end{array}$ & $1,06 \mathrm{ng} / \mathrm{mL}$ & Shi et al., 2006. \\
\hline $\begin{array}{l}\text { Acetato de } \\
\text { Medroxiprogesterona }\end{array}$ & Esteroide & $\begin{array}{l}\text { Carne de } \\
\text { pollo }\end{array}$ & $0,096 \mathrm{ng} / \mathrm{mL}$ & $\begin{array}{l}\text { Chifang et al., } \\
2006 .\end{array}$ \\
\hline Semicarbacida & Nitrofurano & $\begin{array}{l}\text { Carne de } \\
\text { pollo }\end{array}$ & $\begin{array}{l}\mathrm{CC} \beta=0,25 \\
\mathrm{ng} / \mathrm{g}\end{array}$ & $\begin{array}{l}\text { Cooper et al., } \\
2007 \text { a. }\end{array}$ \\
\hline $\begin{array}{l}\text { Dimetridazol } \\
\text { Metronidazol } \\
\text { Ronidazol } \\
\text { Hidroxidimetridazol } \\
\text { Ipronidazol }\end{array}$ & Nitroimidazol & $\begin{array}{l}\text { Carne de } \\
\text { pollo }\end{array}$ & $\begin{array}{l}C C \beta=2 \mathrm{ng} / \mathrm{g} \\
C C \beta=10 \mathrm{ng} / \mathrm{g} \\
C C \beta=20 \mathrm{ng} / \mathrm{g} \\
C C \beta=20 \mathrm{ng} / \mathrm{g} \\
C C \beta=40 \mathrm{ng} / \mathrm{g}\end{array}$ & Huet et al., 2005. \\
\hline $\begin{array}{l}\text { Azaperol } \\
\text { Azaperona } \\
\text { Carazolol } \\
\text { Acepromacina } \\
\text { Clorpromacina } \\
\text { Propionilpromacina }\end{array}$ & Tranquilizantes & $\begin{array}{l}\text { Riñón de } \\
\text { cerdo }\end{array}$ & $\begin{array}{l}5 \mathrm{ng} / \mathrm{g} \\
15 \mathrm{ng} / \mathrm{g} \\
5 \mathrm{ng} / \mathrm{g} \\
5 \mathrm{ng} / \mathrm{g} \\
20 \mathrm{ng} / \mathrm{g} \\
5 \mathrm{ng} / \mathrm{g}\end{array}$ & $\begin{array}{l}\text { Cooper et al., } \\
2007 \mathrm{~b} .\end{array}$ \\
\hline
\end{tabular}


Un ejemplo de esquema del procedimiento general para el análisis de muestras de carne se esquematiza en la figura 10.

Para cada kit ELISA se realizan las rectas de calibración y se expresa la densidad óptica (DO) en función del logaritmo de la concentración. Deben presentar un buen coeficiente de correlación y una buena sensibilidad para que los resultados sean válidos.

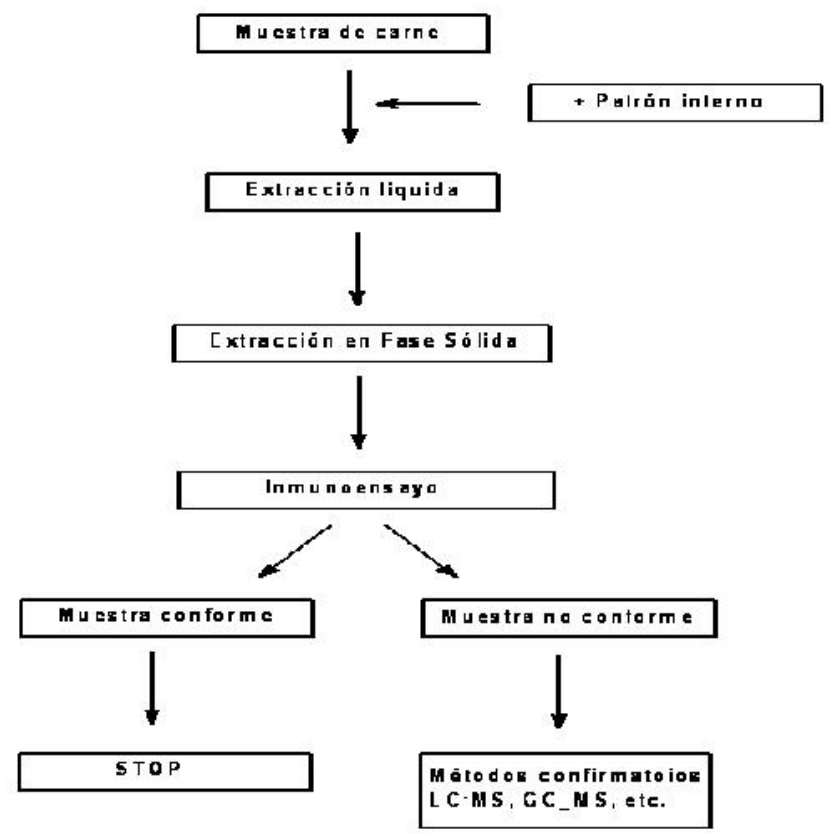

Figura 10 - Ejemplo del esquema general del procedimiento a seguir en el análisis de residuos en carne.

Varios estudios inter-laboratorio han sido realizados para poder comparar los kits ELISA de distintos suministradores como es el caso de la detección de cloranfenicol en porcino, que se realizó en 2002 con la participación de 20 países de la Unión Europea. Este estudio se realizó en muestras de músculo con diferentes niveles de cloranfenicol. Los resultados fueron buenos ya que los falsos positivos encontrados fueron del $0 \%$ y los 
resultados no conformes fueron de 10\% (Gaudin et al., 2003). Otro amplio trabajo de comparación de kits ELISA, se llevo a cabo realizando un estudio interlaboratorio con 15 laboratorios de países de la Unión Europea que representaban Agencias gubernamentales e industrias privadas, fue realizado para la detección de cinco antimicrobianos utilizados como promotores del crecimiento (bacitracina de zinc, espiramicina, tilosina, virginiamicina y olaquindox) los resultados obtenidos fueron de $0 \%$ de falsos conformes y $1.9 \%$ de resultados falsos no conformes (Situ et al., 2006).

Para algunos analitos, como el caso del zeranol, los inmunoensayos no son tan efectivos porque presentan reacciones cruzadas. En el caso del zeranol se observa que presenta reacción cruzada con las toxinas formadas por Fussarium spp, dando resultados falsos no conformes.

En todos los protocolos de análisis se introducen muestras blanco, junto con los patrones y las muestras a analizar, para evitar altos valores en las muestras blanco, es imprescindible realizar una purificación de la muestra, normalmente se realiza una extracción en fase sólida.

\subsubsection{Cromatografía de inmunoafinidad}

Este tipo de cromatografía se ha utilizado para la extracción y purificación de un analito o analitos de un mismo grupo en particular y se basa en una interacción antígeno-anticuerpo específica. En el esquema de la figura 11 se muestra el modo de actuación.

Las columnas están rellenas de una matriz sólida, normalmente un gel como la sefarosa 4B que lleva un anticuerpo ligado el cual es específico para el analito a detectar. La muestra es inyectada en la columna y seguidamente, se lava la columna con tampón de forma que elimine interferencias y sólo quede retenido el analito de interés. A continuación se eluye la muestra y el eluído es llevado a sequedad con nitrógeno. Se redisuelve con fase móvil 
antes de ser inyectado en el sistema cromatográfico (Campbell y Armstrong, 2007). Existen otros protocolos mediante columnas de inmunoafinidad cuyo gel contiene anticuerpos específicos, como puede ser el zeranol, que se acoplan a CNBr-Sefarosa 4B activada (Zhang et al., 2006a). La extracción y purificación de las muestras mediante la columna de inmunoafinidad requiere de un paso posterior de aplicación de la muestra en una placa ELISA, inyección en HPLC, GC, etc. Es decir, las columnas sólo se usan para preparar la muestra para su análisis.

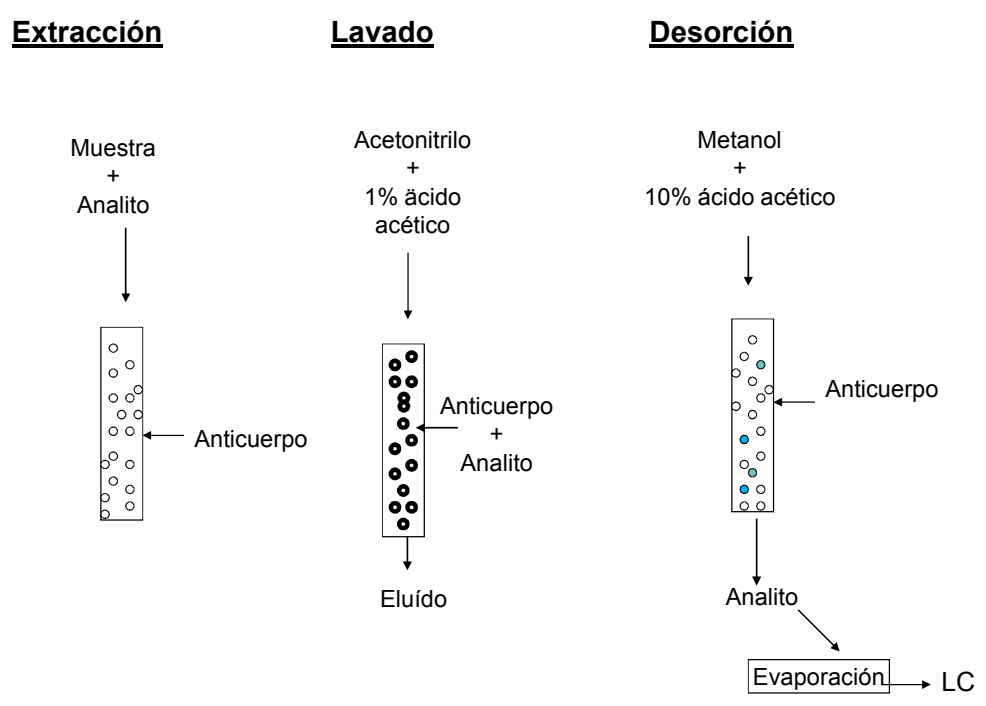

Figura 11 - Esquema de la cromatografía de inmunoafinidad.

Las columnas de inmunoafinidad son altamente específicas para cada tipo de analito, lo cual resulta muy importante para poder reducir el límite de detección. Sólo están limitadas por las reacciones cruzadas que puedan darse entre los distintos analitos de un mismo grupo o de otros residuos que puedan estar presentes en la muestra y que pudieran presentar una reacción 
cruzada con el anticuerpo (Godfrey, 1998). El inconveniente o desventaja que presenta esta técnica es su alto coste ya que son columnas cuyo precio es elevado y el número de usos es limitado.

\subsubsection{Técnicas cromatográficas}

La cromatografía en capa fina (HPTLC) ha sido aplicada con éxito durante muchos años para la detección cualitativa y cuantitativa de residuos en alimentos, aunque actualmente ya no es muy utilizada.

El uso de la cromatografía líquida de alta resolución (HPLC), que se expandió durante la década de los 90 , y su automatización han facilitado su uso como técnica de criba. La cromatografía líquida de alta resolución es una técnica separativa y su poder para discriminar una sustancia de otra va a depender del detector. La elección del sistema de detección es muy importante para la selectividad y sensibilidad del analito a analizar.

Algunos analitos no pueden ser detectados por absorbancia, fluorescencia etc. por lo que necesitan de una modificación química previa para que puedan ser detectados. Se trata de modificar la molécula de forma que sea capaz de emitir fluorescencia, absorber radiación ultravioleta, etc. (Bergweff y Schloeser, 2003). Normalmente, la aplicación de técnicas multiresiduo se basa en una extracción y purificación de la muestra que consiste en una extracción en fase sólida, filtración e inyección de la muestra en el sistema cromatográfico, usando para la separación una columna de fase reversa (RP-HPLC) con un detector por red de diodos (DAD) o detector de ultravioleta (UV). Esta técnica ha sido utilizada para la detección de antibióticos en carne, riñón y leche (Cinquina et al., 2003; Couper et al.,1995, Furusawa, 1999), también se usa en la detección de residuos de medicamentos veterinarios en huevos, leche, pescados y carne (Aerts et al.,1995; Horie et al.,1998), para la detección de agentes antitiroideos en 
orina (Vanden Bussche et al., 2009), así como la detección de corticosteroides, como la dexametasona, en agua de beber de animales de granja, orina y pienso ((Mallison et al. 1995; Reig et al., 2006; Shearan et al.,1991; Stolker, et al., 2000). A modo de síntesis, se muestran en la tabla 5 los métodos de screening o criba más frecuentemente utilizados en la detección de determinados residuos medicamentosos.

Tabla 5 - Métodos de screening o criba utilizados en la detección de determinados analitos específicos.

\begin{tabular}{llllll}
\hline Matriz & $\boldsymbol{\beta}$-Agonistas & Zeranol & Dexametasona & Tiouracilo & Carbadox \\
\hline Pienso & ELISA & ELISA & HPLC-DAD & & HPLC-DAD \\
Agua & ELISA & & HPLC-DAD & & \\
Pelo & ELISA & & & & \\
Orina & ELISA & & & HPLC-DAD & \\
\hline
\end{tabular}

\subsubsection{Métodos confirmatorios}

Los métodos confirmatorios son los utilizados para confirmar que una muestra es no conforme. El uso de estos métodos está definido en la legislación según la Decisión de la Comisión 2002/657/CE, que define la aplicación del método adecuado para cada sustancia.

Los métodos de confirmación para residuos orgánicos deben incluir información estructural. Por lo tanto, los métodos basados exclusivamente en análisis cromatográficos, que prescinden de la detección por espectrometría de masas, no convienen por sí solos como métodos de confirmación. No obstante, si una técnica por sí sola carece de la especificidad necesaria, dicha especificidad se obtendrá por medio de procedimientos analíticos consistentes en combinaciones adecuadas de limpieza, separación cromatográfica y detección espectrométrica. 
Los métodos o combinaciones de métodos que se consideran correctos para la identificación de residuos orgánicos se indican en la tabla 6 .

Tabla 6 - Métodos de confirmación adecuados para residuos de algunas de las sustancias de los grupos A y B del Anexo I de la Directiva 96/23/CE.

\begin{tabular}{lll}
\hline $\begin{array}{c}\text { Técnica de } \\
\text { medida }\end{array}$ & \multicolumn{1}{c}{ Sustancias } & \multicolumn{1}{c}{ Limitaciones } \\
\hline $\begin{array}{l}\text { CL o CG con } \\
\text { detección por } \\
\text { MS }\end{array}$ & Grupos A y B & $\begin{array}{l}\text { Sólo si se utilizan técnicas de barrido completo } \\
\text { o técnicas que no registran los espectro de } \\
\text { masas completos, pero incluyen al menos } 3 \\
\text { (grupo B) o 4 (grupo A) puntos de identificación. }\end{array}$ \\
$\begin{array}{l}\text { CL - DAD } \\
\text { barrido } \\
\text { completo }\end{array}$ & Grupo B & $\begin{array}{l}\text { Deben cumplirse los requisitos específicos de } \\
\text { absorción en la espectrometría de UV }\end{array}$ \\
\hline
\end{tabular}

En los métodos de confirmación existen unos criterios y requisitos de funcionamiento comunes que hay que cumplir. Estos son:

- Los métodos de confirmación proporcionarán información sobre la estructura química del analito.

- Los métodos cromatográficos sin detección de espectrometría de masas no convienen por sí solos como métodos de confirmación.

- Se debe utilizar un patrón interno (IS) adecuado y se añadirá al comenzar el procedimiento de extracción.

- Se emplearán como patrones internos los deuterados, especialmente indicados para la detección por espectrometría de masas, o compuestos relacionados estructuralmente con el analito.

- Cuando no se pueda utilizar un patrón interno adecuado, la identificación del analito se confirmará mediante la co-cromatografía.

- Los materiales de referencia o enriquecidos que contengan cantidades conocidas de analito, así como los materiales de control 
conformes y los blancos de reactivo, deberán utilizarse durante todo el proceso simultáneamente con cada lote de muestras.

- El orden para inyectar las muestras es el siguiente:

1. Blanco de reactivo

2. Muestra de control conforme

3. Muestra a confirmar

4. Muestra de control conforme

5. Muestra de control no conforme

La co-cromatografía se utiliza para la identificación y confirmación del analito cuando no se dispone de espectrómetro de masas

El extracto de la muestra se divide en dos partes iguales antes de la cromatografía, una parte se cromatografía tal cual y la otra se mezcla con el analito patrón que debe medirse y es cromatografiado de nuevo. La cantidad de analito patrón añadido debe ser similar a la cantidad de analito estimada en el extracto. Solamente debe aumentar el área del pico correspondiente al analito no conforme, teniendo en cuenta la cantidad añadida y la dilución del extracto. La anchura del pico a la mitad de su altura máxima debe estar aproximadamente dentro del margen de $\pm 10 \%$ de la anchura inicial y los tiempos de retención serán idénticos, con una tolerancia del $5 \%$.

Este método está diseñado para identificar un analito cuando no se puede utilizar el patrón interno adecuado.

Los métodos confirmatorios están basados preferentemente en la espectrometría de masas, esta técnica nos revela información de la estructura molecular, lo cual nos proporciona una identificación inequívoca del analito a confirmar. 


\subsubsection{Criterios de funcionamiento adicionales $y$ otros requisitos que deben cumplir todos los métodos cuantitativos}

\subsubsection{Veracidad de los métodos cuantitativos}

La veracidad de los métodos cuantitativos se calcula mediante análisis repetidos de un material de referencia certificado. La fracción de masa determinada experimentalmente debe estar dentro de unos límites:

- Fracción de masa $\leq 1 \mu \mathrm{g} / \mathrm{kg}$ el intervalo está entre $-50 \%$ a $+20 \%$

- Fracción de masa > $1 \mu \mathrm{g} / \mathrm{kg}$ a $10 \mu \mathrm{g} / \mathrm{kg}$, el intervalo está entre $-30 \%$ a $+10 \%$.

- Fracción de masa $\geq 10 \mu \mathrm{g} / \mathrm{kg}$, el intervalo está entre $-20 \%$ a $+10 \%$

Cuando no se dispone de material de referencia, la veracidad de las mediciones se valora mediante la recuperación de las adiciones de cantidades conocidas de uno o varios analitos añadidos a una matriz blanco. Los intervalos para las fracciones de masa son idénticos, es decir que la recuperación media sólo es aceptable si está dentro de los intervalos correspondientes a cada fracción de masa.

\subsubsection{Precisión}

La Precisión es el grado de concordancia entre resultados de ensayos independientes obtenidos en condiciones estipuladas. La precisión se calcula como la desviación estándar de los resultados de los ensayos.

\subsection{Descripción de los principales grupos y sustancias más representativas}

El análisis de residuos de medicamentos veterinarios, usados como medicinas o de manera ilegal, en alimentos es una disciplina relativamente joven. Un residuo se puede definir como una traza de una sustancia que se 
encuentra presente en una determinada matriz (carne, orina etc.) después de que haya sido administrada al animal, bien de forma legal por prescripción veterinaria como medicamento o bien de forma ilegal o fraudulenta. En cualquier caso se tiene que detectar dicho residuo y se tiene que cuantificar. Las sustancias que van a ser detectadas se dividen en dos grandes grupos: el grupo A, sustancias con efecto anabólico y grupo B, medicamentos veterinarios. Las sustancias representativas para ambos grupo se muestran en las tablas 7 y 8 .

Tabla 7 - Lista de sustancias pertenecientes al grupo A según la Directiva 96/23/EC y algunas de las sustancias más representativas.

\begin{tabular}{|c|c|}
\hline $\begin{array}{l}\text { GRUPO A: Sustancias con efecto } \\
\text { anabólico }\end{array}$ & Sustancias representativas \\
\hline 1. Estilbenos & $\begin{array}{l}\text { Dietilestilbestrol, hexestrol, } \\
\text { dienestrol }\end{array}$ \\
\hline 2. Agentes antitiroideos & Tiouracilos \\
\hline $\begin{array}{l}\text { Esteroides } \\
\text { Andrógenos } \\
\text { Gestágenos } \\
\text { Estrógenos }\end{array}$ & $\begin{array}{l}\text { Acetato deTrenbolona } \\
\text { Acetato de Melengestrol } \\
17-\beta \text { estradiol }\end{array}$ \\
\hline 4. Lactonas del ácido resorcílico & Zeranol \\
\hline 5. Beta-agonistas & $\begin{array}{l}\text { Clembuterol, mabuterol, salbutamol, } \\
\text { mapenterol, terbutaline, cimaterol, } \\
\text { tulobuterol, bromobuterol }\end{array}$ \\
\hline 6. Otros compuestos & $\begin{array}{l}\text { Nitrofuranos (nitrofurazona, } \\
\text { nitrofurantoina, furazolidona, } \\
\text { furaltadona), cloramfenicol }\end{array}$ \\
\hline
\end{tabular}


Tabla 8 - Lista de sustancias pertenecientes al grupo B según la Directiva 96/23/EC $y$ algunas de las sustancias más representativas.

\section{GRUPO B: Medicamentos veterinarios Sustancias representativas}

1. Sustancias antibacterianas Sulfonamidas y quinolonas
Sulfonamidas (sulfadiazina, sulfathiazola, sulfapyridina, sulfamerazina, sulfamethazina, sulfamonomethoxina, sulfachlorpyridazina, sulfaquinoxalina, sulfadimethoxina), quinolonas (ácido oxolínico, cinoxacina), fluoroquinolonas (enrofloxacina, sarafloxacina, ciprofloxacina, danofloxacina)
2. Otras drogas veterinarias

2.a) Antihelminticos
Benzimidazoles (albendazol, fenbendazol, oxfendazol, thiabendazol), ivermectina, levamisol, rafoxanida, closantel

Anticoccidianos, incluyendo
nitroimidazoles
nitroimidazoles
Nitroimidazoles (metronidazol, dimetridazol, tinidazol, nimorazol, flunidazol, ronidazol), Halofuginona 2.c) Carbamatos y piretroides

2.d) Tranquilizantes

\section{Carbamatos, piretroides}

Acepromazina, azaperona, cloropromazina, xylazina, $\beta$ bloqueante del carazolol

2.e) Antiinflamatorios no esteroideos (AINS) Flunixina

\section{2.f) Otras sustancias farmacológicamente




\subsubsection{Análisis de sustancias del grupo A}

El grupo A o sustancias prohibidas se utilizan en el engorde de animales y se conocen como el grupo de promotores del crecimiento, el cual consta o se clasifica en varios grupos: anabolizantes o esteroides con efecto anabolizante (grupo A1, A3, A4), tireostáticos o agentes antitiroideos (grupo A2), beta agonistas o agentes de reparto (grupo A5), las sustancias del anexo IV dónde encontramos sustancias tan destacadas como el cloranfenicol. Un resumen de los principales métodos de análisis que han sido desarollados en los últimos años y publicados en revistas se muestra en la tabla 9 .

Los esteroides son hormonas y actúan como tales, este grupo de compuestos comprende estrógenos, gestágenos y andrógenos (Grupos A1, A3, A4). Los estrógenos endógenos o esteroides $C_{18}$ (estrona, estradiol, estriol) son menos activos oralmente que sus homólogos sintéticos (etinilestradiol). Otro grupo son los compuestos xenobióticos no esteroideos dónde encontramos las sustancias pertenecientes al grupo A1 (Dietilestilbestrol, hexestrol, dienestrol) y las sustancias pertenecientes al grupo A4 (zeranol). Los gestágenos se emplean en forma de ésteres (acetato de melengestrol) y se pueden usar también en combinación con estrogénos. Entre los andrógenos citaremos la 19-nortestosterona, conocida como nandrolona y la trembolona y la boldenona. (De Brabander et al., 2009). Este tipo de sustancias las encontramos principalmente en orina y se pueden detectar antes del sacrificio de los animales que es dónde se encuentran en mayor concentración asumiendo que le hayan sido suministradas al animal. Se pueden detectar en muestras de riñón e hígado y también en leche, grasa, orina, heces y pelo.

Las sustancias del grupo $A 5$, los $\beta$-agonistas son promotores del crecimiento ilegales que empezaron a utilizarse alrededor de los años 80, 
como ya se ha comentado son sustancias que disminuyen el contenido en grasa de la canal a favor de un aumento de porcentaje de músculo. En la Unión Europea estas sustancias están prohibidas pero en otros países como USA, Méjico y Sud-Africa, algunos $\beta$-agonistas como zilpaterol están autorizados para el engorde de animales (Stachel et al., 2003; Plasencia et al.,1999).

El compuesto más importante y más conocido es el clembuterol, los métodos más utilizados para su detección son los inmunoensayos (ELISA), los biosensores (Lei et al. 2008, Granja et al. 2007, Haughey et al. 2001), la cromatografía líquida de alta resolución (HPLC) y la cromatografía de gases con detección por espectrometría de masas (GC-MS). Actualmente la técnica de elección para los métodos confirmatorios para este tipo de promotores de crecimiento es CL-MS.

Las sustancias más importantes del Grupo A6 (sustancias del anexo IV) son el cloranfenicol (CAP) y los nitrofuranos, principalmente se detectan en las importaciones procedentes de terceros países en carne de pollo y en acuicultura.

El cloranfenicol es un antimicrobiano de amplio espectro y actualmente se prepara sintéticamente. Para la detección del cloranfenicol se utilizan un gran número de métodos entre los que se encuentran los inmunológicos (ELISA) (Ferguson et al. 2005) y para los métodos confirmatorios la cromatografía líquida con detección por espectrometría de masas (CL-MS).

Los nitrofuranos son compuestos sintéticos, antimicrobianos de amplio espectro y que se usan para infecciones gastrointestinales en animales pero fueron prohibidos debido a su efecto genotóxico y a sus propiedades mutagénicas. Son rápidamente metabolizados en el organismo lo cual dificulta su detección. 


\subsubsection{Análisis de sustancias del grupo B}

Dentro de este grupo se encuentran algunos subgrupos que han sido estudiados en el presente trabajo, debido a la gran extensión de sustancias que componen este grupo $B$. Un resumen de los principales métodos de análisis que han sido desarrollados en los últimos años y publicados en revistas se muestra en la tabla 9.

Los corticoides se utilizan tanto en medicina humana como en medicina veterinaria, a menudo de forma fraudulenta se usan en combinación con antimicrobianos o con $\beta$-agonistas. El uso de estos fármacos (dexametasona, betametasona y prednisola por citar los más conocidos) está muy regulado cuando se utilizan de forma legal, cumpliendo los períodos de supresión entre el tratamiento y el sacrificio del animal.

Los métodos más utilizados para la detección de estas sustancias durante los años 80 fueron el radio-inmunoensayo y la cromatografía en capa fina TLC (Neufeld et al., 1998, Vanoosthuyze et al., 1993). Posteriormente se introdujo la cromatografía líquida de alta resolución (HPLC) con detección de ultravioleta visible (UV) (Violin, 1995) y posteriormente la cromatografía de gases por espectrometría de masas (GC-MS) (Hidalgo et al., 2003).

El grupo de las sustancias antibacterianas (grupo B1, 2Ba, B2b, B2c) es muy importante en la producción animal, estas sustancias se utilizan para el tratamiento y prevención de enfermedades. 
Tabla 9 - Resumen de los principales métodos de análisis de las sustancias pertenecientes a los grupos A y B según la Directiva 96/23/EC.

\begin{tabular}{|c|c|c|c|c|c|c|c|}
\hline Residuo & $\begin{array}{l}\text { Tipo de } \\
\text { matriz }\end{array}$ & $\begin{array}{l}\text { Tipo de } \\
\text { columna }\end{array}$ & Detector & $\begin{array}{c}\mathrm{CC \alpha} \\
(\mathrm{ppb})\end{array}$ & $\begin{array}{c}C C \beta \\
(p p b)\end{array}$ & $\begin{array}{l}\text { Recup. } \\
(\%)\end{array}$ & Refs \\
\hline $\begin{array}{l}\text { Melengestrol } \\
\text { Megestrol } \\
\text { Medroxypro- } \\
\text { gesterona }\end{array}$ & $\begin{array}{l}\text { Grasa de } \\
\text { riñón }\end{array}$ & $\begin{array}{l}\text { Hypersil } \\
\text { ODS } \\
5 \mu \mathrm{m}\end{array}$ & $\begin{array}{c}\mathrm{MS} / \mathrm{MS} \\
\mathrm{APCl}^{+}\end{array}$ & $\begin{array}{l}0,20 \\
0,22 \\
0,22\end{array}$ & $\begin{array}{l}0,33 \\
0,38 \\
0,37\end{array}$ & - & $\begin{array}{c}\text { Kaklamano } \\
\text { sa et al. } \\
2009\end{array}$ \\
\hline $\begin{array}{l}\text { Melengestrol } \\
\text { Megestrol } \\
\text { Clormadinona } \\
\text { Medroxypro- } \\
\text { gesterona }\end{array}$ & $\begin{array}{l}\text { Grasa de } \\
\text { riñón }\end{array}$ & $\begin{array}{c}\text { Waters } \\
\text { Sunfire C18 } \\
3,5 \mu \mathrm{m}\end{array}$ & $\begin{array}{c}\mathrm{MS} / \mathrm{MS} \\
\mathrm{ESI}^{+}\end{array}$ & $\begin{array}{l}0,15 \\
0,15 \\
0,37 \\
0,24\end{array}$ & $\begin{array}{l}0,19 \\
0,19 \\
0,47 \\
0,32\end{array}$ & - & $\begin{array}{l}\text { Lohmus et } \\
\text { al. } 2007\end{array}$ \\
\hline $\begin{array}{l}\text { Clenbuterol } \\
\text { Ractopamina } \\
\text { Cimaterol }\end{array}$ & $\begin{array}{l}\text { Hígado } \\
\text { de } \\
\text { bovino }\end{array}$ & $\begin{array}{c}\text { Synergi } \\
\text { MAX- } \\
\text { RP80A } \\
4 \mu \mathrm{m}\end{array}$ & $\begin{array}{c}\mathrm{MS} / \mathrm{MS} \\
\mathrm{ESI}^{+}\end{array}$ & $\begin{array}{l}0,08 \\
0,15 \\
0,13\end{array}$ & $\begin{array}{l}0,27 \\
0,32 \\
0,52\end{array}$ & - & $\begin{array}{l}\text { Blanca et } \\
\text { al. } 2005\end{array}$ \\
\hline Sulfadiacina & Músculo & C8 & DAD & 109,3 & 120,0 & 73 & \\
\hline Sulfatiazol & & $5 \mu \mathrm{m}$ & $270 \mathrm{~nm}$ & 116,2 & 134,9 & 55 & \\
\hline Sulfapiridina & & & & 110,2 & 121,7 & 80 & \\
\hline Sulfameracina & & & & 105,2 & 110,9 & 79 & \\
\hline Sulfametacina & & & & 106,6 & 113,9 & 80 & \\
\hline $\begin{array}{l}\text { Sulfamono- } \\
\text { metoxina }\end{array}$ & & & & 106,6 & 114,1 & 81 & $\begin{array}{l}\text { Peccorelli } \\
\text { et al. } 2004\end{array}$ \\
\hline $\begin{array}{l}\text { Sulfaclorpi- } \\
\text { ridazina }\end{array}$ & & & & 108,8 & 119,1 & 72 & \\
\hline $\begin{array}{l}\text { Sulfameto- } \\
\text { xazol }\end{array}$ & & & & 107,1 & 115,0 & 76 & \\
\hline $\begin{array}{l}\text { Sulfaquino- } \\
\text { xalina }\end{array}$ & & & & 107,8 & 116,4 & 77 & \\
\hline Terbutalina & Hígado & Inertsil C8 & MS/MS & 0,3 & 0,5 & 41 & \\
\hline Ritodrina & de & $5 \mu \mathrm{m}$ & $\mathrm{APCl}^{+}$ & 0,2 & 0,4 & 67 & \\
\hline $\begin{array}{l}\text { Hidroximetil- } \\
\text { clenbuterol }\end{array}$ & bovino & & & 0,1 & 0,2 & 74 & \\
\hline Tulobuterol & & & & 0,1 & 0,2 & 41 & \\
\hline Clenpeterol & & & & 0,1 & 0,2 & 57 & \\
\hline Isoxsuprine & & & & 0,3 & 0,5 & 28 & $\begin{array}{l}\text { resser et } \\
\text { al } 2005\end{array}$ \\
\hline Salbutamol & & & & 0,3 & 0,5 & 65 & al. 2005 \\
\hline Cimaterol & & & & 0,1 & 0,2 & 71 & \\
\hline Ractopamina & & & & 0,2 & 0,3 & 52 & \\
\hline Clenbuterol & & & & 0,1 & 0,2 & 61 & \\
\hline Brombuterol & & & & 0,2 & 0,3 & 53 & \\
\hline Mabuterol & & & & 0,1 & 0,2 & 64 & \\
\hline
\end{tabular}

Abreviaciones: APCI (Atmospheric pressure chemical ionization), ESI (Electrospray ionization) 
Tabla 9 - Continuación.

Abreviaciones: APCI (Atmospheric pressure chemical ionization), ESI (Electrospray ionization), TIS (Turbo

\begin{tabular}{|c|c|c|c|c|c|c|c|}
\hline Residuo & $\begin{array}{l}\text { Tipo de } \\
\text { matriz }\end{array}$ & $\begin{array}{l}\text { Tipo de } \\
\text { columna }\end{array}$ & Detector & $\begin{array}{c}\mathrm{CC \alpha} \\
(\mathrm{ppb})\end{array}$ & $\begin{array}{c}C C \beta \\
(p p b)\end{array}$ & $\begin{array}{l}\text { Recup. } \\
(\%)\end{array}$ & Refs \\
\hline $\begin{array}{l}\text { Minociclina } \\
\text { Tetraciclina } \\
\text { Oxitetraciclina } \\
\text { Clortetraciclin } \\
\text { Doxiciclina }\end{array}$ & $\begin{array}{c}\text { Músculo } \\
\text { de } \\
\text { bovino }\end{array}$ & $\begin{array}{c}\text { Inertsil ODS } \\
3,5 \mu \mathrm{m}\end{array}$ & $\begin{array}{l}\text { HPLC- } \\
\text { DAD }\end{array}$ & $\begin{array}{l}46,53 \\
27,98 \\
29,18 \\
45,95 \\
42,97\end{array}$ & $\begin{array}{l}53,57 \\
31,83 \\
30,97 \\
51,69 \\
47,26\end{array}$ & $\begin{array}{c}104 \\
112 \\
91 \\
115 \\
107\end{array}$ & $\begin{array}{c}\text { Samanidou } \\
\text { et al } 2005\end{array}$ \\
\hline $\begin{array}{l}\text { Hexestrol } \\
\text { Dietilestil- } \\
\text { bestrol } \\
\text { Androsterona } \\
\text { Estradiol } \\
\text { Zeranol } \\
\text { a-Zearalenol }\end{array}$ & $\begin{array}{l}\text { Carne de } \\
\text { cerdo }\end{array}$ & $\begin{array}{c}\mathrm{DB}-5,30 \mathrm{~m} \text {, } \\
0,25 \mu \mathrm{m}\end{array}$ & $\begin{array}{c}\text { GC- } \\
\text { MS/MS }\end{array}$ & $\begin{array}{l}0,2^{a} \\
0,1 \\
0,2 \\
0,1 \\
0,1 \\
0,1\end{array}$ & $\begin{array}{l}- \\
- \\
- \\
- \\
- \\
-\end{array}$ & $\begin{array}{l}84,6 \\
80,1 \\
91,0 \\
95,8 \\
95,3 \\
94,6\end{array}$ & $\begin{array}{c}\text { Fuh et al. } \\
2004\end{array}$ \\
\hline $\begin{array}{l}\text { a-zeranol } \\
\alpha \text {-estradiol } \\
\text { Dietilestil- } \\
\text { bestrol }\end{array}$ & $\begin{array}{l}\text { Músculo } \\
\text { de aves }\end{array}$ & $\begin{array}{c}\text { Alltima C18, } \\
5 \mu \mathrm{m}\end{array}$ & $\begin{array}{c}\text { MS/MS } \\
\text { TIS }^{-}\end{array}$ & $\begin{array}{l}0,08 \\
0,11 \\
0,04\end{array}$ & $\begin{array}{l}0,87 \\
0,85 \\
0,33\end{array}$ & $\begin{array}{c}90 \\
100 \\
80\end{array}$ & $\begin{array}{l}\text { Gentili et } \\
\text { al. } 2006\end{array}$ \\
\hline $\begin{array}{l}\beta \text {-boldenone } \\
\alpha \text {-boldenone }\end{array}$ & Orina & $\begin{array}{c}\text { Nucleosil } \\
\text { C18 } \\
5 \mu \mathrm{m}\end{array}$ & $\begin{array}{c}\mathrm{MS} / \mathrm{MS} \\
\mathrm{API}^{-}\end{array}$ & $\begin{array}{l}0,52 \\
0,70\end{array}$ & $\begin{array}{l}0,70 \\
0,93\end{array}$ & $\begin{array}{l}76,0 \\
71,0\end{array}$ & $\begin{array}{l}\text { Buiarelli et } \\
\text { al. } 2005\end{array}$ \\
\hline $\begin{array}{l}\text { Nitrofurantoin } \\
\text { Furaltadona } \\
\text { Furazolidona } \\
\text { Nitrofurazona }\end{array}$ & $\begin{array}{l}\text { Carne de } \\
\text { pollo }\end{array}$ & $\begin{array}{c}\text { Simmetry } \\
\text { C18 } \\
3,5 \mu \mathrm{m}\end{array}$ & $\begin{array}{c}\mathrm{MS} / \mathrm{MS} \\
\mathrm{ESI}^{+}\end{array}$ & $\begin{array}{l}0,21 \\
0,12 \\
0,11 \\
0,20\end{array}$ & $\begin{array}{l}0,36 \\
0,21 \\
0,19 \\
0,34\end{array}$ & $85-122$ & $\begin{array}{l}\text { Mottier et } \\
\text { al. } 2005\end{array}$ \\
\hline $\begin{array}{l}\text { Zeranol } \\
17 \alpha \text {-trenbolo- } \\
\text { na } \\
\text { Metiltestoste- } \\
\text { rona } \\
17 \beta \text {-estradiol } \\
17 \alpha \text {-testoste- } \\
\text { rona } \\
\text { Melengestrol }\end{array}$ & $\begin{array}{l}\text { Pelo de } \\
\text { bovino }\end{array}$ & $\begin{array}{c}\text { OV-1, } \\
0,25 \mu \mathrm{m}\end{array}$ & $\begin{array}{c}\text { GC- } \\
\text { MS/MS }\end{array}$ & $\begin{array}{c}2,66^{a} \\
0,76 \\
1,02 \\
0,12 \\
0,29 \\
1,12\end{array}$ & $\begin{array}{c}4,48^{\mathrm{b}} \\
1,99 \\
1,74 \\
0,19 \\
0,85 \\
1,07\end{array}$ & $\begin{array}{l}- \\
- \\
- \\
- \\
- \\
-\end{array}$ & $\begin{array}{l}\text { Rambaud } \\
\text { et al. } 2007\end{array}$ \\
\hline
\end{tabular}

ion spray)

a Límite de detección, ${ }^{b}$ Límite de identificación 
Tabla 9 - Continuación.

Abreviaciones: APCI (Atmospheric pressure chemical ionization), ESI (Electrospray ionization

\begin{tabular}{|c|c|c|c|c|c|c|c|}
\hline Residuo & $\begin{array}{l}\text { Tipo de } \\
\text { matriz }\end{array}$ & $\begin{array}{l}\text { Tipo de } \\
\text { columna }\end{array}$ & Detector & $\begin{array}{c}\mathrm{CC \alpha} \\
(\mathrm{ppb})\end{array}$ & $\begin{array}{c}C C \beta \\
(p p b)\end{array}$ & $\begin{array}{l}\text { Recup. } \\
\text { (\%) }\end{array}$ & Refs \\
\hline Cloranfenicol & $\begin{array}{c}\text { Carne de } \\
\text { porcino y } \\
\text { bovino }\end{array}$ & $\begin{array}{c}\text { Synergi } \\
\text { MAX RP } \\
4 \mu \mathrm{m}\end{array}$ & $\begin{array}{c}\mathrm{MS} / \mathrm{MS} \\
\mathrm{ESI}^{-}\end{array}$ & 0,15 & 0,22 & $80-100$ & $\begin{array}{c}\text { Vinci et al. } \\
2005\end{array}$ \\
\hline Cloranfenicol & Riñón & $\begin{array}{l}\text { Nucleodur } \\
\text { C18, } 5 \mu \mathrm{m}\end{array}$ & $\begin{array}{c}\mathrm{MS} / \mathrm{MS} \\
\mathrm{ESI}^{-}\end{array}$ & 0,05 & 0,09 & - & $\begin{array}{l}\text { Ashwin et } \\
\text { al. } 2005\end{array}$ \\
\hline $\begin{array}{l}\text { Trenbolona } \\
\text { Testosterona } \\
\text { Melengestrol } \\
\text { acetato } \\
\text { Progesterona }\end{array}$ & $\begin{array}{l}\text { Músculo } \\
\text { de aves }\end{array}$ & $\begin{array}{c}\text { Alltima C18 } \\
5 \mu \mathrm{m}\end{array}$ & $\begin{array}{c}\mathrm{MS} / \mathrm{MS} \\
\mathrm{APCl}^{+}\end{array}$ & $\begin{array}{c}- \\
0,03 \\
0,03 \\
0,21\end{array}$ & $\begin{array}{l}0,13 \\
0,21 \\
0,26 \\
0,16\end{array}$ & $\begin{array}{l}99 \\
97 \\
90 \\
96\end{array}$ & $\begin{array}{l}\text { Gentili et } \\
\text { al. } 2006\end{array}$ \\
\hline Diclazuril & $\begin{array}{l}\text { Carne de } \\
\text { pollo }\end{array}$ & $\begin{array}{c}\text { Simmetry } \\
\text { C18 } \\
5 \mu \mathrm{m}\end{array}$ & $\begin{array}{c}\mathrm{MS} / \mathrm{MS} \\
\mathrm{ESI}^{-}\end{array}$ & 0,5 & 0,6 & 111 & $\begin{array}{c}\text { Mortier et } \\
\text { al. } 2005\end{array}$ \\
\hline $\begin{array}{l}\text { Diethylestil- } \\
\text { bestrol } \\
\text { Dienestrol } \\
\text { Zeranol } \\
\text { Taleranol } \\
\text { Zearalanona } \\
\text { Zearalanona } \\
\alpha \text {-zearalenol } \\
\beta \text {-zearalenol }\end{array}$ & $\begin{array}{l}\text { Hígado } \\
\text { de } \\
\text { bovino }\end{array}$ & $\begin{array}{l}\text { DB5-MS } \\
0,25 \mu \mathrm{m}\end{array}$ & $\begin{array}{c}\text { GC- } \\
\text { MS/MS }\end{array}$ & $\begin{array}{l}0,10 \\
0,15 \\
0,27 \\
0,32 \\
0,26 \\
0,33 \\
0,33 \\
0,31\end{array}$ & $\begin{array}{l}0,17 \\
0,25 \\
0,45 \\
0,55 \\
0,45 \\
0,57 \\
0,56 \\
0,53\end{array}$ & $29-67$ & $\begin{array}{c}\text { Dickson et } \\
\text { al. } 2009\end{array}$ \\
\hline $\begin{array}{l}\alpha \text {-trenbolona } \\
\beta \text {-trenbolona }\end{array}$ & $\begin{array}{l}\text { Hígado } \\
\text { de } \\
\text { bovino }\end{array}$ & $\begin{array}{c}\text { Zorbax } \\
\text { XDB-C18 } \\
5 \mu \mathrm{m}\end{array}$ & $\begin{array}{r}\mathrm{MS} / \mathrm{MS} \\
\mathrm{ESI}^{+}\end{array}$ & $\begin{array}{l}0,5^{\mathrm{a}} \\
0,5\end{array}$ & - & $\begin{array}{l}76,3 \\
79,1\end{array}$ & $\begin{array}{c}\text { Horie y } \\
\text { Nakazawa, } \\
2000\end{array}$ \\
\hline Amoxicilina & $\begin{array}{l}\text { Carne de } \\
\text { pollo }\end{array}$ & $\begin{array}{l}\text { PLRP-S } \\
100 \mathrm{~A}\end{array}$ & $\begin{array}{c}\mathrm{MS} / \mathrm{MS} \\
\mathrm{ESI}^{+}\end{array}$ & 51,6 & 57,4 & - & $\begin{array}{l}\text { De Baere } \\
\text { et al. } 2005\end{array}$ \\
\hline Halofuginona & $\begin{array}{l}\text { Hígado } \\
\text { de pollo }\end{array}$ & $\begin{array}{l}\text { Prodigy } \\
\text { C18 } \\
5 \mu \mathrm{m}\end{array}$ & MS/MS & 35,4 & 43,6 & - & $\begin{array}{l}\text { Yakkundi } \\
\text { et al. } 2003\end{array}$ \\
\hline
\end{tabular}

${ }^{a}$ Límite de detección 
3. Objetivos 



\section{OBJETIVOS}

Existe un gran número de métodos para la detección, determinación y confirmación de residuos en distintas matrices biológicas como orina, heces, hígado o leche y también para pienso de distintas especies animales que han sido descritos en los antecedentes (Cherlet, et al., 2004; Creaser et al., 1998; Delahuat et al., 1997; Draisci et al., 2001; Stolker et al., 2000) pero hay una gran necesidad de métodos rápidos de detección (Toldrá y Reig, 2006; Aristoy et al., 2007). Recientemente, los métodos y los criterios para la interpretación de los resultados analíticos de los controles oficiales de los laboratorios han sido regulados por la Unión Europea mediante la Decisión 2002/657/EC (EC, 2002).

La Directiva Europea 96/23/EC contiene una guía para el control de los residuos de origen veterinario en animales y alimentos procedentes de estos animales (carne, leche, huevos miel...) y en ella se detallan los procedimientos a seguir por todos los estados miembros de la Unión Europea, para fijar un plan de vigilancia nacional incluyendo los detalles para la toma de muestras en distintos puntos geográficos. Para cualquier tipo de alimento de origen animal hay dos grupos principales de sustancias que tienen que ser controladas y que vienen legisladas en dos grandes grupos: i) Sustancias del grupo A: Sustancias con efecto anabolizante y sustancias no autorizadas (Estilbenos, tiroideos, hormonas, resorcil lactonas y $\beta$-agonistas), ii) Sustancias del grupo B: Medicamentos veterinarios y contaminantes.

La problemática de la investigación de residuos en animales de granja es uno de los temas más complejos que la administración debe afrontar para asegurar la protección de la salud pública, pero también presenta connotaciones económicas que afectan a los productores. Así, la determinación de los residuos de medicamentos veterinarios en los alimentos 
de origen animal se ha convertido en un tema de creciente atención en los últimos años, tanto para las autoridades y profesionales en el campo de la analítica como para los consumidores cuya máxima preocupación está enfocada hacia alimentos seguros y de calidad.

Diversas razones comerciales han apoyado el uso de sustancias no autorizadas como promotores de crecimiento en la producción animal. El problema de la existencia de residuos de medicamentos en los alimentos cobró gran importancia a raíz de las intoxicaciones que se produjeron en los años 90 por $\beta$-agonistas y así, los consumidores, se han ido concienciando seriamente sobre los temas de salubridad y seguridad de los productos alimentarios, especialmente aquellos de origen animal.

Por lo dicho anteriormente y por la adhesión de nuestro país a la EU, se debe llevar a cabo un control de residuos en los alimentos y este control de residuos no se puede separar del marco comunitario y, por lo tanto, diferir en sus aspectos esenciales de los otros países miembros de la EU (Martín, 1997).

Por tanto, el objetivo principal de este trabajo consiste en el desarrollo de métodos analíticos rápidos y la evaluación de su aplicación como técnicas de criba o screening en el control sanitario de residuos medicamentosos y de sustancias promotoras del crecimiento en animales de granja.

Al objeto de conseguir el objetivo principal se establecen los siguientes objetivos específicos:

1 - Desarrollo de métodos rápidos de detección para los analitos clenbuterol, mabuterol, metil-tiouracilo, carbadox, dexametasona, zeranol como representativos de los grupos $\beta$-agonistas, antitiroideos, antimicrobianos, corticoides y lactonas del ácido resorcílico, que deben ser analizados en el actual Plan Nacional de Investigación de Residuos (PNIR). 
2 - Validación de los métodos puestos a punto para los analitos escogidos y su determinación en las matrices de pienso de distintas especies animales, agua de beber y orina de vacuno. 
4. Plan de trabajo

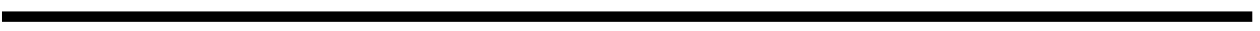





\section{PLAN DE TRABAJO}

Con el fin de llevar a cabo los objetivos propuestos, se planteó el siguiente plan de trabajo:

$\checkmark$ Optimización de protocolos de extracción de $\beta$-agonistas en agua de beber de bovino, orina de bovino y piensos de bovino, porcino y equino.

Validación del método ELISA para clembuterol y mabuterol en agua de beber, orina y en piensos de bovino según la Decisión 2002/657/EC (EC, 2002).

$\checkmark$ Optimización de un protocolo de extracción de zeranol en piensos de bovino y ovino, y validación del método ELISA para el zeranol en piensos según la Decisión 2002/657/EC (EC, 2002).

$\checkmark$ Puesta a punto de un protocolo de extracción de carbadox en piensos avícola y cunicola. Preparación y purificación parcial del analito mediante extracciones líquido-líquido y en fase sólida (SPE). Determinación del carbadox mediante cromatografía líquida de alta resolución con detección por red de diodos (HPLC-DAD) y validación del método según la Decisión 2002/657/EC (EC, 2002).

$\checkmark$ Puesta a punto de un protocolo para la extracción de metil-tiouracilo en orina de bovino. Preparación y purificación parcial del analito mediante extracción líquido-líquido.

Determinación de metil-tiouracilo en orina mediante cromatografía líquida de alta resolución con detección por red de diodos (HPLC- 
DAD) y validación del método según la Decisión 2002/657/EC (EC, 2002).

$\checkmark$ Puesta a punto de un protocolo de purificación y extracción de dexametasona en agua de beber de bovino y piensos de bovino, equino y porcino.

La extracción de dexametasona en agua de beber de bovino se llevó a cabo mediante columnas de inmunoafinidad (IC). Para la extracción de la dexametasona en los piensos de bovino, porcino y equino se realizó una extracción en fase sólida (SPE) seguido de columnas de inmunoafinidad (IC).

La determinación de la dexametasona se realizó por cromatografía líquida de alta resolución con detección por red de diodos (HPLCDAD) y validación del método según la Decisión 2002/657/EC (EC, 2002). 


\section{Materiales y Métodos}





\section{MATERIALES Y MÉTODOS}

\subsection{Determinación de residuos mediante ensayos ELISA}

\subsubsection{Materiales}

Agitador mecánico o magnético de laboratorio, Centrífuga modelo Medrifiger BL-S (Selecta, Barcelona). Lavador de placas ELISA Opsys MW (Dynex Technologies, West Sussex UK), Lector de placas ELISA Opsys MR (Dynex Technologies, West Sussex, UK) equipado con filtro de $450 \mathrm{~nm}$, Software: Revelation QuickLink (Dynex Technologies, West Sussex, USA).

\subsubsection{Reactivos}

Agua bidestilada, etanol absoluto, metanol grado multisolvente, metanol para HPLC, ácido súlfurico 95-98\% para análisis (Panreac, Barcelona).

Kits ELISA para la determinación de $\beta$-agonistas (Euro-Diagnóstica, Vitaltech, Barcelona), y para la determinación de zeranol (ZR 2421, laboratorios Randox, Crumlin, Irlanda del Norte).

Sustancias patrón: clembuterol hidrocloruro 95\% (Sigma C5423), mabuterol (regalo del Instituto Carlos III Majadahonda, Madrid), a-zearalanol (Sigma, St. Louis MO, USA). Orina blanco liofilizada ref. 94M0944 batch 1, bov. 15 (Instituto Nacional de Salud Pública y Medioambiente, RIMV, Holanda).

\subsubsection{Preparación de la muestra}

\subsubsection{Protocolo de extracción de $\beta$-agonistas en agua}

El agua no necesita preparación previa. Se toman $50 \mu \mathrm{L}$ de muestra de agua descongelada y se diluyen con $200 \mu \mathrm{L}$ de tampón de dilución del kit ELISA. Se agita en el vortex, se toman $50 \mu \mathrm{L}$ por duplicado y se vierten en los correspondientes pocillos de la placa ELISA. 


\subsubsection{Protocolo de extracción de $\beta$-agonistas en orina}

La muestra de orina se centrifuga durante 5 minutos a $5000 \mathrm{rpm}$, luego se ajusta el $\mathrm{pH}$ a $7,5(+/-0,5)$ con hidróxido de sodio o con ácido acético $1 \mathrm{M}$. Se toman $50 \mu \mathrm{L}$ de orina en un tubo eppendorf y se le añaden $200 \mu \mathrm{L}$ de tampón de dilución y se agita. La muestra queda cinco veces diluida y finalmente se toman $50 \mu \mathrm{L}$ de la muestra diluida para su adición a los pocillos de la placa ELISA.

\subsubsection{Protocolo de extracción de $\beta$-agonistas en pienso}

Se pesan $2 \mathrm{~g}$ de pienso previamente molido y se le añaden $2 \mathrm{~mL}$ de ácido clorhídrico $1 \mathrm{M}$ y $18 \mathrm{~mL}$ de agua bidestilada, se homogeniza y se deja en agitación horizontal durante 30 minutos Transcurrido este tiempo de agitación se centrifuga durante 15 minutos a $3500 \mathrm{rpm}$ y a $4^{\circ} \mathrm{C}$. Se toma el sobrenadante y se ajusta el $\mathrm{pH}$ entre 7-9 con $\mathrm{NaOH} 1 \mathrm{M}$. Se vuelve a centrifugar con las mismas condiciones y se toma el sobrenadante. Dicho sobrenadante se diluye 10 veces con el tampón de dilución del kit ELISA.

\subsubsection{Protocolo de extracción de zeranol en pienso}

Se pesan $2 \mathrm{~g}$ de pienso previamente molido. Se añaden $20 \mathrm{~mL}$ de la mezcla de metanol:agua (70:30). Se homogeniza en el vortex y se deja en agitación horizontal durante 10 minutos. Se centrifuga el extracto a $3000 \mathrm{rpm}$ durante 15 minutos a $4^{\circ} \mathrm{C}$. Se decanta el sobrenadante a un tubo de poliestireno de $10 \mathrm{~mL}$ limpio y se hace una dilución 1:10 con el tampón de incubación suministrado en el kit ELISA.

\subsubsection{Condiciones de uso de los ensayos ELISA}

Los kits ELISA utilizados fueron comprados a distintos distribuidores pero la forma de trabajo fue independiente y siguiendo siempre los 
respectivos protocolos que se detallan a continuación. En todos los casos, tanto muestras como patrones se ponen por duplicado en la placa. En la figura 12 se muestra el contenido de un kit completo y los principales pasos a seguir.
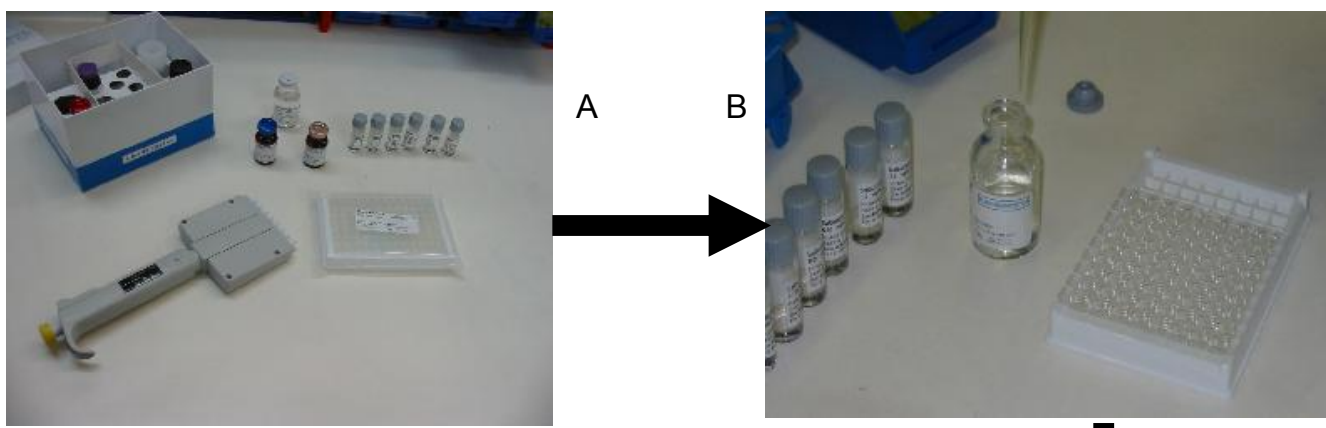

$\mathrm{E}$

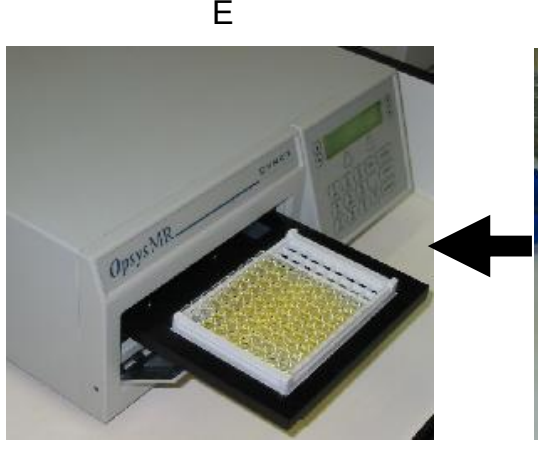

D
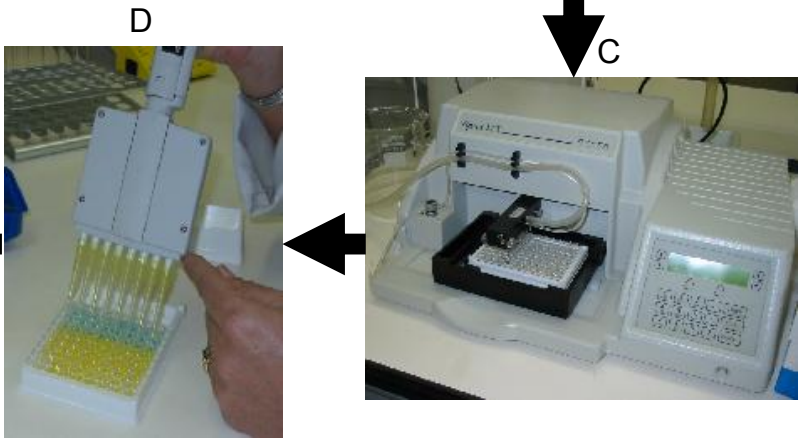

Figura 12 - Kit ELISA: (A) Kit completo (B) Adición de reactivos y muestras (C) lavado de la placa $(D)$ adición de sustrato y $(E)$ lectura de absorbancia.

\subsubsection{1. $\beta$-agonistas}

$1^{\circ}$ - Adición de los reactivos y muestras según se indica en la tabla 10. Tanto los patrones como las muestras se analizan por duplicado en la placa $2^{\circ}$ - Sellado de la placa y agitación durante 1 minuto $3^{\circ}$ - Incubación 1 hora en oscuridad a $4^{\circ} \mathrm{C}$ 
$4^{\circ}$ - Lavado 3 veces con tampón de lavado

$5^{\circ}$ - Adición de $100 \mu \mathrm{L}$ de solución de sustrato a cada pocillo, sellado de la placa y agitación

$6^{\circ}$ - Incubación 30 minutos a temperatura ambiente

$7^{\circ}$ - Adición de $100 \mu \mathrm{L}$ de solución de parada a cada pocillo

$8^{\circ}$ - Lectura de absorbancia de los pocillos a $450 \mathrm{~nm}$

Tabla 10 - Secuencia de adición de reactivos y muestras de $\beta$-agonistas en los kits ELISA.

\begin{tabular}{lcccc}
\hline & Control 1 & Control 2 & Patrón & Muestra \\
\hline Tampón dilución $(\mu \mathrm{L})$ & 100 & 50 & & \\
Patrón $(\mu \mathrm{L})$ & & & 50 & \\
Muestra $(\mu \mathrm{L})$ & & & & 50 \\
Conjugado $(\mu \mathrm{L})$ & 25 & 25 & 25 \\
Anticuerpo $(\mu \mathrm{L})$ & 25 & 25 & 25 \\
\hline
\end{tabular}

\subsubsection{Zeranol}

$1^{\text {a }}$ - Adición de los reactivos y muestras según se detalla en la tabla 11. Tanto los patrones como las muestras se analizan por duplicado en la placa

$2^{\circ}$ - Sellado de la placa y agitación durante unos segundos

$3^{\circ}$ - Incubación 1 hora en oscuridad a temperatura ambiente

$4^{\circ}$ - Lavado 6 veces con el tampón de lavado

$5^{\circ}$ - Adición de $125 \mu \mathrm{L}$ de solución de sustrato a cada pocillo

$6^{\circ}$ - Sellado de la placa, agitación e incubación durante 20 minutos a temperatura ambiente en oscuridad

$7^{\circ}$ - Adición de $100 \mu \mathrm{L}$ de ácido sulfúrico $0.2 \mathrm{M}$ a cada pocillo

$8^{\circ}$ - Lectura de la absorbancia de los pocillos a $450 \mathrm{~nm}$ 
Tabla 11 - Secuencia de adición de reactivos y muestras de zeranol en los kits ELISA.

\begin{tabular}{lccc}
\hline & Control & Patrón & Muestra \\
\hline Tampón dilución $(\mu \mathrm{L})$ & 50 & 50 & 50 \\
Patrón $(\mu \mathrm{L})$ & & 50 & \\
Muestra $(\mu \mathrm{L})$ & & & 50 \\
Conjugado $(\mu \mathrm{L})$ & 25 & 25 & 25 \\
\hline
\end{tabular}

\subsubsection{Procedimiento a seguir en los ensayos ELISA}

\subsubsection{1. $\beta$-agonistas}

En cada lote de muestras de $\beta$-agonistas se preparan:

- Una muestra blanco de agua.

- Una muestra blanco de agua enriquecida $(0.5 \mathrm{ng} / \mathrm{mL}$ de mabuterol y $0.5 \mathrm{ng} / \mathrm{mL}$ de clenbuterol), una muestra de orina blanco enriquecida ( $0.5 \mathrm{ng} / \mathrm{mL}$ de mabuterol y $0.5 \mathrm{ng} / \mathrm{mL}$ de clenbuterol), y una muestra de pienso blanco enriquecido $(2.5 \mathrm{ng} / \mathrm{g}$ de mabuterol y $2.5 \mathrm{ng} / \mathrm{g}$ de clenbuterol).

- Para preparar las orinas enriquecidas o fortificadas se utiliza un blanco de orina certificada, de la cual se toman alícuotas de $2 \mathrm{~mL}$. Previamente se añaden $25 \mu \mathrm{L}$ de una solución metanólica de 40 $\mathrm{ng} / \mathrm{mL}$ de clembuterol y mabuterol, respectivamente, y se llevan a sequedad con nitrógeno, se añaden los $2 \mathrm{~mL}$ de orina blanco y quedan preparadas para trabajar. Las muestras de agua enriquecidas se prepararon de la misma manera. Previamente se comprobó la ausencia de analitos de interés ya que las aguas utilizadas eran las procedentes de las inspecciones.

- Las muestras de pienso enriquecidas se prepararon a partir de piensos procedentes de las inspecciones rutinarias, siendo 
previamente comprobada la ausencia del analito de interés o cualquier contaminante o sustancia que pudiera interferir con los resultados. Se pesaron $2 \mathrm{~g}$ de pienso y se añadieron $50 \mu \mathrm{L}$ de una solución patrón de $100 \mathrm{ng} / \mathrm{mL}$ de clenbuterol y $50 \mu \mathrm{L}$ de una solución patrón de $100 \mathrm{ng} / \mathrm{mL}$ de mabuterol, se dejó reposar durante 30 minutos y posteriormente se realizó la extracción, tal como se describe en el apartado 5.1.3.3.

En la placa se realiza una curva de calibrado con los patrones suministrados por el fabricante. Con la curva de calibrado se pueden estimar los equivalentes de salbutamol presentes en la muestra. La concentración de agonistas en la muestra de orina es 5 veces los equivalentes de salbutamol calculados con la curva patrón.

\subsubsection{Zeranol}

En la placa se realiza una curva de calibrado con los patrones suministrados por el fabricante y un blanco de pienso enriquecido con 200 $\mathrm{ng} / \mathrm{g}$ de zeranol.

En cada lote de muestras de zeranol se preparan un blanco de pienso y un blanco de pienso enriquecido con $200 \mathrm{ng} / \mathrm{g}$.

\subsection{Determinación de residuos de sustancias por cromatografía} líquida de alta resolución con detección por red de diodos (HPLC-DAD)

\subsubsection{Materiales}

Agitadores mecánico o magnético de laboratorio, Centrífuga modelo Medrifiger BL-S (Selecta,Barcelona), baño de ultrasonidos (Selecta, Barcelona), Evaporador concentrador dri-block Tecne, DB-3D (Gomensoro, Madrid), Equipo de cromatografía líquida de alta resolución (HPLC) serie 1100 de Agilent Technologies (Palo Alto, CA, USA) compuesto por 
desgasificador a vacío, autoinyector, bomba cuaternaría, módulo para columna y detector por red de diodos. Software ChemStation. Columna Supersphere RP-C18 de $125 \mathrm{~mm}$ x 4mm con relleno de $4 \mu \mathrm{m}$ (Phenomenex, Torrace, CA, USA), columna Kromasil RP-C18 de $150 \mathrm{~mm}$ x $4.6 \mathrm{~mm}$ con relleno de $5 \mu \mathrm{m}$ (Scharlab, Barcelona), Columna Synergi Max RP de $150 \mathrm{~mm}$ x $4.6 \mathrm{~mm}$ con relleno de $4 \mu \mathrm{m}$ (Phenomenex, Torrace, CA, USA).

\subsubsection{Reactivos}

Agua Milli-Q, etanol absoluto y metanol para HPLC, acetonitrilo para HPLC y acetonitrilo multisolvent (Panreac, Barcelona), columnas de alúmina neutra de $500 \mathrm{mg}$, filtro de fibra de vidrio Whatman GF/A, filtros de membrana de 0,22 $\mu \mathrm{m}$ y 0,45 $\mu \mathrm{m}$.(Supelco, Bellefonte, PA, USA), diclorometano, hexano, tert-butil metil éter (Panreac, Barcelona), columnas amino $\left(\mathrm{NH}_{2}\right)$ y columnas de alúmina neutra (Alox $\mathrm{N}$ ) para extracción en fase sólida (Waters, Mildford, CT, USA). Columnas de inmunoafinidad (Randox, Crumlim, Irlanda del Norte). EDTA.

Sustancias patrón: carbadox, dexametasona, betametasona (Sigma, St. Louis, MO), flumetasona, metil-tiouracilo, propil-tiouracil, tiouracilo (Vetranal, Riedel- de -Haen, Seeize, Germany), dimetil tiouracilo (Aldrich, Madrid).

\subsubsection{Determinación de carbadox}

Para el análisis el carbadox, metil-3-(2quinoxalinilmetileno) carbazato $\mathrm{N}^{1}, \mathrm{~N}^{4}$-dióxido, se utiliza el método de análisis comunitario para la determinación de carbadox en alimentos para animales, según se describe en la Directiva 1999/27/CE (L118/36). El contenido de carbadox se determina mediante cromatografía líquida de alta resolución con detección de diodos (HPLC-DAD). 


\subsubsection{Preparación de la muestra de pienso}

La muestra se equilibra con agua y se somete a extracción con metanol-acetonitrilo. Una parte alícuota del extracto filtrado es purificada en una columna de alúmina neutra. La muestra utilizada es una mezcla de tres piensos de ave. Estos piensos se inyectan por separado para comprobar la ausencia de carbadox, así como la mezcla de los tres. Esta mezcla, denominada pienso blanco, fue la utilizada en toda la validación.

\subsubsection{Extracción}

Se pesan $10 \mathrm{~g}$ de la muestra de pienso molido y se introducen en un erlenmeyer de color ámbar de $200 \mathrm{~mL}$ a los que se añaden $15 \mathrm{~mL}$ de agua, se mezcla y se deja equilibrar durante 5 minutos. Se añaden $35 \mathrm{~mL}$ de metanol-acetonitrilo, se tapa y se deja agitar durante 30 minutos, en agitador mecánico. Se filtra la solución a través de un filtro de fibra de vidrio y se conserva esta solución para la fase de purificación.

\subsubsection{Purificación}

Se pasan $15 \mathrm{~mL}$ del extracto filtrado a la columna de alúmina y se desechan los 2 primeros $\mathrm{mL}$ de eluido. Se recogen los siguientes $5 \mathrm{~mL}$ y se filtra una alícuota a través del filtro de 0,45 $\mu \mathrm{m}$. Se procede a la inyección en el HPLC.

\subsubsection{Determinación mediante HPLC-DAD}

Las condiciones cromatográficas son las siguientes: Se usa una columna de cromatografía líquida Supersphere RP18 (Phenomenex, Torrace CA, USA) de $125 \mathrm{~mm} \times 4 \mathrm{~mm}$, con relleno de $4 \mu \mathrm{m}$. La fase móvil consiste en una mezcla de tampón acetato 0,01 M pH 6, y acetonitrilo (825+175). 
caudal es de $0,5 \mathrm{~mL} / \mathrm{min}$, y el sistema trabaja de forma isocrática. La longitud de onda de detección es de $365 \mathrm{~nm}$ mediante un detector de red de diodos y el volumen de inyección es de $20 \mu \mathrm{L}$.

\subsubsection{Procedimiento general}

Se comprueba la estabilidad del sistema cromatográfico inyectando varias veces la solución de calibración con $5 \mu \mathrm{g} / \mathrm{mL}$, hasta obtener áreas y tiempos de retención constantes. Se inyecta cada solución de calibración varias veces y se determinan las áreas de cada concentración. Se traza una curva de calibrado con las áreas en ordenadas y las concentraciones correspondientes en $(\mu \mathrm{g} / \mathrm{mL})$ en abscisas.

En cada lote de muestras se preparan:

$\checkmark$ Un blanco de reactivo

$\checkmark$ Una muestra blanco de pienso y una muestra blanco de pienso enriquecido con $10 \mu \mathrm{g} / \mathrm{g}$ de carbadox. Para preparar dicho pienso enriquecido, se añade $1 \mathrm{~mL}$ de la solución stock de $100 \mu \mathrm{g} / \mathrm{mL}$ de carbadox en un matraz erlenmeyer de color ámbar de $200 \mathrm{~mL}$. Se evapora la solución en corriente de $\mathrm{N}_{2}$ hasta que quedan unos $0,5 \mathrm{~mL}$. Se añaden $10 \mathrm{~g}$ de pienso blanco, se mezcla y se espera $10 \mathrm{~min}$ antes de pasar a la fase de extracción. El pienso blanco debe ser de tipo similar a la muestra. La recuperación debe ser del $90 \%$.

El orden de inyección utilizado es el siguiente:

$\checkmark$ Blanco de reactivo

$\checkmark$ Pienso blanco (control negativo)

$\checkmark$ Muestras problema

$\checkmark$ Pienso blanco (control negativo)

$\checkmark$ Pienso enriquecido (control positivo) 
Los resultados son evaluados de acuerdo a los siguientes criterios establecidos en la Decisión de la Comisión 2002/657/CE (EC, 2002):

Las longitudes de onda de absorción máxima de los espectros de la muestra y del patrón, registrados en el vértice del pico del cromatograma, deben ser las mismas (365 nm) dentro de un margen determinado por el poder de resolución del sistema de detección. En el caso de la detección por red de diodos se sitúa generalmente en $\pm 2 \mathrm{~nm}$.

Por encima de los $220 \mathrm{~nm}$, el espectro del analito no debe diferir visualmente del espectro del patrón de calibración, para aquellas partes de ambos espectros con una absorbancia relativa $\geq 10 \%$. Este criterio se satisface, en primer lugar, cuando se presentan máximos iguales $\mathrm{y}$, en segundo lugar, cuando en ninguno de los puntos observados la diferencia entre ambos espectros es superior al $10 \%$ de la absorbancia del patrón de calibración.

La presencia del analito sólo se considera confirmada cuando se cumplen todos estos criterios.

A partir de la curva de calibrado se determina la concentración de carbadox $(\mu \mathrm{g} / \mathrm{mL})$ en la solución de la muestra problema. El contenido $(w)$ de carbadox en la muestra es expresado en $\mu \mathrm{g} / \mathrm{g}$ y se obtiene mediante la siguiente fórmula:

donde:

$$
w=\frac{\beta \times V_{1}}{m}
$$

$\beta=$ concentración de carbadox en el extracto de la muestra en $\mu \mathrm{g} / \mathrm{mL}$ $V_{1}=$ Volumen de extracción en $\mathrm{mL}(50 \mathrm{~mL})$

$m=$ masa de la proporción de muestra en gramos $(10 \mathrm{~g})$.

\subsubsection{Confirmación: Co-cromatografía}

Se enriquece un extracto de la muestra mediante la adición de una cantidad adecuada y conocida de la solución de calibración. La cantidad de 
carbadox añadida debe ser similar a la cantidad calculada de carbadox que se encuentre en el extracto de la muestra.

Solamente debe aumentar el área del pico de carbadox, teniendo en cuenta la cantidad añadida y la dilución del extracto. La anchura del pico a la mitad de su altura máxima debe estar aproximadamente dentro del margen del $\pm 10 \%$ de la anchura inicial.

\subsubsection{Determinación de metil-tiouracilo}

Las muestras de orina se someten a extracción con acetato de etilo en ambiente reductor. El contenido de metil-tiouracilo (MTU) se determina mediante cromatografía líquida de alta resolución con detección de diodos (HPLC-DAD). El dimetil-tiouracilo (DMTU) se utilizó como patrón interno.

\subsubsection{Preparación de la muestra de orina y protocolo de extracción}

Se pesan, en un tubo de vidrio Sovirel de $10 \mathrm{~mL}, 0,10 \mathrm{~g}$ de EDTA, se añade $1 \mathrm{~mL}$ de orina previamente centrifugada a $3700 \mathrm{rpm}$ durante 5 minutos. Se añaden $50 \mu \mathrm{L}$ de la solución madre de $1 \mathrm{mg} / \mathrm{mL}$ de dimetiltiouracilo (PI) y se agita. A continuación se añaden $3 \mathrm{~mL}$ de acetato de etilo y $15 \mu \mathrm{L}$ de 2-mercaptoetanol. Se homogeniza y deja en agitación horizontal durante 10 minutos. Se congela la mezcla para facilitar la separación de las fases. Se recoge la fase orgánica en un tubo de vidrio limpio y se lleva a sequedad bajo nitrógeno a $45^{\circ} \mathrm{C}$. Se recoge el residuo seco lavando sucesivamente con metanol, y se pasa a un vial de HPLC. Se lleva a sequedad bajo nitrógeno a $45^{\circ} \mathrm{C}$ y se resuspende en $200 \mu \mathrm{L}$ de fase móvil, se pasa a un inserto de vidrio y se inyectan $10 \mu \mathrm{L}$ en el HPLC.

\subsubsection{Determinación mediante HPLC-DAD}


Se utiliza una columna de cromatografía líquida Kromasil C18 de $150 \mathrm{~mm} \times 4.6 \mathrm{~mm}$ con relleno de $5 \mu \mathrm{m}$ (Scharlab, Barcelona). Las fases móviles son tampón fosfato $0,025 \mathrm{M}$ de $\mathrm{pH} 3$ y metanol. Se utiliza el siguiente gradiente: Inicio con $10 \%$ de metanol, hasta alcanzar el $26 \%$ a los 8 minutos. Aumento hasta el $70 \%$ en 2 minutos y se mantiene durante 7 minutos. Vuelta a las condiciones iniciales en 3 minutos y se reacondiciona la columna durante 10 minutos. El caudal es de $1 \mathrm{~mL} / \mathrm{min}$ y el volumen de inyección de $10 \mu \mathrm{L}$. La longitud de onda de detección es de $276 \mathrm{~nm}$.

\subsubsection{Procedimiento general}

Se comprueba la estabilidad del sistema cromatográfico inyectando varias veces el patrón de $100 \mathrm{ng} / \mathrm{mL}$, hasta obtener áreas y tiempos de retención constantes. Una vez estabilizado el sistema se inyectan los patrones puros para establecer la recta de calibrado.

En cada lote de muestras se realiza la siguiente secuencia de inyección:

- Un blanco de reactivo

- Una muestra blanco de orina

- Una muestra blanco de orina enriquecida con $150 \mathrm{ng} / \mathrm{mL}$ de MTU.

El orden de inyección es el que se detalla a continuación:

Blanco de reactivo

Orina blanco (control negativo)

Muestras problema

Orina blanco (control negativo)

Orina enriquecida (control positivo)

Los resultados son evaluados de acuerdo a los siguientes criterios establecidos en la Decisión de la Comisión 2002/657/CE (EC, 2002):

Las longitudes de onda de absorción máxima de los espectros de la muestra y del patrón, registrados en el vértice del pico del cromatograma, 
deben ser las mismas $(276 \mathrm{~nm})$ dentro de un margen determinado por el poder de resolución del sistema de detección. En el caso de la detección por red de diodos se sitúa generalmente en $\pm 2 \mathrm{~nm}$.

Por encima de los $220 \mathrm{~nm}$, el espectro del analito no debe diferir visualmente del espectro del patrón de calibración, para aquellas partes de ambos espectros con una absorbancia relativa $\geq 10 \%$. Este criterio se satisface, en primer lugar, cuando se presentan máximos iguales y, en segundo lugar, cuando en ninguno de los puntos observados la diferencia entre ambos espectros es superior al $10 \%$ de la absorbancia del patrón de calibración.

La presencia del analito sólo se considera confirmada cuando se cumplen todos estos criterios.

\subsubsection{Confirmación: Co-cromatografía}

Se enriquece un extracto de la muestra mediante la adición de una cantidad adecuada y conocida de la solución de calibración. La cantidad de metil tiouracilo (MTU) añadida debe ser similar a la cantidad calculada de metil tiouracilo que se encuentre en el extracto de la muestra.

Solamente debe aumentar el área del pico de metil tiouracilo, teniendo en cuenta la cantidad añadida y la dilución del extracto. La anchura del pico a la mitad de su altura máxima debe estar aproximadamente dentro del margen del $\pm 10 \%$ de la anchura inicial.

\subsubsection{Determinación de Dexametasona}

El presente método permite la determinación de dexametasona, 9- $\alpha$ Fluoro-16a-metilprednisolona, en agua de beber y en pienso de distintas especies (bovino, porcino y equino). 
La muestra de agua se introduce directamente en la columna de inmunoafinidad específica para dexametasona y flumetasona (patrón interno). En el pienso, las muestras necesitan un paso previo de limpieza que se realiza mediante una extracción en fase sólida con cartuchos amino $\left(\mathrm{NH}_{2}\right)$. El contenido de dexametasona se determina mediante cromatografía líquida de alta resolución con detección de diodos (HPLC-DAD).

\subsubsection{Preparación de la muestra y protocolo de extracción para pienso}

Se pesan en un tubo de centrífuga 2 gramos de pienso molido y se adiciona el patrón interno (flumetasona $300 \mathrm{ng} / \mathrm{g}$ ). Se añaden $10 \mathrm{~mL}$ de tertbutil-metil eter (TBME) y se mantiene en agitación horizontal durante 20 minutos. Seguidamente, se centrifuga a $4^{\circ} \mathrm{C}$ durante 10 minutos a $2700 \mathrm{rpm}$. Se decanta el sobrenadante y se repite la extracción con tert-butil-metil éter (TBME). Las fases orgánicas se recogen en un tubo de vidrio limpio y se filtran con un filtro de nylon de $0,45 \mu \mathrm{m}$. Por otro lado, se acondiciona una columna amino $\left(\mathrm{NH}_{2}\right)$ para la extracción en fase sólida, con $5 \mathrm{~mL}$ de tert-butilmetil éter (TBME), se aplica la muestra y se eluye con $4 \mathrm{~mL}$ de metanol-agua (80:20). El eluido se lleva a sequedad con corriente de nitrógeno a $45^{\circ} \mathrm{C}$ y el residuo seco se resuspende en $200 \mu \mathrm{L}$ de metanol y $4.5 \mathrm{~mL}$ de agua mili-Q.

La muestra resuspendida es purificada con una columna de inmunoafinidad para corticosteroides, siguiendo el protocolo del fabricante de columnas (Laboratorios Randox, Irlanda). Posteriormente, el eluido se lleva a sequedad bajo nitrógeno a $45^{\circ} \mathrm{C}$ y el residuo seco se resuspende con $200 \mu \mathrm{L}$ de fase móvil. En la figura 13 se muestra un esquema de los pasos descritos para la extracción de dexametasona en pienso.

\subsubsection{Preparación de la muestra y protocolo de extracción para agua}


Se parte de una alícuota de $5 \mathrm{~mL}$ de agua a la cual se le adiciona el patrón interno (flumetasona $120 \mathrm{ng} / \mathrm{mL}$ ) y se introduce directamente en una columna de inmunoafinidad para corticosteroides, siguiendo las instrucciones del fabricante. Seguidamente, el eluído se lleva a sequedad bajo nitrógeno a $45^{\circ} \mathrm{C}$ y se disuelve con $200 \mu \mathrm{L}$ de fase móvil (ver figura 14).

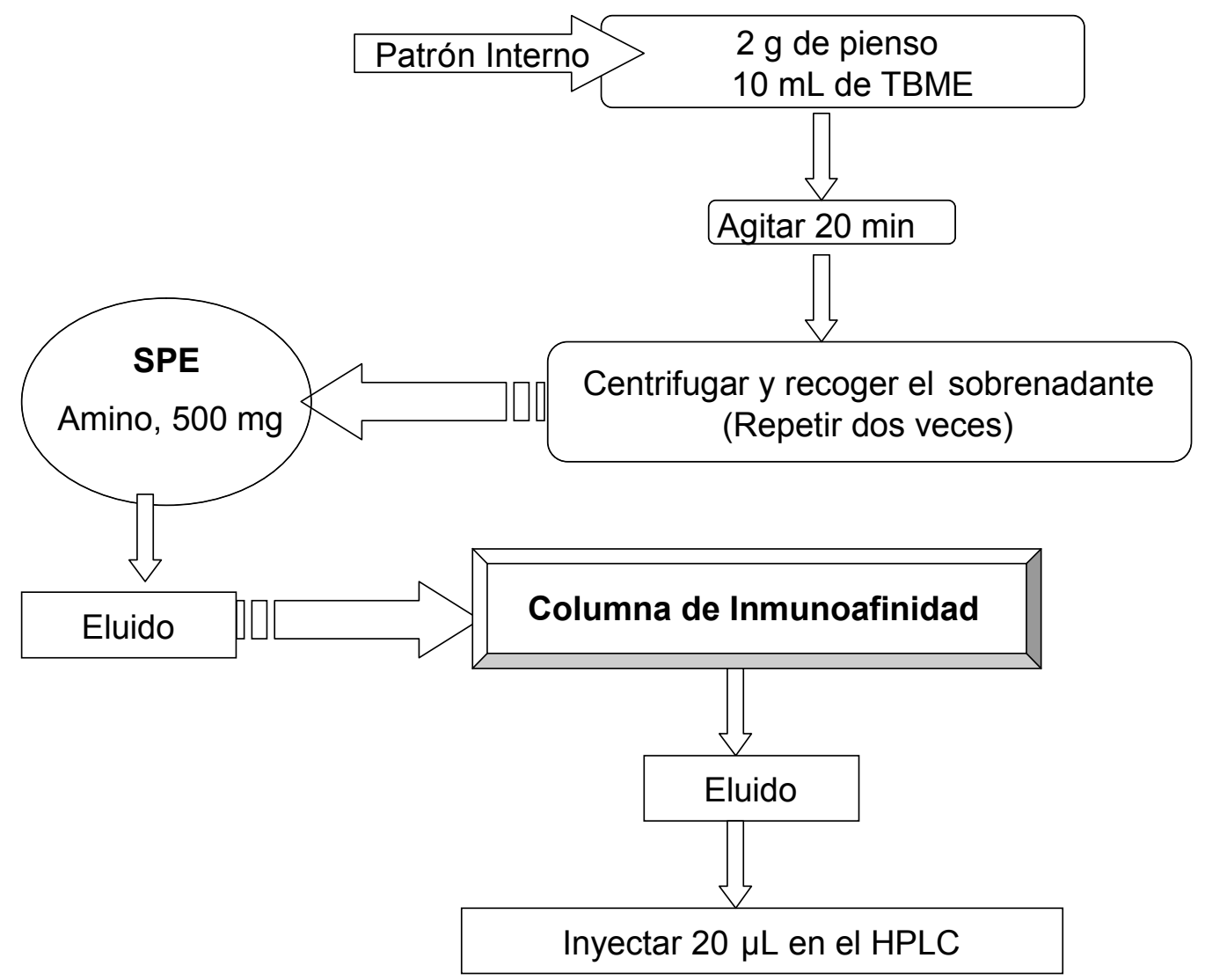

Figura 13 - Protocolo de extracción de dexametasona en pienso

\subsubsection{Determinación mediante HPLC-DAD}


Para la separación cromatografica de estos analitos se utilizó una columna de cromatografía de líquidos Synergi MAX-RP 80 A de 150 x 4.60 $\mathrm{mm}$, con relleno de $4 \mu \mathrm{m}$ (Phenomenex, Torrace, USA). Las fases móviles son agua Milli $Q$ y acetonitrilo. El sistema trabaja de forma isocrática, mezclando el agua y el acetonitrilo en proporciones de 30:70, a un caudal de $1 \mathrm{~mL} / \mathrm{min}$ y el volumen de inyección es de $20 \mu \mathrm{L}$. La longitud de onda de detección es de $242 \mathrm{~nm}$.

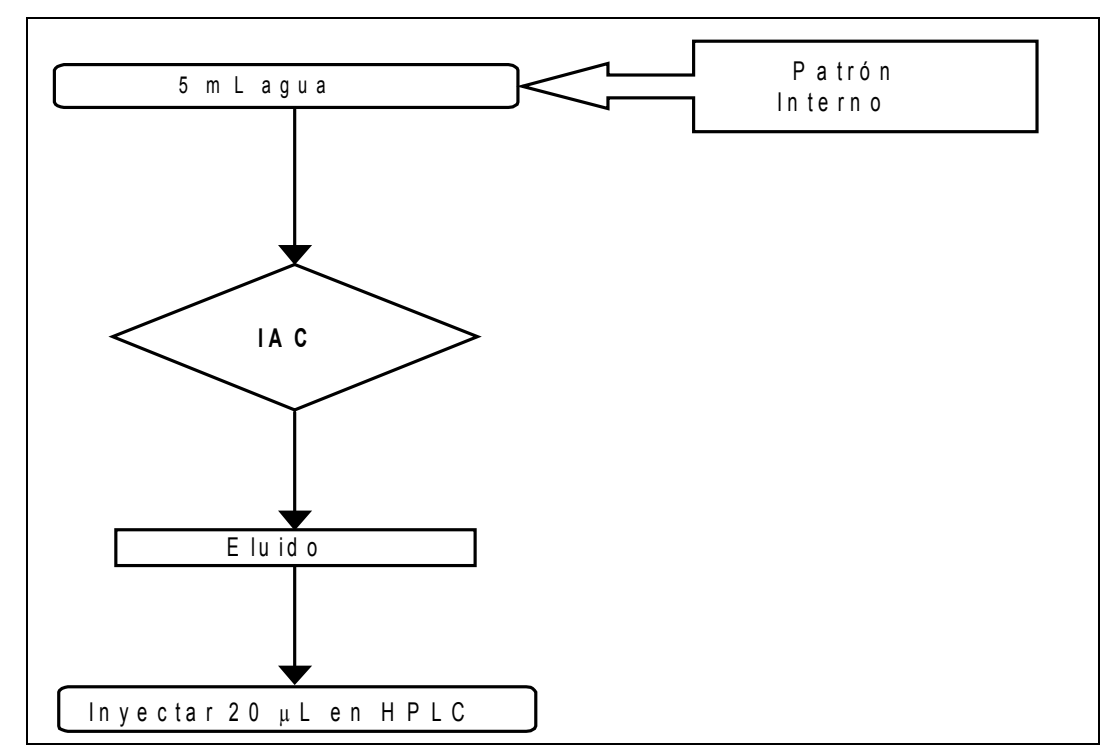

Figura 14 - Protocolo de extracción de dexametasona en agua.

\subsubsection{Procedimiento general}

En primer lugar se comprueba la estabilidad del sistema cromatográfico inyectando varias veces el patrón de $100 \mathrm{ng} / \mathrm{mL}$ dexametasona (DX), al cual se añade flumetasona $(120 \mathrm{ng} / \mathrm{mL})$ como patrón interno, hasta obtener áreas y tiempos de retención constantes. Una vez estabilizado el sistema se procedió a inyectar la recta de patrones puros para 
la recta de calibrado. A continuación, se inyectan diariamente las secuencias de muestras usando el orden que se detalla a continuación:

Para cada lote de muestras se preparan:

- Un blanco de reactivo

- Una muestra blanco de agua y una muestra blanco de pienso

- Una muestra blanco de agua enriquecida con $25 \mathrm{ng} / \mathrm{mL}$ de DX y una muestra blanco de pienso enriquecida con $190 \mathrm{ng} / \mathrm{g}$ de DX.

El orden de inyección es el siguiente:

- Blanco de reactivo

- Muestra blanco (control negativo)

- Muestras problema

- Muestra blanco (control negativo)

- Muestra enriquecida (control positivo)

Los resultados son evaluados de acuerdo a los siguientes criterios establecidos en la Decisión de la Comisión 2002/657/CE (EC, 2002):

Las longitudes de onda de absorción máxima de los espectros de la muestra y del patrón, registrados en el vértice del pico del cromatograma, deben ser las mismas (242 $\mathrm{nm}$ ) dentro de un margen determinado por el poder de resolución del sistema de detección. En el caso de la detección por red de diodos se sitúa generalmente en $\pm 2 \mathrm{~nm}$.

Por encima de los $220 \mathrm{~nm}$, el espectro del analito no debe diferir visualmente del espectro del patrón de calibración, para aquellas partes de ambos espectros con una absorbancia relativa $\geq 10 \%$. Este criterio se satisface, en primer lugar, cuando se presentan máximos iguales $y$, en segundo lugar, cuando en ninguno de los puntos observados la diferencia entre ambos espectros es superior al $10 \%$ de la absorbancia del patrón de calibración. 
La presencia del analito sólo se considera confirmada cuando se cumplen todos estos criterios.

\subsubsection{Confirmación: Co-cromatografía}

Se enriquece un extracto de la muestra mediante la adición de una cantidad adecuada y conocida de la solución de calibración. La cantidad de dexametasona añadida debe ser similar a la cantidad calculada de dexametasona que se encuentre en el extracto de la muestra.

Solamente debe aumentar el área del pico de dexametasona, teniendo en cuenta la cantidad añadida y la dilución del extracto. La anchura del pico a la mitad de su altura máxima debe estar aproximadamente dentro del margen del $\pm 10 \%$ de la anchura inicial.

\subsection{Análisis estadístico}

Se empleó un análisis ANOVA para determinar diferencias significativas entre medias usando el software Statgraphics plus (v 5.1). Se verificó la normalidad de los datos antes de aplicar el tratamiento ANOVA. 
6. Resultados y Discusión 


\section{RESULTADOS Y DISCUSIÓN}

\subsection{Validación de métodos de criba con ensayos ELISA para $\beta$ - agonistas.}

Se realizaron las pruebas de especificidad, robustez, estabilidad y capacidad de detección, que se describen a continuación, siendo los ensayos evaluados y validados según la Decisión 2002/657/EC (EC, 2002).

\subsubsection{Especificidad}

Se utilizaron placas ELISA para ensayar la especificidad frente a $\beta$ agonistas en una matriz compleja como la orina según el protocolo descrito en 5.1.4.1. A tal fin, se ensayaron veinte muestras blanco de la misma orina certificada, ausente de residuos y suministrada por el Instituto Nacional de Salud Pública y Medioambiente (RIVM, Holanda).

EI kit ELISA utilizado estaba basado en anticuerpos desarrollados frente a salbutamol y clembuterol. Por lo tanto, otros compuestos distintos a los $\beta$-agonistas no deberían reaccionar. Sin embargo, cabe destacar que este ensayo presenta reacción cruzada con los siguientes $\beta$-agonistas:

- Salbutamol $100 \%$

- Clembuterol $100 \%$

- Brombuterol $100 \%$

- Cimbuterol $75 \%$

- Mapenterol $70 \%$

- Mabuterol $60 \%$

- Tulobuterol $50 \%$

- Clenpenterol $50 \%$

- Terbutelina $40 \%$ 
- Carbuterol $40 \%$

- Cimaterol $10 \%$

- Zilpaterol $1 \%$

La presencia de algunos de estos $\beta$-agonistas en las muestras puede interferir, en mayor o menor medida según el nivel de reactividad, en el resultado. Por lo tanto, todas las muestras no conformes tienen que ser confirmadas mediante un método de confirmación adecuado para determinar el tipo de agonista con exactitud.

\subsubsection{Aplicabilidad (Cambios menores)}

Se estudiaron variaciones menores de distintos factores que puedan afectar al análisis, entre ellos el operador, procedencia y edad de los reactivos, disolventes y patrones así como las formas de almacenamiento de las muestras hasta su análisis.

Varios operadores (tres) intervinieron en el manejo y análisis de muestras de pienso, orina y agua siendo los resultados obtenidos independientes del operador. Los kits ELISA procedían siempre del mismo fabricante. Se emplearon distintos lotes, tanto de reactivos como de disolventes, y no se observaron diferencias significativas $(p<0.01)$. Respecto a la estabilidad de los patrones, se comprobó que no había diferencia en las soluciones de calibrado dentro del periodo de tiempo estimado como estable por el fabricante del kit. Las distintas formas de almacenamiento de las muestras antes de su análisis vienen reguladas por el tipo de matriz. Ligeras variaciones en las condiciones de almacenamiento, no alteraron significativamente $(p<0.05)$ los resultados analíticos. 


\subsubsection{Estabilidad}

El tiempo y temperatura de conservación del extracto de la muestra podrían constituir un posible factor de variación de los resultados obtenidos. A fin de verificar dicho posible efecto, se analizaron tres lotes de muestras de agua y de orina blanco de bovino enriquecidas con $0,5 \mathrm{ng} / \mathrm{mL}$ de cada una de las dos sustancias, clembuterol y mabuterol, respectivamente. Para cada lote de muestras, una alícuota fue ensayada en la placa ELISA mientras que otra alícuota fue conservada a $4^{\circ} \mathrm{C}$ durante $24 \mathrm{~h}$ y una tercera alícuota a $-20^{\circ} \mathrm{C}$ durante una semana. No se observaron diferencias significativas $(p<0.05)$ en los resultados obtenidos.

La solución stock de clembuterol (concentración $1 \mathrm{mg} / \mathrm{mL}$ ) fue conservada en congelación $\left(-20^{\circ} \mathrm{C}\right)$ y demostró buena estabilidad (5 meses sin alteración significativa a $p<0,05)$. La solución madre de clembuterol (concentración $10 \mu \mathrm{g} / \mathrm{mL}$ ), obtenida por dilución a partir de la solución stock, fue también conservada en congelación $\left(-20^{\circ} \mathrm{C}\right)$ siendo la estabilidad observada de un mes. La solución de trabajo de clembuterol $(20 \mathrm{ng} / \mathrm{mL}$ de concentración), obtenida por dilución a partir de la solución madre, fue conservada en congelación $\left(-20^{\circ} \mathrm{C}\right)$ y su estabilidad fue de una semana.

\subsubsection{Capacidad de detección (CC $\beta)$}

Según la normativa comunitaria 2002/657/EC (EC, 2002), la capacidad de detección del método es igual al nivel de concentración en el que sólo se obtiene $\leq 5 \%$ de resultados de falso conforme. A fin de garantizar la fiabilidad de esta determinación, se debe realizar un mínimo de 20 análisis para al menos un nivel de concentración.

Para calcular el CC $\beta$ se partió de muestras blanco de agua, pienso y orina, previamente verificada la ausencia del analito de interés, fortificadas a distintas concentraciones de dicho analito y todas ellas fueron analizadas 
independientemente como muestras diferentes en el ensayo dando como resultado:

Clembuterol: 19 muestras positivas (no conformes) y 1 muestra negativa (conforme) para agua y orina, que supone un 5\%. En el caso del pienso, también se obtuvieron 19 muestras positivas y una negativa. Por tanto, según los resultados obtenidos el CC $\beta$ para el clembuterol para agua y orina resultó ser de $0,5 \mathrm{ng} / \mathrm{mL}$ y para pienso de $4 \mathrm{ng} / \mathrm{g}$.

Mabuterol: 20 muestras positivas (no conformes), ninguna negativa para agua y orina. 19 muestras positivas (no conformes) y 1 muestra negativa (conforme) para el pienso. Según los resultados, el CC $\beta$ para las matrices agua y orina fue de $0,5 \mathrm{ng} / \mathrm{mL}$ y para el pienso fue de $4 \mathrm{ng} / \mathrm{g}$.

\subsubsection{Robustez (cambios importantes)}

La robustez del método fue verificada mediante la intervención de tres operadores con distintos grados de experiencia, en la manipulación y análisis de las muestras, obteniendo los mismos resultados sin diferencias significativas $(p<0.05)$.

Respecto a la estabilidad de los patrones, se comprobó que no había diferencia en las soluciones de calibrado dentro del periodo de tiempo estimado por el fabricante del kit. Durante la validación se emplearon distintos lotes, tanto de reactivos como de disolventes, y no se observaron diferencias significativas $(p<0.05)$. Los kits ELISA procedían siempre del mismo fabricante.

Las condiciones de muestreo siempre fueron las mismas, y no dependían del laboratorio. Las muestras de orina y agua procedentes del muestreo en granja fueron conservadas en congelación hasta el momento del análisis mientras que las de pienso se mantuvieron en ambiente fresco, seco 
y en oscuridad. No se observó un efecto significativo $(p<0.05)$ de la procedencia de las muestras.

6.2 Validación del método de criba con ensayo ELISA para zeranol ( $\alpha$ zearalanol)

\subsubsection{Especificidad}

El kit ELISA que fue utilizado en la determinación del zeranol presentaba la siguiente reactividad cruzada con las sustancias de la familia de las lactonas del ácido resorcílico:

$\begin{array}{lr}\text { Zeranol } & 100 \% \\ \text { Zearalanona } & 80 \% \\ \text { a-Zearalenol } & 65 \% \\ \text { Zearalenona } & 20 \%\end{array}$

Cualquiera de estas sustancias puede interferir, en mayor o menor media según su nivel de reacción, en la determinación del zeranol si estuviera presente en las muestras. Por tanto, la presencia y concentración de zeranol siempre debe ser confirmada por una técnica analítica de confirmación como, por ejemplo, la cromatografía de gases-masas.

\subsubsection{Aplicabilidad (cambios menores)}

Varios operadores (tres) intervinieron en la manipulación y análisis de muestras $\sin$ cambios significativos $(p<0.05)$ en los resultados. Se utilizaron piensos de bovino y ovino procedentes del muestreo del Plan Nacional de Investigación de Residuos. Respecto a la estabilidad de los patrones, se comprobó que no había diferencia en las soluciones de calibrado dentro del periodo de estabilidad estimado por el fabricante.

Durante la validación se emplearon distintos lotes, tanto de reactivos como de disolventes y no se observaron diferencias significativas $(p<0.05)$. 
Las distintas formas de almacenamiento de las muestras antes de su análisis vienen reguladas por el tipo de matriz. Ligeras variaciones en las condiciones de almacenamiento, no alteraron significativamente $(p<0.05)$ los resultados analíticos.

\subsubsection{Estabilidad}

Las soluciones patrón de los kits ELISA estaban liofilizadas y siempre fueron utilizadas antes de su fecha de caducidad. Una vez reconstituidas, las soluciones de los patrones fueron estables durante 24 días cuando eran conservadas entre 2 y $8{ }^{\circ} \mathrm{C}$. La estabilidad del resto de reactivos viene indicada por el fabricante del kit.

Se comprobó que la solución stock de zeranol $(1 \mathrm{mg} / \mathrm{mL})$ era estable durante un mes cuando se conservaba a $-20^{\circ} \mathrm{C}$. La solución madre (10 $\mu \mathrm{g} / \mathrm{mL}$ ), preparada a partir de la solución stock, debía ser preparada cada semana y la solución de trabajo $(50 \mathrm{ng} / \mathrm{mL})$, preparada a partir de la solución madre, debía ser preparada inmediatamente antes de ser utilizada.

Para estudiar la estabilidad del analito en el extracto se analizaron tres lotes de muestras de pienso bovino y ovino enriquecidos con $200 \mathrm{ng} / \mathrm{g}$ de zeranol, tal como se describe en el apartado 5.1.5.2. Para cada lote de muestras, una alícuota fue ensayada en el ELISA inmediatamente, otra alícuota fue conservada a $4^{\circ} \mathrm{C}$ durante $24 \mathrm{~h}$ y una tercera alícuota a $-20^{\circ} \mathrm{C}$ durante una semana. Los resultados en el ensayo ELISA no mostraron diferencias significativas $(p<0.05)$.

\subsubsection{Capacidad de detección (CC $\beta)$}

Según la normativa comunitaria 2002/657/EC (EC, 2002), la capacidad de detección del método es igual al nivel de concentración en el que sólo se obtiene $\leq 5 \%$ de resultados de falso conforme. A fin de garantizar 
la fiabilidad de esta determinación, se debe realizar un mínimo de 20 análisis para al menos un nivel de concentración.

La capacidad de detección fue calculada enriqueciendo matrices blanco de pienso, hasta un total de 22 piensos por nivel de fortificación. En el caso de las muestras de pienso blanco fortificadas con $200 \mathrm{ng} / \mathrm{g}$ de zeranol, sólo una resultó falso conforme $(<5 \%)$, por lo que la capacidad de detección de este método se estableció en $200 \mathrm{ng} / \mathrm{g}$ de zeranol en pienso.

\subsubsection{Robustez (cambios importantes)}

Este método de análisis fue validado para piensos de bovino y de ovino. El análisis de zeranol en otro tipo de piensos requeriría la validación del método para cada una de las especies que se quisiera analizar.

La robustez del método fue verificada mediante la intervención de tres operadores con distintos grados de experiencia, en la manipulación y análisis de las muestras, obteniendo los mismos resultados sin diferencias significativas $(p<0.05)$.

Respecto a la edad de los patrones, se comprobó que no había diferencia en las soluciones de calibrado dentro del periodo de estabilidad estimado por el fabricante del kit. Durante la validación se emplearon distintos lotes, tanto de reactivos como de disolventes, y no se observaron diferencias significativas $(p<0.05)$.

Las condiciones de muestreo siempre fueron las mismas, y no dependían del personal del laboratorio. El pienso procedente del muestreo fue conservado en lugar fresco y seco, protegido de la luz. 


\subsection{Validación del método de criba por cromatografía líquida de alta resolución (HPLC) para carbadox}

\subsubsection{Especificidad}

Se estudió la posible interferencia de diversos nitrofuranos, que también pueden ser empleados como promotores del crecimiento, en la detección de carbadox. Los nitrofuranos estudiados fueron nitrofurazona (NFZ), furaltadona (NFT), furazolidona (FZD) y nitrofurantoína (FZT).

Para ello, se analizaron 20 muestras de pienso ovino, cunícola y avícola comprobando la ausencia de picos cromatográficos en la región de interés. Se ensayaron dos longitudes de onda, $306 \mathrm{~nm}$ y $365 \mathrm{~nm}$, que son las de máxima absorción del carbadox (ver figura 15).

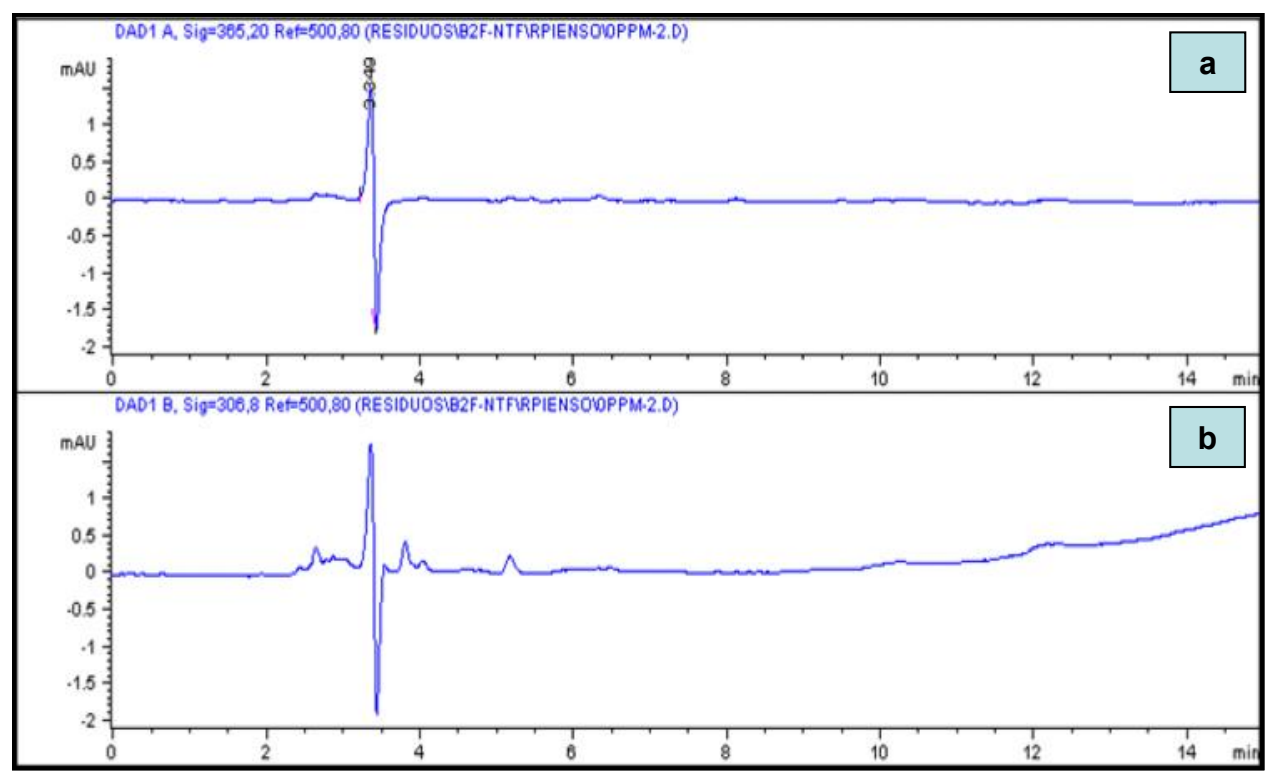

Figura 15 -Cromatograma de una muestra blanco de pienso. (a) Lectura a $365 \mathrm{~nm}$, (b) lectura a $306 \mathrm{~nm}$. 
Posteriormente, se enriquecieron las muestras blanco de pienso con una mezcla de carbadox y nitrofuranos. Los nitrofuranos se detectan a una longitud de onda $\lambda=365 \mathrm{~nm}$ pero en los cromatogramas resultantes (ver figura 16) se pudo comprobar que ninguna de estas sustancias estudiadas interfería con el carbadox; de hecho, quedaban claramente identificadas.

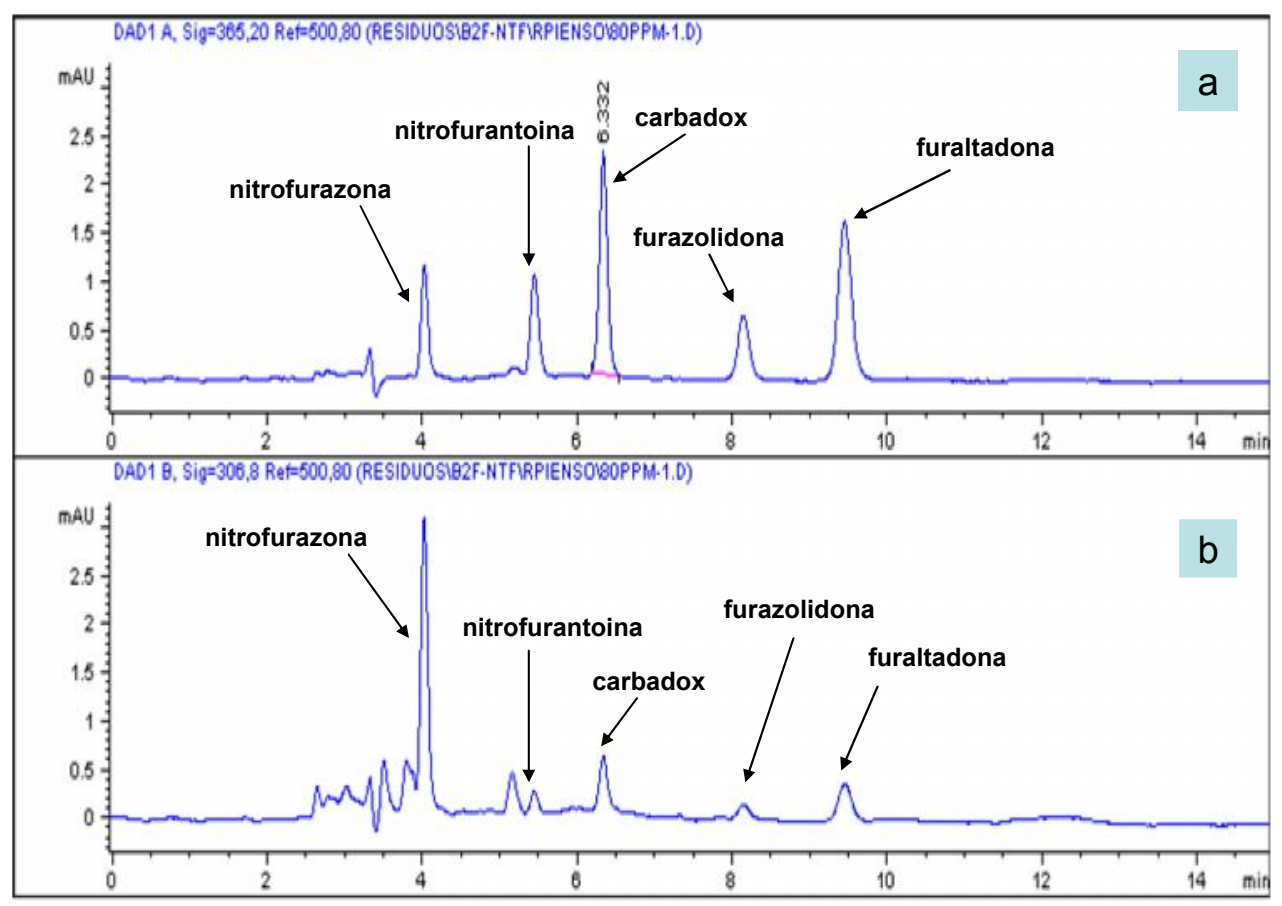

Figura 16 -Cromatograma de una muestra blanco de pienso enriquecido con $80 \mu \mathrm{g} / \mathrm{g}$ de carbadox, nitrofurazona, nitrofurantoína, furazolidona y furaltadona. (a) Lectura a $365 \mathrm{~nm}$, (b) lectura a $306 \mathrm{~nm}$.

\subsubsection{Aplicabilidad (cambios menores)}

Tres operadores intervinieron en la manipulación y análisis de las muestras. La procedencia de los piensos no fue siempre la misma, se utilizaron piensos blanco procedentes de distintas explotaciones ganaderas 
de distintas localidades y previamente analizadas para verificar la ausencia de carbadox.

Respecto a la estabilidad de los patrones, se comprobó que no había diferencias significativas en las soluciones de calibrado dentro del periodo de tiempo estimado. Durante la validación se emplearon distintos lotes, tanto de reactivos como de disolventes y no se observaron diferencias significativas $(p<0.05)$.

\subsubsection{Estabilidad}

La estabilidad del analito en el pienso viene determinada por las condiciones de almacenamiento. El analito es sensible a la luz y por tanto las muestras fueron almacenadas en lugar fresco y seco dentro de bolsas opacas. Los análisis se realizaron con luz tenue natural, sin luz artificial y en material de vidrio de color ámbar. La solución madre de patrón de carbadox fue estable durante un mes en oscuridad a $4^{\circ} \mathrm{C}$. Las soluciones de calibrado fueron preparadas justo antes de su utilización.

\subsubsection{Rectas de calibrado}

Se realizaron diversas rectas de calibrado con las soluciones patrón de carbadox de $0,2,5,10,15$ y $20 \mu \mathrm{g} / \mathrm{mL}$, tal como se muestra en la figura 17, manteniendo todas ellas muy poca dispersión. La figura 18 muestra un cromatograma con carbadox a una concentración de $20 \mu \mathrm{g} / \mathrm{mL}$.

A continuación se realizaron las rectas de calibrado con muestras de piensos de diferentes especies (avícola, ovino, cunícola) enriquecidas con $0,2,5,10,20$ y $50 \mu \mathrm{g} / \mathrm{g}$ de carbadox. Los resultados obtenidos también demostraron muy poca dispersión tal como se puede comprobar en la figura 19. 


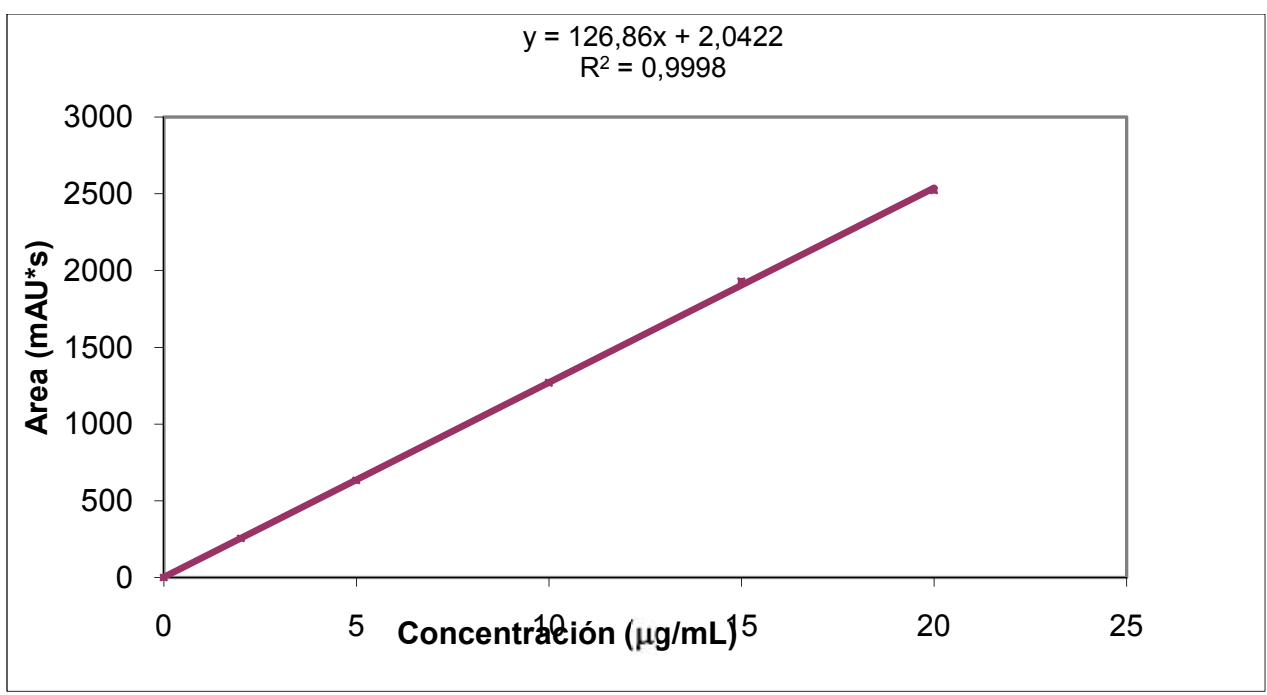

Figura 17. - Recta de calibrado con patrones puros de carbadox.

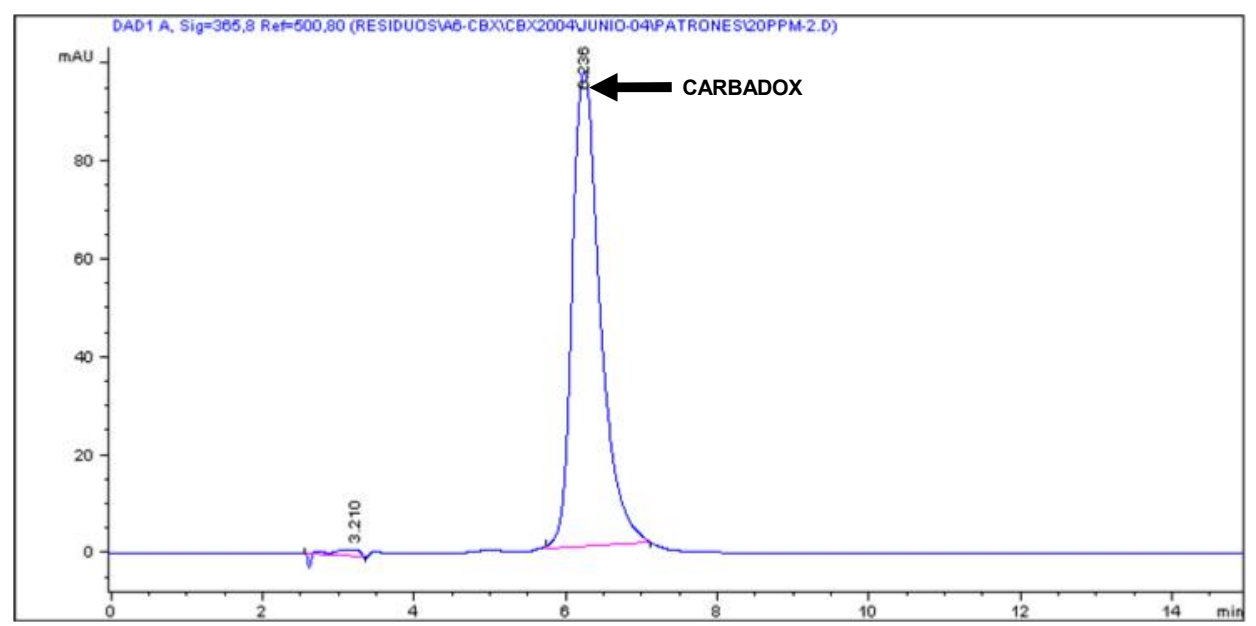

Figura 18 -Cromatograma de una solución patrón de $20 \mu \mathrm{g} / \mathrm{mL}$ de carbadox.

\subsubsection{Recuperación}

Para calcular la recuperación se seleccionaron 18 alícuotas de un pienso blanco, que era el resultado de la mezcla de tres piensos avícolas blanco, y fueron enriquecidos en grupos de 6 con 1, 1.5 y 2 veces el límite de determinación (10 mg/kg), según el siguiente esquema: 


$$
\begin{aligned}
& 6 \text { muestras blanco }+10 \mu \mathrm{g} / \mathrm{g} \\
& 6 \text { muestras blanco }+15 \mu \mathrm{g} / \mathrm{g} \\
& 6 \text { muestras blanco }+20 \mu \mathrm{g} / \mathrm{g}
\end{aligned}
$$

Se analizaron las muestras y se calcularon las concentraciones en cada una de ellas. Se determinó la recuperación en cada muestra, así como el promedio de la recuperación, la desviación estándar y el coeficiente de variación (CV) para cada nivel (ver tabla 12).

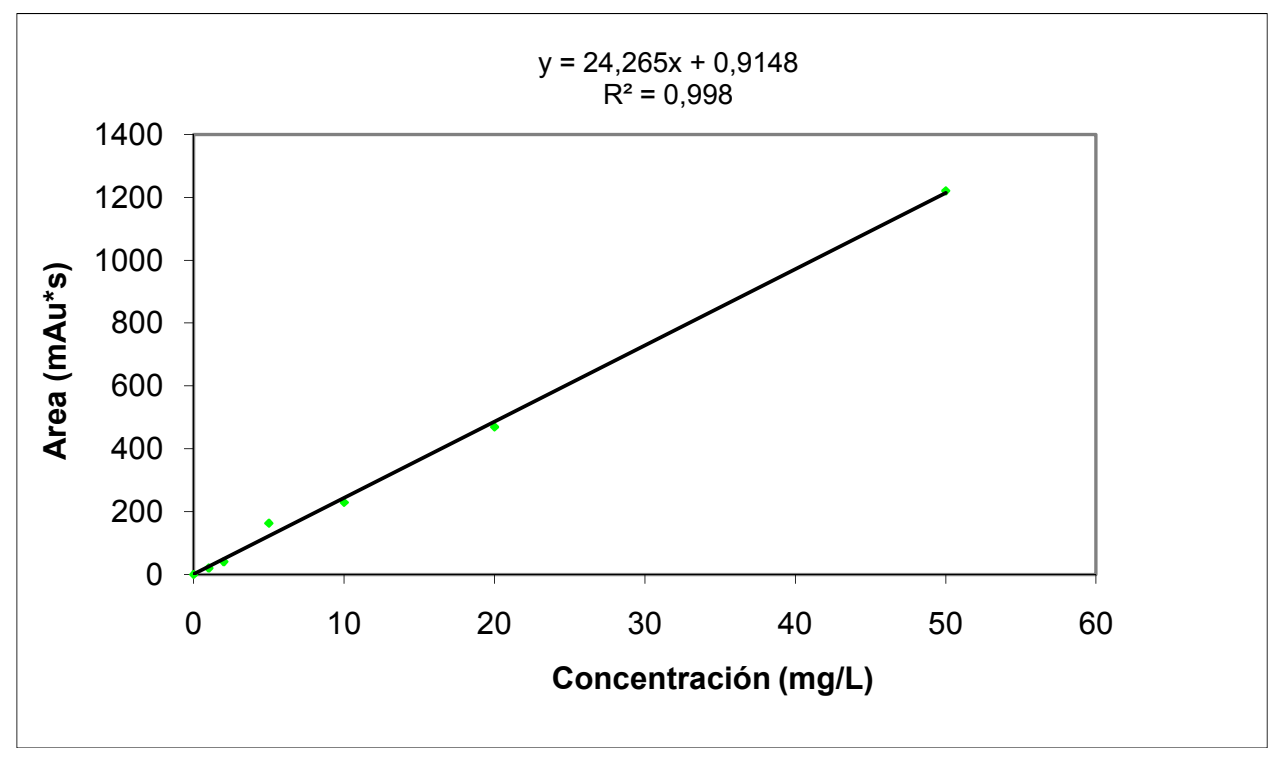

Figura 19 - Recta de calibrado sobre pienso enriquecido con carbadox.

\subsubsection{Repetibilidad}

Se prepararon 3 grupos de 6 piensos blanco enriquecidos con carbadox a tres niveles de concentración por grupo. Las muestras enriquecidas con 10, 15 y $20 \mu \mathrm{g} / \mathrm{g}$, que fueron utilizadas para la recuperación, sirvieron también para obtener los datos referentes a este apartado. Los grupos eran los siguientes: 


$$
\begin{aligned}
& 6 \text { muestras blanco }+10 \mu \mathrm{g} / \mathrm{g} \\
& 6 \text { muestras blanco }+15 \mu \mathrm{g} / \mathrm{g} \\
& 6 \text { muestras blanco }+20 \mu \mathrm{g} / \mathrm{g}
\end{aligned}
$$

Tabla 12 - Recuperación de carbadox en muestras de pienso avícola con adición de cantidades controladas.

\begin{tabular}{cccc}
\hline $\begin{array}{c}\text { Concentración } \\
(\boldsymbol{\mu g} / \mathbf{g})\end{array}$ & $\begin{array}{c}\text { Recuperación } \\
(\%)\end{array}$ & $\begin{array}{c}\text { Desviación } \\
\text { standard }\end{array}$ & $\begin{array}{c}\text { Coef. Var. } \\
(\%)\end{array}$ \\
\hline 10 & 94 & 5 & 5 \\
15 & 99 & 3 & 3 \\
20 & 103 & 2 & 2 \\
\hline
\end{tabular}

Los resultados que se obtuvieron fueron los que se muestran en la tabla 13. La diferencia entre las determinaciones paralelas efectuadas con la misma muestra no debían superar el 15\% del resultado superior, como así fue. Para esta característica, la Directiva 2002/657/CE exige la determinación de la concentración promedio, la desviación estándar y el coeficiente de variación (\%) para los tres niveles de concentración.

Tabla 13 - Repetibilidad del análisis de las muestras de pienso enriquecidas con 3 concentraciones distintas de carbadox.

\begin{tabular}{cccc}
\hline $\begin{array}{c}\text { Concentración } \\
(\boldsymbol{\mu} \mathbf{g} / \mathbf{g})\end{array}$ & $\begin{array}{c}\text { Promedio } \\
(\boldsymbol{\mu g} / \mathbf{g})\end{array}$ & $\begin{array}{c}\text { Desviación } \\
\text { standard }\end{array}$ & $\begin{array}{c}\text { Coef. Var. } \\
(\%)\end{array}$ \\
\hline 10 & 9 & 0,5 & 5 \\
15 & 15 & 0,4 & 3 \\
20 & 21 & 0,5 & 2,4 \\
\hline
\end{tabular}




\subsubsection{Reproducibilidad intralaboratorio}

Se preparó un conjunto de distintas muestras de piensos blanco enriquecidos con el analito para dar concentraciones de 5, 10, 15 y $20 \mu \mathrm{g} / \mathrm{g}$. En cada nivel de concentración se analizaron un mínimo de seis muestras idénticas o diferentes. Cada uno de estos niveles fue analizado por un operador distinto, en diferentes días y con distintos lotes de reactivos. Se calculó la concentración detectada en cada muestra y se determinó la concentración media, la desviación estándar y el coeficiente de variación (\%) de las muestras enriquecidas. Los resultados obtenidos se muestran en la tabla 14 donde se puede observar una buena reproducibilidad.

\subsubsection{Límite de decisión ( $\mathrm{CC} \alpha)$}

El límite de decisión se estableció, tal y como recomienda la normativa comunitaria en la Decisión 2002/657/CE (EC, 2002), analizando 25 piensos blanco. En cada uno de ellos se calculó la relación señal/ruido en el intervalo de tiempo en el que se espera que eluya el carbadox. El límite de decisión es igual al triple de la relación señal/ruido en esa banda de tiempo. El límite de decisión obtenido fue CC $\alpha=5 \mu \mathrm{g} / \mathrm{g}$.

Tabla 14 - Reproducibilidad intralaboratorio del método de análisis de piensos enriquecidos con 4 concentraciones de carbadox.

\begin{tabular}{ccccc}
\hline $\begin{array}{c}\text { Concentración } \\
(\boldsymbol{\mu} \mathbf{g} / \mathbf{g})\end{array}$ & $\begin{array}{c}\text { Promedio } \\
(\boldsymbol{\mu} \mathbf{g} / \mathbf{g})\end{array}$ & Desv Std. & $\begin{array}{c}\text { Coef. Var. } \\
(\%)\end{array}$ & $\begin{array}{c}\text { Recuperación } \\
(\%)\end{array}$ \\
\hline 5 & 4 & 0,6 & 14 & 80 \\
10 & 9 & 0,4 & 4 & 94 \\
15 & 15 & 0,4 & 2,4 & 98 \\
20 & 20 & 0,9 & 5 & 99
\end{tabular}




\subsubsection{Capacidad de detección (CC $\beta)$}

La capacidad de detección se calculó enriqueciendo 21 matrices blanco al nivel del límite de decisión $(5 \mu \mathrm{g} / \mathrm{g})$.

La capacidad de detección es igual al límite de decisión más 1.64 veces la desviación estándar de la reproducibilidad intralaboratorio del contenido medido (la desviación estándar de la concentración medida). El valor así obtenido para ambos tipos de pienso fue $\mathrm{CC} \beta=6 \mu \mathrm{g} / \mathrm{g}$.

\subsubsection{Robustez (cambios importantes)}

Se estudió la robustez del método introduciendo modificaciones para ver la posible influencia sobre el método. Se introdujeron factores tales como distintos operadores, distintos lotes de reactivos, distintos métodos de agitación en horizontal u orbital y variando la velocidad de agitación que se fijó entre 100 y $170 \mathrm{U} / \mathrm{min}$. Con la introducción de este tipo de variables no se observaron diferencias significativas $(p<0.05)$ entre determinaciones paralelas. Este método de análisis fue validado para piensos avícola, cunícola y ovino, y no se observaron diferencias en la determinación de carbadox en estos tipos de pienso.

\subsection{Validación del método de análisis de metil-tiouracilo mediante cromatografía líquida de alta resolución (HPLC)}

\subsubsection{Especificidad}

Se analizaron 26 muestras blanco de orina bovina. Se comprobó que había ausencia de picos cromatográficos en la región de interés en la mayoría de ellas (ver figura 20). Sin embargo, en algunas orinas blanco aparecía un pico en el intervalo de tiempo de retención del metil-tiouracilo 
(3,6 min) aunque el espectro entre 220 y $400 \mathrm{~nm}$ fue visiblemente distinto al que muestra el metil-tiouracilo.

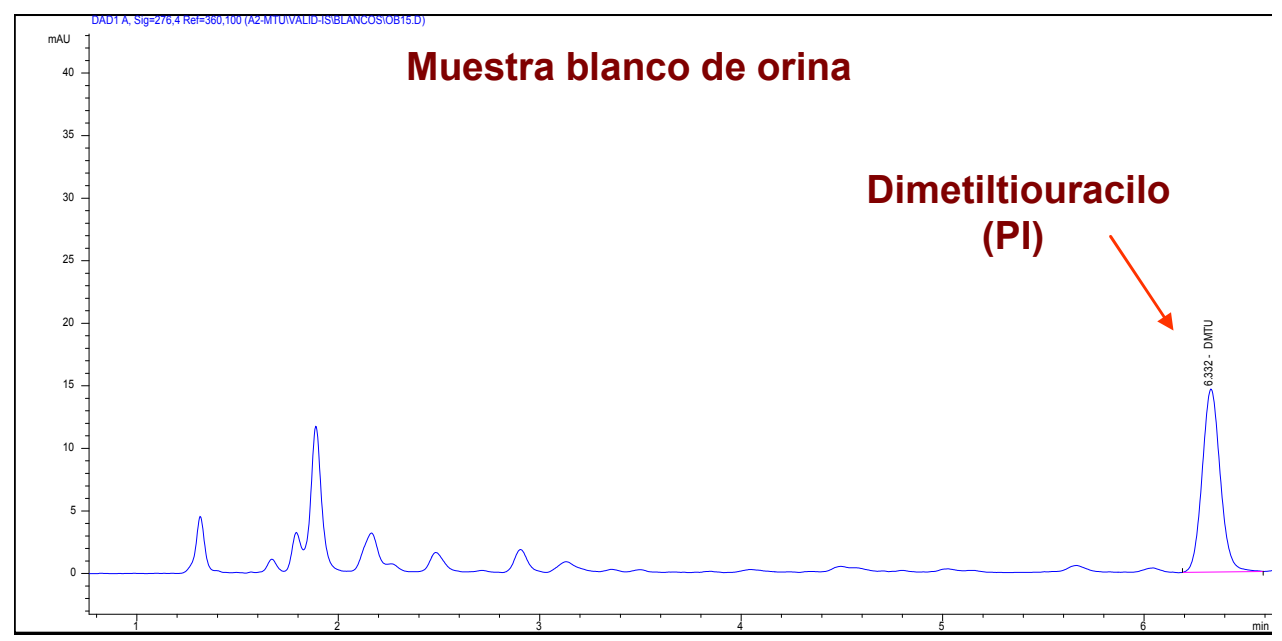

Figura 20 - Cromatograma de una muestra blanco de orina con adición de 5,6dimetil-tiouracilo (PI).

Por otra parte, se enriqueció orina blanco con $200 \mathrm{ng} / \mathrm{mL}$ de distintas sustancias que podrían interferir en el análisis del metil-tiouracilo (MTU). Estas sustancias fueron las siguientes: 5,6-dimetil-tiouracilo (DMTU), que fue utilizado como patrón interno, 6-propil-2-tiouracilo (PTU) y 2-tiouracilo (TU). Los tiempos de retención de estas sustancias (figura 21) no coincidieron con el del metil-tiouracilo (MTU), por lo que queda descartada toda interferencia.

\subsubsection{Aplicabilidad (cambios menores)}

Varios operadores (tres) intervinieron en la manipulación y análisis de muestras sin cambios significativos $(p<0.01)$ en los resultados.

La procedencia de las orinas no fue siempre la misma ya que se utilizaron orinas blanco liofilizadas suministradas por el RIMV (Instituto Nacional de Salud Pública y Medioambiente, Holanda) y orinas del muestreo 
del PNIR (Plan Nacional de Investigación de Residuos) tras verificar la ausencia de MTU.

En cuanto a la estabilidad de los patrones, se comprobó que no había diferencia en las soluciones de calibrado dentro del periodo de estabilidad estimado. Finalmente, durante la validación se emplearon distintos lotes tanto de reactivos como de disolventes y no se observaron diferencias significativas $(p<0.05)$.

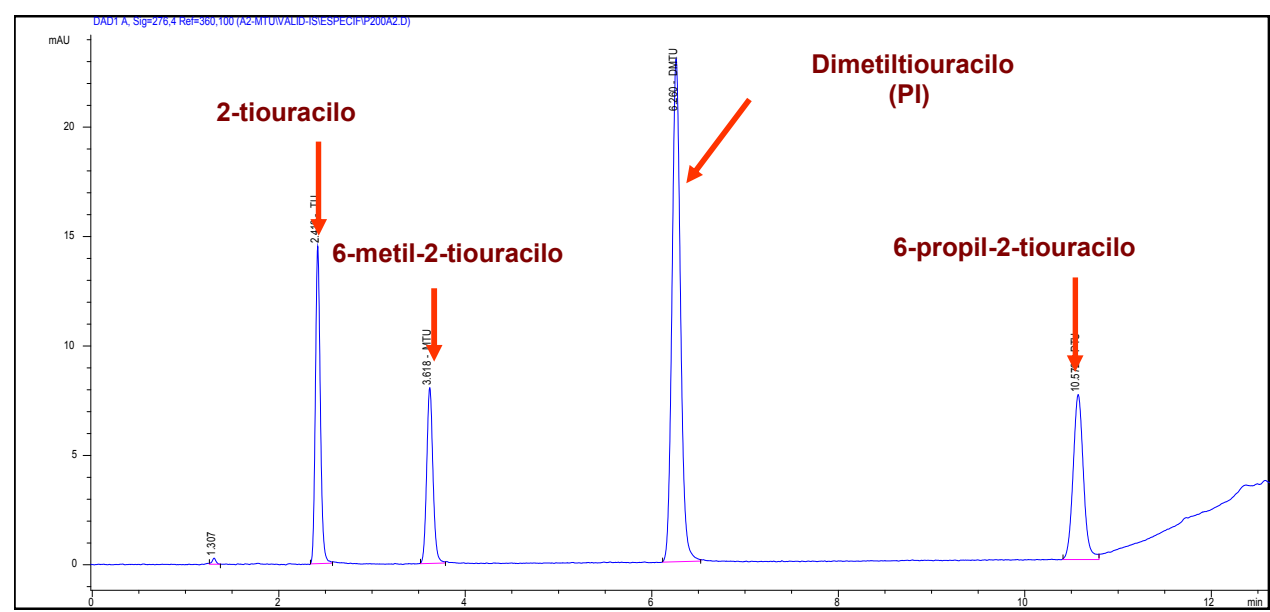

Figura 21 - Cromatograma que muestra los tiempos de retención de 5,6-dimetiltiouracilo (DMTU), 6-propil-2-tiouracilo (PTU), 2-tiouracilo (TU) y 6-metil-2-tiouracilo (MTU).

\subsubsection{Estabilidad}

Se pudo comprobar que las soluciones stock de metil-tiouracilo (MTU) y del patrón interno (DMTU) se mantenían estables durante tres semanas conservadas $\mathrm{a}-20^{\circ} \mathrm{C}$. Sin embargo, las soluciones madre se debían preparar cada semana.

Para estudiar la estabilidad del analito en la matriz se prepararon tres lotes de orinas blanco enriquecidas con $200 \mathrm{ng} / \mathrm{mL}$ de MTU. Para cada lote, 
se analizaron dos alícuotas en fresco, otras dos alícuotas fueron conservadas a $4^{\circ} \mathrm{C}$ y otras dos a $-20^{\circ} \mathrm{C}$ durante $24 \mathrm{~h}$. Al mismo tiempo, se analizaron dos alícuotas después de una semana de conservación en congelación. Los resultados obtenidos se pueden observar en la tabla 15.

La estabilidad del analito en la orina en refrigeración y congelación así como la posibilidad de la congelación del extracto seco de la muestra también fueron estudiados. Se analizaron seis alícuotas de orina enriquecida con $200 \mathrm{ng} / \mathrm{mL}$ de MTU. Tres extractos fueron resuspendidos inmediatamente y se inyectaron en el cromatógrafo, otros tres extractos fueron mantenidos $24 \mathrm{~h}$ a $-20^{\circ} \mathrm{C}$ y otros tres extractos 7 días a $-20^{\circ} \mathrm{C}$. Los resultados, que se muestran en la tabla 15, indican que las muestras debían ser analizadas inmediatamente después de descongelar la orina, pudiendo conservar el extracto seco congelado al menos durante $24 \mathrm{~h}$.

Tabla 15 - Estabillidad del analito en la matriz orina enriquecida con $200 \mathrm{ng} / \mathrm{mL}$ de MTU.

\begin{tabular}{lccccc}
\hline Matriz & $\begin{array}{c}\text { Sistema de } \\
\text { conservación }\end{array}$ & $\begin{array}{c}\text { Tiempo } \\
\text { (días) }\end{array}$ & $\begin{array}{c}\text { Concentración } \\
\text { promedio MTU } \\
\text { (ng/mL) }\end{array}$ & $\begin{array}{c}\text { Desv. } \\
\text { standard }\end{array}$ & $\begin{array}{c}\text { Pérdida } \\
\text { (\%) }\end{array}$ \\
\hline Orina & fresco & 0 & $189^{\mathrm{a}}$ & 24 & 0 \\
Orina & $4^{\circ} \mathrm{C}$ & 1 & $37^{\mathrm{b}}$ & 1,7 & 80 \\
Orina & $-20^{\circ} \mathrm{C}$ & 1 & $59^{\mathrm{c}}$ & 2,2 & 69 \\
\hline Ext. seco & $-20^{\circ} \mathrm{C}$ & 1 & $183^{\mathrm{a}}$ & 3,4 & 3 \\
Ext. seco & $-20^{\circ} \mathrm{C}$ & 7 & $0^{\mathrm{d}}$ & 0 & 100 \\
\hline
\end{tabular}

$a, b, c, d$ : resultados significativamente distintos $(p<0.05)$ cuando las letras son distintas en una misma columna.

También se estudió la conservación de la muestra enriquecida en viales de plástico y de vidrio para comprobar posibles interacciones con el material empleado. Tres alícuotas de orina enriquecidas con $200 \mathrm{ng} / \mathrm{mL}$ de MTU fueron conservadas en refrigeración a $4^{\circ} \mathrm{C}$, en viales de vidrio durante 
$24 \mathrm{~h}$ y otras tres alícuotas de la misma orina, fueron conservadas en refrigeración a $4^{\circ} \mathrm{C}$, en viales de plástico durante $24 \mathrm{~h}$. Los resultados se muestran en la tabla 16 . Se observó una pérdida en fresco del $11 \%$ en las orinas almacenadas en los contenedores de plástico que, aunque no es estadísticamente significativo, recomienda mantener las muestras en contenedores de vidrio. La conservación en refrigeración muestra una pérdida muy elevada del analito independientemente del material escogido.

Tabla 16 - Pérdida del analito en la matriz orina enriquecida con $200 \mathrm{ng} / \mathrm{mL}$ de MTU y conservada en frascos de vidrio o plástico y en fresco o $4^{\circ} \mathrm{C}$.

\begin{tabular}{lcccc}
\hline $\begin{array}{l}\text { Sistema de } \\
\text { conservación }\end{array}$ & $\begin{array}{c}\text { Tiempo } \\
\text { (días) }\end{array}$ & $\begin{array}{c}\text { Concentración } \\
\text { promedio MTU } \\
\text { (ng/mL) }\end{array}$ & $\begin{array}{c}\text { Desv. } \\
\text { standard }\end{array}$ & Pérdida (\%) \\
\hline Vidrio, fresco & 0 & $189^{\mathrm{a}}$ & 27 & 0.0 \\
Plástico, fresco & 0 & $167^{\mathrm{a}}$ & 28 & 11 \\
Vidrio, a $4^{\circ} \mathrm{C}$ & 1 & $37^{\mathrm{b}}$ & 1,6 & 80 \\
Plástico, a $4^{\circ} \mathrm{C}$ & 1 & $34^{\mathrm{b}}$ & 1,1 & 82 \\
\hline
\end{tabular}

$a$, $b$ : resultados significativamente distintos $(p<0.05)$ cuando las letras son distintas en una misma columna.

\subsubsection{Rectas de calibrado}

\subsubsection{Recta de calibrado con patrones puros}

Se utilizaron cinco niveles de concentración (incluyendo el cero), siendo la recta válida para concentraciones entre 0 y $600 \mathrm{ng} / \mathrm{mL}$. Se representó la ratio entre el área del metil-tiouracilo (MTU) y el área del patrón interno, la concentración de patrón interno añadido fue de $500 \mathrm{ng} / \mathrm{mL}$, en el eje de ordenadas frente a la concentración de metil-tiouracilo (MTU), expresada en $\mathrm{ng} / \mathrm{mL}$ de orina, en el eje de abcisas (ver figura 22). Con cada lote de muestras se inyectaba un patrón de calibrado y se recalibraba la recta de manera automática. 


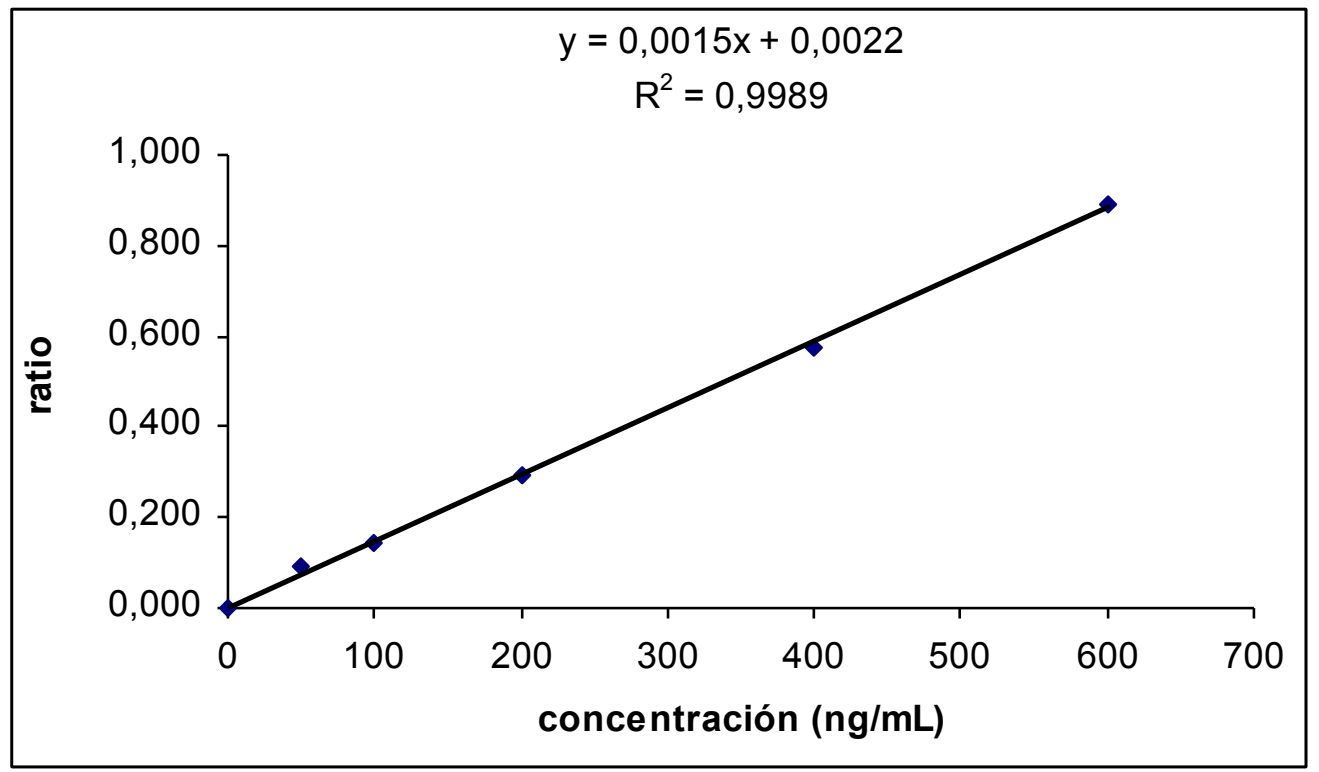

Figura 22 - Recta de calibrado del análisis de MTU con patrones puros.

\subsubsection{Recta de calibrado sobre orina enriquecida con patrones puros}

De manera análoga, se realizaron curvas de calibrado con orina enriquecida a cinco niveles de concentraciones (incluyendo el cero). En la Figura 23 se puede observar un ejemplo de recta de calibrado representando la ratio entre el área de MTU y el patrón interno en el eje de las ordenadas y la concentración de MTU, expresada en $\mathrm{ng} / \mathrm{mL}$ de orina, en el eje de abcisas.

\subsubsection{Recuperación}

Se seleccionaron 87 alícuotas de orina blanco y se enriquecieron 28 , 29 y 30 de ellas con 100, 150 y 200 ng/mL de metil-tiouracilo (MTU), respectivamente. Se analizaron las muestras y se determinó la concentración en cada una de ellas. También se determinó la recuperación en cada muestra, así como el promedio de la recuperación, la desviación estándar y el coeficiente de variación para cada nivel (tabla 17) 
Con el valor promedio se calculó el factor de recuperación a aplicar a las muestras de orina, que fue de 1,54. Con cada lote de muestras se hacía una prueba de recuperación con orina blanco enriquecida con $150 \mathrm{ng} / \mathrm{mL}$ de metil-tiouracilo (MTU). El factor de recuperación de 1,54 se aplicaba a ese lote de muestras siempre que la recuperación obtenida fuese del $65 \%$, con un margen de error de \pm 14 .

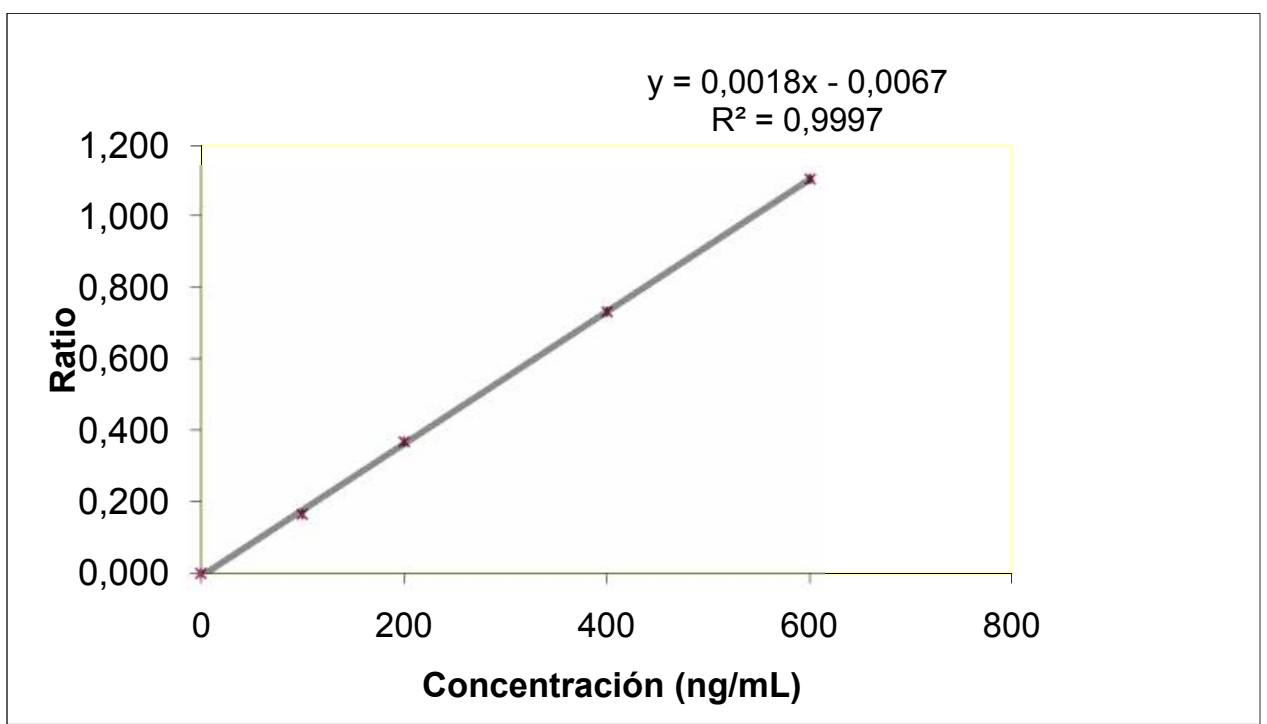

Figura 23 - Recta de calibrado del análisis de MTU en orina

Tabla 17 - Recuperación de MTU en el análisis de muestras de orina enriquecidas a distintos niveles.

\begin{tabular}{cccc}
\hline $\begin{array}{c}\text { Nivel } \\
(\mathbf{n g} / \mathbf{m L})\end{array}$ & $\begin{array}{c}\text { Promedio recuperación } \\
(\%)\end{array}$ & $\begin{array}{c}\text { Desviación } \\
\text { standard }\end{array}$ & $\begin{array}{c}\text { CV } \\
\mathbf{( \% )}\end{array}$ \\
\hline 100 & 60 & 15 & 24 \\
150 & 64 & 9 & 14 \\
200 & 70 & 16 & 23 \\
\hline Promedio & 65 & 14 & 22 \\
\hline
\end{tabular}




\subsubsection{Repetibilidad}

Se preparó un conjunto de orinas blanco homogeneizadas y enriquecidas con metil tiouracilo (MTU) a tres niveles de concentración: 100, 150 y $200 \mathrm{ng} / \mathrm{mL}$. Para cada nivel se analizaron 6 alícuotas, se calculó la concentración de cada muestra, así como la concentración promedio, la desviación estándar y el coeficiente de variación (CV) para cada nivel.

Este análisis se repitió tres veces. En la tabla 18 se muestran las concentraciones medias, la desviación standard y los coeficientes de variación obtenidos.

Tabla 18 - Repetibilidad del análisis de MTU en muestras de orina enriquecidas a distintos niveles.

\begin{tabular}{cccc}
\hline $\begin{array}{c}\text { Nivel } \\
(\mathbf{n g} / \mathbf{m L})\end{array}$ & $\begin{array}{c}\text { Concentración promedio } \\
(\mathbf{n g} / \mathbf{m L})\end{array}$ & $\begin{array}{c}\text { Desviación } \\
\text { standard }\end{array}$ & $\begin{array}{c}\text { CV } \\
(\%)\end{array}$ \\
\hline 100 & 66 & 13 & 20 \\
150 & 106 & 7 & 6 \\
200 & 166 & 28 & 17 \\
\hline
\end{tabular}

\subsubsection{Reproducibilidad intralaboratorio}

Se preparó un conjunto de diferentes orinas enriquecidas con metiltiouracilo (MTU) para dar concentraciones de 100, 150 y $200 \mathrm{ng} / \mathrm{mL}$. Para cada nivel se analizaron 6 muestras. Cada lote de 18 muestras (6 de cada nivel) fue analizado por un operador distinto, en distintos días y con diferentes lotes de reactivos (distintas soluciones madre y fase móvil). Se calculó la concentración detectada en cada muestra, así como la concentración media, la desviación estándar y el coeficiente de variación para cada nivel. Los resultados obtenidos se muestran tabla 19. 
Tabla 19 - Reproducibilidad intralaboratorio de los análisis de MTU en muestras de orina enriquecidas a distintos niveles.

\begin{tabular}{cccc}
\hline $\begin{array}{c}\text { Nivel } \\
(\mathbf{n g} / \mathbf{m L})\end{array}$ & $\begin{array}{c}\text { Concentración promedio } \\
(\mathbf{n g} / \mathbf{m L})\end{array}$ & $\begin{array}{c}\text { Desviación } \\
\text { standard }\end{array}$ & $\begin{array}{c}\text { CV } \\
(\%)\end{array}$ \\
\hline 100 & 56 & 14 & 25 \\
\hline 150 & 94 & 19 & 20 \\
\hline 200 & 122 & 20 & 17 \\
\hline
\end{tabular}

\subsubsection{Límite de decisión ( $\mathrm{CC} \alpha)$}

El límite de decisión se estableció según recomienda la normativa comunitaria, analizando 26 orinas blanco. En cada una de ellas se calculó la relación señal/ruido en el intervalo de tiempo en el que se esperaba que eluyera el metil tiouracilo (MTU). El límite de decisión se considera igual al triple de la relación señal:ruido en esa banda de tiempo. En este caso, el límite de decisión $\mathrm{CC} \alpha=100 \mathrm{ng} / \mathrm{mL}$.

\subsubsection{Capacidad de detección (CC $\beta)$}

La capacidad de detección se calculó enriqueciendo matrices blanco a un nivel similar al límite de decisión $(100 \mathrm{ng} / \mathrm{mL})$, hasta un total de 34 orinas (ver figura 24). La capacidad de detección es igual al límite de decisión más 1.64 veces la desviación estándar de la reproducibilidad intralaboratorio del contenido medido (la desviación estándar de la concentración medida). El valor así obtenido fue $C C \beta=130 \mathrm{ng} / \mathrm{mL}$.

\subsubsection{Robustez (cambios importantes)}

Este método de análisis sólo fue validado para orina de bovino, ya que no fue utilizado para otro tipo de matrices. 
Las condiciones de muestreo en principio siempre fueron las mismas y no dependieron del personal del laboratorio. En cualquier caso, se estudiaron orinas blanco congeladas provenientes de un muestreo normal del PNIR, y orinas blanco liofilizadas del RIVM, y no se observaron diferencias entre ellas $(p<0.05)$. Se introdujeron factores tales como distintos operadores, distintos lotes de reactivos y de soluciones patrón.

Se evaluó la posibilidad de introducir puntos de corte en el método que consistían en guardar la orina en refrigeración para analizarla al día siguiente pero las pérdidas de analito fueron elevadas (tabla 16) con lo cual no se pudo establecer este punto de corte. Sin embargo, la extracción completa del analito hasta el extracto seco permitía su conservación a $-20^{\circ} \mathrm{C}$ durante un día.

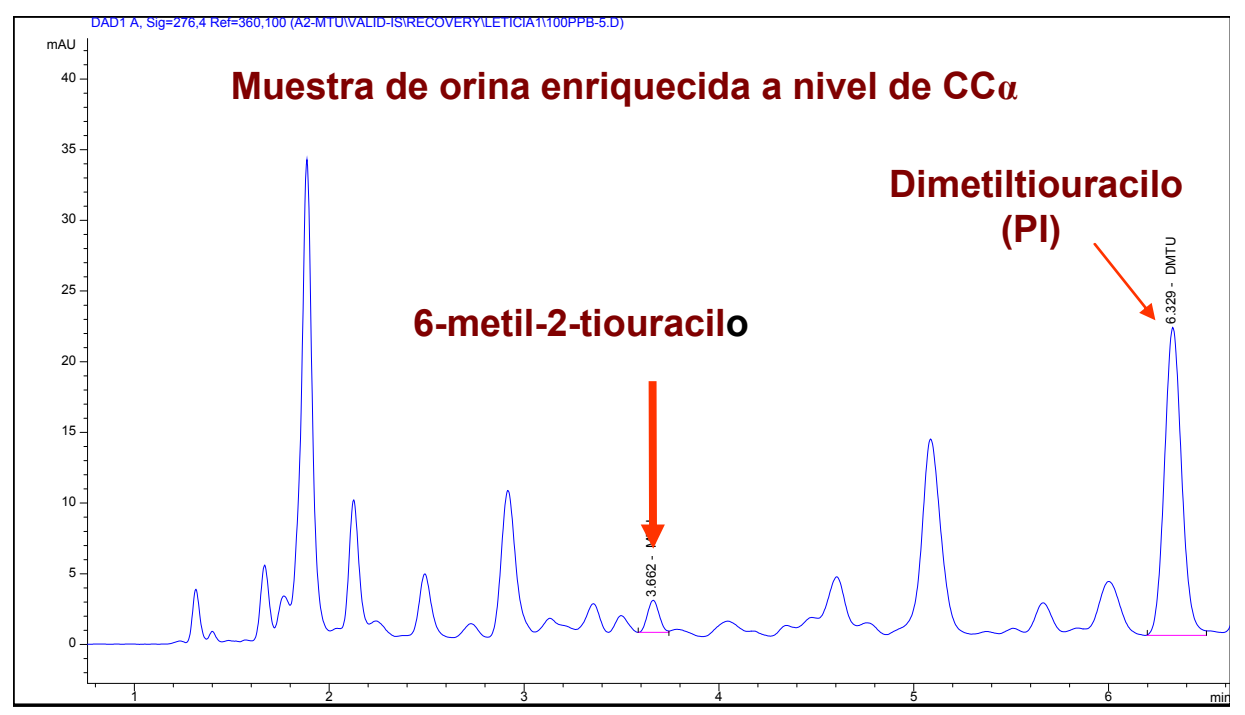

Figura 24 - Cromatograma de una muestra blanco de orina enriquecida a nivel de límite de decisión. 


\subsection{Validación del método de análisis de dexametasona mediante cromatografía líquida de alta resolución (HPLC)}

\subsubsection{Especificidad}

Se analizaron 20 muestras blanco y se comprobó que en la región de interés de la dexametasona y del patrón interno no existían posibles interferencias, tales como señales o picos.

Por otro lado, se seleccionaron varias sustancias que por su similitud con la dexametasona podían interferir en su detección como son la flumetasona y la betametasona. Se enriquecieron muestras blanco a distintas concentraciones con estos analitos, tanto individualmente como juntos, y se comprobó que su presencia no podía conducir a una falsa identificación, ya que aparecían a tiempos de retención totalmente distintos (ver figura 25).

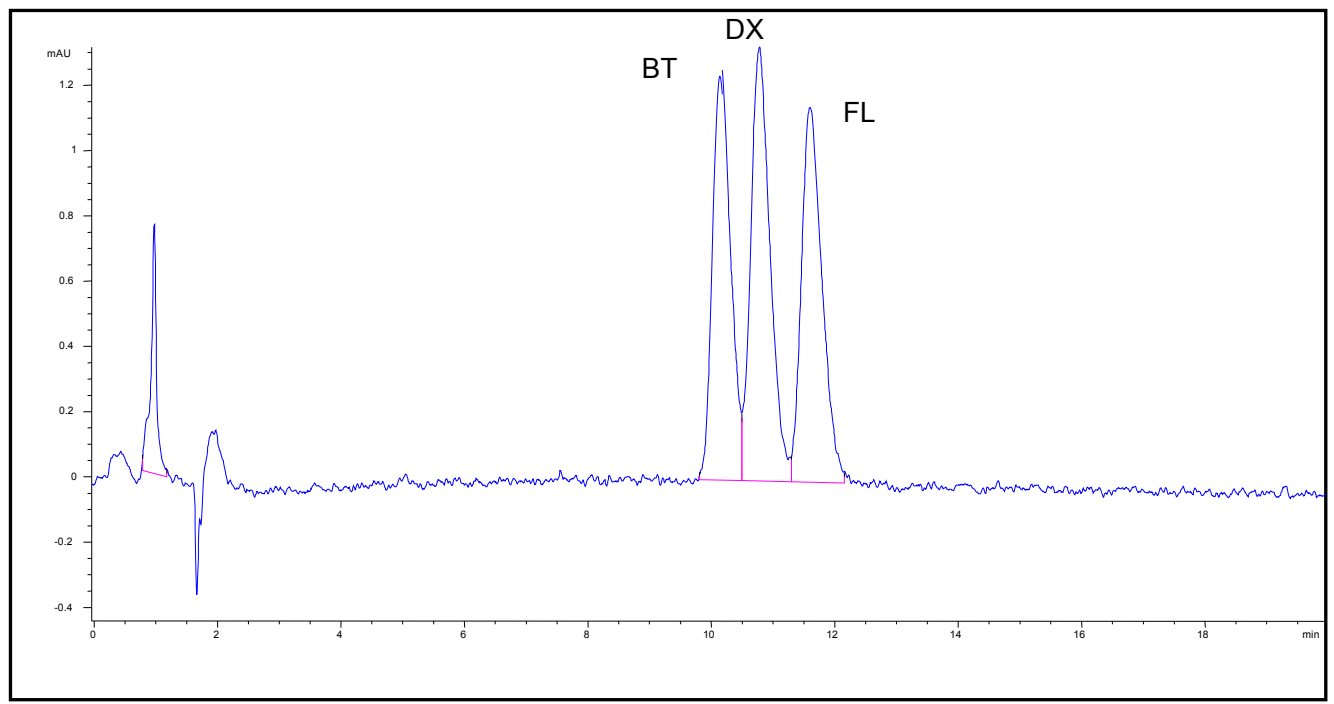

Figura 25 - Cromatograma con patrones puros de corticoides: betametasona (BT), dexametasona $(D X)$, flumetasona $(F L)$. 


\subsubsection{Aplicabilidad (cambios menores)}

Tres operadores intervinieron en la manipulación y análisis de las muestras. La procedencia de las aguas y de los piensos no fue siempre la misma, se utilizaron aguas y piensos blanco procedentes de distintas explotaciones ganaderas de distintas localidades y previamente analizadas para verificar la ausencia de corticoides.

Respecto a la estabilidad de los patrones, se comprobó que no había diferencias significativas $(p<0,05)$ en las soluciones de calibrado dentro del periodo de estabilidad estimado. Durante la validación se emplearon distintos lotes, tanto de reactivos como de disolventes y no se observaron diferencias significativas $(p<0,05)$.

Se estudió la influencia de crear puntos de corte en el protocolo de extracción, observando que no habían cambios significativos $(p<0,05)$ en los resultados tras guardar en congelación $\left(-20^{\circ} \mathrm{C}\right)$ el extracto llevado a sequedad bajo $\mathrm{N}_{2}$, debido a la gran estabilidad de la dexametasona y del patrón interno (flumetasona) cuando se conservan en congelación.

\subsubsection{Estabilidad}

Se estudió la estabilidad del analito en la solución madre de $10 \mu \mathrm{g} / \mathrm{mL}$ de dexametasona y en la solución madre de $10 \mu \mathrm{g} / \mathrm{mL}$ de flumetasona, y se comprobó que ambas sustancias eran estables durante meses cuando eran conservadas a $-20^{\circ} \mathrm{C}$. Sin embargo, las soluciones de trabajo debían prepararse antes de cada uso.

Se preparó una solución concentrada de dexametasona de $10 \mu \mathrm{g} / \mathrm{mL}$ y se tomaron diferentes alícuotas, una de ellas fue analizada inmediatamente y el resto de alícuotas se mantuvieron en congelación $\left(-20^{\circ} \mathrm{C}\right)$ y se fueron analizando por triplicado pasadas una, dos, tres, cuatro, nueve y trece 
semanas. No hubo variaciones significativas $(p<0.05)$ ya que la estabilidad era muy buena (ver figura 26).

Para el agua, también se realizó un estudio de estabilidad de la siguiente manera: La muestra de agua libre de corticoides, se fortificó a nivel del límite de decisión ( $\mathrm{CC} \alpha$ ) y se analizó una muestra inmediatamente, las otras se mantuvieron en congelación a $-20^{\circ} \mathrm{C}$ y se fueron analizando por triplicado a distintos tiempos (una, dos, cuatro y seis semanas). Los resultados se muestran en la figura 27.

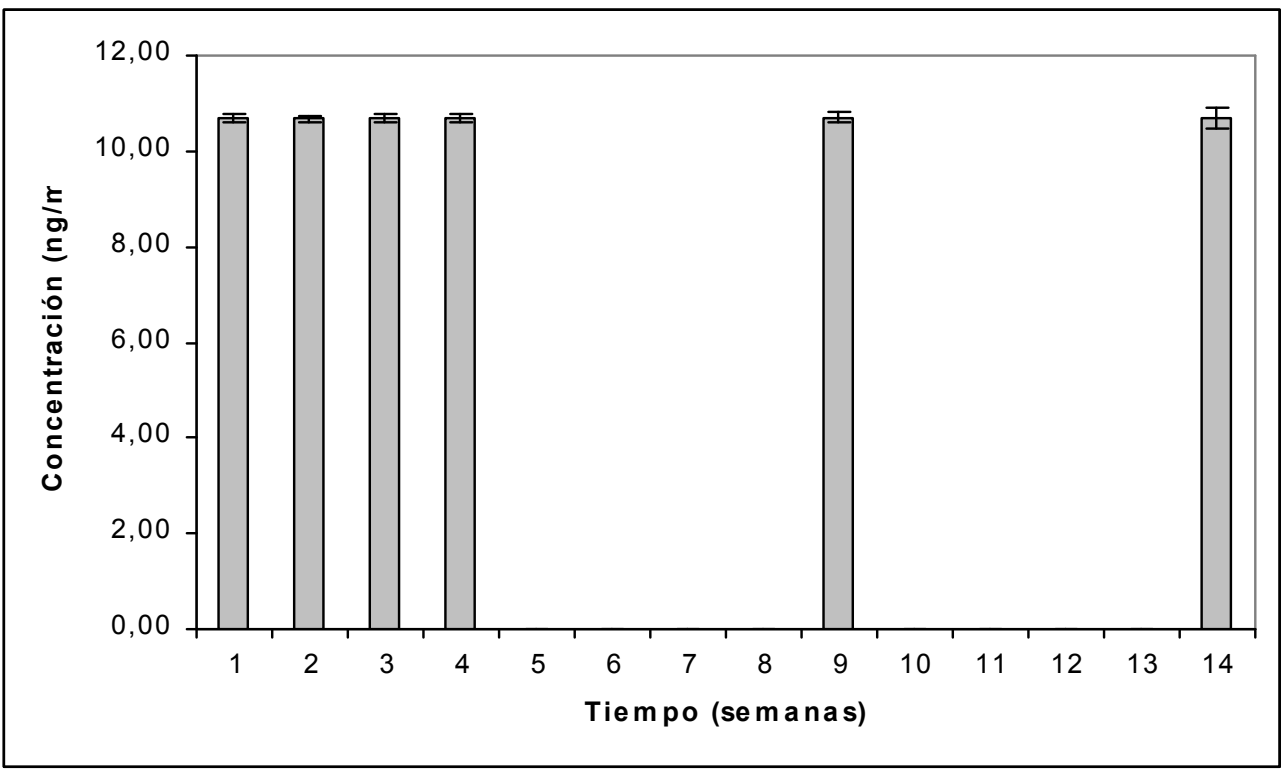

Figura 26 - Estabilidad del patrón puro de dexametasona, almacenado en congelación.

\subsubsection{Rectas de calibrado}

\subsubsection{Rectas de calibrado de patrones puros.}

Se utilizaron seis niveles de concentración, incluyendo el cero, la recta fue válida para concentraciones entre 0 y $600 \mathrm{ng} / \mathrm{mL}$. Se representaba la ratio entre el área de la dexametasona y el área del patrón interno, en el eje de las 
ordenadas, frente a la concentración de dexametasona, expresada en $\mathrm{ng} / \mathrm{mL}$, en el eje de las abscisas (ver figura 28). Antes de inyectar en el cromatógrafo cada lote de muestras, se inyectaba un patrón para comprobar que el área y el tiempo de retención eran los adecuados.

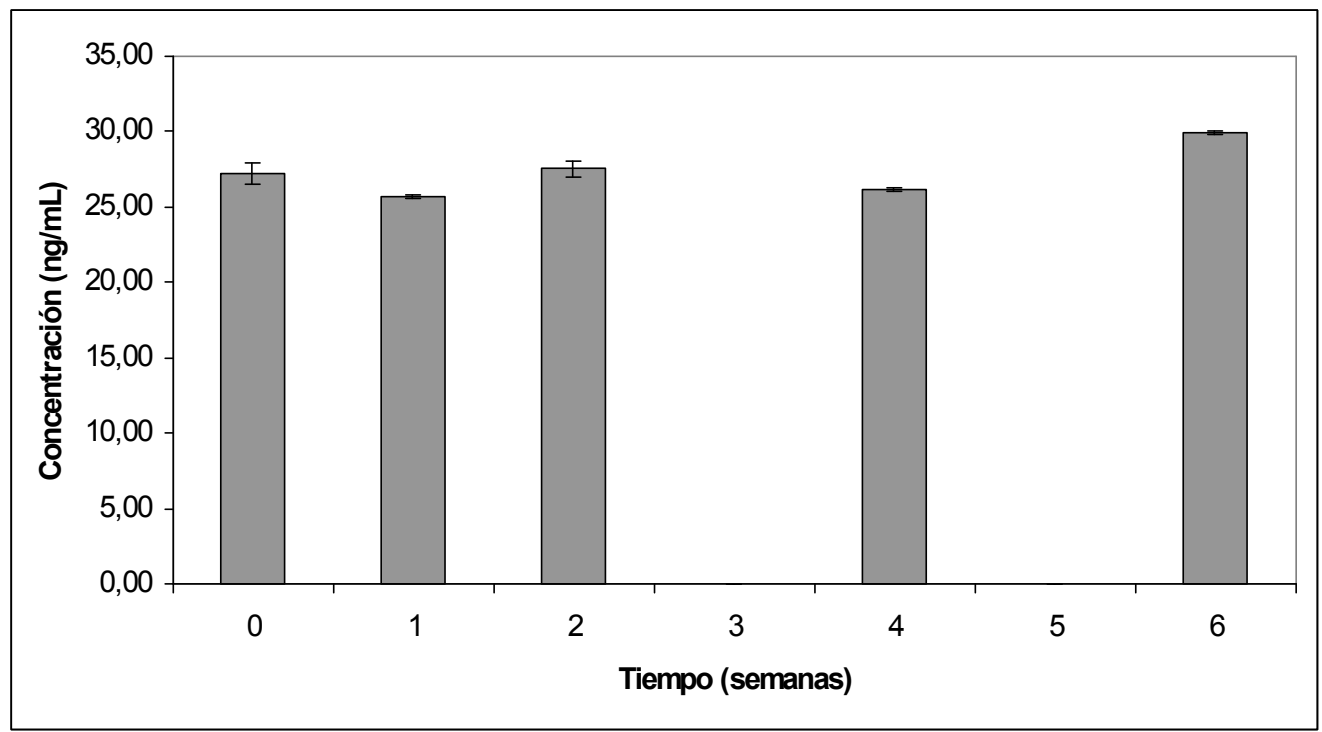

Figura 27 - Estabilidad de la dexametasona en la matriz agua, siendo las muestras fortificadas con dexametasona a nivel del CCa y almacenadas en congelación.

\subsubsection{Rectas de calibrado sobre agua.}

De manera análoga se realizaron rectas de calibrado con agua fortificada a siete niveles de dexametasona, incluyendo el cero. En la figura 29 se representa la ratio (área de dexametasona frente al área de patrón interno) frente a la concentración de dexametasona, expresada en $\mathrm{ng} / \mathrm{mL}$. 


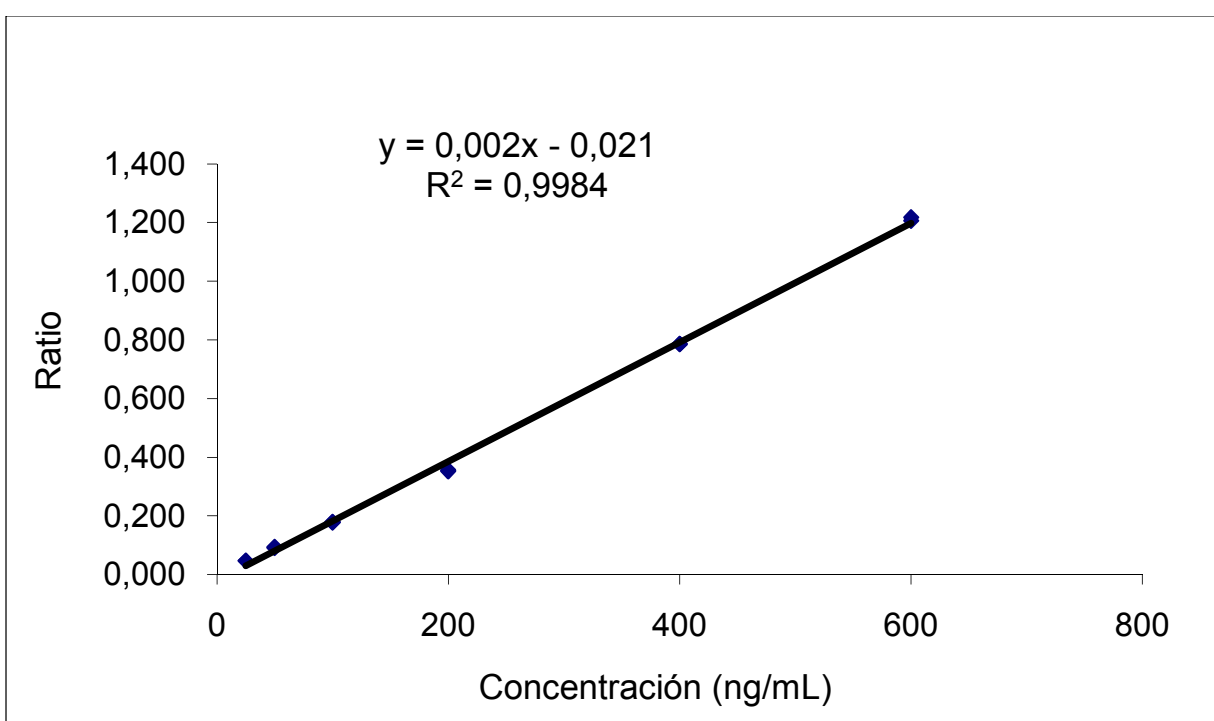

Figura 28 - Recta de calibrado en el análisis de patrones puros de dexametasona.

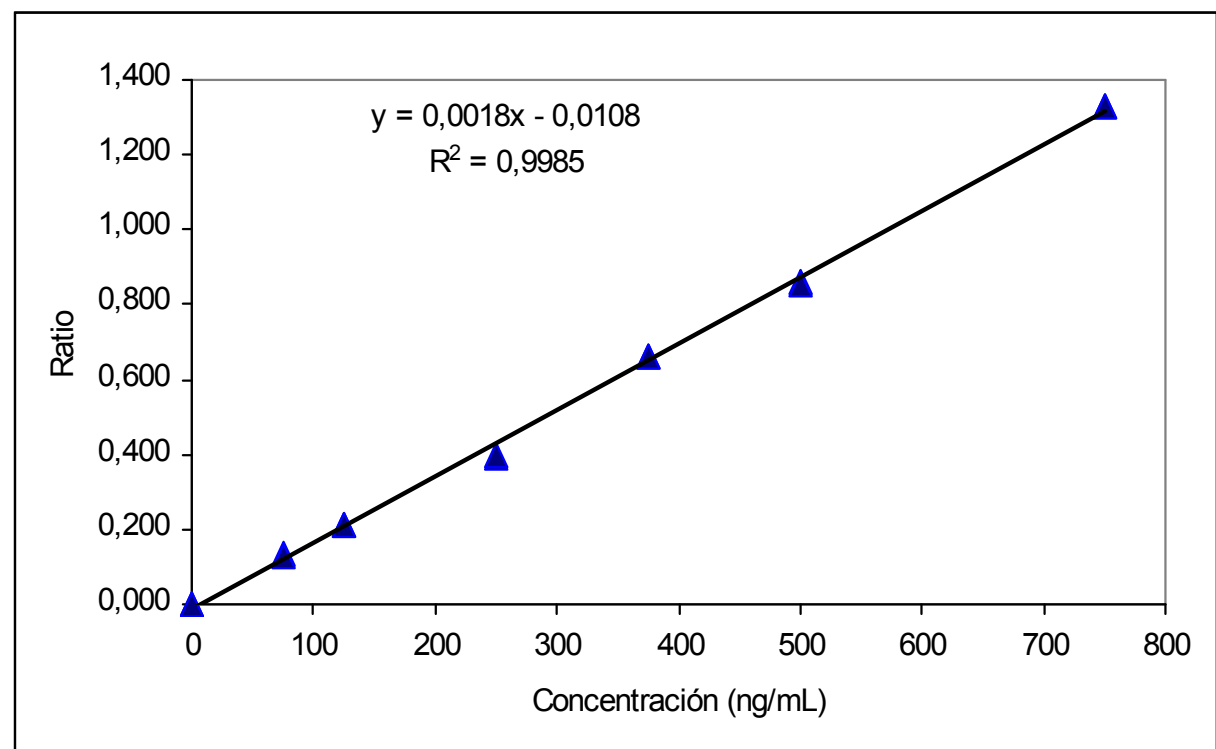

Figura 29 - Recta de calibrado en el análisis de dexametasona en agua. 


\subsubsection{Rectas de calibrado sobre pienso}

Las rectas de calibrado para el pienso se realizaron enriqueciendo piensos que previamente se habían inyectado y se había comprobado que estaban libres de corticoides y de cualquier sustancia que pudiera interferir. En la figura 30 se muestra un ejemplo de la recta patrón en pienso donde se representa la ratio (área de dexametasona frente al área de patrón interno) frente a la concentración de dexametasona $(\mathrm{ng} / \mathrm{mL})$.

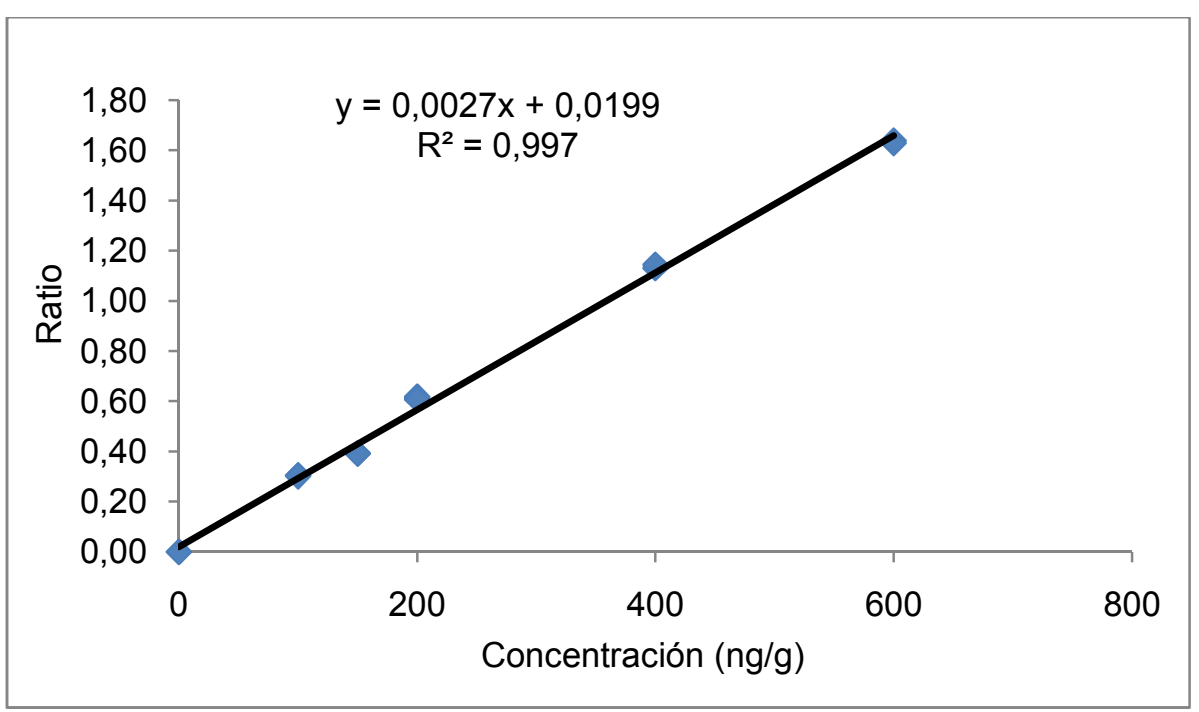

Figura 30 - Recta de calibrado en el análisis de dexametasona en pienso.

\subsubsection{Recuperación}

Se utilizó un grupo de 18 muestras fortificadas para el pienso y otro grupo de 18 muestras fortificadas para el agua. El nivel de fortificación de las muestras fue de $1,1.5$ y 2 veces el límite de decisión (CC $\alpha$ ) y para cada nivel se analizaron 6 replicados. En cada caso se determinó la concentración real, el \% de recuperación, la desviación standard y el coeficiente de variación. Los resultados se muestran en la tabla 20. 
Tabla 20 - Recuperación de dexametasona en muestras de agua y pienso.

\begin{tabular}{|c|c|c|c|c|}
\hline Matriz & $\begin{array}{c}\text { Nivel de } \\
\text { fortificación } \\
\text { (ng/mL) }\end{array}$ & $\begin{array}{c}\text { Recup } \\
(\%)\end{array}$ & SD & $\begin{array}{l}\text { CV } \\
(\%)\end{array}$ \\
\hline \multirow{3}{*}{ Agua } & 26 & 105 & 1.7 & 6.3 \\
\hline & 39 & 98 & 1.1 & 2.8 \\
\hline & 52 & 94 & 1.1 & 2.2 \\
\hline \multirow[t]{2}{*}{ Matriz } & $\begin{array}{c}\text { Nivel de } \\
\text { fortificación } \\
\text { (ng/g) }\end{array}$ & $\begin{array}{l}\text { Recup } \\
(\%)\end{array}$ & SD & $\begin{array}{l}\text { CV } \\
(\%)\end{array}$ \\
\hline & 190 & 109 & 15 & 7.4 \\
\hline \multirow[t]{2}{*}{ Pienso } & 285 & 118 & 7 & 2.1 \\
\hline & 380 & 109 & 17 & 4.1 \\
\hline
\end{tabular}

\subsubsection{Repetibilidad}

La repetibilidad fue calculada analizando 18 muestras de agua y 18 muestras de pienso fortificadas con el analito a concentraciones equivalentes a 1,1.5 y 2 veces el límite de decisión ( $\mathrm{CC} \alpha$ ) y se analizaron seis replicados por nivel. En cada caso se determinó la concentración media, la desviación estandard y el coeficiente de variación. Los resultados se muestran en la tabla 21.

\subsubsection{Reproducibilidad intralaboratorio}

La reproducibilidad intralaboratorio se realizó mediante análisis en diferentes días, por distintos operadores y con distintos grupos de reactivos, y fue calculada analizando seis replicados por nivel de fortificación. En cada caso se determinó la concentración media, la desviación standard y el coeficiente de variación. Los resultados se muestran en la tabla 22. 
Tabla 21 - Repetibilidad en el análisis de dexametasona en muestras de agua y pienso.

\begin{tabular}{ccccc}
\hline Matriz & $\begin{array}{c}\text { Nivel de } \\
\text { fortificación } \\
(\mathbf{n g} / \mathbf{m L})\end{array}$ & $\begin{array}{c}\text { Concentración } \\
\text { media } \\
\text { (ng/mL) }\end{array}$ & SD & $\begin{array}{c}\text { CV } \\
\text { (\%) }\end{array}$ \\
\hline Agua & 26 & 28 & 2 & 7 \\
\hline Matriz & 39 & 45 & 0.7 & 1.7 \\
& $\begin{array}{c}\text { Nivel de } \\
\text { fortificación } \\
\text { (ng/g) }\end{array}$ & $\begin{array}{c}\text { Concentración } \\
\text { media } \\
\text { (ng/g) }\end{array}$ & SD & $\begin{array}{c}\text { CV } \\
\text { (\%) }\end{array}$ \\
\hline Pienso & 190 & 205 & 14 & 7 \\
& 285 & 314 & 19 & 6 \\
\hline & 380 & 431 & 35 & 8 \\
\hline
\end{tabular}

Tabla 22 - Reproducibilidad intralaboratorio en el análisis de dexametasona en muestras de agua y pienso.

\begin{tabular}{lcccc}
\hline Matriz & $\begin{array}{c}\text { Nivel de } \\
\text { fortificación } \\
(\mathbf{n g} / \mathbf{m L})\end{array}$ & $\begin{array}{c}\text { Concentración } \\
\text { media } \\
(\mathbf{n g} / \mathbf{m L})\end{array}$ & SD & CV \\
\hline Agua & 26 & 27 & 1.7 & 6 \\
\hline Matriz & 39 & 40 & 2.9 & 7 \\
\hline & $\begin{array}{c}\text { Nortificación } \\
\text { (ng/g) }\end{array}$ & $\begin{array}{c}\text { Concentración } \\
\text { media } \\
\text { (ng/g) }\end{array}$ & SD & 8 \\
\hline Pienso & 190 & 196 & 17 & CV \\
& 285 & 314 & 19 & 9 \\
\hline & 380 & 431 & 35 & 6 \\
\hline
\end{tabular}




\subsubsection{Límite de decisión (CCa)}

El límite de decisión ( $\mathrm{CC} \alpha$ ) se calculó analizando 22 materiales blanco para el agua y 22 materiales blanco para el pienso y se calculó la relación señal/ruido, para cada matriz en el intervalo de tiempo correspondiente al tiempo de retención donde se espera encontrar el analito.

El límite de decisión ( $\mathrm{CC} \alpha$ ), tanto para el pienso como para el agua, se calcula como tres veces la señal ruido tal como se indica en la fórmula:

\section{$\mathrm{CCa}=3 * \mathrm{~S} / \mathrm{N}$}

donde $\mathrm{S} / \mathrm{N}=$ relación señal/ruido.

Los límites de decisión (CCa) se establecieron en $26 \mathrm{ng} / \mathrm{mL}$ para el agua y en $190 \mathrm{ng} / \mathrm{g}$ para el pienso. En la figura 31 se muestra un cromatograma de agua enriquecida con dexametasona a nivel de CCa (26 $\mathrm{ng} / \mathrm{mL})$.

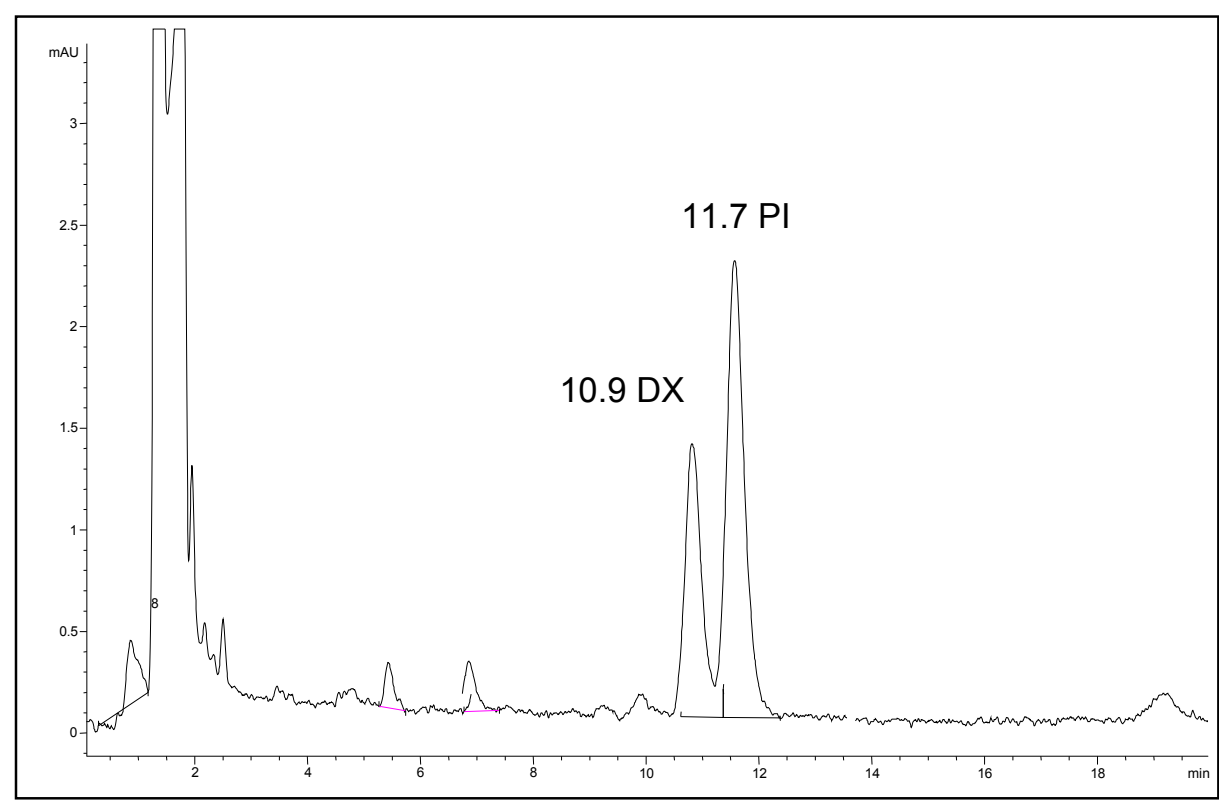

Figura 31 - Cromatograma de agua enriquecida con dexametasona a nivel de CCa (26 $n g / m L)$. 


\subsubsection{Capacidad de detección (CC $\beta)$}

La capacidad de detección (CC $\beta$ ) se calculó como el límite de decisión más 1.64 veces la desviación standard de la reproducibilidad intralaboratorio del contenido medido. La capacidad de detección (CC $\beta$ ) nos da la cantidad mínima de analito presente en la muestra que puede ser detectado, identificado o cuantificado con un nivel de probabilidad del 95\%.

La capacidad de detección (CC $\beta$ ) fue de $30 \mathrm{ng} / \mathrm{mL}$ para el agua y 217 ng/g para el pienso.

\subsubsection{Robustez (cambios importantes)}

Las condiciones de muestreo en principio siempre fueron las mismas, y se comprobó que no dependen del personal del laboratorio. Se introdujeron factores tales como distintos operadores, distintos lotes de reactivos, distintos métodos de agitación en horizontal $u$ orbital y variando la velocidad de agitación que se fijó entre 100 y $170 \mathrm{U} / \mathrm{min}$. Con la introducción de este tipo de variables no se observaron diferencias significativas $(p<0.05)$ entre determinaciones paralelas.

\subsubsection{Precisión}

La precisión fue confirmada calculando el coeficiente de variación de la reproducibilidad (CV) en las respectivas fracciones de masa analizadas, utilizando la ecuación de Horwitz:

$$
\begin{aligned}
& C V=2^{(1-0.5 \log C)} \\
& \text { donde } C=\text { fracción de masa expresada en base } 10 \text {. }
\end{aligned}
$$


Los valores calculados del coeficiente de variación de la reproducibilidad se muestran en la tabla 23 . Así pues, se comprueba que la precisión es aceptable dado que los coeficientes de variación de la reproducibilidad intralaboratorio mostrados en la tabla 22 son menores que los respectivos coeficientes de variación de la reproducibilidad calculada.

Tabla 23 - Reproducibilidad calculada mediante la ecuación de Hortwitz como referencia para la precisión del método de análisis de dexametasona en agua y pienso.

\begin{tabular}{ccc}
\hline Matriz & $\begin{array}{c}\text { Nivel de fortificación } \\
(\mathbf{n g} / \mathbf{m L})\end{array}$ & $\begin{array}{c}\text { CV } \\
(\%)\end{array}$ \\
\hline \multirow{3}{*}{ Agua } & 26 & 28 \\
& 39 & 26 \\
& 52 & 25 \\
\hline \multirow{2}{*}{ Matriz } & Nivel de fortificación & $\mathbf{C V}$ \\
& (ng/g) & $(\%)$ \\
\hline \multirow{2}{*}{ Pienso } & 190 & 20 \\
& 285 & 19 \\
& 380 & 18 \\
\hline
\end{tabular}


7. Conclusiones 
Las conclusiones principales de este trabajo son las siguientes:

- Se han desarrollado protocolos de extracción y preparación de las muestras al objeto de analizar las sustancias $\beta$-agonistas en orina de bovino, pìenso de distintas especies animales, agua de beber de vacuno y para el zeranol en piensos de bovino y ovino mediante ensayos inmunológicos de tipo ELISA. Los métodos han sido validados satisfactoriamente.

- Se han desarrollado técnicas de extracción líquido-líquido, extracción en fase sólida y purificación por inmunoafinidad para el análisis del antimicrobiano carbadox en piensos de aves y conejos, el corticoide dexametasona en piensos para bovino, porcino y equino, y agua de beber y los tiouracilos en orina de vacuno. En cada caso, se consiguió optimizar las condiciones de extracción y cromatográficas para conseguir una disminución de sustancias interferentes así como un aumento de la relación señal/ruido y un aumento de la especificidad. Estos métodos cromatográficos han sido validados satisfactoriamente pudiendo confirmar los analitos tanto por el tiempo de retención como por los respectivos espectros obtenidos con el detector de diodos e incluso por co-cromatografía.

- En todos los casos se ha comprobado que las estabilidades de los analitos en las diversas matrices estudiadas eran muy buenas. El estudio de estabilidad también ha incluido los tiempos máximos de conservación en congelación tanto de las soluciones de patrones como de las muestras así como de su manipulación en el laboratorio. 
- Todos los métodos puestos a punto y optimizados para los analitos y respectivas matrices estudiados demostraron buena sensibilidad y robustez y han sido validados conforme a la normativa vigente que afecta a todos los países miembros de la Unión Europea. Estos métodos son rápidos y relativamente sencillos, usando además instrumentación asequible y normalmente disponible en un laboratorio de control, por lo que pueden ser usados como métodos de criba o screening, especialmente cuando resulta preciso analizar un gran volumen de muestras en un corto periodo de tiempo. 
Apéndice I: 
Stability of B-agonist methyl boronic derivatives before GC-MS analysis. Analytica Chimica Acta, 2005, 529, 293-297. 


\title{
Stability of $\beta$-agonist methyl boronic derivatives before gas chromatography-mass spectrometry analysis
}

\author{
Milagro Reig, Natalia Batlle, José Luis Navarro, Fidel Toldrá*

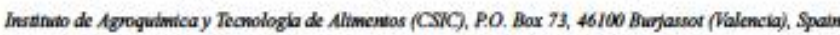 \\ Receisiod $31 \mathrm{Mry} 2004$; rocaivod in revirad form 20 haly 2004; accoptod 20 July 2004
}

Aurilable online 8 Docenewber 2004

\section{Abstract}

A method for the confinmatory analysis of clenbuterol, mabuterol and salbutamol in bovine urine and feeds by gas chromatography-mass spectrometry (GC-MS) is described B-Agonist residues were extracted and firther purified and concentrated by immunoaffinity chromatography. Methyl boronic acid (MRA) was used for the derivatisation of $\beta$-agonist resiches and time and temperature of derivatisation were optimised. These derivatives allowed the use of shorter columns while improving the chromatographic resolution. Methyl boronic derivatives were stored either at room temperature or at $-20^{\circ} \mathrm{C}$ and then injected into the gas chromatograph-mass spectrometer at specific time intervals. Methyl boronic derivatives showed a slight decrease for clenbuterol and a more marked loss for mabuterol when stored at $-20^{-} \mathrm{C}$ up to 3 days and then remained stable up to 7 days. However, the stability for salbutamol was poorer as it rapidly decreased at 2 days. When derivative were stored at room temperature, clenbuterol and intemal standard (IS) showed good stability up to $6 \mathrm{~h}$ while the stability of mabuterol was progressively reduced. Salbutamol dropped to very low vahes at just the first bour Under these conditions it is clear that the analysis should be performed as soon as possible after derivatisation. The combination of immumoaffinity chromatography, MBA derivatisation and gas chromatography-mass spectrometry has shown a high sensitivity, good reproducibility and short chromatography time for the control of the stadied B-agonists.

O 2004 Elsevier B.V. All rights reserved.

Kcywonds: Agomists; Clembutarol; Derivatives stability, Urias; Frosen storage

\section{Introduction}

Clenbuterol was originally used for the medical treatment of pulmonary diseases but later had other applications as growth promoter in cattle although at higher dose than those used for therapeutic purposes. B-Agonists activate the repartition metabolism, favouring muscle protein accretion and decreasing body fat deposition, and thus an improved meatto-fat ratio is obtained [1]

The control of agonists addition is usually performed through its analysis by gas chromatography-mass spectrometry (GC-MS) after derivatisation [2]. Typical derivatising agents are $\mathrm{N}$-methyl- $\mathrm{N}$-trimethylsilylurifluoroacetamide

- Corrosponting author. Tol: +34 $963900022 \times 2112$

fax +34963636301

E-mall address: ffoldraianta cwic en (F. Toldra).

0003-2670/S - se0 fout mattar O 2004 Elsoriar B.V. All rights rvarrvod doi 10.1016 j.aca 2004.07 .047
(MSTFA) and N,O-bis(trimethylsilyl)triftuoroacetamide (BSTFA) [3-6]. Alternative derivatisation methods are based on the use of methyl boronic acid (MBA). This derivatising agent has several advantages such as the higher abundances of the diagnostic ions at electronic impact and the possibility to use shorter chromatographic columns, reducing time and saving belium [7-9]. A progressive decline in clenbuterol recovery when clenbuterol-containing urine samples were kept under frozen storage at $-15^{\circ} \mathrm{C}$ has been reported [10] Other authors have also reported some data on the stability of agonists derivatives when stored before its injection in the gas chomatograph-mass spectrometer $[3,9]$.

The objective of this work was to study the use of methyl boronic acid as derivatising agent for the simultaneous analysis of several B-agonists (clenbuterol, mabuterol and salbutamol) in bovine urine and feed samples and verify the stability of these boronic deriva- 
tives prior its injection into the gas chomatograph-mass spectrometer.

\section{Materials and methods}

\subsection{Reagents and supplies}

Standards and chemicals were from Sigma ChemicalAldrich (St. Louis, MO, USA) except mabuterol that was kindly supplied by the National Reference Laboratory of Majadahonda (Spain). Immunoaffinity chromatography columns were from Randox Laboratories (Crumlin, UK) Internal standard (IS) (d 6 -clenbuterol) was provided by the RIVM (Bilthoven, The Netherlands). All further reagents were standard reagent grade.

\subsection{Extraction}

The bovine urine samples ( $5 \mathrm{~mL}$ ), after addition of $5 \mathrm{ng}$ of the internal standard $\left(\mathrm{d}_{6}\right.$-clenbuterol), were adjusted to pH 5.0 with either $\mathrm{HCl} 1 \mathrm{M}$ or $\mathrm{NaOH} 1 \mathrm{M}$. Then, 5000 units of $\beta$-glucuronidase from Helix pomatia were added and the mixture was homogenised and incubated for $2 \mathrm{~h}$ at $37^{\circ} \mathrm{C}$. Once cooled to room temperature, the hydrolysed urine was adjusted to $\mathrm{pH} 8.0$ with $\mathrm{NaOH} 1 \mathrm{M}$. The urine was injected in the immumoafinity column previously conditioned with the wash buffer, and ehuted with $4 \mathrm{~mL}$ of ethanol/water $(70 / 30)$ at $\mathrm{pH} 4.0$. The elutant was collected and evaporated to dryness under stream of nitrogen

The milled feed samples $(2 \mathrm{~g})$, after addition of $50 \mu \mathrm{L}$ of the internal standard ( $5 \mathrm{ng} \mathrm{d} 6$-clenbuterol), were added $20 \mathrm{~mL}$ of $\mathrm{HCl} 0.1 \mathrm{M}$. The solution was shaked for $30 \mathrm{~min}$ and centrifuged at $3500 \mathrm{rpm}$ for $15 \mathrm{~min}$. The supernatant was collected and the $\mathrm{pH}$ adjusted to 8.0 with $\mathrm{NaOH} 1 \mathrm{M}$ before centrifuging again at $3500 \mathrm{rpm}$ for $15 \mathrm{~min}$. Then, the supernatant was collected and injected in the immunoaffinity column as described above. The elutant was also evaporated to dryness with nitrogen

\subsection{Derivatisation}

The dry elutant was then resuspended in methanol, transferred to a derivatising vial and evaporated to dryness. Fifty microliters of methyl boronic acid solution was added and vortexed. Different MBA concentrations (between 2, 10 and $50 \mathrm{mg} \mathrm{mL}^{-1}$ in ethyl acetate), times (15,30 and $\left.45 \mathrm{~min}\right)$ and temperatures $\left(50,55\right.$ and $\left.60^{\circ} \mathrm{C}\right)$ of derivatisation were assayed. In all cases, vials were left to cool to room temperature before being transferred to the autosampler.

\subsection{Stability}

Stability assays were performed after derivatisation with the optimal conditions consisting in $10 \mathrm{mg} \mathrm{MBA} \mathrm{mL}^{-1}$ for $15 \mathrm{~min}$ at $50^{\circ} \mathrm{C}$. Vials with the methyl boronic derivatives were stored up to $11 \mathrm{~h}$ at room temperature and up to 7 days at $-20^{\circ} \mathrm{C}$ and sampled at periodic intervals, three vials each time, for GC-MS analysis.

\subsection{GC-MS}

The analyses were performed in a Trace GC-MS Polaris Q model from Thermo-Finnigan (Austin, Texas, USA) equipped with a high-resolution gas chromatography column HP- 5 MS $(15 \mathrm{~m} \times 0.25 \mathrm{~mm}$ i.d $\times 0.25 \mu \mathrm{m})$ from Agilent Technologies (Palo Alto, CA, USA). The carrier gas was helium at a flow rate of $1 \mathrm{~mL} \mathrm{~min}^{-1}$ and the injection volume was $1 \mu \mathrm{L}$. Injection was made in splitless mode and the injector temperature was set at $280^{\circ} \mathrm{C}$. Oven temperatures were programmed as follows: initial temperature at $100^{\circ} \mathrm{C}$ for $2.5 \mathrm{~min}$ and increased at $20^{\circ} \mathrm{C} \mathrm{min}^{-1}$ up to $260^{\circ} \mathrm{C}$, then at $5^{\circ} \mathrm{C} \mathrm{min}-1$ till $290^{\circ} \mathrm{C}$ and hold for $10 \mathrm{~min}$. The analyses were performed in the $\mathrm{EI}$ mode and the ionization voltage was fixed at $70 \mathrm{eV}$. Acquisition was made by the selected ion monitoring (SIM) mode. Selected ions were: $\mathrm{m} / \mathrm{z} 277,319$, 321,334 for mabuterol methyl boronate; $m / z$ 188, 230, 272 , 287 for salbutamol dimethyl boronate; $m / z 243,245,285,300$ for clenbuterol methyl boronate and $\mathrm{m} / \mathrm{z} 246$ for the internal standard ( $\mathrm{d}_{6}$-clenbuterol methyl boronate). The internal standard was equivalent to $1 \mathrm{ng} \mathrm{mL}{ }^{-1}$ urine and $2.5 \mathrm{ng} \mathrm{g}^{-1}$ feed, respectively. Integrated peak area data, corrected for IS, was used to calculate results.

\section{Results and discussion}

Different conditions for MBA derivatisation were studied. The best results were obtained when either 10 or $50 \mathrm{mg} \mathrm{mL}^{-1}$ MBA were used at 50 and $55^{\circ} \mathrm{C}$ with $15-30 \mathrm{~min}$ derivatisation period. Thus, optimal conditions were established for a solution of methyl boronic acid solution that contained $10 \mathrm{mg}$ MBA mL ${ }^{-1}$ and derivatisation at $50^{\circ} \mathrm{C}$ for $15 \mathrm{~min}$. Under these conditions, bovine urine samples initially spiked with clenbuterol at $1 \mathrm{ng} \mathrm{mL}$ - $^{-1}$ gave a final concentration of $1.12 \pm$ $0.14 \mathrm{ngmL}-1$. Other authors have reported $55^{\circ} \mathrm{C}$ for $60 \mathrm{~min}$ as good conditions for MBA derivatisation [9]. An example of SIM chromatogram obtained for the three studied $\beta$-agonist boronic derivatives is shown in Fig. 1. Full separation with good resolution could be reached for the studied agonists in less than $10 \mathrm{~min}$ and four ions for each boronic derivative were determined (see Fig. 1). These ions with respective relative intensity for each derivative are shown in Table 1.

Methyl boronic derivatives were stored either at room temperature or at $-20^{\circ} \mathrm{C}$ and then injected into the gas chomatograph-mass spectrometer at specific time intervals in order to check their stability. The results obtained when the methyl boronic derivatives were stored at room tenperature up to $11 \mathrm{~h}$ are shown in Fig. 2. Mabuterol progressively decreased reaching $70 \%$ of the initial area in just $4 \mathrm{~h}$. Salbutamol exhibited a very poor stability, dropping down to less than $25 \%$ of the initial area in less than one hour. Better 

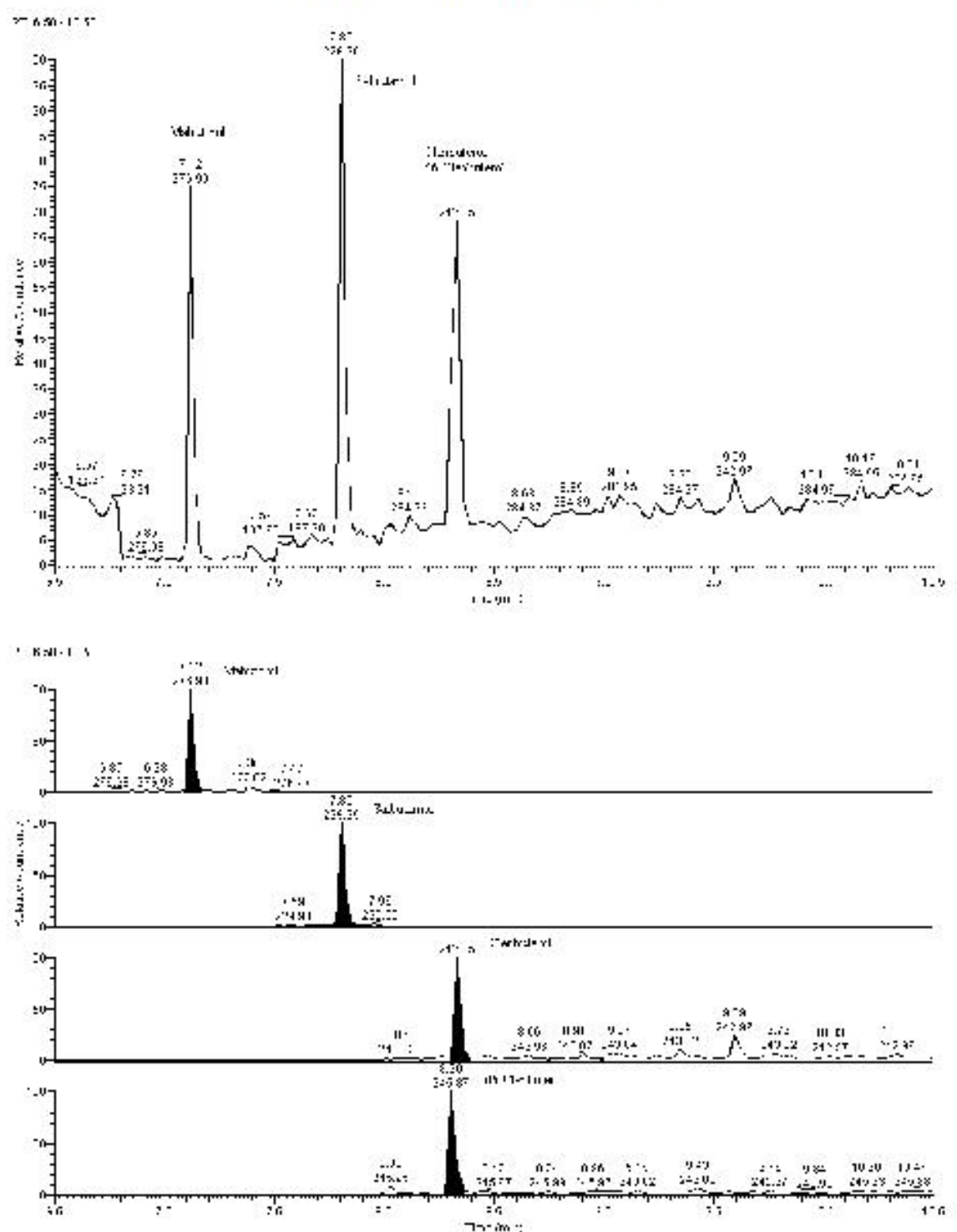

Fig, 1. Saloctod ion monitoring (SMM) chromaxtogram of borime urine fortified with $0.5 \mathrm{ng} \mathrm{mL}-1$ for claubuterol, $0.5 \mathrm{ngmL} \mathrm{m}^{-1}$ for mabuterol, $0.75 \mathrm{ngmL}^{-1}$ for salbutamol and $1 \mathrm{ng} \mathrm{mLL}^{-1}$ for $\mathrm{d}_{6}$-clanbuterol as $\mathrm{IS}$. 


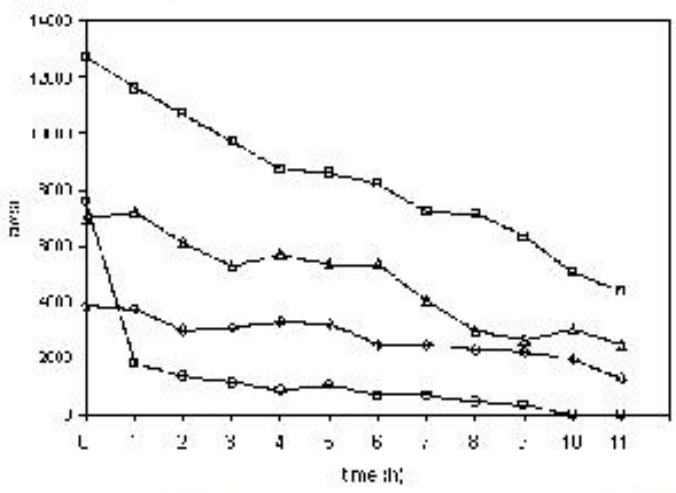

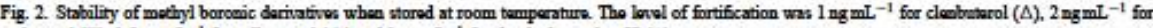

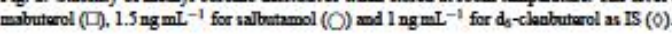

stability was observed for clenbuterol that exhibited areas near the initial values after $7 \mathrm{~h}$ of storage at room temperature. Same behaviour was observed for the IS. This is in accordance to Polletini et al. [3] who observed constant peak height ratios (clenbuterol versus internal standard) up to $48 \mathrm{~h}$ after the derivatisation Under these conditions it is clear that the analysis for $\beta$-agonists other than clenbuterol should be performed as soon as possible after derivatisation.

The results obtained when methyl boronic derivatives were stored at $-20^{\circ} \mathrm{C}$ are shown in Fig. 3. Progressive decreases for clenbuterol and, more markedly, for mabuterol were observed up to 3 days of frozen storage but then both remained quite stable up to 7 days. The internal standard also showed very good stability up to 2 days of storage with a slight decrease afterwards. Salbutamol derivative exhibited good stability restricted to only the first day of storage, experiencing a rapid decrease at the second day, reaching almost

Table 1

Menitored ioms of MBA derivativs of $\beta$-agomists with theirrolativo intonsity

\begin{tabular}{|c|c|c|}
\hline$\beta-A g r a m i s t$ & $\begin{array}{l}\text { Selectod ions } \\
\text { manitorod (miz) }\end{array}$ & $\begin{array}{l}\text { Rolativo } \\
\text { intuanity (\%) }\end{array}$ \\
\hline Clentutarol & $\begin{array}{l}243 \\
245 \\
285 \\
300\end{array}$ & $\begin{array}{r}100.00 \\
66.61 \\
44.03 \\
2.57\end{array}$ \\
\hline de-Clenbutarol & 246 & 100.00 \\
\hline Mabuterol & $\begin{array}{l}277 \\
319 \\
321 \\
334\end{array}$ & $\begin{array}{r}100.00 \\
59.34 \\
22.66 \\
0.50\end{array}$ \\
\hline Salloutansol & $\begin{array}{l}230 \\
272 \\
188 \\
287\end{array}$ & $\begin{array}{r}100.00 \\
52.25 \\
12.95 \\
0.60\end{array}$ \\
\hline
\end{tabular}

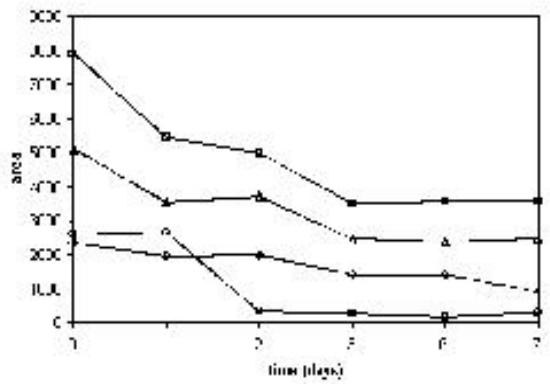

Fig. 3. Sabality of mothyl boronic derination bept moder frozen storage at $-20^{\circ} \mathrm{C}$. The levol of fortification was $\operatorname{lng} \mathrm{mL}^{-1}$ far clanbuterol

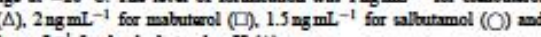
$1 \mathrm{ngmL} \mathrm{mL}^{-1}$ for do-clanbaterol as IS $(\mathrm{C})$

negligble values. Good stability of boronic derivatives of $\beta_{2}$ adrenergic residues stored at $-20^{\circ} \mathrm{C}$ over a period of 4 days has been reported by other authors [9]. However, based on the results of this study, the storage of the boronic derivatives should be kept to a mininum period of time as possible.

The combination of inmmmoaffinity clromatography, MBA derivatisation and GC-MS has shown a high sensitivity, good reproducibility and short time required for the chromatography, confirming this methodology as adequate for the control of the studied $\beta$-agonists.

\section{Acknowiedgements}

Grant from Conselleria de Agricultura, Pesca y Alimentacion from Generalitat Valenciana is fully ackmowledged. 


\section{References}

[1] G. Vha Vyacht, S. Proece, P. Gaspar, G. Maghain-Rogister, E. DeParw, J. Clromatogr. A 750 (1996) 43-49.

[2] L. Leysons, JP. Noben, D. Courtheyn A. Bosuke, Food Add Contam. 13 (1996) 883-895.

[3] A. Poletrini, A. Groppi, M.C. Ricossa, M. Montagna, Biol. Mass Spectrom. 22 (1993) 457-461.

[4] L.X. Whaitos, J.E Mubby, J. Chromstoge. B 728 (1999) 67-73.

[S] L. Damasceno, R. Ventum, J. Ortublo, J. Segura, J. Man Spectron 35 (2000) $1285-1294$
[6] B.F. Spisso, C.L. Loper, M.AS. Marquen, FR.A. Nato, I. Anal Toxicol. 24 (2000) 145-152

T7 J.W. Blanchfower, A.S. Hewitt A. Comangn, T.C. Elliot, D.G

Kernody, Biol. Mass Spectrom. 22 (1993) 326-330.

[8] F. Ramon, M.C. Castillho, M.I. Noronha, I. AOAC Int. 81 (1998)

544-548.
S.C. Castiliba, MI. Norouha, J. AOAC Int 81 (1998) [9] F. Ramos, C. Santos, A. Sikna, MI Noreaha, J. Carousatogy B 716 (1998) $366-370$.

[10] P. Gonatlez-Gigonon, C. Foute-Sumpayo, C. Frasco-Abuin, A Copoda-Ssez, B.J. Verquez-Belda, Food Add Contam. 19 (2002) 1010-1014 


\section{Apéndice II:}

Methods for rapid detection of chemical and veterinary drug residues in animal foods. Trends in Food Science and Technology, 2006, 17, 482-489. 
Review

\section{Methods for rapid detection of chemical and veterinary drug residues in animal foods}

\author{
Fidel Toldrá* and Milagro Reig \\ Department of Food Science, Instituto de \\ Agroquímica y Tecnologia de Alimentos (CSIC), \\ P.O. Box 73,46100 Burjassot, Valencia, Spain \\ (Tel.: + 3496 3900022; fax: + 34963636301 ;
} e-mail: ftoldraeiata.csic.esi

Rapid methods and automation for the detection and characterisation of chemical and veterinary drug residues in foods of animal origin constitutes a dynamic area in food processing and is experiencing important developments mainly from the standpoint of food safety. Residues from these substances maxy be present in edble tissues, milk and eggs for human consumption and may exert different level of toxicity on consumers when consuming them. Thus, easy, rapid and sensitive tests are really needed for an effective at line use. This manuscript is presenting latest developments for rapid detection of chemical and veterinary drugs residue: in foods of animal origin.

\section{Introduction}

Veterinary and chemical drugs having anabolic effect are used for therapeutic and prophylactic purposes as well as for improved breeding efficiency, although most of them are banned in the European Union and can only be administered in specific circumstances (therapeutic purposes) but under strict control. In general, these

- Corresponding author.

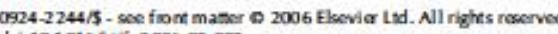
dol: $10.1016 / 2)+18.2006 .02 .001$ substances are illegally added to act as growth promoters, improving feed conversion efficiency and increasing the lean to fat ratio. The gain in protein deposition is thus based on an improved feed conversion rate. However, these substances may remain in all animal-treated derived foods.

Growth promoters exert some effects on meat quality, usually towards poorer quality. An increase in connective tissue production and collagen cross-linking because a reduction in protein degradation allows more time for collagen molecules to cross-link and thus, increase the toughness of the meat (Moloney, Allen, Joseph, \& Tarrant, 1991). In addition, muscle proteases are inhibited by the presence of some of these substances. For insance, calpains are inhibited by $\beta$-agonists but rotein synthesis is increased. The myofibrillar protein fragmentation is also decreased in agonists-treated animals (Fiems, Buts, Boucque, Demeyer, \& Cattyn, 1990). The result is a substantial reduction in tendemess (Moloney et al., 1991). On the other hand, lipolysis rate is increased by activation of the hormone-sensitive lipase and then breakdown of triacylglycerols (Brockman \& Laarveld, 1986). Thus, the amount of fat is substantially reduced with the subsequent loss in juiciness and poorer flavour development.

Some substanoes, like thiouracyk, produce a noticeable retention of water that is suddenly los when cooking the meat. The result is tougher meat with poor juiciness. But what is more important, most of these substances present in residual amounts in animal foods may have some important toxic effects. Some of them may exert genotoxic, inmunotoxic, carcinogenic or endocrine effects on consumers, constituting an important health risk that must be controlled. Thus, the presence of these residues must be monitored in foods of animal rigin (Croubels, Daeselaire, De Baere, De Backer, \& Courtheyn, 2004).

Antibiotics act as growth promoters but can contribute b an increased human exposure to antibiotics, development of pathogens with antibiotic-resistance and increased allergies due to its presence in foods. In fact, the presence of residual antibiotics in animal foods constitute an important bealth risk because the increased microbial resistance detected in latest years (Butaye, Devriese, \& Haesebrouck, 2001). In addition, the resence of residual amounts of antibiotics produces 
important difficulties to food processors for the extent and control of food fementation.

It is evident that there are important benefits for the farmer when using these illegal substances, mainly consisting in an increased feed conversion yield and an increased lean meat with less fat. But, it is also evident that there are important prejudices for the processing industry, like lower quality of products and problems in fermentation and very important prejudices to the consumers, not only for the worse quality or the higher water content but because of the presence of residues and its associated harmful health effects on humans. For al these reasons, there is an evident interest of both officia arganisms and food industry to control the presence of these substances in fams and foods of animal origin. Recently, the EC Quality of Life Programme supported European collaborative projects in the area of antimicrobials and hormone residues analysis (Boenke, 2002). These projects consisted in the development and validation of screening and confirmatory analytical methods and sensors for a cost-effective and time efficient control of synthetic glucoconticoids, nitrofurans, coccidiostatics, $\beta$-lactam residues and androgen residues in live and post-mortem animals.

The use of substances having hormonal of thireostatic action as well as $\beta$-agonists is banned in the Europea Union. Main veterinary drugs and substances with anabolic effect are listed in Table 1. Only a few substances are authorised for therapeutic purposes and under the control of a responsible veterinarian (Van Pteghem \& Daeselaire, 2004). The presence of these substances in foods are controlled by official inspection and analytical services following EC Directive 96/23/EC on measures to monitor certain substances and residues in live animals and animal products. Analytical method dogy, including criteria for identification and confir mation, for the monitoring of compliance was also given in Decisions $93 / 256 / E E C$ and $93 / 257 / E E C$. Since the implementation of these Directives, a clear decrease i the use of growth promoting agents, including $\beta$-agonists, was observed (Kuiper, Noordam, V an Dooren-Flipsen, Schilt, \& Roos, 1998). More recently, the Commission Decision 2002/657/EC implemented Council Directive
$96 / 23 / E C$. This Decision, which is in force since 1 September 2002, provides rules for the analytical methods to be used in testing of official samples and specific common criteria for the interpretation of analytical results of official control laboratories for such samples. This Decision includes concepts like the decision limit ( $\mathrm{CC} \alpha)$ and the detection capability (CC $\beta)$ for assessing non-compliant samples. The guidelines given in the Directive imply the use of sophisticated analytical instrumentation like GC-MS or LC-MS. These controls are based on screening and those suspected noncompliant samples are then confirmed through methods based on the use of gas or liquid chromatography coupled to mass spectrometry, or other sophisticated methodologies and analytical instrumentation, for accurate characterisation and confirmation.

\section{Screening methodologies}

The full procedure and the methodologies for confirmatory analysis ane costly in time, equipments and chemicals. In addition, they require trained personnel with high expertise. Control laboratories mus face a large number of samples, with a variety of analytes, to be analysed in relatively short periods of time. Thus, there is a need for screening methods that allow the analysis of such a large number of samples in short periods of time. This means that high through-put methods with low cost must be available. These methods must be able to detect an analyte or class of analytes at the level of interest (Van Peteghem, Daeselaire, \& Heeremans, 2001). Some false positives (false compliant) are acceptable, as they will be further submitted for confirmatory analysis but the method must avoid of reduce to a minimum the number of false negative results (non-compliant) because they will not be further analysed. The main requirements, that are generally contemplated for a screening method, are summarised in Table 2.

Appropriate sampling preparation procedures, especially when dealing with solid foods like most of those of animal origin, are also getting increased attention due to the miniaturisation of commercial tests and kits. These sample preparation ensures better

\begin{tabular}{|c|c|}
\hline Groep A: substances having anabolic effect & Group B: veterinary druss \\
\hline 1. Silhenes (dicthylstil bestrol) & 1. Antilacterial suhtances \\
\hline 2. Antithyroid agents (thiouradik) & Sulsonamides and quinolones \\
\hline 3. 9 cenidk & 2. Other veterinary drugs \\
\hline Andogens (trenbolone acetaxe) & 2) Antihelmintics \\
\hline Gestagens (melengestrol acetate) & b) Anticonccid iak, including n itroimid 2zoles \\
\hline Estogens (17 $\beta$ estradiol) & c) Cartamates and pyrethroids \\
\hline 4. Resoncycilic acid lactones (zeranol) & d) Sedatives \\
\hline 5. Betaegonists (clenbutorol) & e) Non-steroided anti-inflammatory duggr \\
\hline 6. Other compounds (nitrofunans) & f) Other pharmacologically active substances (decamethasone) \\
\hline
\end{tabular}




\begin{tabular}{|l|}
\hline Table 2. Main requirements for a screening methodology \\
\hline Requirements \\
\hline Easy to use \\
Low set up cosst \\
Hight through-put \\
Reducod time and low nunning costs for results \\
Sensitivity (mo pos itives are lost) \\
Specificity (min imum number of false positives) \\
Repeatabi liny
\end{tabular}

sensitivity of the screening tests. Different extraction techniques are usually based on solid phase extraction for sample clean-up. Different types of cartridges may be used depending on the analytes, ensuring the elimination of potential interferents present in foods (Stubbings e d., 2005).

There are different techniques available for the screening of residues in animal foods as shown in Table 3. In general, the limits of detection will depend on the previous extraction and clean-up of the sample. The immunological methods mainly consist of ELISA test kits. There are many kits commercially available. Other immunological methods are based on radioimmunoassay and, more recently, several methods using biosensors are commercially available. The chromatographic methods mainly consist in two types, HPTLC and HPLC, coupled to different detection systems.

Immunological techniques

Antigen and antibody reaction has boen used for many years to detect a wide variety of food constituents including substances responsible for adultrations and contaminations. The interaction antigen-antibody is very specific and useful for the detection of residues of chemical and veterinary drugs in animal foods. The most usual technique consists in the enzyme-linked-immunosorbent assay (ELISA) and the detection system is usually based on enzyme-labelled reagents. There are different formats for antigen quantification. In double antibody of sandwich ELISA tests a primary antibody i bound to the plate well. The antigen of the sample extract added to the well complexes with the bound antibody and remains bound to the plate after washing.

\begin{tabular}{|c|c|}
\hline $\begin{array}{l}\text { Immanological } \\
\text { methods }\end{array}$ & Chromatography methods \\
\hline EUSA test kits & $\begin{array}{l}\text { High peformance thin-lyyer } \\
\text { charmatography (HPIC) }\end{array}$ \\
\hline Radioimmunasasay & $\begin{array}{l}\text { High peformance liquid chomatography } \\
\text { HPLO }\end{array}$ \\
\hline $\begin{array}{l}\text { Multiaray } \\
\text { bicseneors }\end{array}$ & \\
\hline
\end{tabular}

Then, a second antibody labelled with an enzyme such as peroxidase is added to the well followed by a new wash. The quantity of conjugate bound to the plate is detected after incubation with a specific substrate. Colour is developed during incubation and measured with a microplate reader, which is proportional to the amount of analyte in the sample.

In direct competitive ELISA tests, a primary antibody is coated onto the plate wells and incubated with the sample extract containing the antigens. Once the equilibrium is reached, an enzyme-labelled antigen is added. This conjugate will bind to the free binding sites of the primary antibody. Thus, the more antigen in the sample, the bwer amount of enzyme-labelled antigen bound. Appropriate specific substrate is added and the plate is incubated for colour development. In this case, there is an inverse relationship between the colour developed and the concentration of the analyte in the sample.

Radioimmunoassay (RIA) implies the measure of radioactivity of immundogical complex using a counter (Samarajeewa, Wei, Huang, \& Marshall, 1991). Other possibilities include the measure of chemiluminiscence with a luminometer when a chemiluminiscent compound is bound to the antibody or fluorescence with a fluorimeter when a fluorescent compound is used. They allow an enhanced detectability in relation to conventional colorimetry (Roda et al., 2003).

Main advantages and disadvantages of immunological bits are compiled in Table 4 . These kits offer important advantages like the large number of samples to be analysed per kit, fast to operate and its high specificity and sensitivity in comparison to conventional detection methodk. Another advantage is the possibility to use the lit within the food-processing facility without the need to transport the sample to the laboratory. Many diagnostic companies have marketed ELISA test kits for the detection of such residues. Thus, ELISA kits are available for a large number of substances within each group listed in Table 1 like $\beta$-agonists, corticoids, seroids, stilbenes, resorcylic acid lactones and several antibiotics. Research continues for the development of new ELISA tests for other substances like sedatives and the $\beta$-blocker carazolol (Cooper, Delahault, Fodey, \& Elliott, 2004). Regarding antibiotics ELISA kits have shown good performance for analysing antibiotic residues like tylosin and tetracyclin in water, meat and fish (De Wasch ef al., 2001; Draisci ef al., 2001; Lee, Lee, Ryu, Lee, \& Cho, 2001 ; Kumar, Thompson, Singh, Chander, \& Gupta, 2004), chloramphenicol in milk and meat (Gaudin, Cadieu, \& Maris, 2003), nitroimidazoles in eggs and chicken (Huet et al., 2005), gentamicin in milk (Jin, Iang, Han, \& Lee, 2005), dihydrostreptomycin and colistin in milk (Suhren \& Knappstein, 2004), bacitracin, spiramycin, tylosin, olaquindox and virgiamycin in feedstuffs (Situ \& Elliott, 2005). In general, these 


\begin{tabular}{|c|c|}
\hline Advantages & Disadvantages \\
\hline 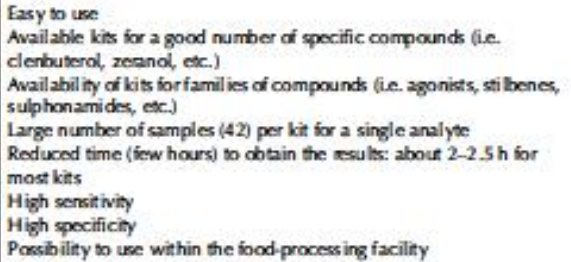 & $\begin{array}{l}\text { Increased costs since } 2002 \text { (more than } 6650 \text { per kit) } \\
\text { Limited storage (few montha) under refingeation } \\
\text { Expensive in the case of RIA and neod for waste dispocal } \\
\text { Interierences giving some false positives } \\
\text { Only one kit per residue searched }\end{array}$ \\
\hline
\end{tabular}

methods require some time of manual operation for the addition of sample, incubation, washing and discarding of liquids, reagents for colour development, etc. This has prompted the development of automated ELISA tests by some companies.

Another recent approach to screen animal products for veterinary drugs, ensuring quality and safety of meat and dairy products consists in the development of biosensors. These instruments comprise two elements: a biologica recognition element, usually an antibody, and a signal transduction element which is in close contact and connected to data acquisition and processing system (Patel, 2002).

Biosensors are getting expanded applications in food analysis. In general, there are several elements The target analyte contacts the biological receptor (antibody) and the biochemical signal is converted by a transduce into an electronic signal. Then, these signals ane procesed by a microprocessor that gives the final resul (White, 2004). The construction of biosensors requires good knowledge of the basic principles of immunochemical reactions, pathways for receptor-based signa amplification and the interfacial behaviour of biocom pounds at the artificial transducer surface (Grindig \& Renneberg, 2002). Biosensors are designed to operate in real time and be able for the simultaneous detection of single or multiple veterinary drugs residues in a sample at a time. Some authors have reported no need for sample clean-up (Elliott et al., 1998). The biomolecula interaction analysis is based on surface plasmo resonance that measures variations in the refractive index of the solution close to the sensor when there are changes in the mass concentration of molecules in that solution (Gillis, Gosling, Sreenan, \& Kane, 2002). The target residue is covalently immobilised onto the sensor chip surface. This technology is applied by Biacore AB (Uppsala, Sweden) to analyse different veterinary drug residues. Some recent applications include progesterone in milk (Gillis et al., 2002) and tylosine in honey (Caldow et al., 2005).

Other biosensors are based on the use of biochip arrays that allow a real time monitoring of the interaction between the recognition molecule and the analyte. The recognition signal is converted into a quantifiable signal. This technology is applied by Randox Laboratories Ltd (Antrim, UK). However, the number of residues ready to use in an array is still commercially limited. Several factors like sensor surface ligand density, active antibody concentration and biosensor flow rate affect the assay performance (Johanson \& Hellenas, 2001). Enzymic biosensors use a specific enzyme for the capture and catalytic generation of the product. For instance, penicillin V and $\mathrm{G}$ can be detected with penicillinase immobilised on a surface, either a membrane or porous glass, that produces penicilloic acid and thus a reduction in $\mathrm{pH}$ and either a decrease in the fluorescence intensity of the dye or an increase in the electrical conductivity (Patel, 2002). Other type of biosensors are based on antibiotic sensor protein which are sensible to specific classes of antibiotics. These sensors are high-throughput and compatible with the ELISA-type format. The biosensor protein is chemically linked to the solid surface of the well in a microtitre plate which, in the absence of antibiotic, remains bound to the operator

Table 5. Main advantages and disadvantages of biochip amay biosensors

Easy to use

Disadvantages

E2sy to use

High initial imestment (equipment)

Resuls ani able in shot time High aperative anst (chips)

Multiples residues analysed in one shot (as many aschips in an aray) Analysis restrictod to anei lable chips

Full automatiotion: higher productivity
High through-put tochnique: $u p$ to 120 samples per hour and aray 


\begin{tabular}{|c|c|}
\hline Advantages & Dikadvantages \\
\hline $\begin{array}{l}\text { High number of samples for a single analyse } \\
\text { Reduced time (few hours) to obtain the results } \\
\text { Possib ility of automatication for higher productivity } \\
\text { Sensitive } \\
\text { Specificity depend ing on the detoction tochnique } \\
\text { Sepacted ample can be recovered for further confir }\end{array}$ & $\begin{array}{l}\text { Expetise required } \\
\text { Neod of smple preparation (entaction, filtration, exc.) } \\
\text { Interferences giving some false positives } \\
\text { Only ane thin layer plate per residue searched }\end{array}$ \\
\hline
\end{tabular}

sequence and after detection by antibodies and coupling to peroxidase produces a colour readout. However, the biosensor is unable to bind the operator when the antibiotic is present and, depending on its amount, this operator is more or less lost in the washing steps. The loss of colour gives a readout that is proportional to the antibiotic concentration (Weber et al., 2004). These sensors have shown successful detection of tetracycline, streptogramin and macrolide antibiotics at nanogram per millilitre concentrations in milk and serum (Weber et al. 2004).

Main advantages and disadvantages of biosensors are compiled in Table 5. These new tochnologies are getting good reception in control laboratories due to the reduction in total time and possibility to analyse simultaneously multiple residues in short time for a large number of samples (Franek \& Hruska, 2005). In fact, these technologies are fully sutomated (injection, addition of reagents, washing, incubation and output) and computer-controlled.

Chromatographic techniques

High performance thin-layer chromatography (HPTLC) has been applied successfully for the qualitative and quantitative detection of multi-residues in food samples even though its use has rapidly decreased during the last decade. Visualisation of the components can be performed either by spraying an appropriate chromogenic reagent or under UV light. Quantitative determination is possible through the relative intensity of the spot in the plate, which is measured against that of the intemal standard by scanning densitometry. Recent developments allow for automation in a similar way to HPLC with the appropriate equipment. HPTLC has been applied to dfferent residues like thyreostatic drugs (De Brabender, Batjoens, \& Van Hoof, 1992; De Wasch et al., 1998), clenbuterol and other agonists (Degroodt, De Bukanski, Beemaert, \& Courtheyn, 1989; Degroodt, De Bukankki, De Groof, \& Beernaert, 1991), nitroimidazol (Gaugain \& Abjean, 1996) and sulfonamides (De Bukandki, Degroodt, \& Beemaert, 1988; Haagsma, 1985; Van Poucke, Depourcq, \& Van Peteghem, 1991) in animal tissues. It has also been applied to the analysis of corticosteroids (Hoebus, Daneels, Roets, \& Hoogmartens, 1993; Vanoosthuyze, Van Poucke, Deloof, \& Van Peteghem, 1993) and antibiotics in milk (Choma, Grenda, Malinowska, \& Suprynowicz, 1999; Van Poucke et al., 1991). The spots can be A variation, named TLCbioautography, consists in the combination of thin-layer chromatography with microbiological detection directly on the plate resulting in enhanced sensitivity. It has been applied to the detection of flumequine in milk (Choma, Choma, \& Statszczuk, 2002). The main advantages and disadvantages of HPTLC are compiled in Table 6.

The use of high performance liquid chromatography (HPLC) expanded during the 1990 s and the availability of automation somehow facilitated its use as a screening technique. HPLC is a separative technique and its ability to detect compounds depends on the type of detector used. The choice of the detection system is very important for selectivity and sensitivity. Some analytes not detected by absorbance, refractive index or fluorescence may require chemical modifications to render chromophore, fluorescent or UV-absorbing compounds (Bergweff \& Schloeser, 2003). Usually, the detection of multi-residues is based on a solid-phase extraction clean$u$ followed by filtration and injection into a reversephase HPLC with UV-diode array detection. It has been

Table 7. Main advantages and disadvantages of HPLC

\begin{tabular}{|c|c|}
\hline Advantages & Disadvantages \\
\hline $\begin{array}{l}\text { Shart time (few min/sample) to obtain the resuls } \\
\text { Sensitive }\end{array}$ & $\begin{array}{l}\text { Expetise required } \\
\text { Neod of sample preparation (extaction and filtration, addition of } \\
\text { internal standard, efc.) }\end{array}$ \\
\hline Specificity depending an detector & High intial imestment (equipment) \\
\hline $\begin{array}{l}\text { A utomatication leading to higher productivity } \\
\text { Possibility to find mose information from specta when using diode } \\
\text { arrey detoctor. }\end{array}$ & Cast of column \\
\hline
\end{tabular}


applied for detection of antibiotics in meat, kidney and milk (Cinquina et al., 2003: Cooper, Creaser, Farrington, Tarbin, \& Shearer, 1995; Funusawa, 1999; Kirbis, Marinsek, \& Flajs, 2005), veterinary drugs in eggs, milk, fish and meat (Aerts, Hogenboxm, \& Brinkman, 1995: Horie, Yoshida, Saits, \& Nakazawa, 1998), methyl thiouracils in urine (Reig, Batlle, Navamo, \& Toldrá, 2005), anabolic steroids in nutritional supplements and wine (De Cock et al., 2001; Gonzalo-Lumbreras \& Inquierdo-Hornillos, 2000) and corticosteroids like dexa methasone in water, feed and meat (Mallinson, Dreas, Wilson, \& Henry, 1995; Reig, Mora, Navarm, \& Toldrá, 2005: Shearan ef al, 1991; Stolker, Schwillens, Vai Ginkel, \& Brinkman, 2000). A good number of substances with anabolic properties, that can be considered as growth promoters, have been sucoessfully separated and identified for screening purposes in urine (Koole, Franke, \& Zeeuw, 1999). HPLC with fluorescence detection has also been used for the simultaneous determination of 10 quinolone antibacteria residues in multipecies animal tisues (Verdon, Couedor, Rodaut, \& Sanders, 2005). The main advantages and disadvantages are compiled in Table 7.

HPLC is getting expanded ue in control laboratories due to the possibility to analyse simultaneously multiple residues in a sample in relatively short time. Recen developments of high speed HPLC can reduoe sample treatment and analysis time. In addition, this technology is fully antomated (injection, elution, washing of column, detection) and computer-controlled, facilitating its use as a screening technique.

The next step after initial screening with HPLC is the injection of the presumed positive samples in a system combining HPLC with mass spectrometry detection. I this sense, the coupling of high speed HPLC with MS MS can substantially reduce the analysis time. The use of HPLC-electrospray ionisation (ESI) tandem mas spectrometry has been proposed as a simultaneous screening-confimatory technique (Hewitt, Kearney, Currie, Young, \& Kennedy, 2002; Thevis Opfermann, \& Schănzer, 2003). Other authors have used liquid chromatography-mass spectrometry with atmospheric pressure chemical ionisation (APCI) for the analysi (Maurer, Tenberken, Kratzsch, weber, \& Peters, 2004; Puente, 2004: Tumipsoed, Roybal, Andersen, \& Kuck, 2005). Both ionisation techniques facilitate the analysis of small to relatively large and hydrophobic to bydrophylic molecules and are thus very adequate for the analysis of veterinary drug rexidues (Bergweff \& Schloesser, 2003). Both techniques have been reported to show matrix effects being ESI more susceptible than APCI (Dams, Huestis, Lambert, \& Murphy, 2003). Another methodology based on the application of ' $F$ NMR has also been proposed as a screening echnique for the analysis of steroid cocktails and veterinary drug formulations administered to livestock (Lommen et al,, 2000).

\section{Future trends}

There are several arising problems in this field such as the increased number of new substanoes in the black market'. Every year, new substances with anabolic properties and used as growth promoters are being detected. An example of the evolution of this type of substances may be observed in the ligh competitive sports. Another important problem is an extended practice consisting in the mixture of low amounts of several substances, like a 'cocktail' that exerts a synergistic effect giving similar efficiency to the use of a single substance at higher and, thus, detectable amounts Finally, the development of interfering substances to mask immunoassay detection systems also complicates the efficient detection of the illegal substances.

In addition to these problems, control laboratories face more strict requirements for the performance of analytical methods according to new Directives. This situation is creating some problems to control labor atories because of the large number of samples $b$ analyse, the great variety in samples and residues to be analysed, the need to adapt analytical methodologies to new Directives with strict guidelines, the increased costs in developing such new methodologies the increased number of residues to search per sample and the need to invest on powerful new instruments.

The availability of screening methodologies facilitates the control of chemical and veterinary drugs in foods of animal origin, reducing the number of samples to be confirmed through tedious and costly confimatory analysis. Recent new developments, already available in the market, will probably be routinely implemented in the next few years, increasing the number of screened samples with high sensitivity. The improvements in sreening methodologies and its implementation will contribute to a better safety assurance of foods of animal origin.

\section{Acknowledgements}

Grant from Conselleria de Agricultura, Pesca y Alimentación from Generalitat Valenciana is fully acknow ledged.

\section{References}

Aert, M. M. L., Hogenboom, A. C., \& Brinkman, U. A. T. (1995). Analytical strategies for the screen ing of vetorinary drugs and the ir residues in ed ble products. Journal of Chroma to gra phy B Biomedical Applications, 667, 1-40,

Bergweff, A. A., \& Schloesser, 1. (2003). Residue determination. In B. Caballera, L Truza, \& P. Finglas (Edk t) Encyclapedia of Food 
Sciences and Nutrition (2nd ed.) (pp. 254-261). London, UK: Eleevio

Boenke, A. (2002). Contribution of European rescarch to antimicrobials and hormones. Analytica Chimica Acta, 473 , $83-87$

Bocieman, R. P., \& Larveld, R. (1986). Hormonal megulation of metabolism in ruminants. Review. Livestock and Production Science, 14, 313-317.

Bulanski, B. W, Degroodt, 1. M, \& Beemaert, H. (1988). A two dimensional high-performance thin-byer chroma togaphic. screening method for sulphomamides in animal tissues. Zeits chrift für Lebersmired Untersuchung und forschung, 187, 242-245.

Butayc, P, Devricse, L A, \& Hesechouck, F. (2001). Diflenences in ant ibiotic resistance patterns of Enterococcus faecalis and Enterococcus faecium strains isolated from farm and pet animak. Antimicrobial Agents and Chemothen py, 45, 1374 anima

Galdow, M., Stead, S. L, Dax, L, Sharman, M., Situ, C., \& Ellickt, C

(2005). Develo s. L, Day, L, Sharman, Mr, Situ, C, \& Elict, C (2005). Development and validation of an optical SPR biosensor
ascay for tyles in residues in honey. Journal of A griculural and ascay for tylos in residues in hone
Food Chemisty, 53, 7367-7370.

Chama, 1.M. Choma, A, \& Staszczulk, K. (2002). Determination of flumequine in milk by thin-byer chroma toga phy-biosutogra. phy. journal of Liquid Chroma togn phy and Rela tod Technologies, 25, 1579-1587

Choma, 1., Crenda, D., Malinowska, L, \& Suprynowicz, Z. (1999). Desemination of flumequine and doxycycline in milk by a simple thin-layer chromatographic method. Journal of Chromatography $B, 734,7-14$

Cinquina, A. L., Roberti, P., Gianeeti, L, Lango, F, Draisci, R. Fagiolo, A, et al. (2003). Detemination of enroflexacin and its metabol ite ciprofloxacin in gaat mill by high-performance liquid chromatography with diode aray detoction. Optimiz ation and validation. joumal of Chromatography A, 987, 221 226.

Cooper, A. D., Greaser, C. S., Farringron, W. H. H., Tarbin, 1. A., \&

Sheser, C. (199S). Deve lopment of muiti residue methodology for the HPLC determination of veterinary das in animal-tissues. for the HPLC, determination of veterinary dags in

Cooper, 1., Delahaut, P, Fodey, T. L, \& Elliot, C. T. (2004).

Development of a rapid scroening test for veterinary sedatives and the beta-blocker carazolol in porcine kidney by ELSA. Analyst, 129, 169-174.

Croubek, S., Daesebiare, E, De Bsere, S., De Backer, P, \& Courtheyn, D. (2004). Feed and drug residues. In W. Yensen, C. Devine, \& M. Dikemann (Eds), Encyclopedia of Meat Sciences (pp. 1172-1187). London, UK: Elsevier.

Dams, R., Huestis, M. A, Lambert, W. E, \& Murphy, C. M. (200B). Matrix effects in bio-ana hysis of illicit drugs with LC-MSMS: Influence of ionization type, sample pseparation and biofluid fournal of the American Society of Mass Spectromety, 14, $1290-1294$.

De Brahendes, H. F, Batjoens, P., \& Van Hoof, V. (1992). Desemination of thyreostatic drugs by HPTC with confir. mation by GC-MS. Journal of Planar Chromatogaphy, 5 , mation by

De Cock, K.J. S., Delbekc, F. I, Van Eenoo, P., Desmee, N., Roek, K. \& De Backer, P. (2001). Detoction and determination of anabolic steroids in nutritional supplements. Journal of Pha antholic steroids in nutritional supplements. Journal

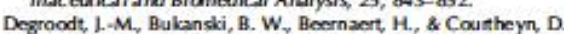

Degroodt, L.-M, Bukanski, B. W, Beernaert, H., \& Courtheyn, D. (1989). Chenturerol residue analysis by HPLC-HPTLC, in urin and animal tissues. Zeitschrift für Lebersmitrel Untersuchung und forschung, $189,128-131$

Degroodt, 1.-M., Bukanski, B. W, De Crood, 1, \& Beernaen, H. (1991). Cimaterol and clenhuterol residue a nalysis by HPLC.
HPTLC. Zeitschrift für Lebensmittel Untes uchung und For. schung 192, 430-432.

De Wasch, K., De Babender, H. F., Van Ginkel, L. A., Spaan, A. Sterk, S.S., \& Meiring. H.D. (1998). Confiemation of nesidues thyreostatic dnugs in thyroid glands by multiple mass spec. trometry atter thin-kyer chromatography. joumal of Chroma. togaphy A, 819, 99-111.

De Wasch, K., Okerman, L., Croubek, S., De Brahander, H., Van Hod, 1, \& De Backer, P. (2001). Detoction of residues of tetracyclime art biotics in pork and chicken meat Correbtion betwoon results of screening and confirmatory tests. Analyst. 123, $2737-2741$.

Draisci, R., Quadi, F. D., Achene, L, Volpe, G, Palleschiand, L., \&

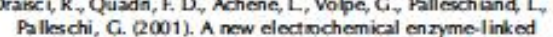
Pa lleschi, C. (2001). A new electrochemical enzyme- inked immunosorbent 2ssay for the screening of macrolich

Ellickt, C. T, Baxter, G. A., Hewitt, S. A., Arts, C. . M., Van Bank, M, Hellenas, K. E, of al, (1998). Use of biosensors for rapid der Hellenas, K. E, ef al. (1998). Use of biosensors for rapid drug residue anahysis without sample deconjugation or
possible way forward. Analyst, $123,2469-2473$.

Fiems, L. O, Bus, B, Boucque, Oh. V, Demeyer, D. 1, \& Cottyn, B. G. (1990). Effoct of a $\beta$ agonist on mest qual ity and myofbril ber prokein fragmentation in bulls. Meat Science, 27 , 29-35.

Franck, M., \& Hruska, K. (2005). Antibody based methods for emvironmental and food a nal ysis: A review. Veterinary Medicine Crech, s0, 1-10.

Furusewa, N. (1999). Rapid liquid chromatographic detemination of axpetacycline in millk, journal of Chromatography, 839 , of axpertion 2451.

Caudin, V, Cadicu, N., \& Maris, P. (2003). Inter Lahoratory studies for the evaluation of BlisA $k$ its for the detection of chloam phenicol residues in milk and muscle. food and A gricuitural Immundogy, 15, 143-157.

Caugain, M. \& Abjean, 1. P. (1996). High-petformance thin-layer chroma togaphic method for the fluorescence desection of thee nitroimich zole residues in podk and poultry tissue. Journal of Chmomatography A, 737, 343-346.

Gillis, E. H., Goskling, 1. P, Sreenan, J. M. \& Kane, M. (2002). Development and va lidation of a biosenson-based immunoassay for progesterone in bovine milk. foumal of $/ \mathrm{mm}$ undogial Methods, 267, 131-138.

Conzalo-Lumbresos, R. \& Izquierdo-Hornillos, R. (2000). Highperformance liquid chrom toga phy optimization study for the sepanation of natural and synthetic. anabolic storoids. Appli separation of natural and synthetic an abolic steroids. App Cation to urine and phamacestic
Chmomatography $B, 742,1-11$.

Cruindig, B, \& Renneberg, R. (20012). Chemical and biochemical Cruindig, B, \& Renneberg, R. (2002). Chemical and biochemical
sensors. In A. Katerkamp, B. Crundig, \& R. Renneberg (Eck), UNmann's Encyelopedia of industrial chemistry (pp. 87-98). Weinheim: Wiky.

Hangsma, N. (1985). Rapid thin-byer chromatognaphic screening method for the detoction of five sulfonamides in swine tissuer Collaboa tive study. Zeitschrit for Lebensmintel Untersuchung und forschung 181, 45-46,

Hew it, S. A, Kearney, M, Currie, 1. W, Young, P. B. \& Kennedy, D. G. (2002), scroming and confirma boy to togies for the surveillance of a mabolic steroid abuse within Northern Ireland. Analytica Chimica Acta, 473, 99-109.

Hoebus, 1., Daneek, E, Roes, E, \& Hoogmatens, 1. (1993) Ident fication of corticosternid hormones by thin-lyer chroma ident fication of corticoste noid hormones by thin layer ch.

Hovic, M., Yoshida, T., Saita, K., \& Nakazmwa, H. (1998). Rapid

screen ing method for residual veterinary drugs in meat and fish by HPLC loumal of the Food Hygienic Socicty of Japan, 39 383-389. 
Huet, A. C, Mortier, L, Daeseleire, E, Fodey, I, Ellioe, C., \& Delahaut, P. (2005). Development of an HiSA screening test for nitroimida zoles in $\mathrm{egg}$ and chicken muscke. Analytica Chimica Acta, 534, 157-162.

lin, Y, lang, 1.W, Han, C. H, \& Loc, M.H. (2005). Development of ELISA and immunochomatographic assy for the detoction of gentamicin. joumal of Agricuitural and Food Chemistry, 53 , $7639-7643$.

Johansson, M. A, \& Hellenas, K. E. (2001), Sensor chip preparation and assay construction for immunchiosensor detormination beta-agonists and hormones. Analyst, 126, 1721-1727.

Kirbis, A, Marinsel, I) \& Flaj, V. C. (2005). Introduction of the Halc method for the desermination of quinolone residues in various.

Kooke, A, Fanke, J.P., \& De Zoouw, R. A. (1999). Multi-residue analysis of anabolics in calf urine using high-performance liquid chroma tag a phy with diode
matognaphy B, 724, 41-51.

Kuiper, H. A, Noordam, M. Y. Van Dooren-Flipsen, M. M. H,

Schilt, R., \& Roos, A. H. (1998). Il legal use of $\beta$ sedrenergic

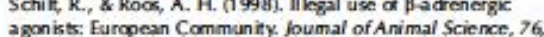
agonists: E.
195-207.

Kumar, K., Thompson, A, Singh, A. K., Chander, Y, \& Gupta, S. C (2004). Enzyme tinked immunosobent asory for ultratace determination of a nt bictics in aqueous samples. fournal of Envimnmental Quality, 33, 250-25

Lec, H. I., Lec, M. H. Ryu, P. D. Lee, H. \& Cho, M. H. (2001). Enzymet inked immunosorbent asery for scocening the plasma residues of tetracycline ant ibiotics in pigr. fournal of Veterinar Medicine Science, 63, 553-556.

Lammen, A, Schil, R., Weseman, 1., Roos, A. H, Van Velde, 1. W, \& Nielen, M. W. F. (2002). Application of $1 D^{1}$ H NMR for tas non-tagered screening and compos itional anahysis of steroid cocktails a nd veterinary drug formu bations admin istered to I ives sock. journal of Pharmaccutical and Biomedical Analysis, 28,87-96.

Mallinson, E. T, Drexs, L. S., Wikon, R. T. \& Henry, A. C. (1995). Desemination of decamethasone in liver and muscle by liquid chromatogaphy and gas chroma tography/mass spectsometry. Journal of Agricul ura land food Chemistry, 43, 140-145. Mauser, H. H., Tenberken, O., Kratzsch, C., Weber, A. A., \& Pesers, F. T. (2004). Screening for library-assisted identification and full validated quantification of 22 beta. blockers in blood plasma by liquid chomatography-mass spectrometry with atmospheric pressure chemical ionization. Journal of Chromatography, 105.8
$169-181$.

Moloney, A, Al len, P, Joseph, R., \& Tarrant, V, (1991). Influence of beta-adrenergic agonists and similar compounds on growth. In A. M. Pearson, \& T. R. Duson (Eds.), Growth Regulation in Farm Animak (pp. 455-513). London: Elsevier.

Aatel, P. D. (2002). Bio seneors for me asurement of a nal yes implicated in food safery: A review. TEAC Trends in Analytical Chemistry, 21, 96-115.

Puente, M. L., (2004). Highly sensit we and a pid normal-phasechiral screen using high-performance liquid chmomatography atmos. pheric pressure ionization tandem mass spectrometry

(HPLCMSS). journal of Chromatography, 1055, 55-62.

HPLC method for the detection of 6 -methyl-2-thiouracil in cattle urine, In Pmocedings of intemational Congress in Meat Science and Technology, Baitimore, Maryland, August 7-12, (pe. 90).

Reig, M, Mora, L, Navaro, 1. L, \& Toldd, F. (2005). Method for the detection of dexamethasone in cattle drinking waser, in Proceedings of international Congress in Meat Science and Technology, Baitimors, Maryland, Augut 7-12, (pp. 90).
Roda, A., Manceta, A. C, Portanti, O., Mirasoli, M, Guardigli, M., Pasini, P., ef al. (2003). A apid and sensitive 384 well microtitre format chemiluminescert enzyme immunassay for 19 notes tosterone. Luminescence, 18, 72-78.

Sumarajecwa, U., Wei, C. L., Huang T.S, \& Marshall, M. R. (1991). Application of immunoassay in the food industry. Critical Reviews in Food Science and Nutrition, 29, $403-434$.

Shesan, P, OKeese, M, \& Smyth, M. (1991). Reversed-phase highperiormance iquid chromatogaphic determination of dese

Situ, C, \& Elliott, C. T. (2005). Simultaneous and apid desection of five banned anthiotic growth promoses by immunoassay. Analytica Chimica Acta, 529, 89-96.

Stolker, A. A. M., Scthwillens, P.L.W.I., Van Ginkel, L A., \& B rinkman, U. A. Th. (2000). Comparison of different liquid chroma sogaphy methods for the determination of corticosteroids in biological matrices. Journal of Chromatography A, 893 , oids in
$55-67$.

Stubhing, G, Tarbin, 1., Cooper, A., Shaman, M., Bigwood, T, \& Robh, P. (2005). A multi-residue cation-exchange clean up procedure for hasic drugs in produce of animal origin. Analytica Chimica Acta, $547,262-268$.

Suhren, G. \& Knapptein, K. (2004). Detection of residues of ant biotics in milk of tre atod cows by screening methods. Milchwissenschaft - Milik Science International, 59, 656-660

Thevik, M., Opiemann, G, \& Schlinzer, W. (2003). Liquid chroma togaphy/electrospay ionization tandem mass spectro. metric screen ing and corfirmation methods for $\beta_{2}$-agonists in human or equine urine, lournal of Mass S pectrometry, 38, 1197-1206.

Turnipseod, S. B., Roybal, J.E., Andesen, W. C, \& Kuck, L.R. (2005). Anahys is of avermectin and moxidectin residues in millk by liquid chroma toga phy tandem mass spectormetry using an atmos. chroma toga phy - tandem mass spectometry using an atmos. pheric. pressure chemical innization/atmospheric, pressure
photoionization source. Analytica Chimica Acta, 529, 159-165. photoionization source. Analytica Chimica Acta, 529, 159-165.
Vanoosthuyze, K. E., Van Poucke, LS. G. Deloof, A. C. A., \& Van Vamooshuryze, K. E, Van Poucke, LS. G, Deloci, A. C. A., \& Van
Peseghem, C. H. (1993). Devel opment of a high performance thin-layer chromatographic method for the multi-scroening analysis of corticosteroids. Analytica Chimica Acta, 275, $177-182$.

Van Peteguem, C, \& Daese hime, E. (2004). Residues of growth promoters, In L. MLL Nollet (Ed.), Hanchook of Food Analysis (2nd ed) (pp. 1037-1063). New Yodk: Marcel Delke:

Van Peseguem, C., Daeselaix, E. \& Hooremans, A. (2001). Residues of growth promoters. In L. M.L Nolles (Ed.), Food Analysis by HPLC (2nd ed) (ph. 965-985). New York Marcel Delber.

Van Poucke, L.S. G, Depourcq, C. C. I, \& Van Peteg hem, C. H. (1991). A quantitative method for the detection of sulphonamide residues in meat and mi lk samples with a high-performance thin layer chromatographic method. Journal of Chmomatography, 29 , layer chrom
$423-427$

Verdon, E, Couedoc, P, Rouchut, B, \& Sanders, P. (2005). Multises idue method for simulanoous desemination of ten quinolone antibacterial residues in multimatrix/multippecies a nimal tiss ues by liquid chromatography with fluorescence detection: Single baboratory val idation study. fournal of $A O A C$ Interna tional, 88, 1179-1192.

Weber, C. C, l ink, N., Fux, C, Zisch, A. H, Weher, W, \& Fussenegger, M. (2004). Brosd spectrum protein biosensors for class spec ific defoction of a nt biotics. Biofechnology and Biocngineering $99,9-17$.

White, S. (2004). Biosensors for food analysis. In L. M. L. Nollesd (Ed.). Handbook of Food Analysis (2nd ed.) (pp. 2133-2148). New Yod: Marcel-Delker. 


\section{Apéndice III:}

A chromatography method for the screening and confirmatory detection of dexamethasone Meat Science, 2006, 74, 676-680. 


\title{
A chromatography method for the screening and confirmatory detection of dexamethasone
}

\author{
Milagro Reig, Leticia Mora, José L. Navarro, Fidel Toldrá •

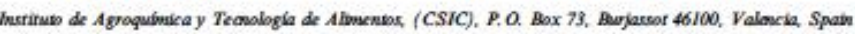 \\ Received 27 Jamuary 2006 ; received in revieed form 16 May 2006 , accepted 20 May 200
}

\section{Alstract}

Corticosteroids, such as dexamethasone, have been illegally uxed as growth promoting agents to obtain an economical benefit from increased muscle development. These substances remain in meat and other arimal products and may have negative toxic consequences for consumers. A screening and confirmatory method for dexamethasone detection in feed and drinking water in livestock has bean developed and validated. This method is based on immunoaffinity chromatography followed by reverse-phase high-performance liquid chromatrography (IAC-HPLC) with diode array detection (DAD) at $242 \mathrm{~nm}$. Flumethasone was used as internal standard.

The method has been val idated aceording to the Eutopean Union regulation 2002/657/EC for banned substances and, thus, the speo.
. ificity, deckion limit, detaction capability, reovery and repeatability have ben determinal. The decision limits $(C \mathrm{C} \alpha)$ were $26 \mathrm{ng} / \mathrm{mL}$ for water and $190 \mathrm{ng} / \mathrm{g}$ for feed while detection capabilities $(C C \beta)$ were $30 \mathrm{ng} / \mathrm{mL}$ for water and $217 \mathrm{ng} / \mathrm{g}$ for foed. The method showed good accuracy and precision. The stability of dexamethasone under frowen storage has been studied over a 3.5-month pariod. No looses wen observed, thus confiming that water samples taken by inspectors can be stored frozen for a few weeks until analysis. This method has proved to be relatively simple and useful for rapid screening and confirmation of the presence of dexamethasone in water and feed usal for meat-producing animals.

o 2006 Elsevier Lid. All rights reserved.

Keywoodve Veterinary druss; Rexidues detection; Deramethasone; Cortionsteroids; HPLC detection; Animal origin foods

\section{Introduction}

Corticosteroids, such as dexamethasone, have many physiological roles. Dexamethasone ( $9-\alpha$-fluoro-16- $\alpha$-methylprednisolone) is a synthetic glucocorticoid that is authorized for therapeutic use in veterinary medicine but its use as a growth promoting agent is banned in the European Union. Low concentrations of glucocorticosteroids are known to increase weight gain, to improve feed conversion and to have a synergetic effect with other molecules like $\beta-$ agonists or anabolic steroids (Croubels, Daeselaire, De Baere, De Backer, \& Courtheyn, 2004). Due to these effects, dexame thasone has been illegally used to obtain an economical benefit through increased muscle development. Cortico-

"Carresponding authar. Td.: +3496 3900002-2112; fax: +3496 3636301 .

E-mall addresc froldraging ocices (F. Toldrá).

0309-17401S - see front matter $\oplus 2006$ Ekevier Ltd. All rights renerved. doi:10. $1016 \mathrm{j}$ mentsi. 1006.05018 steroids are orally active so that they can be given through the feed or water, leaving no trace of percut aneous administration (Van Peteghem \& Daeselaire, 2004).

A number of methods for the detection, determination and confirmation of dexamethasone in different biological matrices like feed, urine, faeces, liver or milk have been previously reported (Cherlet, De Baere, \& De Backer, 2004; Creaser, Feely, Houghton, \& Seymour, 1998; Delahaut et al., 1997; Draisci, Marchiafava, Palleschi, Cammarata, \& Cavalli, 200I; Stolker, Schwillens, Van Ginkel, \& Brinkman, 2000). There is a noed for rapid methods of detection (Toldrá \& Reig, 2006). Recently, the performance of methods and the criteria for the interpretation of test results of official control laboratories within the European Union has been regulated in the Decision 2002/657/EC (EC, 2002).

In this paper, a simple and rapid screening and confirmatory method for the detection of dexamethasone in 
livestock feed and drinking water used in farms for meatproducing animals has been validated according to this Decision. The method is based on immunaffinity chromatography followed by reverse-phase high-performance liquid chromatography (IAC-HPLC).

\section{Materials and methods}

\subsection{Materials and reagents}

The chemical and chromatographic reagents used were of HPLC grade. Acetonitrile, ethanol, tert-butyl methyleter (TBME) and methanol were purchased from Scharlau (Barcelona, Spain). The synthetic corticosteroids dexamethasone and flumethasone were obtained from SigmaAldrich Chemie. Amino propyl $\left(\mathrm{NH}_{2}\right) \mathrm{SPE}$ cartridges were purchased from Waters (Etten-Leur, Netherlands). Immunoaffinity chromatography extraction columns containing gel with immobilised antibodies, which are specific for dexamethasone, flumethasone and betamethasone were purchased from Randox Laboratories (Ardmore, UK). Stock solutions containing $100 \mu \mathrm{g} / \mathrm{mL}$ of dexamethasone and $100 \mu \mathrm{g} / \mathrm{mL}$ of flumethasone, were prepared in methanol and stored at $-20^{\circ} \mathrm{C}$. Working solutions $(10 \mu \mathrm{g} / \mathrm{mL})$ were prepared by diluting stock solutions 10 times.

\subsection{HPLC-DAD equipment and conditions}

Chromatography was performed in a HPLC Agilent 1100 Series equipped with autosampler and diode array. The chromatographic separation was accomplished in $30 \mathrm{~min}$ with isocratic conditions on a Sinergy MAX-RP $80 \mathrm{~A}(150 \times 4.60 \mathrm{~mm}, 4 \mu \mathrm{m})$ analytical column (Phenomenex, Torrance, CA, USA). The isocratic mobile phase was pumped at $1 \mathrm{~mL} / \mathrm{min}$ flow rate. The detector was set at $242 \mathrm{~nm}$.

\subsection{Samples and fortification}

Feed samples were fortified with dexamethasone at levek between 100 and $600 \mathrm{ng} / \mathrm{g}$. Water samples, that were kept under frozen storage until analysis, were fortified at levels ranging from 15 to $150 \mathrm{ng} / \mathrm{mL}$. To each sample, the internal standard flumethasone was added as either $300 \mathrm{ng} / \mathrm{g}$ of foed or $125 \mathrm{ng} / \mathrm{mL}$ of water as used by Draisci et al. (2001).

\subsection{Procedure}

Feed was homogenised and $2 \mathrm{~g}$ were weighed. After fortification, equilibration and addition of the internal standard (flumethasone), the samples were extracted with $10 \mathrm{~mL}$ of TBME, shaked over $20 \mathrm{~min}$ and centrifuged for $10 \mathrm{~min}$ at $1000 \mathrm{~g}$. The clear TBME phase was collected and the extraction was repeated. These extracts, were applied to a $\left(\mathrm{NH}_{2}\right)$ solid phase extraction (SPE) column and eluted with $4 \mathrm{~mL}$ of methanol-water $(80: 20$, v/v).
The eluate was evaporated to dryness at $45^{\circ} \mathrm{C}$ under a stream of nitrogen and the residue resuspended in $200 \mu \mathrm{L}$ of methanol and $4.5 \mathrm{~mL}$ of water. The resuspended elutant was applied to a SPE immunoaffinity column and the procedure was performed as described by the manufacturer. The eluted solution was evaporated to dryness, resuspended in $200 \mu \mathrm{L}$ of acetonitrile-water $(30: 70, \mathrm{v} / \mathrm{v})$ and then injected into the HPLC-DAD system.

In the case of water, $5 \mathrm{~mL}$ were taken and the internal standard (flumethasone) also added before its application to the SPE-immunatfinity column.

\subsection{Stability study}

Different aliquots of dexamethasone concentrated solution $(10 \mu \mathrm{g} / \mathrm{mL})$ were prepared. One of them was analysed immediately and the remaining samples were kept under frozen storage $\left(-20^{\circ} \mathrm{C}\right)$ and analysed in triplicate after 1 , $2,3,4,9$ and 13 weeks. In a similar way, water matrix was fortified with dexamethasone at the decision ( $\mathrm{CC} \alpha)$ level and analysed in triplicate after 1, 2, 4 and 6 weeks of frozen storage.

\subsection{Analysis and validation}

The analysis for feed and water were performod following the guidelines defined in the decision 2002/657/EC (EC, 2002 ). In this way, the decision limit (CC $\alpha)$ needs to be calculated because it gives the minimum amount of analyte present in the sample that allows us to conclude that the sample is not compliant, with a $99 \%$ level of probability. The decision limit (CCa) was established by analysing 22 blank materials for water and 22 blank materials for foed and calculating the respective signal to noise ratios at the time window in which the analyte is expected. For each matrix, feed or water, the decision limit CC $\alpha$ was set as 3 times the signal to noise ratio.

The recovery was determined in two sets of 18 fortified blank samples, one set for water and one for feed. Samples were fortified with the analyte to yield concentration equivalent to $1,1.5$ and 2 times the $\mathrm{CC}$. At each level the analysis was performed with six replicates. The measured content, the \% recovery (expressed as $100 \times$ measured content/fortification level), standard deviation and coefficient of variation were determinod in each case. The repeatability and within-laboratory reproducibility were calculated by analysing 18 samples of water and 18 samples of feed fortified with the analyte to yield concentrations equivalent to $1,1.5$ and 2 times the $\mathrm{CCa}$. At each level the analysis was performed with six replicates. The within-laboratory reproducibility was performed by different operators, days and batches of chemicak. The mean concentrations, standard deviations and coefficients of variation were determined in each case.

The detection capability $(C C \beta)$ was taken as the value of the decision limit plus 1.64 times the standard deviation of the within-laboratory reproducibility of the measured con- 
Tahle 1
Recovery, repeatabiifty and within-laboratory reproduability far the analyais of dexamethasone

\begin{tabular}{|c|c|c|c|c|c|c|c|c|c|c|}
\hline \multirow[t]{2}{*}{ Level (ppb)" } & \multicolumn{3}{|c|}{ Recovery } & \multicolumn{3}{|l|}{ Repeatability } & \multicolumn{3}{|c|}{ Within-lab reproducibility } & \multirow{2}{*}{$\begin{array}{l}\text { Calaulated reproduibifity } \\
\mathrm{CV}(99)\end{array}$} \\
\hline & $\%$ & SD & $\mathrm{CV}(\%)$ & $\begin{array}{l}\text { Mean canc. } \\
(\mathrm{ppb})^{*}\end{array}$ & $S D$ & $\mathrm{CV}(\%)$ & Mean conc. (ppb) & SD & $\mathrm{CV}(\%)$ & \\
\hline 26 & 105.10 & 1.73 & 6.33 & 27.90 & 205 & 735 & 26.96 & 1.69 & 6.27 & 27.7 \\
\hline 39 & 98.50 & 108 & 2.80 & 44.94 & 0.73 & 1.62 & 39.61 & 289 & 730 & 26.1 \\
\hline 52 & 94.50 & 1.09 & 2.22 & 59.25 & 286 & 4.83 & 54.65 & 4.24 & 7.76 & 250 \\
\hline 190 & 108.9 & 15.3 & 7.4 & 205.06 & 14.45 & 7.05 & 196.15 & 17.35 & 8.85 & 20.5 \\
\hline 285 & 118.2 & 7.2 & 2.1 & 30281 & 10.59 & 3.50 & 314.14 & 18.97 & 6.04 & 19.3 \\
\hline 350 & 100.7 & 16.8 & 4.1 & 415.35 & 14.26 & 3.43 & 430.91 & 34.66 & 8.04 & 18.5 \\
\hline
\end{tabular}

phk ng/mL. for water samples and $\mathrm{ng} / \mathrm{g}$ for feed samples.

- Reproduability caloulated by the Harwitz equation as reference for the precision of the method.

tent. The detection capability (CC $\beta$ ) gives the minimum amount of analyte present in the sample that can be detected, identified or quantified, with a $95 \%$ level of probability. The precision was checked by calculating the reproducibility coefficient of variation (CV) at the respective analysed mass fractions using the Horwitz equation, $\left.\mathrm{CV}=2^{(1-0.5 l o g} \mathrm{C}\right)$ where $C$ is the mass fraction expressed as a power of 10 (see calculated values in last column of Table 1). Then, acceptable procision is achieved when the within-laboratory reproducibility $\mathrm{CV}$ is lower than the calculated reproducibility $\mathrm{CV}$.

\section{Results and discussion}

Synthetic glucocorticoids dexamethasone ( $9 \alpha$-fluoro16a-methylprednisolone), betamethasone (9x-fluoro-16xmethylprednisolone) and flumethasone (9a-difluoro-16x- methylprednisolone) belong to a group of drugs frequently administered in livestock production (Van den Hauwe, Schneider, Sahin, Van Peteghem, \& Naegeli, 2003). The structural formulas for these three substances are shown in Fig. 1.

The analysis of dexamethasone in a complex matrix like feed required an adequate clean-up of the feed extracts. So, the assayed analytical method consisted of three steps: Liquid-liquid extraction, sample clean-up through solid phase extraction cartridges and immunoaffinity chromatography followed by HPLC analysis. The first step, consisting of liquid-liquid extraction, was performed using tert-butyl methyl ether (TBME). This solvent gave a good recovery and was adequate in terms of background absorbance during detection after chromatographic separation as reported by other authors (Stolker et al., 2000). The second step consisted of an amino propyl $\left(\mathrm{NH}_{2}\right)$ solid phase

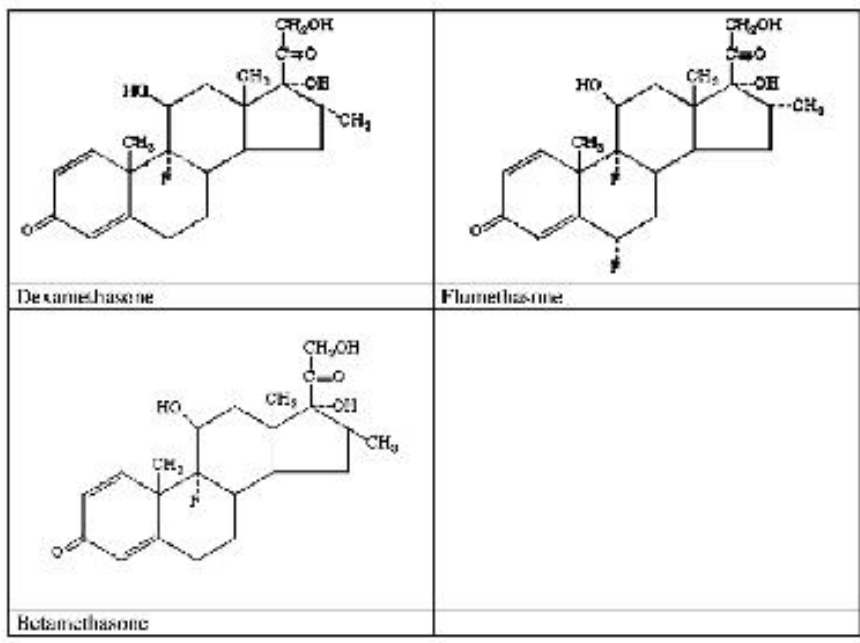

Fig. 1. Chemical structures of dexamethasone, betame thasone and flumethasone 
A
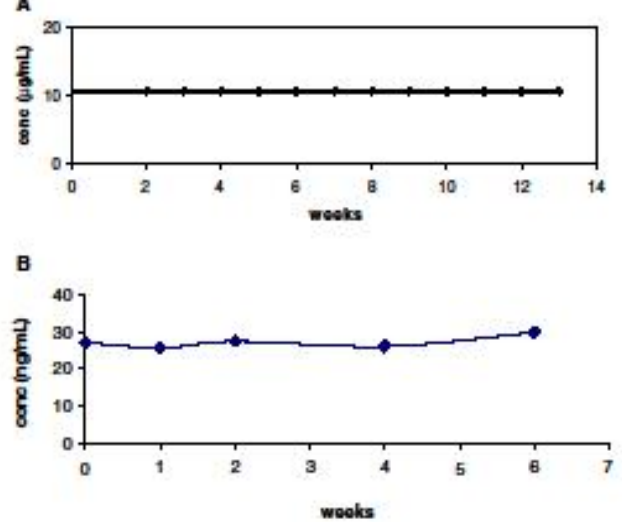

Fig. 2. Stability of deramethasone: (A) deramethasone concentrated solution $(10 \mu \mathrm{g} / \mathrm{mL}$ ) kept under frozen starage (B) dexamethasone in water matrix fortified at the $\mathrm{COx}$ level.

extraction and the third step was injection through an immunoaffinity chromatography column, which is a very useful technique for sample clean-up and analyte concentration (Van Peteghem, Daeselaire, \& Hecremans, 2001). The partially purified analyte minimizes the interfering compounds, increases the signal to noise ratio and enhances the specificity (Antignac, Le Bizec, Monteau, Poulain, \& Andre, 2001). The analysis of drinking water,

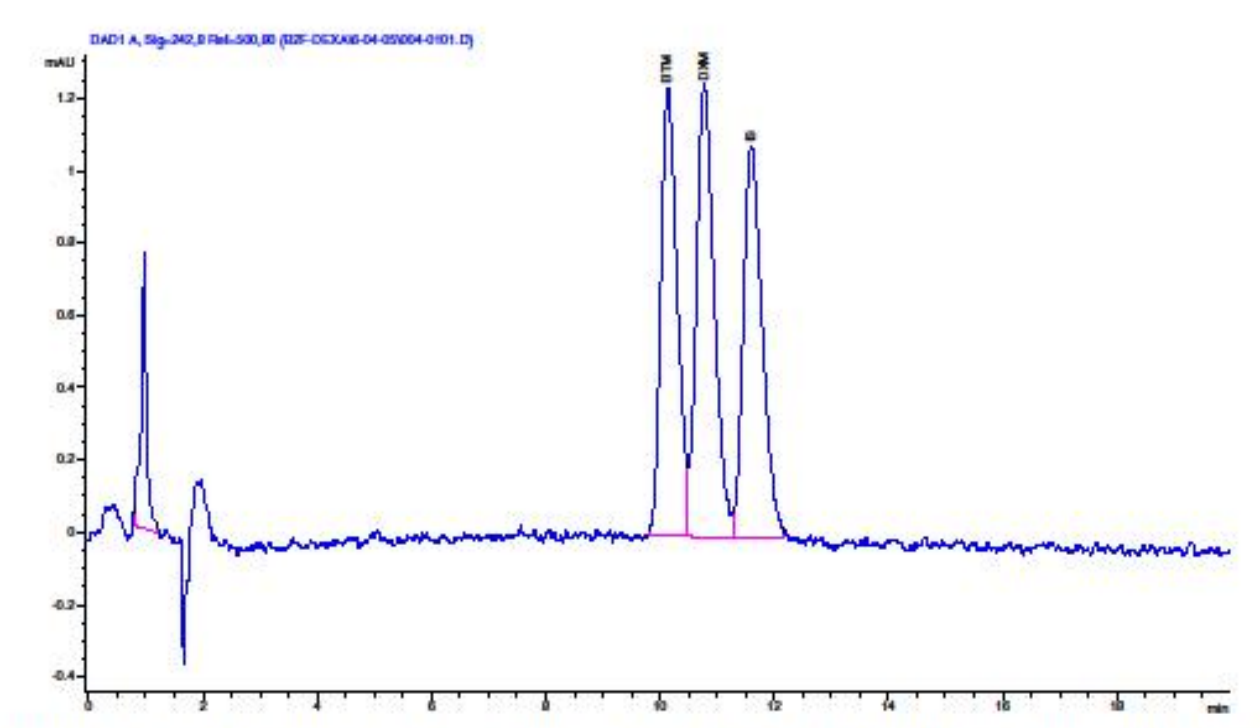

Fig. 3. Chromatogram of dexamethasone and closely related substancer. Reten fion times 10.14 , 10.8 and $11.60 \mathrm{~min}$ corresponded to hetamethasone (BTM), derame thasone (DXM) and flumethasone (IS), respectively. which is a clean matrix, only required the immunoaffinity chromatography (IAC) step (Fig. 2).

The stability of dexamethasone solutions kept under frozen storage was very good. Stock solutions $(10 \mu \mathrm{g} / \mathrm{mL})$ maintained the dexamethasone concentration during 3.5 months. In a similar way, fortified water with dexamethasone at $\mathrm{CC} x$ level also showed good stability, demonstrating that water samples taken by inspectors may be kept frozen for several woeks without affecting its content.

The analysis showed a very good specificity, being able to discriminate very well between the analyte (dexamethasone) and closely related substances like betamethasone and flumethasone (internal standard). A chromatogram showing the separation of these three substances is shown in Fig. 3. The performance criteria for liquid-chromatography with DAD detection, as fixed in the EC decision (EC 2002 ), were accomplished. The retention time of the analyte was over twice the retention time corresponding to the void volume of the column. The ratio of the retention time of the analyte in the matrix to that of the internal standard was the same as that of the calibration standard (pure dexamethasone) to within $\pm 2.5 \%$. The detection by diode array was necessary for confirmatory purposes by comparing the spectrum of the analyte at the dexamethasone elution time with the spectrum of the pure dexamethasone. The absorption maxima in the spectrum of the analyte in the matrix was at the same wavelength as that of pure dexamethasone within $2 \mathrm{~nm}$.

After the analysis, the limits of decision (CC $\alpha)$ were established as $26 \mathrm{ng} / \mathrm{mL}$ for water and $190 \mathrm{ng} / \mathrm{g}$ for feed. 
The detection capabilities (CCB) were found to be $30 \mathrm{ng} /$ $\mathrm{mL}$ for water and $217 \mathrm{ng} / \mathrm{g}$ for foed. The rocovery and repeatability studies were performed with matrix samples fortified at $1,1.5$ and 2 times the $\mathrm{CC} \alpha$. So, water samples were fortified at 26,39 and $52 \mathrm{ng} / \mathrm{mL}$ and foed samples were fortified at 190,285 and $380 \mathrm{ng} / \mathrm{g}$ (see Table 1). The recoveries were much higher than those reported for muscle and liver (Mallinson, Dreas, Wilson, \& Henry, 1995) but were between $-10 \%$ and $+10 \%$ thus showing good accuracy of measurement. Only the feed sample at $285 \mathrm{ng} / \mathrm{g}$ was out of that range. The within laboratory reproducibility was also performed by different operators, days and batches of chemicals using the same levels of fortification. The resulting mean concentrations standard deviations and coefficients of variation were determined in all cases and are shown in Table 1. Feed samples gave worse repeatability and within-laboratory reproducibility than water at the assayed level, which is logical because foed is a more complex matrix. However, the precision of the method was good for both matrices, water and feed, at all the assayed level because the obtained experimental withinlab reproducibility CVs were less than half, the respective calculated reproducibility $\mathrm{CV}$ s as can be observed in Table 1.

\section{Conclusions}

A method for the analysis of dexamethasone in cattle drinking water and feed based on immunoaffinity chromatography (IAC) followed by reverse-phase high-performance liquid chromatography (RP-HPLC) has been validated using water/food fortified at levels up to $150 \mathrm{ng}$ $\mathrm{mL}$ for water and $380 \mathrm{ng} / \mathrm{g}$ for foed. The main recovery was $99.4 \pm 1.3 \%$.and the method proved to have good accuracy and precision. The decision limits (CC $\alpha$ ) were $26 \mathrm{ng} / \mathrm{mL}$ for water and $190 \mathrm{ng} / \mathrm{g}$ for feed while detection capabilities (CCB) were $30 \mathrm{ng} / \mathrm{mL}$ for water and $217 \mathrm{ng} / \mathrm{g}$ for feed. Specificity, sensitivity and repeatability have also been validated using this protocol. This method has proved to be relatively simple and useful for a rapid screening and confirmation of the presence of dexamethasone in water and foed for meat-producing animals.

\section{Acknowledgement}

Grant from Conselleria de Agricultura, Pesca y Alimentación (Generalitat Valenciana, Spain) is acknowledged.

\section{References}

Antignac, L.P, Le Bizec, B, Monteau, F, Poulain, F, \& Andre, F. (2001). Mul6-residue extraction-purification procedure for cortionst roids in hiological simples for efficient control of their misure in Givestock production. Jownal of Clevomatography B, 757, 11-19.

Cherlet, M., De Buere, S., \& De Bucker, P. (2004). Quantitative determination of dexamethasone in bovine milk by hiquid chromatog. raphy-atmospherio pressure chenical ionimation-tandem mass spectrometry. Jownal of Chromatognaphy B, 805, 57-65.

Creaser, C. S. Felly, S. J., Houghton, E, \& Seymour, M. (1998) Immunoaffinity chromatography ocmbined on-line with high-per formance liquid chromatography mass spectrometry for the determination of corticostercida. Jownal of Chromatography $A$ 794, 37-43.

Croukek, S., Duesed aire, E, De Buere, S., De Bucker, P, \& Courtheyn, D. (2004). Feed and drug residues. In W. Jeneen, C. Devine, \& M. Dikemann (Eds.), Encydopotia of Meat Sckeness (pp. 1172-1187) Landon, UK: Elevier.

Delahaut, Ph, Jacquemin, P., Colemonts, $Y_{7}$ Duboia, M, De Graeve, I. \& Deluyker, H. (1997), Quantitative determination of several syn thetic corticosteroids by gas chromatography mass spectrometry afte corticasteroids by gas chromatography mass spectrometry after
purifiontion by immunoaffinity chromatography. Journal of Chroma. purification by immunaaf
tography $B, 696,203-215$

tography B, 696, 201-215.
Draisci, R. Marchiafrva, C., Palleschi, L, Cammarata, P. \& Cavalli, S. Drainci, R, Marchiafrva, C, Pal leschi, L, Cammarata, P., \& Cavali, S
(2001). Accelerated solvent extraction and hiquid chromatography tandem mass spectrometry quantitation of corticosteroid residnes in bovine tiver. Jownal of Chromatography B, 758, 217-223.

EC (2002). Commixion Decision implemen fing Council Directive 96/23/ EC concerning the performance of analytical methods and the interpretation of results. Offical Jaynal of the European Communirises, 178.2002

Mallinem, E. T., Dreas, I. S, Wikon, R. T. \& Henry, A. C (1995) Determination of deramethesone in liver and mucke by hiquid chromatography and gas chromatography/mass spectrometry. Jownal of Agriculnural and Foad Ohemistry, 43, 140-145.

Stoller, A. A. M., Sch will lens, P. L. W. I., Van Ginkel, L. A, \& Brinkman, U. A. Th. (2000). Comparison of different hiquid chromatography methods for the determination of orrtionter oids in biological matri cer. Journal of Chromatography A, 893, 55-67.

Toldrí, F, \& Rag, M. (2006). Methods for rapid detection of chemion and veter inary drug residues in animal foods. Trands in Food Screpone and Techuabogy, 17, 4\$2-489.

Van den Hauve, O Schneider, M., Sahin, A., Van Peteghem, C, s Naeseli, H. (2003). Immunochemioul screening and liquid chromatographictandem mass spectrometric confirmation of drug residues in edible tissues of calves injected with a therapeutio dose of thesynthetic edible tissues of calves injocted with a therapeutio dose of the syn thetio glucocorbicoids dexamethas one and flu
ture and Food Chavisoy, 51, 326-330.

Van Petzghem, C, \& Daeselaire, E (2004). Residues of grouth promoters In L. M. L. Nollet (Ed), Handhook of Food Analysir (2nd of (pp. 1037-1063). New York: Marcel Delker Inc.

Van Petsghem, C., Daeselaire, E, \& Heeremans, A. (2001). Residues of groath promoters. In L M L Nollet (Ed). Houchook of ford analysis by HPLC (2nd ed) (pp. 965-985). New York Marcel Dekleer Inc. 


\section{Apéndice IV:}

Liquid chromatography for the rapid screening of growth promoter residues in meat. Food Analytical Methods, 2008, 1, 2-9. 


\title{
Liquid Chromatography for the Rapid Screening of Growth Promoters Residues in Meat
}

\author{
Milagro Rekg + Fidel Toldrá
}

Recaived 19 September 2007/Accopted: 24 Oetsob 2007/Published online 29 Decemba 2007

Recaved, 19 September $2007 /$ Accopted. 24 Octob

Abstract The detection of growth promoter residues in meat requires rapid and sensitive methods for an effective scroening before further confimation with more expensive and time-consuming sophisticated instrumentation. The presence of these residues in meat would constitute a risk for consumers' heatth, and cument European Directives establish the mechanisms for screening and confimation of

all these residues in foods of animal origin. The large amount of samples and the diversity of residues to be analyzed make easy, rapid, and sensitive analytical methodologies necessary for screening. This manuscript presents the developments in liquid chromatography for its use as screening technique and rapid detection of growth promoter residues in meat

Keywords Growth Promoters. Veterinary Dnigs . Residues Detection - Screening Methods - Meat Liquid Chromatography. HPLC

\section{Introduction}

In general, growth promoters constitute a large group of substances that are illegally added to improve feed

\section{Raig}

hscitus Universitario de Ingenieria de A fimentrs para el Desarollo, Polyterhnical University of Valencin.

Camino de Vera s/n,

46022 Vilencis Spain

F. Tolati(घ)

hstituro de Agroquimica y Tecnologia de Alimentos (CSIC).

PO Box 73, 46100 Burjassor, Valencia, Spin

omail: foldragintacsices

conversion efficiency and increase the lean to fat ratio in animals The protein deposition is usually linked to fat utilization that decreases the fat content in the carcass and increases meat leanness Lone (1997). An usual practice to avoid an effective analytical detection consists in the ure of "cocktaik" or mixtures of low amount of several substances, for instance, $\beta$-agonists (clenbuterol) and corticosteroids (dexamethasone) andior anabolic steroids. The important issue of these substances is that they may remain in all animal-treated derived foods and can constitute an important health risk for consumers (Reig and Toldrá 2007, 2008a). Some of the reported effects observed in animals include genotoxic, immunotoxic, carcinogenic, of endocrine effects and therefore pose a risk to consumer Recently, the European Food Safety Authority has recently issued an opinion about substances with hormonal activity, specifically testosterone and progesterone, as well as trenbolone acetate, zeranol, and melengestrol acetate EFSA (2007). Furthemore, when antibiotics are used as growth promoters, they may give rise to allergic reactions and emergence of drug-resistant bacteria Cinquina et al. (2003) and/or selection of resistant bacteria in the gastrointestina tract and disnuption of the colonization barrier of the resident intestinal microflora Cemiglia and Kotarski (2005), which can increase its susceptibility to infection by pathogens like Salmonella spp. and Escherichia $c a l$ (Cemiglia and Kotarski (1998). Anticoccidials may be used in poultry not only to prevent and control coccidiosis a contagious infection by parasites, but may also be used as a growth promoter leaving coccidiostat residues in the products, and humans may be susceptible to its toxic effects Hagren et al. (2005). Thus, the residues of all these substances mus be monitored in foods of animal origin Croubels et al (2004)

\section{Antrox}


Official Regulations for the Control of Growth Promoters

The use of substances having homonal of thyreostatic action as well as $\beta$-aganists is bannod in the European Union (EC 1996). A list with main groups and some representative substances is shown in Table 1. Group A inchudes unauthorized substances having anabolic effect, and group B inchudes veterinary drugs some of them having established maximum residue limits (MRL).

Table 1 List of subctances having mabolio effect belonging to grouss $A$ and $B$ acoording to Cormail Directive 96/23/EC (EC 1996) and some represatative substances fir exh group

Rquesentative substmos

\begin{tabular}{|c|c|}
\hline Stilhenes & $\begin{array}{l}\text { Diethy lestillbestrol, herestrol, } \\
\text { dienestol }\end{array}$ \\
\hline Antithyroid agents & Thiourails \\
\hline \multicolumn{2}{|l|}{ Steroids } \\
\hline Androgens & Trenbolme acarte \\
\hline Gestagens & Meleng etsol aceture \\
\hline Estrogens & $17-\beta$ estndiol \\
\hline Rescroyálic acid lactones & Zeanol \\
\hline Beta-agonists & $\begin{array}{l}\text { Clan buterol, mabuterol, sal butumol, } \\
\text { mapentarol, tabutaline, cimatarol, } \\
\text { tulobutarol, bromo buterol }\end{array}$ \\
\hline Other compounds & $\begin{array}{l}\text { Nitrofurans (nitrofuramne, nitrofurm toin, } \\
\text { furwolidone, furaltadone), } \\
\text { chloramphonicol }\end{array}$ \\
\hline \multicolumn{2}{|l|}{ Group B: Veterinary dngs } \\
\hline $\begin{array}{l}\text { Antibxterial substances } \\
\text { Sulfonmides and } \\
\text { quinolones }\end{array}$ & 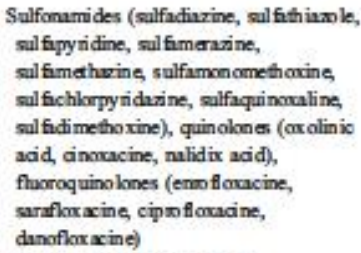 \\
\hline $\begin{array}{l}\text { Other vatainary drugs } \\
\text { Antihelmintics }\end{array}$ & 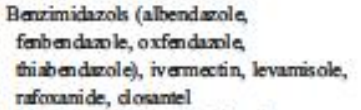 \\
\hline $\begin{array}{l}\text { Anticocaidiak, induding } \\
\text { nitroimideroles }\end{array}$ & $\begin{array}{l}\text { Nitroimidanoles (metronid wrole, } \\
\text { dimetridızole, tinidamole, nimarzole, } \\
\text { flunidunole, ronidırole), Hal ofiginone }\end{array}$ \\
\hline $\begin{array}{l}\text { Cahmmites and } \\
\text { pyrethroids }\end{array}$ & Carhumutes, pyrethroids \\
\hline Sedutives & $\begin{array}{l}\text { Aceqromarine, waperone, } \\
\text { chlorpromurine, xylarine, } \beta \text {-blodker } \\
\text { carawlol }\end{array}$ \\
\hline $\begin{array}{l}\text { Non-steroidal anti- } \\
\text { inflammatory drugs }\end{array}$ & Fhanixin \\
\hline $\begin{array}{l}\text { Other pharmacologically } \\
\text { active substmaes }\end{array}$ & Dexamethasone \\
\hline
\end{tabular}

Adapted finm Toltri and Reig (2006)
Official inspections and analytical services take care of the control of residues of these substances following EC Directive $96 / 23 / \mathrm{EC}$ on measures to monitor certain substances and residues in live animals and animal products (EC 1996). Analytical methodology, including criteria for identification and confirmation, for the monitoring of compliance was given in Decisions 93/256/EEC (EC 1993a) and 93/257/EEC (EC 1993b), and more recently, the Commission Decision 2002/657/EC (EC 2002) implemented Council Directive 96/23/EC (EC 1996) by providing rules for the analytical methods to be used in testing of official samples and specific common criteria for the interpretation of analytical results of official control laboratories for such samples. New concepts like the decision limit $(C C \alpha)$ and the detection capability $(C C \beta)$ for assessing non-compliant samples were inchuded in this Directive. $C \mathrm{C} \alpha$ is defined as the limit at and above which it can be conchuded with an error probability of $\alpha$ that a sample is non-compliant, and $C C \beta$ is the smallest content of the substance that may be detected, identified, and/or quantified in a sample with an error probability of $\beta$. Both $C C \alpha$ and $C C \beta$ are important for the daily control of the performance of a specific method, using a specific instrument and under specific laboratory conditions. In this way, it is possible to estimate the level of confidence in the routine analytical result

Controk are based on screening, and those suspocted non-compliant samples are then confimed through other sophisticated methodblogies and analytical instrumentation for accurate characterization and confirmation. For instance, when mass fragments are measured, the criteria established in the Commission Decision 2002/657/EC (EC 2002) states that four identification points would be required for substances in group $A$, whereas those in group B would only require a minimum of 3 . The number of identification points eamed per ion depends on the type of mass spectrometric echnique.

\section{LC-Based Screening Methodologies}

The large amount of meat samples, the diversity of substances potentially used as growth promoters, and the relatively short available time, makes necessary to use screening methodologies for routine monitoring of the meat samples. According to the Commission Decision 2002/657/EC (EC 2002), the methods must be validated and have a detection capability with an error probability $(\beta)$ lower than $5 \%$. The screening method must be capable to detect the residue below the MRL if the substance has such limit. Due to the large number of samples, screening methodblogies must have a large throughput, low cost, and enough sensitivity to detect the analyte with a minimum of false negatives (Toldrá and Reig 2006). 


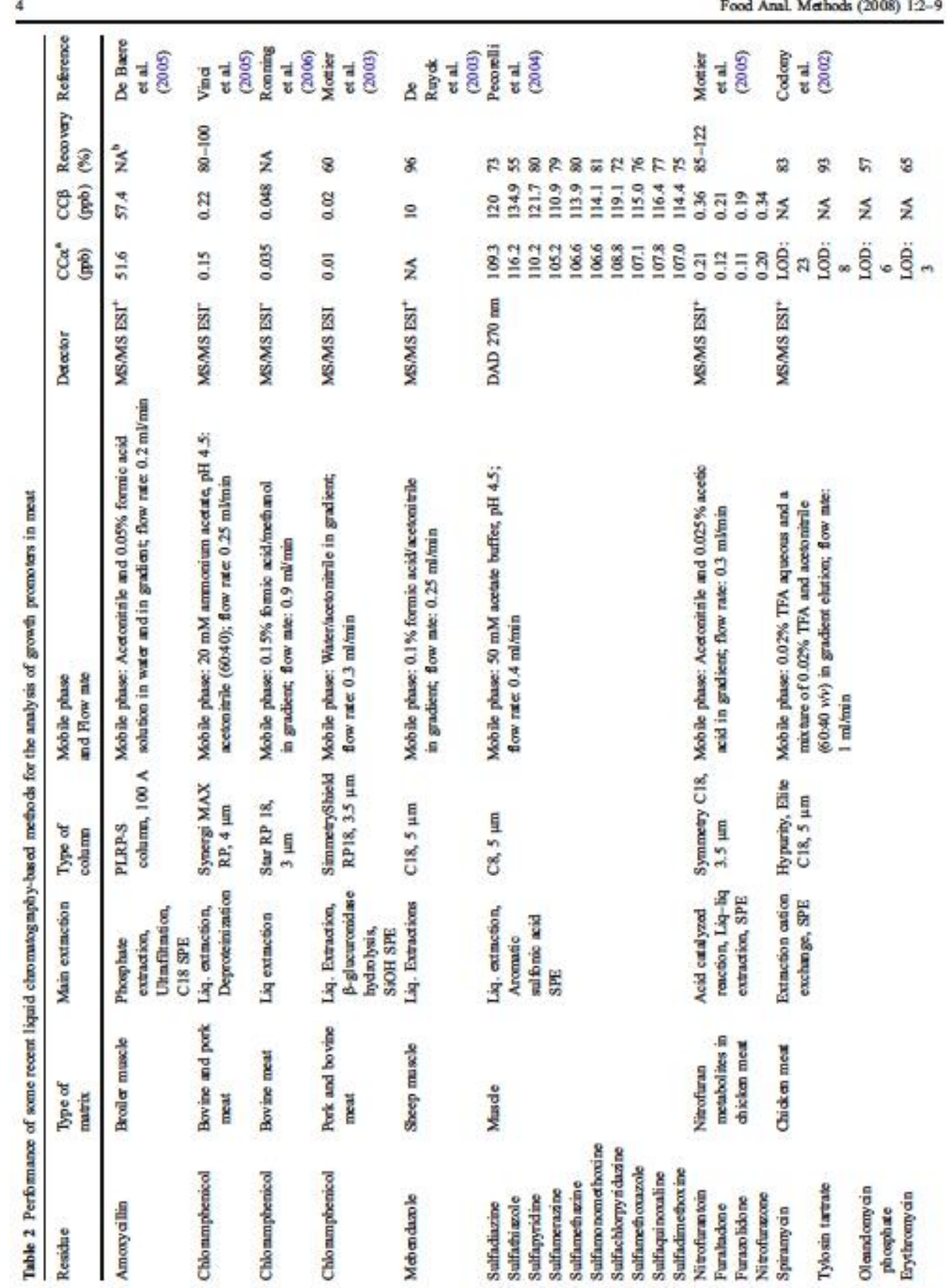

\section{anserse}




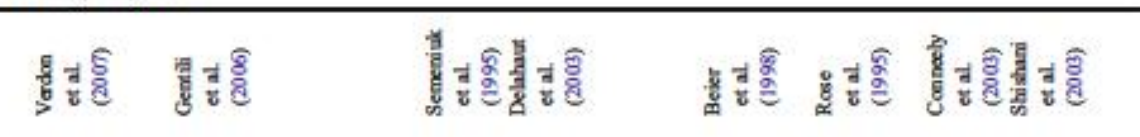

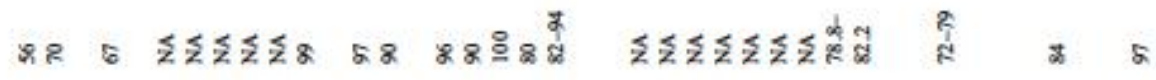

敌手

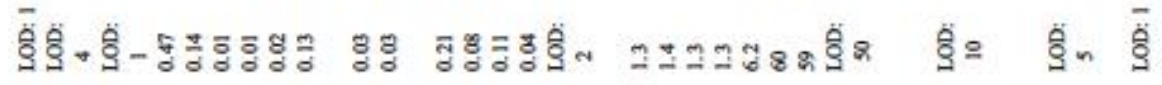

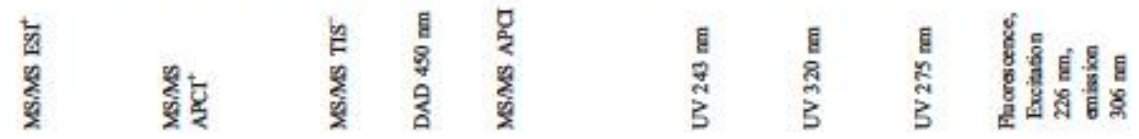

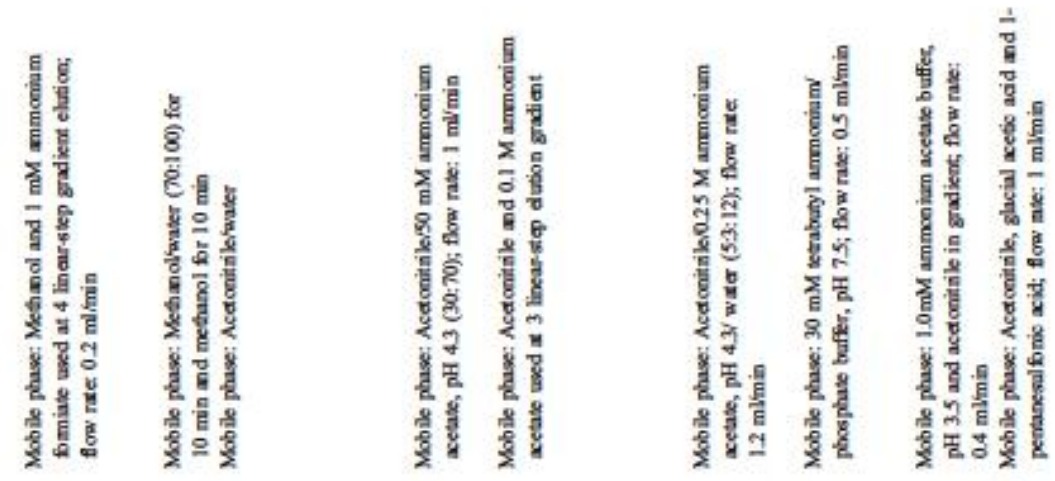

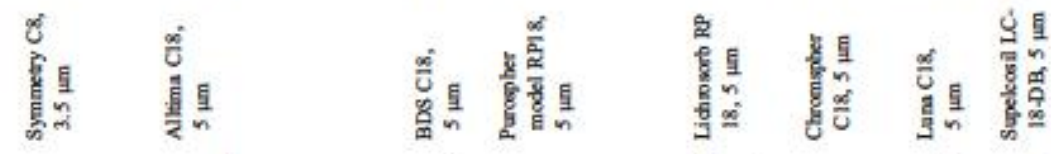

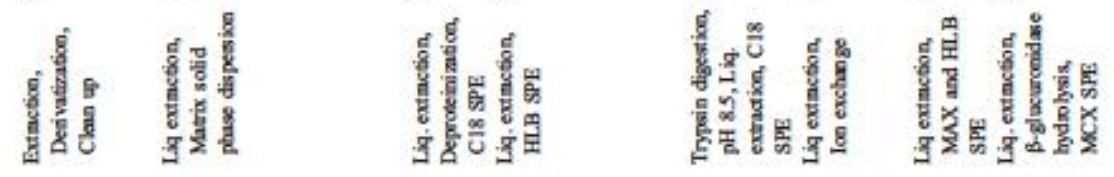

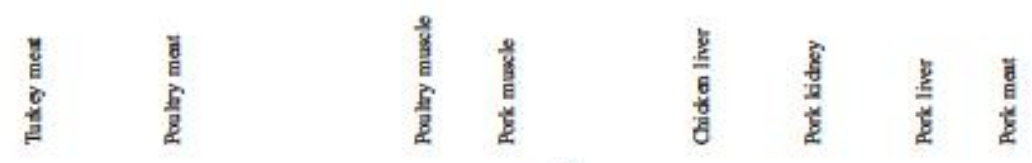

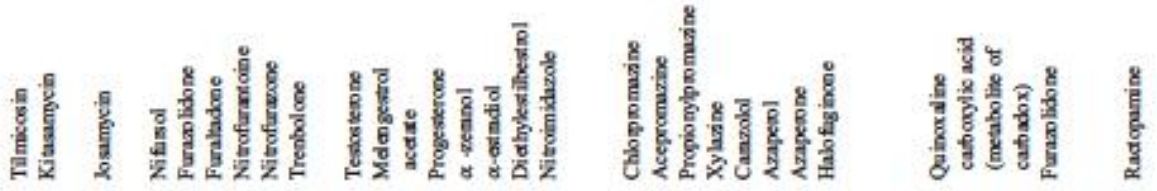


Compliant samples are accepted, but those resulting as noncompliant must be further analyzed using confimatory methodk. Some fake non-compliant results may be acceptable because they will be further analyzed for confimation, but the number of false non-compliant results must be reduced to a minimum.

There are different techniques available for the screening of residues in foods of animal origin, but the limits of detection will depend on the previous extraction and cleanup of the sample (Reig and Toldra 2008b).

The use of high performance liquid chromatography (HPLC) expanded during the 1990s as an efficient separative technique (Van Peteguem et al. 2001). It has got expandod use for screening of non-volatile residues due to the possibility to analyze a good number of residues in a sample in relatively short time that can be even reduced with recent high-speed HPLC developments with packaging materials of reduced particle size and automation (Aristoy et al. 2007). It has been applied to the detection of sulfonamides, $\beta$-lactam antibiotics, quinolones, aminoglycosides, chloramphenicol, ionophores, nitrofurans, and macrolides (Niessen 1998). Furthermore, HPLC has been reported as a multi-residue technique for the determination of ten quinolone antibacterial residues (Verdon et al, 2005; $\mathrm{K}$ irbis et al. 2005), five nitrofurans (Verdon et al, 2007), anabolics (Koole et al. 1999), mono- and dibasic penicillins (Boison and Keng 1998), and sulfonamides, benzimidacoles, nitroimidazoles, and nitrofurans in animal tissues (Cooper et al. 1995).

The ability to detect a perticular analyte depends on the type of column (usually reverse phase) and detector (mainly absorbance or fluorescence) used. In some cases, it is necessary to perform chemical modifications of the analyte to render chromophore, fluorescent, or UV-absorbing compounds. Typical methodology used for the detection of multi-residues in meat consist in a solid-phase extraction clean-up followed by filtration and injection into a reverse-phase HPLC with diode amay detection. This methodblogy has been used for the detection of a good number of residues like veterinary drugs (Cooper et al. 1995; Aerts et al. 1995; Horie et al. 1998; Kao et al. 2001; Wang et al. 2006), anabolic steroids (Gonzalo-Lumbrearas and hquierdo-Homillos 2000; De Cock et al. 2001), quinolone residues (Verdon et al. 2005), and corticosteroids (Shearan et al. 1991; Stolker et al, 2000; Reig et al, 2006; Mallinson et al. 1995) in meat.

\section{LC-Based Confimatory Analysis}

The use of liquid chromatography coupled to tandem mass spectrometry has expanded since the development of adequate atmospheric pressure interfaces able to couple the mass spectrometer to the HPLC (Balizs and Hewitt 
2003). Applications to the analysis of veterinary dnug residues have been recently reviewed (Niessen 1998; Balizs and Hewitt 2003; Gentili et al, 2005). LC-tandem mass spectrometry has also been proposed as a simultaneous screening-confimatory technique (Thevis et al, 2003; Maurer et al. 2004). The strategy may be based on multiple reaction monitoring of one precursor ion, transition product ion for each tested residue (i.e., steroids), using internal standards to allow for quantitation Hew itt et al. (2002). This is feasible when the instrumentation is available, although its cost is high. However, the usual practice is to confim with mass spectrometry detection only those presumed noncompliant samples due to the high cost of these equipments and the variability of substances to confirm. The coupling of mass spectrometry (MS)-MS can reduce the analysis time. The usual practice is the use of LC-MS with either atmospheric pressure chemical ionization (APCL; Maurer et al. 2004; Puente 2004) or electrospray ionization (ESI; Thevis et al. 2003; Hewitt et al, 2002). Both ionization techniques produce negligible fragmentation. ESI appears to be more sensible to matrix effects than APCI Dams et al (2003). Some exsmples of analysis of growth promoter residues in meat are shown in Table 2, CC $\alpha, C C \beta$ and the recovery, which is the percentage of the true concentration of a substance recovered during the analytical procedure, are included in such table.

There is a phenomenon in LC-MS, known as ion suppression, which must be taken into account when analyzing compounds in complex matrices like meat. Ion suppression appears to be due to the presence of matrix interfering compounds that appear to reduce the detection capability of the analyte and the repeatability Antignac et al. (2005). Ion suppression can be prevented through appropriate preparation, improved purification, and cleanup of the sample Antignac et al, (2005).

In summary, the continuous development of new substances with anabolic properties and used as growth promoters and the low levels to be detected due to the extended practice of "cocktails" (mixtures of low amounts of several substances exerting a synergistic effect) makes residues detection a difficult task, In addition, control laboratories must face a lange number of samples with a high variety of residues to analyze. LC consitutes an attractive technique to be used for the screening of relatively polar, non-volatile growth promoters in meat, contributing to a reduction in time and effort needed, as only those presumed non-compliant samples are submitted to further confirmatory analysis.

Adknowled gements Gant from Consellaria de Agricultura, Pesca y Alimentación from Goneralita Valenciann is fully adknowledgo Work propared within the Unidad A sociada LAD (UPV)-UTA (CSKC) framework
References

Aerts MML, Hogenboom AC, Brinkman UAT (1995) Analytical trategies for the screening of veterinary drugs and their nesidues in edible products. J Chrom B Biomed Appl 667:1-40

Antignac IP, de Wash K, Montexil F, De Bribunder H, Andre F, Le Bizo B (2005) The ion suppression phenomenon in liquid chomatogaphy-mass spectrometry and its consoquences in the field of residue malysis, And Chim Acta 529:129-136

Aristoy MC, Reig M, Tolda F (2007) Rapid liquid chromatognaphy techniques for detection of key (bio)chemical marken. In: Nollet LMI., Toltti F (eds) Advances in food dingnostics. Blackwell, Ames, IO, USA, Pp 229-25]

Balis G, Hewitt A (2003) Dearmination of vacrinary drug sesidues by hiquid chromisography and tandam mas spectromatry. Anal Chim Acta 492:105-131

Beier RC, Dutho TJ, Buckley SA et al (1998) Detection of halofiginone residues in chicken liver tissue by HPLC and a monochnal based immunossay. J Agrie Food Ohem 46:10491054

Boison 10, Keng LJY (1998) Multizesidue liquid chromatognghy method for determining residues of mono and dihasio penicillins in bovine muscle tissue. J AOAC Int 81:1113-11 20

Cerniglia $C E$, Kotanki $S$ (1998) Evaluation of veterinary dmig rexidues in food for their potential to affect human imtestinal miaroflon. Regul Tox Pharmacol 29:238-261

Cerniglin CE, Kotarski S (2005) Approaches in the safety evaluntions of veterinary antimicrobial agonts in food to detemine the effeds on the human intestinal microflora. J Vet Pharmacol Therap 28:3-20

Ginquina AL, Roberti P, Gianeti L, Longo F, Drisai R, Fagiolo A, Brizioli NR (2003) Determination of enrofloxacin and its metabolite ciproflocadin in goat milk by high-performance liquid homatognphy with diodo-array datation. Optimintion and validation. J Chrom A 987:221-226

Codony R, Compano R, Grnados M, Gaxin-Regueiro JA, Pant MD (2002) Residue andysis of marrolides in poultry musele by liquid chromatogaphy-electroggray max gectrometry. I Chrom A 959:131-141

Comnecly A, Nugant A, OKeeffe $M$ a al (2003) Isolation of bound residues of nitrofunan drugs from tissue by solid phrse extraction with detamination by liquid chromatography with UV and tandem mass spectrometio detaction, Anal Chim Act 483.91-98

Cooper AD, Creaser CS, Frrington WHH, Tatin JA, Sherrer G (1995) Development of multi-residue methodology for the HPLC detemination of veterinary drugs in animal tissues. Food Add Contam 12:167-176

Croubek S, Dreselaire E, De Bere S, De Backer P, Courtheyn D (2004) Feed and drug residues. In: Jensen W, Devine C, (2004) Feed and dnug residues In: Jensen W, Devine C, London, UK, pp 1172 -1187

Dams R, Huestis MA, Lambert WE, Maphy OM (2003) Marix effeats in bio-andlysis of illicit drugs with LC-MS/MS: Influence of ionization type, sample preparzion and biofluid. $\mathrm{J} \mathrm{Am} \mathrm{S} \propto$ Mass Spectrom 4: 1290-1294

De Bacre S, Wascink P, Coubels S, de Boeva S, Bart K, de Badker $P(2005)$ Quntitative liquid chromatognghio mass spedrometric malysis mmiallin in troiler edible tissues. Anal Ohim Acte 529:221-22?

De Cock KuS, Dalbdke FT, Van Eenoo P, Desmet N, Roek K, De Backer P (2001) Detection and dearmination of anabolio steroids in matribional supplements, J Pharm Biomed Anal 25:843-852

De Rurydk H, Daeseleire E, De Ridder H, Van Renterghem R (2003) Liquid chromato graphicelectrospay tandem mass spectsometric 
method for the detemination of mebendarole and its hydrolysed and reluced metabolites in sheep masde Anal Chim Acta 483:111-123

Dedahat Ph, Lovarx C, Eloy P, Duhois M (2003) Vahidation of a method for detecting and quntifying tanquillises and a $\beta$. blocker in pig tissues by liquid chromiography-tandem mas spectrometry. Anal Chim Act 483/335-340

EC (1993a) Commission Deasion 93/256/EEC of 14 Mry 1993 laying down the methods to be used for detecting residues of
substances having hormonal or a thyreostrtic action. Off J Eur Comm L $118 \times 64$

EC (1993b) Commission Decision 93/256/EEC of 15 April 1993 laying down the refierence methods and the list of the national laying down the refierence methods and the list of the national reference
$118: 730$

EC (1996) Council Directive 96/23/EEC of 29 April 1996 on measures to monitrr certain substances and residus thereof in live animals and mimal products. Off J Eur Comm L. 125:10

EC (2002) Commission Decision 2002657/EEC of 17 August 2002 implementing Council Directive 96/23/EC conceming the per fomance of the anahytical methods and the imerpretation of resulk. Off J Eur Comm L. 22 1:8

EFSA (2007) Opinion of the sciantific panel on contaminants in the food chain on a request from the Europen Commission related to hormone residues in bovine meat and meat product. The ERSA J 510:1-62

Gentili A, Perre D, Markese S (2005) Liquid chromatography. tandem mass spectromatry for porforming confirmatory and ysis of veterinxy dmeg in mimal food ponducts. Trends A nal Che 24:704-733

Gantili A, Sergi M, Parret D, Maxhese S, Curini R, Lismdin S (2006) Figh- and low-sesolution mass spectrometry coupled to
hiquid dromatography as confirmxory methods of anabolic liquid dromatography as confirmstory methods of anabohi
residues in erude mex and infant frodk. Rapid Commm Mas residues in crude mex a
Spectrom 20:1845-1854

Gonzalo-Lumbrairs R, Izquiardo-Homillos R (2000) High-performma liquid chromsogaphy optimization stuty for the squantion of nutual and synthetio anabolio staroid. Appliantion to urine and phrmaceutical smple. J Chom B 742:1-11

Hagren V, Connolly L, Elliot CT, Lövgren T, Tuomola M (2005) Rapid screaning method for halofuginone residues in poultry os and liver using timeresolved fluorometry combined with the all-in-coe dy chemistry asary concopt. Anal Chim Acta 529:21-25

Hewitt SA, Keurney M, Currie JW, Young PB, Kennedy DG (2002) Screening and onfirmatory stategies for the surveillmos of mabolic steroid abuse within Northern Ireland Anal Chim Act 473:99-109

Horie M, Yochida T, Scito K, Nakazava H (1998) Rapid scueening method for residual varinary drugs in meat and fish by HPLC. J Food Hyg Soo Japan 39:383-389

Ka YM, Ohng MH, Cheng OC, Chou SS (2001) Multinesidue detemination of veterinary drugs in chicken and swine mascle by high parformance liquid chromatography. J Food Drug Ama 9:84-95

Kirbis A, Marinsek J, Flajs VC (2005) Introduction of the HPLC method for the determination of quinolone residues in various musde tismes. Biomed Chrom 19:259-265

Koole A, Fanke J-P, De Zeeuw RA (1999) Multi-resitue analysis of maholics in alf urine using high-performance liquid chrom tography with diodoarray dataction. J Chrom B 724;41-5 I

Lone KP (1997) Natunl sex steroids and their xenobiotio mulogs in mimal production: Growth, carcass quality, phamacokinetion, metabolism, mode of action, resitues, mathods, and quidemiol ogy. Crit Rev Food Sa Nut 37:93-209
Mallinwon ET, Drass SS, Wiken RT, Hanry AC (1995) Datamination of decmethasone in liver and mascle by liquid chromatogaphy and gas chromatography/mass spectrometry. I Agrio Food Cham 43: 140-145

Murrer HH, Tenberken Q, Kratrseh C, Weba AA, Peters FT (2004) Sereaning for libary-assisted identification and fully validated quantificution of 22 betablockers in blood plama by liquid dhomatognghy-mass spectrometry with atmospherio pressure chemical ionintion. J Chrom 1058: 169-181

Mortier L, Daeseleire E, van Peteghem C (2005) Detarminution of the coccidiostat dichrouril in poultry feed and meat by liquid chomatography tandem mass spectometry. Anal Chim Acta 529:229-224

Motier P, Parisod V, GremudE, Guy PA, Stadler RH (2003) Detemination of the antitiotic chlormpheniool in meat and seufood products by liquid dhomatognaphy-electospray icoizs. tion tandem mas spectrometry. J Chom $\mathrm{A}$ 994:75-84

Mottier P, Khong S.P, Gremand E at al (2005) Quntitative deternination of fur nitsofian metabolites in mex by ixotope dilution liquid chromsography-dectrospay ionisation-tandam mass spectrmetry. J Chrom A 1067:85-91

Niessen WMA (1998) Analysis of antibiotics by liquid chnmatognphy-mass spectrometry. J Chrom A 8 12-53-75

Pecorelli I, Bubi R, Fiorni L, Galarini R (2004) Vahidstion of a confurmutory method for the determintion of sul phonmides in muscle aconding to the Europen Union regulation 2002/657/ EC. J Chrom A 1032:23-29

Puente ML. (2004) Highly sensitive and apid nommalphase chiral sereen wing high-performance liquid chomatography-atmosphario pressure ionizision tandem mas spectrometry (HPLC/ MS). J Ohrom 1055-55-62

Reig M, Toldn F (2007) Chemical arigin tmiv compounds. In: Toltai F, Hui YH, Astiusain I, Nip WK, Sebanek JG, Silveira ETF, Stahnke LH, Talon R (edk) Hand book of famented meat and poultry. Bludkwll Publishing, Ames, IO, USA, pp $469-475$

Reig $\mathrm{M}$, Toldnin $\mathrm{F}$ (2008a) Veterinury drug residues in ment: Concems and npid methods for detextion. Mant Sei 78.60-67

Reig M, Toldri F (200Sb) Grow th promoters. In: Nollet LML, Toltrí F (ads) Handbook of masde foods analysis. CRC Press, Boca Raton, F., USA (in press)

Reig M, Mora L, Navarro R, Toldn F (2006) A chromatogaphy method for the screening and comfinmany detection of dea. methmone. Mext Sci 74:676-680

Reyns T, De Boeva S, De Bxere S, De Racker P, Croubels \$ (2007) Quntitative malysis of clavulmic adid in porine tissues by liquid chromitography combined with dectrospray icniration tundem mas spectromary. Anal Chim Ada 5972:282-289

Romning HT, Einarsen K, Aøp TN (2006) Detemination of chloram phenicol residues in meat, seafood, egg, honoy, milk, pluema and urine with bquid ehomatogaphy-tandem mass spectrometry, and the validrion of the method hased on 200265 7/EC. J Chom A $11182226-233$

Rose MD, Bygave I, Tarbin IA (1995) Detemination of quinoxaline arboxylic-aid (metabolite of cabadox) in animal tissue by HPLC. Food Add Contam 12:177-183

Semenink S, Posynink A, Niedrielda J, Zmadki J (1995) Detemination of nitroimidusole residues in poultry tissues, senum and eggs ty high-performance liquid-ehromitography Biomed eggs by high-perf
Chmm $9.238-242$

Sharan P, O'Keef M, Smyth M (1991) Revarsed phase Highpefformmoe liquid chromatographic detemination of deameth. asone in bovine tissues. Analyst 116: 1365-1368

Stivhmi E, Chai SC, Jamolha S, Arnar G, Hoffmn MK (2003) Determination of ractopamine in animal tissues by liquid

\section{Antrot}


chromatognaphy fluorescence and liquid chsomatognaphy' tun dem mass spectsometry. Anal Ohim Acta 483:137-145

Stolker AMM, Schwillens P.L.WJ, Van Ginkel LA, Brinlman UAT (2000) Comparisen of different liquid ehrom ormhy methods for the detemination of anticostenids in biologial matrice J Ohrom A $893: 55-67$

Thevis M, Opfemmnn G, Schinzzer W (2003) Liquid chromatography/ dectrospray ionization tandem mass spectrometrio sereening and

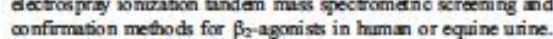
Confirmution methods for $\beta_{2}-1$ gon

Toldrí F, Reig M (2006) Methads for rapid detection of chemical and veteingry (2006) Methods for rapid detection of chemical mnd veterinary drug residyes

Van Pacguem C, Dreseluire E, Heeremms A (2001) Residues of Growth Promotes. Food analysis by HPLC, 2nd ech. Mrrcel Ddker, New York, pp 965-985

Vealon E, Couedor P, Roudut B, Sanders P (2005) Multizsidue method for simultmecus dearmination of ten quinolone antibx serial residues in mulimatrix/multispecies animal tissues by liquid chromatography with flucrescence detection: Single laboratory validarion study. J AOAC ht 88:1179-1192

Verdon E, Coueder P, Sunders P (2007) Mall ti-resitue monitoring for the simultmexus determination of five nitrofurns (firazolidone, funltadone, nitrofurame nitrofuntoine, nifursol) in poultry

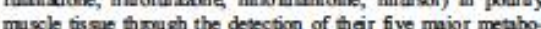
muscle tis sae through the desection of thar five major metabolites ( $A O Z, A M O Z, S E M, A H D, D N S A H)$ by hiquid chromm. sognaphy coupled to dectrospriny tandem mass spectrometryInhouse validtion in line with Commission Decision 657/2002/
BC. And Orim Acta 596:336-347

Vinci F, Gualagmaob G, Danese V, Salini M, Serpe L, Gallo P (2005) In-house validation of a liquid chromatography/ electrospray tundem mass spectrometry mathod for confirma. tion of chloramphenicol residues in musde according to Dedison 2002657FEC. Rapid Commun Mass Spatrom 19: 3349-3355

Wing S, Thang HY, Wing L, Dun ZJ, Kennedy I (2006) Analysis of sul phon mide resitues in edible animal products: A review. Food Add Contm 23:362-384 


\section{Apéndice V:}

Veterinary drug residues in meat: Concerns and rapid methods for detection. Meat Science, 2008, 78, 60-67. 


\title{
Veterinary drug residues in meat: Concerns and rapid methods for detection
}

\author{
Milagro Reig a , Fidel Toldrá ${ }^{\mathrm{b}, *}$

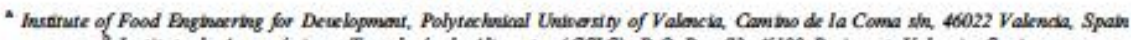

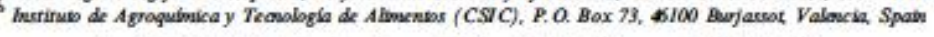 \\ Received 22 April 2007 ; received in revived form 27 July 2007 ; accepted 27 July 2007
}

\begin{abstract}
Alstract
The use of substances having hormonal or thyreostatic action as well as $\beta$-agonists is banned in the European Union. However, some times forbidden drugs may be added to feals for illegal administration to farm animals for promoting increasal muscle development or increased water retention and thus obtain an economical benefit. The result is a fraudulent overweight of meat but, what is worse, res idues of these substances may remain in meat and may pose a real threat to the consumer either through exposure to the reaidues, transfer of antibiotic resistance or allergy risk. This has exerted a great concern among European consumens.

The control of the absence of these forbidden substances in animal foods and feeds is regulatal in the European Union by Dirac tive $96 / 23 / \mathrm{EC}$ on measures to monitor certain substances and residues in live animals and animal products. Amalytical methodology, including criteria for identification and confirmation, for the monitoring of compliance was also given in Decisions 93/256/EEC and 93/257/EEC. More recently, Decision 2002/657/EC provided rules for the anslytical methods to be used in testing of offidal samples. A crucial step is the screning of veterinary drug residues in tive animak, feods and animal products in view of the remarkable number of samples and bre variaty of residues to be analysed. In recent years, different rapid methods having easy performance, high sensitivity and high throughput have been proposal and are being extensively used. These methods as well as other new methods are reviewed in and high

2007 Esevier Ltd. All nights reserved.
\end{abstract}

Keywordk Veterinary drugs; Residues detection; Screeningmethodk, A nimalorigin foodk; Food safety; Immunological methodologies; Chromatographic techniques

\section{Introduction}

Veterinary drugs are generally used in farm animals for therapeutic and prophylactic purposes and they include a large number of different types of compounds which can be administered in the feod or in the drinking water. In some cases, the residues may proceed from contaminated animal foedstuffs (McEvoy, 2002). But many of these substances may exert other effects when administered to animak for other purposes like growth promotion. A primary effect is the increase in the protein deposition, usu-

\footnotetext{
"Corresponding author. Tel: +34 963900022 ; fax +34 963636301
} E-mad address foldraiainta cric.es (F. Toldra).

0309-1740S - see front matter a 200 I Elevier Ltd All rights reserved. doi:10. 1016j meatsi. 1007.02 .029 ally linked to fat utilisation that decreases the fat content in the carcass and increases meat leanness (Lone, 1997). This allows a better efficiency in the feed conversion rate and a leaner meat. In addition, some practices consists in the use of "cocktails" (mixtures of low amounts of several substances that exert a synergistic effect) to have a similar growth promotion and reduce the margin for an effective analytical detection. The residues of these substances or its metabolites in meat and other foods of animal origin may cause adverse effects on consumers' bealth as described below.

The presence of residues and its associated harmful health effects on humans makes the control of veterinary drug residue an important measure in ensuring consumer 
protection. The European Union has strictly regulated the use of veterinary drugs in food animal species. Some of these drugs can be permitted only in specific circumstances (therapeutic purposes) but under strict control and administration by a veterinarian (Van Peteguem \& Daeselaire, 2004).

This manuscript is summarising the main effects of veterinary drugs on human health as well as its effects on meat quality and revising the current methods for rapid detection.

\section{Concerns of the presence of veterinary drugs residues in} foods of animal origin

The residues of veterinary drugs or its metabolites in meat and other foods of animal origin may cause adverse toxic effects on consumers' health. In fact, the European Food Safety Authority has recently issued an opinion on the effect of hormones residues in meat and reflected that epidemiological data provided evidence for an association between some forms of hormone-dependent cancers and red meat consumption (EFSA, 2007). Furthermore, recent intoxications by consumption of lamb and bovine meat containing residues of clenbuterol resulted in 50 intoxicated people with symptoms described as gross tremors of the extremities, tachycardia, nausea, headaches and dizzines (Barbosa et al., 2005). Other important effects mainly due to the presence of residual antibiotics consist in allergic reactions or the selection of a resistant bacteria that could be transferred to humans through the food chain (Butaye, Devriese, \& Haese brouck, 2001). In addition, the consumption of trace levels of antimicrobial residues in foods from animal origin may have consequences on the indigenous human intestinal microflora which constitutes an essential component of human physiology. This flora acts as a barrier against colonization of the gastrointestinal tract by pathogenic bacteria (Vollard \& Clasener, 1994) and has an important role for food digestion. So, the ingestion of trace levels of antimicrobials in foods must take into account potentially harmful effects on the human gut flora (Cerniglia \& Kotarski, 1999).

In view of all these circumstances, foods of animal origin must be monitored for the presence of veterinary drug residues (Croubels, Daeselaire, De Baere, De Backer, \& Courtheyn, 2004).

\section{Effects of veterinary drugs on meat quality}

Most of the drugs used as growth promoters may exert more or less important effects on meat quality, usually towards poorer eating quality (Lone, 1997). The meat tends to be tougher because there is an increase in connective tissue production and also a higher rate of collagen cross-linking (Moloney, Allen, Joseph, \& Tarrant, 1991) as well as an increase in the insoluble fraction of the intramuscular collagen (Miller, Judge, Dikeman, Hudgens \& Aberle, 1989; Miller, Judge, \& Schanbacher, 1990).
Another factor, which is important from the point of view of meat tenderness, consists in the inhibitory action that these substances may exert against muscle proteases enzymes responsible for protein breakdown in postmortem meat (Moloney et al., 1991). For instance, myofibrillar protein fragmentation has been reported to be decreased in agonists-treated anima $\mathbf{k}$ probably due to calpains inhibition by R-agonists (Fiems, Buts, Boucque, demeyer, \& Cottyn, 1990). On the contrary, other endogenous enzymes like the hormone-sensitive lipase appear to be activated, increasing the lipolysis rate and the breakdown of triacylglycerols (Brockman \& Laarveld, 1986; Duquette \& Muir, 1985). The final result of the altered lipid metabolism is a sensible reduction in the amount of fat although this reduction in fat is associated to a lower sensory quality (poor juiciness and flavour). As mentioned above, some toxic effocts in humans have been reported after consumption of lamb and bovine meat containing residues of clenbuterol (Barbosa et al., 2005). In other cases, like thiouracyls, the result is a substantial retention of water which is rapidly lost during cooking, giving a meat with lower juiciness.

\section{Control of veterinary drugs residues in meat}

The use of substances having hormonal or thyreostatic action as well as p-agonists is controlled by official inspection and analytical services following Commission Directive $96 / 23 / \mathrm{EC}$ on measures to monitor certain substances and residues in live animals and animal products. Thi Directive gave procedures for European Union Member States to set up national monitoring programmes and sampling procedures. This Directive contributed to a sensible reduction in the number of growth promoting reported cases (Kuiper, Noordam, Van Dooren-Flipsen, Schilt, \& Roos, 1998). However, laboratories in charge of residues control usually face a large number of samples with a great varieties of residues to search in short periods of time making it rather difficult. The availability of simple and useful screening techniques is really necessary for an effoctive control.

Main veterinary drugs and substances with anabolic effect are listed in Tables 1 and 2 . In these tables, two

Table 1

List of substances having anabolic effect belonging to group $\mathrm{A}$ according to Counal Directive 96/23/EC

\begin{tabular}{ll}
\hline Suhstance & Main representative \\
\hline
\end{tabular}

Group A: subctances having anabalic effect

1. Stithenes

2. Antithyroid agent

(DiethylestiThestrol)

2. Antithyroids (Thiouracyls)

Androgens

Gestagens

Es trogens

4. Resoreyolic acid lactone

5. $\beta$-agonists

6. Other compounds
(Trenbolone acetate) (Melen gestrol ace tate)

(17- $\beta$ estradial)

(Zeranol)

(Clen buterol) (Nitr of urans) 
Tahle 2

Lists of veterinary drugs belonging to group $B$ according to Counal Directive $96 / 23 / \mathrm{EC}$

Growp \& sete hary drugs

1. An tibacterial substances

Sulphonamides and quinolones

2. Other veterinary drugs

(a) Antihelmintics

(b) Antioocidials, inchuding nitroimidazoles

(c) Oarhemates and pyre throids

(d) Sedatives

(e) Non-steroideol anti-inflammatory drugs

(f) Other pharmacologically active substances (deramethasone)

groups of substances may be differentiated: those unauthorised substances having anabolic effect belonging to group A and those veterinary drugs of group B, some of them having established maximum residue limits (MRL). Analytical methodology, including criteria for identification and confirmation, for the monitoring of compliance was also given in the Commission Decisions 93/256/EEC and 93/257/EEC. The Commission Decision 2002/657/ EC, which is in force since 1 September 2002 , implemented Council Directive $96 / 23 / \mathrm{EC}$ by providing rules for the analytical methods to be used in testing of official samples and specific common criteria for the interpretation of analytical results of official control laboratories for such samples. For instance, substances in group A (see Table 1) would require 4 identification points while those in group B (see Table 2) only require a minimum of 3 . The guidelines given in the new Directive imply new concepts like the decision limit $(\mathrm{CC} \alpha)$ which means the limit at and above which it can be concluded with an error probability of $\alpha$ that a sample is non-compliant, and the detection capability (CCF) that means the smallest content of the substance that may be detected, identified and/or quantified in a sample with an error probability of $\beta$.

Recently, the EC Quality of Life Programme supported European collaborative projects in the area of antimicrobials and hormone residues analysis (Boenke, 2002). These projects consisted in the development and validation of sereening and confirmatory analytical methods and sensors for a cost-effective and time efficient control of synthetic glucocorticoids, nitrofurans, coccidiostatics, B-lactam residues and androgen residues in live and postmortem animak.

\section{Analytical methods for rapid screening}

These controls are based on the screening of a large number of samples. Compliant samples are accepted while those suspected non-compliant samples have to be confirmed through other confirmatory methods that are described later. A scheme of the typical analysis procedure is shown in Fig. 1. High throughput methods with low cost and able to detect an analyte or class of analytes at the level of interest are thus required (Van Peteguem, Daeselaire, \& Heeremans, 2001). Main requirements for a scroening

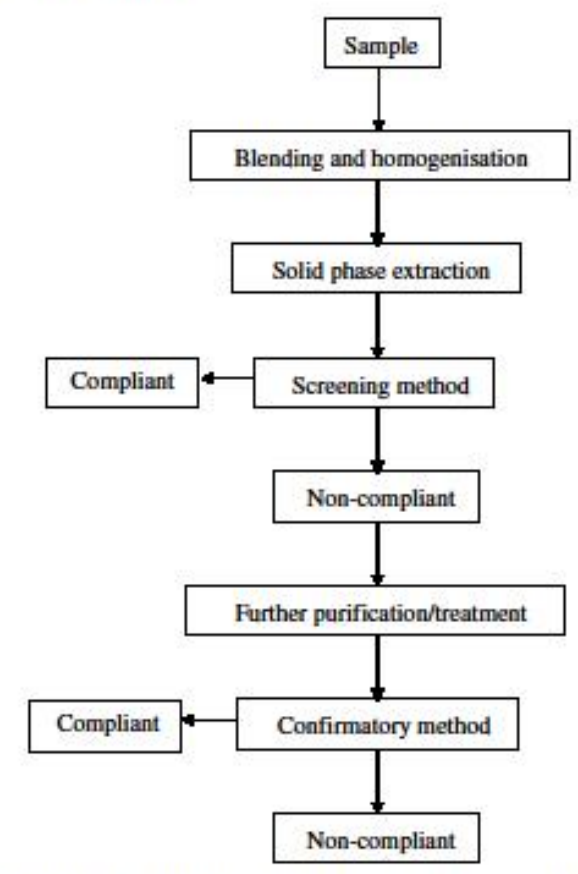

Fig. 1. Example of typical proced ure for the analyais of a given analyte in a meat sample.

method are summarised in Table 3. In case the residue has a maximum residue limit (MRL), the screening method must be capable to detect the residue below this limit. The screening methods must also avoid or reduce to a minimum the number of false negative results because they will be considered as compliant samples and will not be further analysed. According to the Commission Decision 2002/ $657 / \mathrm{EC}$, the methods must be validated and have a detection capability (CC $\beta$ ) with an error probability $(\beta)$ lower than $5 \%$. On the other hand, it must not give an excessive number of false non-compliant samples, that will be later confirmed as compliant, due to the excessive cost and time involved.

Tahk

Main requirements for a screening metho

Requibanents

Easy to wee and hande

Low set up and running oosts

High throughput

Possibility of autcmatisation

Reasuced fime to obtain the resul

Good sensitivity and s pecificity

Detection capahility $(C C \phi)$ with an error probability $(\sigma)<5 \%$ 
Preparation procedures and handling of samples especially solid and heterogeneous foods like meat, kidney or liver, are very important in order to ensure better sensitivity of the scroening tests (MoCracken, Spence, \& Kennedy, 2000 ). Samples are usually cut, blended, homogenised and liquid extracted. Next step is usually based on solid-phase extraction for sample clean-up and concentration. The type of cartridge is chosen depending on the analyte for the appropriate elimination of potential interferents (Stubbings et al., 2005). In other cases, the residues may be bound of conjugated and need further cleavage before the analysis is performed. The main types of screening techniques are summarised below.

\subsection{Immunological techniques}

The immunological methods are based on the interaction antigen-antibody which is very specific for a particular residue. The most usual tochnique consists in the enzyme linked-immunosorbent assay (ELISA) and the detection system is usually based on enzyme-labeled reagents. There are different formats for antigen quantification like the double antibody or sandwich ELISA tests and direct competitive ELISA tests Radioimmunoassay (RIA) is based on the measurement of the radicactivity of the immunolog ical complex (Samarajeewa, Wei, Huang, \& Marshall, 1991). Other assays have enhanced detectability by using of a luminescence detector if using a chemiluminescent compound or a fluorimeter in the case of using a fluorescent compound (Roda et al., 2003).

Today, there are many different types of ELISA kits commercially available for a large number of substances within each group listed in Table 1 like B-agonists, corticoids, steroids, stilbenes, resorcylic acid lactones and several antibiotics. ELSA kits are available for a specific residue (i.e., sulphametazine) or a group of related compounds (i.e., sulphonamides). In some cases, the possibility of cross reactions must be taken into account. These kits allow the analysis of a large number of samples per kit, do not require sophisticated instrumentation, the results are available in a few hours and are quite specific and sensitive. ELISA kits have shown good performance for the analysis of antibiotic residues in meat like tylosin and tetracyclin (De Wasch et al., 2001; Draisci et al., 2001; Kumar, Thompson, Singh, Chander, \& Gupta, 2004; Lee, Lee, Ryu, Lee, \& Cho, 2001), chloram phenicol (Gaudin, Cadieu, \& Maris, 2003), nitroimidazoles (Huet et al., 2005) and sulphonamides (Wang, Zhang, Wang, Duan, \& Kennedy, 2006) and ako for sedatives (Cooper, Delahaut, Fodey, \& Eliott, 2004). In general, ELSA tests require some manual operation (pipetting and discarding of liquids) that is progressively replaced by automated systems.

Dipstick constitutes another system which basically consists of a membrane strip with the receptor ligands. The sample with the antibiotics is applied and left to interact and, after dipping into two different solutions, the devel- oped colour can be quantified either by comparison to a standardised colour scale or by measuring spectrophotometrically (Link, Weber, \& Fussenegger, 2007).

\subsection{Bibsensors}

Different types of biosensors have been developed in recent years as an alternative approach to screen veterinary drugs in meat. In general, these sensors usually contain an antibody as a recognition element that interacts with the analyte. The resulting biochemical signal is measured optically or converted into an electronic signal that is further processed in appropriate equipments (Patel, 2002; White, 2004). Biosensors can be able to detect simultaneously multiple veterinary drugs residues in a sample at a time (Gründig \& Renneberg, 2002) and some authors have reported no need for sample clean-up (Elliott et al., 1998). In general, these sensors are valid for control laboratories because they can detect multiple residues in one sample and can thus allow the analysis of a large number of residues and samples (Franck \& Hruska, 2005).

There are differences in the design of the biosensors depending on bow the interaction between the recognition molecule and the analyte is performed and the type of detection. In some sensors, the biomolecular interaction analysis is based on surf ace plasmon resonance (SPR). Thi type of optical biosensors measures variations in the refractive index of the solution close to the sensor when there are changes in the mas concentration of molecules in that solution (Gillis, Gosling, Sreenan, \& Kane, 2002). The biosensor allows real time monitoring on the interaction analyte-receptor at the sensor chip surface. Some recent applications of this SPR sensor for the detection of antibiotics, $\beta$-agonists and antiparasitic drugs in foodstuffs have been recently reviewed (Akkoyun, Kohen, \& Bilitewski 2000; Bergweff, 2005; Haughey \& Baxter, 2006).

Other biosensors are based on the use of biochip arrays especific for a certain number of residues, that also allow a real time monitoring of the interaction of the analyte with the recognition molecule. These sensors are affected by several factors like the surface ligand density in the array, the concentration of active antibody and the flow rate (Johansson \& Hellenas, 2001). Some residues like chloramphenicol, clenbuterol and tylosin have been reported to be detected with a small molecule microarray. The drus molecules were immobilised on glass slides and after incubation with corresponding antibodies and samples, the binding was detected using cy 5 labeled secondary antibody (Zuo \& Ye, 2006).

Other types of biosensors are designed against specific classes of antibiotics and, in fact, have shown good detec tion of tetracycline, streptogramin and macrolide antibiotics in milk and serum. The design of these sensors is compatible with the ELISA-type format and the loss of colour gives a readout that is proportional to the antibiotic concentration (Weber et al, 2004). 
5.3. High performance thin-kyer chromatography (HPTLC)

HPTLC allows the qualitative and quantitative detection of multi-residues in meat but its use has rapidly decreased due to the expansion of other techniques like HPLC. Reported uses of HPTLC applied to meat include the detection of residues like clenbuterol and other agonists (Degroodt, Bukanski, Beernaert, \& Courtheyn, 1989, Degroodt, Bukanski, De Groof, \& Beernaert, 1991), nitroimidazol (Gaugain \& Abjean, 1996) and sulphonamides (De Bukanski, Degroodt, \& Beernaert, 1988; Haagsma, 1985; Van Poucke, Depourcq, \& Van Peteghem, 1991) and thyreostatic drugs (De Brabender, Batjoens, \& Van Hoof, 1992; De Wasch et al., 1998).

The plates are sprayed with an appropriate chromogenic reagent or viewed under UV light for visualisation of compounds. Detection by fluorescence is also applied. Quantitation is achieved by measuring the relative intensity of the spot vs that of the internal standard by scanning densitometry. Modern HPTLC has been automatised at a high level.

\subsection{High performance liquid chromatography (HPLC)}

HPLC expanded its use in the 1990s due to the availability of columns, good performance, variety of available detectors and possibility of automation. Recent developments like the ultraperformance liquid chromatography systems or types of columns with improved packagings in terms of smaller size, geometry and inertness are also very valuable. HPLC is a separative technique where the choice of the detection system is very important for selectivity and sensitivity. Some analytes require chemical modifications to render chromophore, fluorescent or UV-absorbing compounds (Bergweff \& Schloesser, 2003). Typical detections of multi-residues in meat samples are relatively simple and rapid, requiring a preliminary clean-up through solid-phase extraction followed by filtration before injection into a reverse-phase HPLC with diode array detection. This procedure has been applied to meat for detection of antibiotics like quinolones (Kirbi, Marinsek, \& Flajs, 2005), sulphonamides (Pecorelli, Bibi, Fioroni, \& Galarini, 2004), B-lactams and macrolides (Nagata, Ashizawa, \& Hashimoto, 2004) and tetracyclines (Samanidou, Nikolaidou, \& Papadoyannis 2005), veterinary drugs (Aerts et al., 1995; Cooper et al., 1995; Horie et al., 1998; Kao et al., 2001; Reig, Batle, Navarro, \& Toldrá, 2005a, 2005b), anabolic steroids (De Cock et al., 2001; GonzaloLumbrearas \& Izquierdo-Hornillos, 2000) and corticosteroids like dexamethasone (Mallinson et al, 1995; Reig, Mora, Navarro, \& Toldrá, 2006; Shearan et al., 1991; Stolker et al., 2000). In some cases, the compounds can be further identified through diode array or fluorescence detection. Ten quinolone residues (ciprofloxacin, danofloxacin, difloxacin, enrofloxacin, flumequine, marbofloxacin, nalidixic acid, norfloxacin, oxolinic acid, sarafloxacin) in meat have been screened and confirmed with HPLC and fluorescence detection (Verdon, Couedor, Roudaut, \& Sanders, 2005).

Latest developments in liquid chromatography include the development of new smaller columns with packagings of reduced size as well as the use of higher pressures (i.e., UPLC systems). This allows considerable reductions in elution times increasing substantially the number of samples per day.

Liquid chromatography techniques are getting expanded use in control laboratories due to the possibility of automation (injection, elution, washing of column, detection), computer-controlled use and data manipulation and the relatively short time neoded per sample. Recent developments in new systems and columns that allow high speed and reduced analysis time are being already commercialised and will contribute its expanded use.

It must betaken into account that sample extraction and clean-up are the rate-detemining steps in drug analyses. The use of on-line solid-phase extraction (SPE) with chromatography coupled to mass spectrometry or other spectroscopic techniques are getting widely used in recent years. They allow for screening with simultaneous confirmation for those suspicious samples. Even though the cost of the instrument is high, when a large number of samples are analysed the costs are reduced and are more competitive. For instance, nineteen veterinary drugs have been reported to be screened in meat by using an extraction cartridge packed with hydrophilic-hydrophobic polymer sorbent followed by fast LC using a short C18 column and direct analysis by LC/MS/MS (Tang, Ho, \& Lai, 2006). Other analytical strategies consist in the use of liquid chromatography-tandem mass spectrometry (LC-MS-MS) for the analysis of different groups of substances in meat like corticosteroids (Antignac, Monteau, Negriolli, Andre, \& Le Bizoc, 2004), B-agonists, chloramphenicol and penicilins (Munoz et al., 2005), sulphonamides (Gentili et al., 2004) or ionophore coccidiostats in broiler meat (Rokka \& Peltonen, 2006).

\section{Confirmatory analytical methodologies}

The next step after initial screening consists in the unambiguous identification and confirmation of the veterinary drug residues in foods of animal origin. The full procedure and the methodologies for confimatory analysis are costly in time, equipments and chemicals. In addition, they require trained personnel with high expertise (Toldrá \& Reig, 2006). Different analytical techniques are available for such purpose. When the target analyte is clearly identified and quantified above the decision limit for a forbidden substance (i.e., substances of group A) or exceeding the maximum residue limit (MRL) in the case of substances having a MRL, the sample is considered as non-compliant (unfit for human consumption). Identification is easier for a limited number of target analytes and matrices of constant composition (Milman, 2005). Some examples of the available confimatory 
methodologies are as follows The use of HPLC-electrospray ionisation (ESI) tandem mass spectrometry (Hewitt, Kearney, Curne, Young, \& Kennedy, 2002; Thevis, Opfermann, \& Schänzer, 2003) or liquid chromatography-mass spectrometry with atmospheric pressure chemical ionisation (APCI) (Maurer, Tenberken, Kratzsch, Weber, \& Peters, 2004; Puente, 2004; Turnipseed, Roybal, Andersen, \& Kuck, 2005). ESI ionisation tochnique facilitates the analysis of small to relatively large and hydrophobic to hydrophilic molecules and is thus very adequate for the analysis of veterinary drug residue (Bergweff \& Schloesser, 2003) even though it is more sensible to matrix effects than APCI ionisation (Dams, Huestis, Lambert, \& Murphy, 2003). ESI and APCI interfaces are the sources of choice to promote the ionisation of antibiotics and both complement each other well with regards to polarity and molecular mass of analytes (Gentili, Perret, \& Marchese, 2005). The assay of chloramphenicol in meat has been suocessfully identified and quantitated by liquid chromatography/electrospray ionisation tandem mass spectrometry (ESI- LC/MS/MS) in the negative ion mode coupled to ion trap analyser (Mottier, Parisod, Gremaud, Guy, \& Stadler, 2003; Vinci et al., 2005). The same technique with positive ESI has been sucoessully applied to the analysis of four nitrofuran compounds (furazolidone, furaltadone, nitrofurantoin, and nitrofurazone) in meat (Mottier et al., 2005).

\section{Conclusions}

New substances with anabolic properties are being detected year by year increasing the list of forbidden compounds to be tested. Furthermore, the extended practice consisting in the use of "cocktails" (mixtures of low amounts of several substances that exert a synergistic effect) to have a similar growth promotion, reduces the margin for an effective analytical detection. Thus, the evolution of the "black market" is making really difficult to have an effective analytical control of the residues of these substances in foods of animal origin.

Control laboratories must face an increasing demand of analysis like the growing number of residues to be analysed in different types of samples, the strict guidelines for analytical methodologies according to the latest Directives, the increased costs of such new methodologies, the variety of residues to search per sample and the need to invest on powerful new instruments for identification and confirmatory purposes.

Rapid and versatile screening methodologies make its control easier and reduce the number of non-compliant samples to be confirmed through tedious and costly confirmatory analytical methodologies. For instance, the multiresidue analysis can be performed better by using fast LC methods. Thus, the availability of new screening methodologies and the improvement of the existing ones will contribute to a better safety assurance of meat and other foods of animal origin.

\section{Acknowledgements}

Grant from Conselleria de Agricultura, Pesca y Alimentación from Generalitat Valenciana is acknowledged. Part of this work has been performed in the framework of the Associated Unit Iu-IAD (UPV)-IATA (CSIC).

\section{References}

Aerts, M. M. I. Hogenhoom, A. C. \& Brinkman, U. A. T. (1995) Analytical strategies for the screening of veterinary drugs and the Analytical strategies for the screening of veterinary drugs and ther
residues in edible products. Jownal of Chromatography B - B bowedival Applicanowe, 667, 1-40.

Akkoyun, A, Kohen, V. F, \& Bilitersiki, U. (2000). Detection of sulphamethaxine with an optical biosensor and anti-idiotypic an tibodies. Skneors and Actuators $B, 70,12-18$.

Antignac, J. P., Montean, F, Negriolli, I, Andre, F, \& Le Bime, B (2004). Application of hyphenated mass spectrometric techniques to the determination of cortiosseroid residues in biologionl matricer. Chromatognaphia, $59, \$ 13-\$ 22$.

Bur bosa, L, Gruz, C, Martina, J, Silva, J. M., Neves, C., Alver, C, et al (2005). Food poisoning by denbuteral in Portugal. Food Addirives and Contominante. 22, 563-566.

Bergweff, A. A. (2005). Rapid assays for detection of residues of veterinary drugs. In A. van Ameron gen, D. Barug, \& M. Lauarars (Eds.), Rapild merhods for biabogical and chomital contamibants in faod and feert (pp, 259-292). Wageningen Academic Publishers.

Bergweff, A. A., \& Schloesser, J. (2003). Residue determination. In B Cahallero, L. Truga, \& P. Finglas (Edk.), Encydapedia of Food Salencer and Nurian (2nd ed) (pp. 254-261). London, UK: Elevier.

Boen le, A. (2002). Contribution of European research to anti-microbials and hormones. Anafyrica Olimina Acta, 473, 83-87.

Brockman, R. P, \& Larveld, R. (1986). Hormonal regulation of trodkman, R. P, \& hasreid, R. (1986). Hormonal regulation of metabohm $14,313-317$

14, 313-317.
Butaye, P., Devriese, L. A., \& Haesebrouck, F. (2001). Diflerences in anthiotio resistance patterns of Enterococus faccalis and Enterococ. $\mathrm{cus}$ frecium strains ionlated from frrm and pet animak. Aurbuicosobia Agars and Cham adienapy, 45, 1374-1378.

Cernighiz, C. E, \& Kotarsih, S. (1999). Evaluation of veterinary drug residues in food for their potential to affoct human intestina misroflora. Regulabory Toxionlagy and Phammanology, 29, 238-261.

Cooper, A. D. Creaser, C. S., Farrington, W. H. H., Tarhin, J. A., \& Shearer, G. (1995). Development of multi-residue methodology for the HPLC determination of veterinary drus in animaltissues. Foad

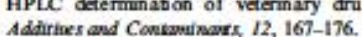

Cooper, I, Delahaut, P., Fodey, T. L, \& Elliott, C. T. (2004) Development of a rapid screening tert for veterinary sodatives and the betablocker caramolol in porcine kitney by ELISA. Analyst 129 169-174.

Croubek, S, Deeselaire, E, De Raere, S, De Racker, P, \& Cour theyn, D (2004). Feed and drug residues. In W. Jensen, C Devine, \& M Dikemann (Eda.), Eacydopedia of meat sciances (pp. 1172-1157). London, UK: Elsevier.

Dams, R, Huestis, M. A., Lambert, W. E., \& Murphy, C. M (2003). Matrix effect in bio-analysis of illiait drugs with LCMS/ MS: Influence of ionization type sample preparation and bicfluid Jownal of the Amerikan Sodety of Masr Spectrometry. biofluid Jownal $1290-1294$

I4, $1290-1294$. De Brabender, H. F, Bafioens, P, \& Van Hoof, V. (1992). Determination
of thyreastatic drugs by HPTLC with omfirmation by GC-MS. Jownal of Plangr Cliromatography, 5, 124-130.

De Bukanaki, B. W., Degroodt, J.M., \& Bermaert, H. (1988). A twodimensional high-performance thin-layer chromatographic screeining method for sulphonamides in animal tiscues. Zatrecte iff for Lahese somined Uhrorsuchung und Forsedumg, 187, 242-245. 
De Codk, K. J. S., Delheke, F. T, Van Eenoo, P., Desmet, N., Roek, K. \& De Backer, P. (2001). Detection and determination of anabohic steroids in nitrtional supplements. Jownal of Phamaceurial and

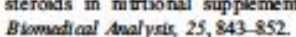

Degroodt, J.M., Bukanaki, B. W, Beer naert, H, \& Courtheyn, D. (1989) Clenbuterol residue analysis by HPLCHPTLC in urine and animal

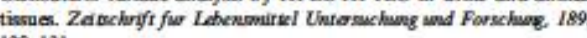
$128-131$

Degroodt, IM. Bubanshi, B. W., De Groof, I., \& Beernaer, H (1991). Cimaterol and clenbuterol residue analysis by HPL.C

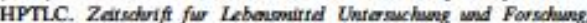
$192,430-432$.

De Wasch, K., De Brabender, H. F., Van Ginkel, L. A., Span, A, Sterk S. S. \& Meiring, H. D. (1998). Confirmation of residues of thyrees tatie drugs in thyroid glands by multiple mass spectrometry after thin-laye drugs in thyroid glands by multiple mass spectrometry after th
chromatography. Joumal of Oremabgraphy $A, 8 / 9,99-111$.

De Wasch, K, Okermin, L, Croubek, S, De Brabander, H., Van Hoof J. \& De Backer, P. (2001). Detection of residues of tetracydine antibiotics in pork and chisken ment. Correlation between reoults of scree inig and confirmatory test., Anafyst, 123, 2737-2741.

Draisci, R, Qundri, F. D, Achene, L, Volpe, G, Palleschind, L, \& Palleschi, G. (2001). A new electrochemical enzyme finked immunosorbent asay for the soreening of macrohide anthiotic residnes in bovine meat. Analyst, 126, 1942-1946.

Duquette, P. F., \& Murr, L A. (1985). Effoct of the $\beta$-adrenergic agonist is oproterenol, denbuterol, L 640,033 and BR L 35135 on lipolysis and lipogenesis in rat adipose fissue in vitro. Jownd of Animal Scionce $6 I$ (Suppl. 1), 265.

EPSA (207). Opinion of the scien tific panel on oontuminants in the food chain on a request from the Europoun Commiskion related is hormon residues in bovine meat and meat products. The EFSA Journal 510 $1-62$

Elliott, C. T., Bater, G. A., Hewitt, S. A, Arts, C. J. M., Van Bank, M. Hellenas, K. E., et al. (1998). Ulee of binenenors for rapid drug residue analyais without sample deconjugation or dean-up: A possible way forward. Anabyss, 123, 2469-2473.

Fiems, L. O , Buts, B., Boucque, Ch. V., demeyer, D. L, \& Cottyn, B. G. (1990). Effect of a $\beta$-agonist on meat quality and myofibrillar protein (1990). Efiect of a $\beta$-agonist on meat quality and

Pranek, M. \& Hruska, K. (2005). Antibody hased methods for environmental and food analysic: A review. Veterinary Metiche Ceech, 50 , $1-10$.

Gaudin, $\mathbf{V}_{7}$ Cadiel, N., \& Maris, P. (2008). Inter-daboratory studies for the evaluation of ELISA bits for the detection of chloramphenicol residues in mill and muxke. Fond and Agriailaral humumabgy, 15, 143-157.

Gaugain, M., \& A hjean, J. P. (1996). Figh-performance thin-layer chromatographic method for the fluoressence detection of three nitroimidazole residues in por
matognaphy $4,737,343-346$.

Gentili, A, Perret, D, \& Marchese, S. (2005). Liquid chromatography tandem mass spectrometry for performing confirmatory analysis of veterinary drugs in animal-food products. Thends on Analyrion Chemieryy, 24, 704-733.

Gentili, A., Perret, D., Marchese, S., Sergi, M., Olmi, C, \& Curini, R (2004). Acelerated solvent extraction and confirmatory analysis of sulfonamide residues in raw meat and infant foods by liquid chromatography electrospray tandem mass spectrometry, Journal of Agriculturd and Foad Chomisoy, 52, 4614-4624.

Gillis, E. H., Goeling, I. P. Sreenan, I. M. \& Kane, M. (2002) Development and validation of a bisceneor-based immunoassay for Development and vahidation of a bicsenoor-based immunoascay for progester.

Gonzalo-Lunbrearas, R, \& Izquierdo-Hornillos, R. (2000). Fighperformance liquid chromatography optimization study for the separation of natural and synthetic anabolic ster oids. Application to wrine and pharmaceutical samplex. Jounal of Chromarography $B, 742,1-11$.
Gründig, B, \& Renneberg, R. (2002). Chemionl and biochemionl sensors. In $\boldsymbol{A}$. Katerkamp, B. Grundig, \& R. Ren neberg (Eds.), Ulbuaser's encyelopectia of huducrial chanistry (pp, 87-98). Ver lag. Wiley-VCH.

Hagems N. (1985). Rapid thin-laye chromatographic scening method angema, N. (1985). Rapid thin-layer chromatographic sceening method
for the detertion of five sulfonamides in swine fissues: Collhborative

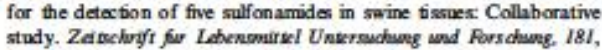
study. 2 .

Haughey, S. A., \& Baxter, C. A. (2000). Bicseneor screening for veterinary drug residues in foodatuffs. Jownal of AOAC hutemational, 89 $862-867$.

Hewitt, S. A., Kearney, M. Currie, I. W., Young, P. B, \& Kennedy, D. G. (2002). Screening and confimmatary strategies for the surveillance of anabolis ster oid abuse within Northern Ireland. Amalyaca Chamice Acta, 473, 99-109.

Horie, M. Yoshida, T., Saito, K, \& Nakazawa, H. (1998). R apid screening method for residual veterinary drugs in meat and fah by HPLC. burnd of the Food Hygienic Sadety of Japan, 99, 383-399.

Huet, A. C., Mortier, L., Deeseleire, E, Fodey, T., Elliott, C., \& Delahaut, P. (2005). Development of an ELISA sereening test for nitr oimidazoles in egg and chicken muscke Analyoca Chibuica ACE, $594,157-162$.

Johanewon, M. A., \& Hellenas, K. E. (2001). Sensor chip preparation and usery construction for immunobinseneor deternination of bet agorists and hormones. Avalyas, $126,1721-1727$.

Kan, Y. M. Chang, M. H. Cheng, C. C, \& Chou, S. S. (2001) Multiresidue determination of veterinary druss in chichen and saine muxcles by high performance hiquid chromatography. Jownal of Fond and Drug Analysik, 9,84-95.

Kirbi, A., Marinsek, J, \& Flajk, V. C. (2005). Introduction of the HFLC method for the determination of quinolone residues in various muack tissues. Basmedical Chromatography, 19,259-265.

K uiper, H. A., Noordam, M. Y, Van Dooren-Flipen, M. M. H, Schilt R., \& Roos, A. H. (1998). Illegal we of $\beta$-adrenergic agonist: Europeen community. Jownal of Adeimal Scionce, 76, 195-207.

K umar, K., Thompron, A., Singh, A. K., Chander, Y, \& Gupta, S. C (2004). Encymo linked immuncoorbent assay for ultratrace determination of anthiotis in aqueous samples. Jownel of Enviroumeneal Oualin, 33, 250-256.

Lee, H. J. Lee, M. H. Ryu, P. D. Lee, H., \& Cho, M. H. (2001). Enzyme linked immunoworbent assay for screening the plasma residues of tetracydine antibiotics in pige. Jownal of Veterinary Mediche 63 $553-556$.

Link, N. Weber, W., \& F uswenegger, M. (2007). A novel generic diprtick. based technology for rapid and precive detection of tetracyctine streptogramin and macrohide antihiobies in food samplea. Jownal of Biakdinabogy, 128, 688-600.

Lone, K. P. (1997). Natural ser steroids and their xenobiotic analogs in animal producfion Growth carcess quality, pharmacolinetics, metab animal producton: Growth, carcass quafity, pharmacoibinetics, metab-

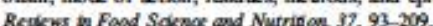

Mallineon, E. T., Dreas, I. S. Wikon, R. T., \& Henry, A. C (1995) Determination of deramethasone in liver and muscle by liquid chromatography and gas chromatography/mass spectrometry. Jown of Agrioulrumal and Food Ciemierry, 43, 140-145.

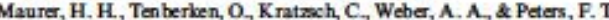
(2004). Screening for library-assisted identification and fully validato quantification of 22 beta-blockers in blood plarma by liquid chrome tography-mass spectrometry with atmospheric presarte chemicil ionization. Jownal of Chromatography, 1058, 169-181.

MeGracken, R. I Spence, D. E, \& Kennedy, D G. (2000) Comparison of extraction techniques for the reoovery of veterinary drus residues from animal tionues. Food Addirives and Contamb. drug residues from

McEvoy, J. D. G. (2002). Contamination of animal feedstuffs as a cause of residues in food: $\mathbf{A}$ review of re gulatory aspect, incidence and control. Analyrina Chibuica Acta, 473, 3-26.

Miller, L. F., Judge, M. D, Dikeman, M. A., Hudgens, R. E., \& Aberie E. D. (1989), Relationships among intrammecular collanen, ser 
hydraxyproline and serum testosterone in growing rams and wethers. hydroxyproline and serum testoster.
Jound of Animal Scknax, 67,698.

Miller, L. F. Judge, M. D \& Schanbacher, B. D. (1990). In tramuscular colliggen and serum hydraxyproline as related to implanted testoster one and estradiol $17 \beta$ in growing wethers. Jownal of Anbual Sciance $68,1044$.

Milman, B. L. (2005). Identification of chemical compounds. Thends a Analyrimal Chanis oy, 24, 493-508

Mol oney, A, Allen, P, Joseph, R, \& Tarrant, V. (1991). Influence of betaddrenergio agorists and similar compounds on growth. In A.M. Pears on \& T. R. Dutson (Eda.), Growth resularion in farm axibuals (pp. 455-513). London: Elevier Applied Science.

Mottie, P, Khong, S.P., Gremad, E, Richer, J, Delatow, T. Goldmann, $T_{\text {r }}$ et al. (2005). Quantitative determination of four nitrofuran metabolites in meat by inotope filution hiquid chromatog. nitrofuran metabolites in meat by isotope dilution hiqud chromatos raphy-electrospray ionis ation-tande
Chromatography A, 1067, 85-91.

Mottier, P., Parisod, V., Gremand, E., Guy, P. A., \& Stadler, R. H (2003). Determination of the antibiotic chlorampheniool in meat and seafood products by liquid chromatography-eloctrospray ionization tandem mass spectrometry. Jownal of Chromabgraphy A, $994,75-84$

Muhor, P., Blanon, J, Ramos, M, Bartolomé, M, Gardia, E, Méndez, $N_{7}$ et al. (2005). A versatile liquid chromatography-tandem mass spectrometry system for the analysis of different groups of veterinary spectrometry system for the analysis of differe

Nagata, T., Ashizara, E, \& Hashimoto, H. (2004). Simultaneou determination of residual fourten linda of beta-lactam and macrolide antibiotios in bovine muscles by high-performance liquid chromatog raphy with a dode array detecior. Jownal of the Food Hygianic Sodkty of Japar. 45, 161-164.

Patel, P. D. (2002). Bio sensors for measurement of analyzes implicated in food safety: A review. Trands in Food Sciace and Teduabgy, 2I, 96-115.

Pecorelli, L, Bibi, R., Fioroni, L., \& Galarini, R. (2004). Validation of a confirmatory method for the determination of sulphonamides in muscle acoording to the European Union regulation 2002/657/EC. Journal of Chromatography $A, 1032,23-29$.

Puente, M. L. (2004). Fighly sensitive and rapid normal-phase chiral sereen using high performance hiquid chromatography-atmospheri pressure ionization tandem mass spectrometry (HPLCMS). Jownal of Chromatography, 1055, 55-6:

Reig, M. Batlle, N, Navarro, I. L, \& Toldri, F. (2005a). A modified HPLC method for the detection of 6methyl-2-thiouracil in cattle

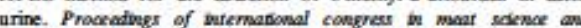
terhabogy (pp. 90), Baltimore, Maryland, August 7-12

Reig, M., Batlle, N., Naunrro, I. L, \& Toldri, F. (2005b). Stability of $\beta$ agonist methyl boronio derivatives before GC-MS analysis Analyrion agonist methyl boronio dervi.

Reig, M., Mora, L, Navarro, J. L, \& Toldri, F. (2006). A chromatography method for the screening and confirmatory detection of dexamethasone. Mart Saknar, 74, 676-690

Roda, A., Maneth, A. C, Portanti, O, Mirasoli, M, Guardigh, M. Pasini, P. A al. (2003). A rapid and sensitive 384 -well microtitre format chemiluminescent enzyme immunassay for 19-nortentosterone Lambusenace, $18,72-78$

Rolka, M. \& Peltonen, K. (2006). Simultaneous determination of fou cocoidiostats in eges and hroiler meat Validation of an LC-MS/M

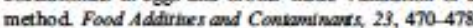

Samanidou, V. F., Nikolaidou, S. L, \& Papadoyannis, I. N. (2005) Laboratory of Analytioal Development and validation of an HPLC confimatory method for the determination of tetracycine antihiotics residues in bovine muscle acoording to the European Union otics residues in bovine muscle acoonding to the European Union
regulation 2002/657/EC. Joumal of Spparation Sciance 28, regulation
Samarajeewa, U, Wei, C L, Huang, T. S, \& Marshall, M. R. (1991) Application of immunaesay in the food industry. Oincal Reuless in Food Sclace and Nuridon, 29, $403-434$.

Shear an, P., OKeefe, M. \& Smyth, M. (1991). Reversed-phase highperformance hiquid chromatographic determination of dexamethasone in hovine tissues. Analyst, $116,1365-1368$

Stolker, A. A. M., Schwillens, P.L.W. J, Van Ginkel, L. A., \& Brin kman, U. A. Th. (2000). Comparioon of different liquid chromatography methods for the determination of corticosteroids in biologioal matri cer. Jounal of Clemomatagraphy A, 893, 55-67.

Stubhings, G. Tarbin, J., Cooper, A, Sharman, M., Bigrood, T, \& Robh, P. (2006). A multiresidue cation-exchange dean up procedure

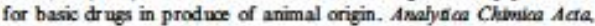
$547,262-268$.

Tang, H. P. Ho, C., \& Lai, S. S. (2000). Highthroughput screening for ming. H. P, Ho, C, \& Lai, S. S. (2006). Figh thro ughput screening for
multi-das veterinary drug residues in animal musde using liquid multi-class veterinary drug residues in animal muscle using hquid
chromatography/tandem mass spectrometry with on-line solid-phase extraction. Rapuld Commentiontions in Mass Spectromeby, 20, 2565-2572.

Thevis, M, Opfermann, G, \& Schlinzer, W. (2003). Liquid chromatog: raphy/electrospray ionization tandem mass spectrometric screening and confir mation methoda for $\beta_{2}$ egonists in human or equine wine Journal of Macr Spectrometry, 38, 1197-1206.

Toldtí F. \& Reig, M. (2006). Methods for rapid detection of chemion and veterinary drug resitues in animal foods. Trouds in Food Sciance and Tedualogy, 17, 42-489.

Tumipreed, S. B, Roybal, J. E., Andersen, W. C. \& Kudk, L. R. (2005) Analysis of avermectin and maridectin residues in mill by liquid chromatographytandem mass spectrometry using an atmospheric pressure chemical ioniration/atmospherio pressure photionization source And yica Chibuica Acta, 529, 159-165.

Van Peteguem, C, \& Daeselaire, E. (2004). Residues of growth promoters In L. M. L. Nollet (Ed). Handhook of food analyair (2nd of (pp. 1037-1063). New York. Marcel Dek ker Inc.

Van Peteguem, C, Daeerehire, E, \& Heeremans, A. (2001). Residues of growth promoters. In L. M. L. Nollet (Ed), Food asalysis by HPLC (2nd ed) (pp. 965-985). New Y ork Mared Delker Ine.

Van Poucke, L. S. G., Depoureq, G. C. L. \& Van Peteghan, C. H. (1991) A quantitafive method for the detection of sulphanamide residues in meat and milk samples with a high-performance thin-layer chromatomeat and milk samples with a high-performance thin-laye

graphic method. Joumal of Cloomabography, 29, $423-427$.
Verdon, E, Couedor, P. Roudaut, B, \& Sanders, P. (2005). Multiresidue Verdon, E, Couedor, P, Roudaut, B, \& Sanders, P. (2005). Multiresidue
method for simultaneous determination of ten quinolone antihacteria residues in mul fimatrix/mults pecies animal tivases by fiquid chroms tography with fluorescence detection: Single laboratory validatio study. Jownal of AOAC Irtemabowal, 88, 1179-1192.

Vinci, F, Guadagn uolo, G., Danese, V, Salini, M. Serpe, L, \& Gallo, P. (2005). In-house validation of a hiquid dromatogr aphy/electrospray (20nd). tandem mass spectrometry method for confir mation of chloramphen-
icol residues in muscle acoording to Decision 2002/657/EC. Rapld Comprumicanower in Maes Spectromegy, 19, 3349-3355.

Compumikabover bu Maes Spectromeby, 19, 3349-3355.
Vollard, E. J., \& Clavener, H. A. L. (1994). Colonimation resistance Anrbuianabial Agenes Chamotharapy, 38, 409-414.

Wang, S, Zhang, H. Y, Wang, L, Duan, Z. J, \& Kennedy, I. (2006) Analysis of sulphonamide residues in editile animal proctucts: A review. Foad Addirines and Conszm buanex, 23, 362-384.

Weber, C C, Link, N, Fw, C, Zisch, A. H., Weber, W., \& Fussenegger,

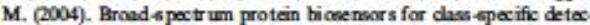
tion of antibiotion. Biavedrabogy and Bangeginar ing, 89, 9-17.

White, S. (2004). Bimensors for food analysic. In L. M. L. Nollet (Ed) Handhook of food analysir (2nd ed) (pp. 2133-2148). New York Marcel Delker Inc.

Zno, P, \& Ye, B. C. (2006). Small molocule mir aerrays for drug residue detaction in foodstuff. Jaurnal of A grikulnual and Food Chemicry, 54 $6978-6983$. 
Apéndice VI: Capítulos de libros 


\title{
12 Rapid Liquid Chromatographic Techniques for Detection of Key (Bio)Chemical Markers
}

\author{
M.-Concepción Aristoy, Milagro Reig, \\ and Fidel Toldrá
}

\section{Introduction}

Modern agricultural practices and novel food processes are including new additives and processing aids and other changes in processing to improve productivity and thus increase competitiveness and profitability. These changes may lead to substantial changes in the nutritional value and sensory properties of foods. In addition, the presence of chemical contaminants and residues is getting increased attention due to environmentat contamination and/or the use of illegal veterinary drugs or antibiotics for animal growth promotion.

Most countries have established official regulations to control the levels of chemical additives, residues, or contaminants in foods. Analytical methodologies have been developed for the qualitative and quantitative determination of these chemicals in foods. But most of these methodologies are expensive, tedious, and time-consuming. Due to the large amount of samples to be analyzed, high-performance liquid chromatography (HPIC) offers the possibility of relatively rapid analysis for a good number of chemicals. In spite of the swift development of other rapid immunological techniques, like enzymelinked immunosorbent assays (FILISAs) or biosensors. HPLC is maintaining a number of applications due to its versatility, simplicity, and economy of use. Furthermore, thesc applications are being expanded through the continued development of better column packages and equipment (through automation, robustness, sensitive detectors, etc.). For instance, increased attention is being given to HPLC coupled to mass spectrometry for official confirmatory purposes. In addition, liquid chromatography can be used by the food industry as a routine technique for controlling processes, raw materials, and products. In fact, day by day a large number of new and rapid specitic applications are being published in scientific and technical literature.

HPLC constitutes a technique that has been widely used for the analysis of foods. It has been used for a large number of applications, including the analysis of nutrients, chemical and biochemical contaminants, markers for processing control, detection of adulterations, and control of raw materials and products. The challenge is to improve the throughput for better competition with other techniques that have been appearing lately. The fundamentals of this technique and a summarized description of its applications are described in this chapter. As sample preparation is the most tedious and time-consuming step in food analysis, this chapter is mainly focused on those methodologies with less sample manipulation before HPLC analysis. 


\section{4 \\ Chemical Origin Toxic Compounds}

Fidel Toldrá and Milagro Reig

\section{INTRODUCTION}

The development of modern analytical technologies linked to epidemiologic sludies and investigations on safety aspects of food components have revealed in the latest decades that some toxic compounds may be present or generated in certain types of meat process ing. This is the case of $\mathrm{N}$-nitrosamines when using nitrite as a preservative under certain conditions, the polycyclic aromatic hydrocarbons generated in certain smoking processes, oxidation of lipids and proteins, and other products that may be present in the raw materials used for processing (veterinary drug residues, environmental contaminants, etc.). Even though meat fermentation is an old technology used for generations in many countries, corrective measures (i.e., reduction in the addition of nitrite, contro of raw materials, etc.) have been taken to minimize this problem. All these hazardous compounds are hriefly described in this chapter. Biogenic amines, which are generated by microbial decarboxylation of certain amino acids are dealt with in Chapter 43 "Biogenic Amines and Nitrosamines."

\section{N-NITROSAMINES}

Nitrite is the main additive used as a preservative in fermented meats because of its powerful inhibition of the outgrowth of spores of putrefactive and pathogenic bacteria like Clostridium boinlinum. Nitrite also has some other technological roles, such as it contribution to the color through the formation of nitrosylmyoglobin, its contribution to the oxidative stability of lipids, and its contribution to the development of typical and distinctive curcd meat flavor.

Nitrite can be converted to nitric oxide, which is a nitrosating agent. This agent can react with secondary amines and produce potent carcinogenic nitrosemines. Compounds such as $\mathrm{N}$-nitrosodimethylamine have been shown to be carcinogenic in a wide range of animal species. The presence of volatile $\mathrm{N}$-nitrosamines have been largely studied in cured meat products. Some of the most important are $\mathrm{N}$-nitrosodimethylamine, N-nitrosopirrolidine, $\mathrm{N}$-nitrosopiperidine, $\mathrm{N}$-nitrosodiethylamine, $\mathrm{N}$-nitrosodi-n-propylamine, $\mathrm{N}$-nitrosomorpholine and $\mathrm{N}$-nitrosocthylmethylamine. In addition, a large number of nonvolatile nitroso compounds, higher in molecular weight and more polar, have also been reported. Some of the most important are $\mathrm{N}$-nitrosoaminoacids such as $\mathrm{N}$-nitrososarcosine and $\mathrm{N}$-nitrosothiazolidine4-carboxylic acid hydroxylated $\mathrm{N}$-nitrosamines, $\mathrm{N}$-nitroso sugar amino acids, and $\mathrm{N}$-nitrosamides such as $\mathrm{N}$-nitrosoureas, $\mathrm{N}$-nitrosoguanidines, and N-nitrosopeptides (Pegg and Shahidi 2000). The amount of $\mathrm{N}$-ritrosamines in meat peoducts depends on many variables, such as the amount of added and residual nitrite, processing conditions, amount of lean meat in the product, heating if any, and presence of eatalysts or inhibitors (Hotchkiss and Vecchio 1985; Walker 1990). Table 44.1 lists some carcinogenic nitrosamines.

The presence of $\mathrm{N}$-nitrosamines in certain cured meat products was the reason for a serious debate 
En: Handbook of fermented meat and poultry (F. Toldrá, YH. Hui, I. Astiasarán, WK. Nip, JG. Sebranek, ETF. Silveira, LH. Stahnke y R. Talon Eds.), Blackwell Publishing, Ames, Iowa, USA, 2007, 469-475. 


\title{
Chapter 16 \\ Immunology-Based Techniques for the Detection of Veterinary Drug Residues in Foods
}

\author{
Milagro Reig and Fidel Toldrá
}

\section{Introduction}

Veterinary drugs are used in fam arimals, via the feed or the drinking water, to prevent the outhreak of diseases or even for the trestment of dsesses. Howewer the growth of animals may be promoted through the use of hormones and antibiotics. Depending or the type of residue and the application and washing conditions, these substances or its metabolites may remain in meat and other foods of animal origin and may cause adverse effects on consumers' health. This is the main reason why its use is stricly regulated or even barned (case of the Europen Union) in dfferent countries. Antibiotics typically used for growth promotion include chloramptenicol, nitrofurans, and earofloxacin but others like sulphonamides, macrolides ec. myy also be used (Reig \& Toldrá, 2007). An irreversible type of bone murrow depression that might lead to aplestic anaemia may be caused by chloamphenicol (Mottier et a., 2003), while sone alergic reactions as well as emergence of drug-resistant backria may be caused by enrofloxacin (Cinquina, Longo, Anastasi, Giannetti, \& Cozzani, 2003). One of the major metabolites of nitrofurans is furazolidone that has been reported to have mutagenic and carcinogenic properties (Guo, Chou, \& Liao, 2003). There is also some evidence on the toxicity of sulpbonamides on the thyroid gland (Pecorelli, Bibi, Fioron, \& Galarini, 2004). Other important concern about the presence of antibiotics residues in animal foodstuffs is related to the selection of resistant bacteria in the gastrointestinal tract and disrtption of the colonization burrier of the resident intestinal microflona (Cerniglia \& Kotarski, 2005). Intestinal flon may vary depending on the diet and thes is subject to large variatims in the proportion of mijor hacterial species (Monre \& Mrome, 1005). The presence of antibiotics in neat may alter the intestinal microflcra that is essential for h.man physiolcgy, food digession, and metabolism of nutrients (Chadwick, Gecrge, \& Chaxton, 1992; Vollard \& Clasener, 1994) contrituting to the developmert of antibiotic resistance in the ind genous microflora and impairing colonization 


\title{
Chapter 41
}

\section{Growth Promoters}

\author{
Milagro Reig and Fidel Toldrá
}

\section{Contents}

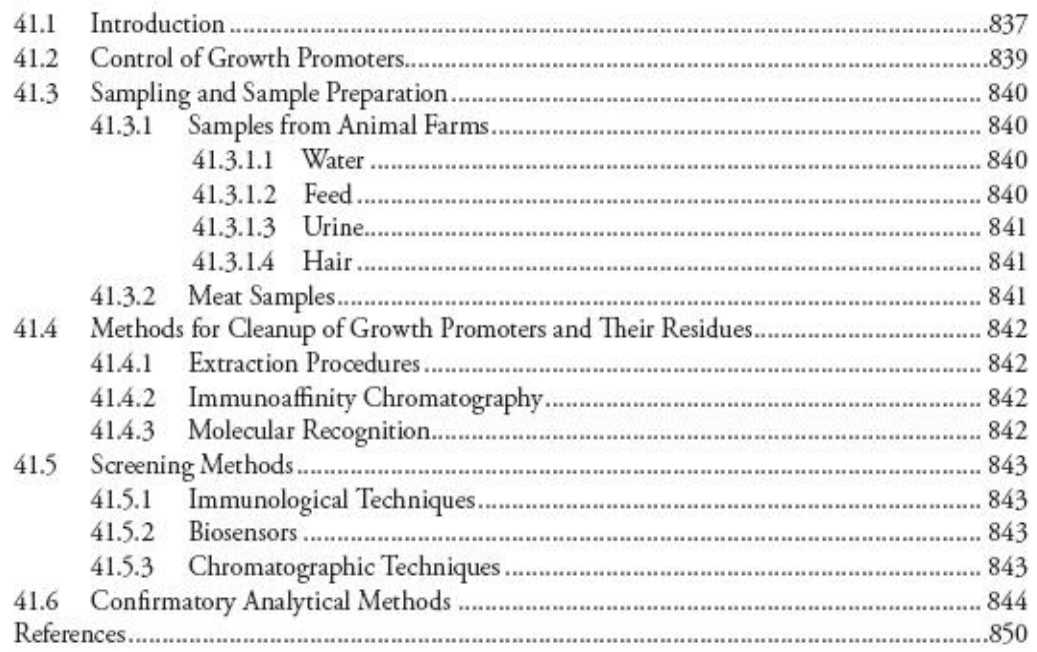

\subsection{Introduction}

Growth promoters include a wide range of substances that are generally used in farm animals for therapeutic and prophylactic purposes. These substances can be administered through the feed or 
En: Handbook of Muscle Foods Analysis (L.M.L. Nollet y F. Toldrá, Eds.), CRC Press, Boca Raton FL, USA, 2009, 837-853.

\section{Chapter 30}

\section{Veterinary Drug Residues}

Milagro Reig and Fidel Toldrá

\section{Contents}

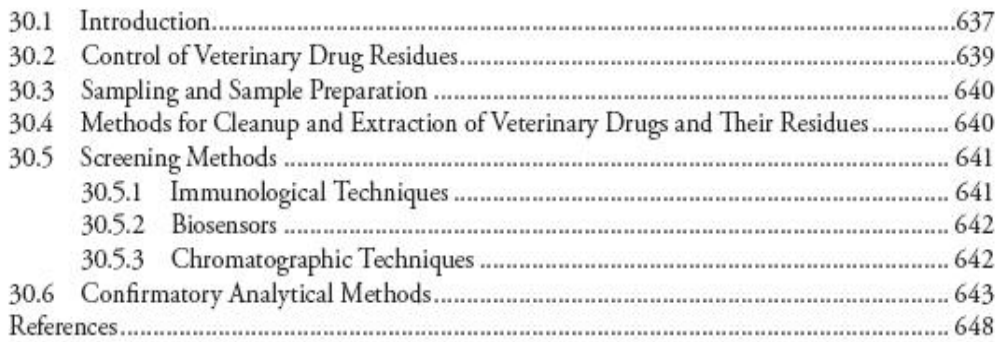

\subsection{Introduction}

Veterinary drugs are generally used in farm animals for therapeutic and prophylactic purposes; they include a large number of different types of compounds which can be administered in the feed or in the drinking water. In some cases, residues may come from contaminated animal feedstuffs. ${ }^{1}$ Many of these substances, along with others that have anabolic effects, may have other effects when administered to animals for purposes such as growth promotion. Anabolic promoters have been administered in the United States to meat-producing animals, including, among others, estradiol, progesterone, and testosterone. The regulations in 21 Code of Federal Regulations (CFR) Part 556 list acceptable concentrations of residues of approved animal drugs that may remain in edible tissues of treated animals. ${ }^{2}$ 
En: Handbook of Processed Meats and Poultry Analysis (L.M.L. Nollet y F. Toldrá, Eds.), CRC Press, Boca Raton FL, USA, 2009, 637-653. 


\section{Chapter 9}

\section{Growth Promoters}

Milagro Reig and Fidel Toldrá

\section{Contents}

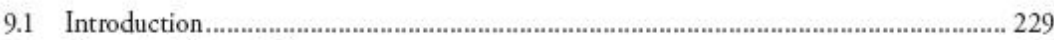

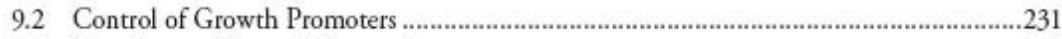

9.3 Sampling and Sample Preparation...............................................................................233

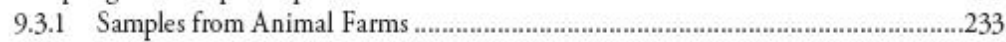

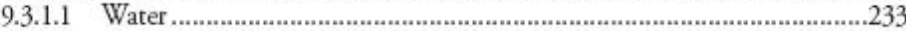

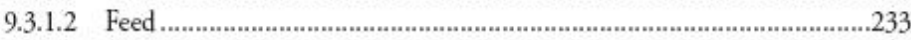

9.3.1.3 Urine

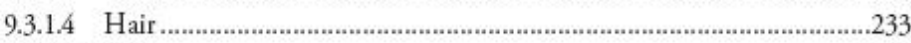

9.3.2 Meat Samples .................................................................................... 234

9.4 Methods for Cleanup of Growth Promoters and Their Residues ..................................... 234

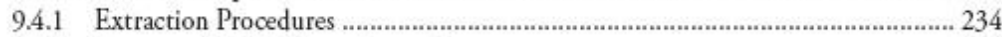

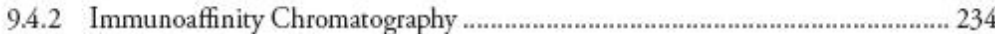

9.4.3 Molecular Reoognition...............................................................................235

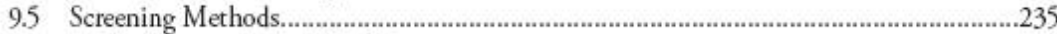

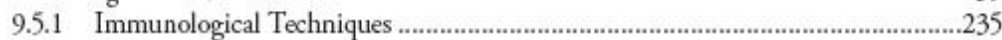

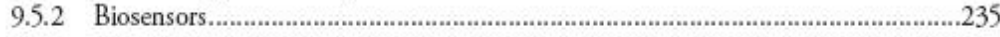

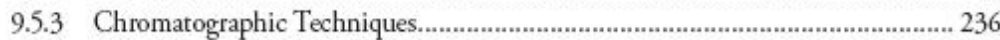

9.6 Confirmatory Analytical Methods ……...................................................................... 236

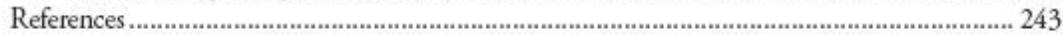


En: Safety Analysis of Foods of Animal Origin (LML. Nollet y F. Toldrá, Editors), CRC Press, Boca Raton, FL, USA, 2010, 229-247. 


\title{
Chapter 14 \\ Veterinary Drugs and Growth Promoters Residues in Meat and Processed Meats
}

\author{
Milagro Reig and Fidel Toldá
}

\section{Introduction}

Veterina ry drugs, which comprise a lar ge number oi different types of substances, are generally intended for therapeutic (to control infectious diseases) and prophylactic (to prevent agains. infections) purposes in farm animals. Otker substances with growth promotng eflet may exert antumcrobial eflect aganst the microtial flora in the gut to take maximum profit of nutrients in the feed or by affecting the animal's metabolism. Most of thece substances are orally active and can be administered either in the feed or in the drinking water. Other active hormones are applied in the form of small implant into the subcutaneous tissue of the ears. These areslow release (several weeks or mon ths) devies and the ears are disarded at the slaughte. Growth promoters allow a better efficiency in the feed conversion rate. The net effect is an increased protein deposition, partly due to musle proteases irhibition (Fiems, Buts, Boucque, Demeyer, \& Cottyt, 1990), usually linked to fat utilization (Btockman \& Laarveld, 1986). The result is a leaner meat (Lone, 1997) with some toughness derived from the production of connective tissue and collagen crosslinking (Miller, Judge, Diekman, Hudgens, \& Aberle, 1989; Miller, Judge, \& Schanbacher, 1990). Some recent fraudulent practices, consisting of the use of a kind of "cocktails" or mixtures of several substances like $\beta$-agonists and cor icosteroids at very low amounts (Monsón et al., 2007), are difficult to detect with modern analytical instrumentation. They try to obtain a synergisic effect for a similar growth promotion with bwer probability of detection by official control liboratories (Reig \& Toldra, 2007).

Thus, the tse of veterinary drug substances as well as other sabstances with growth promoting effects nay usually constitute a clear economic betefit for farm producton. However, its residues in the meat and other animal-derived 
365-390 


\section{Chapter 27}

\section{Detection of Chemical Hazards}

Milagro Reig and Fidel Toldrá

\section{Introduction}

The development of modern analytical technologies linked to epidemiologic studies and investigations on the safety aspects of food components has revealed in recent decades that some toxic compounds may be present or generated in certain types of meat and processed meat. Three groups of compounds have received great attention because they are potential carcinogens, and, even when not present in the raw meat, they can be generated during further processing or cooking. These groups are nitrosamines, heterocyclic amines, and polycyclic aromatic hydrocarbons. $\mathrm{N}$-nitrosamines can be generated under cerlain processing conditions when using nitrite as a preservative. The polycyclic aromatic hydrocarbons ( $\mathrm{PAH}$ ), which are generated in certain smoking processes, can also be produced when cooking at high temperatures. This is also the case with the heterocyclic amines, which are generated when cooking at high temperatures. In fact, diets associated with meats cooked at high temperatures may increase the risk of certain types of cancer (Jakszyn et al. 2004). Other compounds that can also exert adverse effects on consumers' health are the biogenic amines that are generated by the microbial decarboxylation of certain amino acids, which have potential vasoactive or psychoactive toxicological effects. Amines may also constitule a source of secondary amines that can react with nitrite and produce nitrosamines with potential carcinogenic activity. Finally, other toxic compounds may result from the oxidation of lipids and proteins, as well as other products that may be present in the raw materials used for processing (veterinary drug residues, environmental contaminants. etc.). The main routes for the presence of these compounds in meat are summarized in Table 27.1.

Controls and effective corrective measures (i.e., control of raw materials, reduction in the addition of nitrite, control of microbial decarboxylase activity, etc.) can been taken to minimize this problem in cooked, cured, and dry-cured meat products. All these hazardous compounds and the main analytical techniques used for their control are briefly described in this chapter.

\section{$\mathrm{N}$-nitrosamines}

Nitrosamines are $\mathrm{N}$-nitroso compounds that have received much attention in the last 50 years due to their recognition as potential carcinogenic compounds. Nitrosamines are formed in cured meats through the reaction of nitrous acid in its dissociated form, generated from nitrite, with secondary amines. Some of the most important nitrosamines detected in cured meats are $\mathrm{N}$ nitrosodimethylamine, $\mathrm{N}$-nitrosopirrolidine, $\mathrm{N}$-nitrosopiperidine, $\mathrm{N}$-nitrosodiethylamine, $\mathrm{N}$-nitrosodi-n-propylamine, $\mathrm{N}$-nitrosomorpholine, and N-nitrosoethylmethylamine. Some are carcinogenic in a wide range of animal species. In addition, a large number of nonvolatile nitroso compounds, higher in 



\section{Analysis of Meat-Containing Food}

Fidel Toldrá and Milagro Reig

Instiruta de Agrogaimico y Tecnologia de Alimentos (CSIC), Valencia Spain

\section{INTRODUCTION}

There are important authenticity issues in meat containing foods like the origin of the meat in the food and the identification of any substituting meat (1). The detection of fraudulent substitutions or adul terations in a food is very important for consumers. For instance, addition of low-cost meat like kangaroo or whale instead of beef is an important and challenging task in food control. The substitution of high-value meats by cheaper meats, offal, or other proteins constitules a major fraudulent practice. However, there are other important reasons for the correct determination of ment species such as specific food allergies for particular groups of people, controlled dicts (i.c. pregnant women, athlels, etc.), or religious restrictions (i.e., rejection of pork meat by Muslem pcople). The treatment of meat is also important as it also may affect the quality. In fact, the use of frozen/thawed meat or even mechanically recovered meat instead of fresh meat is another important issue

The definition of meat is important in order to decide the most appropriatc analytical methodology. The CODEX Standard for Luncheon Meat (Codex Stan 89-1891) and Cooked Cured Chopped Meat (Codex Stan 98-1891) define meat, considering it as a raw material contained in these products, as "the edible part, including edible offal, of any mammal slaughtered in an abattoir" (2). The EC Meat Products Directive 94/65/EFC. consider meat as all parts of domcstic animals that are suitable for human con sumption and the meat species must be labeled except when it is clearly indicated by the product name (2). This chapter summarizes the analytical methodologies available for the analysis of meat in foods, especially focusing on the determination of the meat species. meat content, detection of substitution by mechanically recovered meat, and production processes lik. frozen/thawed meat.

\section{IDENTIFICATION OF THE MEAT OF ORIGIN}

\section{A. Electrophoretic Methods}

Electropheresis constitutes a well known technique applied for many years to the separation of meat proteins in either nondenaturing or denaturing condilions. The separation of protein bands may be easily achieved in homogeneaus gels $(7.5,10$, or $12.5 \%$ polvacrylamide concentration), concentration-gradient gels (usually $5-15 \%$ polyactylamide), or pH-gradient gels (isoelectric focusing). Proteins may be applied in the native state or denatured with the detergent sodium dodecyl sulfate (SDS). under reducing conditions and heal, giving proteins a constant charge per unit mass (SDS-PAGE-Polyacrylamide (iel Electrophoresis). In general, the extraction procedure is as follows: portions of the meat or food are weighed and fromogenized with 10 volumes of $0.03 \mathrm{~N}$ phosphate buffer (pH 7.4) to extract sarcoplasmic proteins of $0.1 \mathrm{~N}$

En: Handbook of Food Analysis, $2^{a}$ ed., (LML. Nollet, Ed.), Marcel-Dekker Inc., New York, USA, 2004, 1941-1959. 
